\title{
Investor and Firm Perspectives on Impression Management in Earnings Press Releases: Insights from TSX Venture Exchange Firms
}

\author{
by \\ Alisher Mansurov \\ A thesis submitted to the Faculty of Graduate and Postdoctoral Affairs in \\ partial fulfillment of the requirements for the degree of \\ Doctor of Philosophy \\ in \\ Management \\ Carleton University \\ Ottawa, Ontario \\ (C)2019 \\ Alisher Mansurov
}




\section{Abstract}

The TSX Venture Exchange, one of the global leaders in providing opportunities to raise equity capital for small and emerging firms, plays an important role in the Canadian economy. However, TSX Venture Exchange firms have not yet received significant attention from academic scholars. This study examines 1,317 earnings press releases (EPRs) of TSX Venture Exchange firms to investigate whether, and how, low-visibility firms engage in impression management practices. It also explores investor perspectives on impression management by examining stock market and online investment discussion board reactions to apparent impression management. Overall, findings of this study indicate that low-visibility firms use various impression management strategies such as tone management, readability manipulation, causal reasoning, and the emphasis of positive performance by thematic manipulation, reinforcement, and repetition in their EPRs. Results of stock market reaction tests suggest that tone management and emphasis of positive performance positively affect cumulative abnormal return around the issue of EPRs; however, these effects dissipate or reverse in the longer-term. Similarly, online investment board participants are initially drawn to EPRs which emphasize positive performance and abnormally high positive tone around the issuance of EPRs. However, in the longer-term, discussion participants pay less attention to those EPRs and switch their interest to EPRs with higher reading complexity.

Drawing on literature on impression management, firm visibility, and investor reaction, this study makes four important contributions to the existing literature. First, it exclusively focuses TSX Venture Exchange firms to study impression management practices of low-visibility firms. Second, this research offers a broad examination of firms' engagement in impression management practices by examining several impression management strategies together. Third, this study combines both the firm and the investor perspectives on impression management to effectively study impression management and its consequences. Finally, it analyzes online investment discussion board data to explore investors' reactions to apparent impression management, in addition to investigating stock market reaction.

This study benefits low-visibility firms, individual investors and academics by expanding their knowledge of impression management and its consequences. Findings can also help financial regulators make policy decisions and educate investors on impression management and its consequences. 


\section{Acknowledgements}

This dissertation would not have been possible without the continued help and support of my thesis supervisor, Dr. Merridee Bujaki. Her encouragement, guidance, and insight have been crucial to the development of this work. I have grown tremendously as a researcher and writer thanks to her. I am deeply grateful and eternally indebted for her mentorship throughout my $\mathrm{PhD}$ years.

Many thanks to the members of my thesis committee, Dr. Francois Brouard and Dr. Howard Nemiroff, who also participated on my comprehensive exam committee. I greatly appreciate their invaluable comments, feedback, and support. I am grateful to the external committee member Dr. Pascale Lapointe-Antunes and the internal committee member Dr. Olga Baysal for their feedback and recommendations. I would also like to thank CPA Ontario for supporting this research financially.

Finally, I would like to thank my family. Thanks to my wife Sitora, my daughter Madina, and my son Komil, for their sacrifices, endless patience, and love. I am truly thankful to my parents and siblings for always being there for me. I dedicate this thesis to my family. 


\section{Table of Contents}

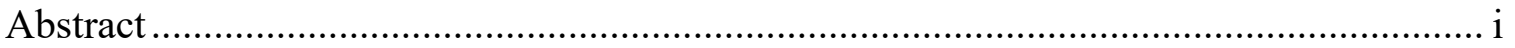

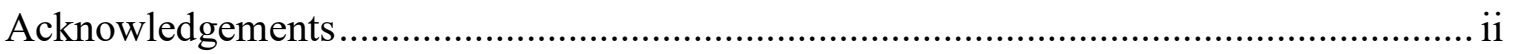

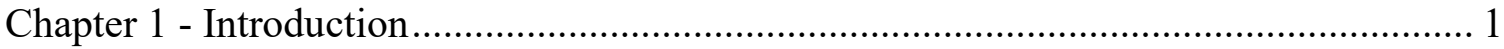

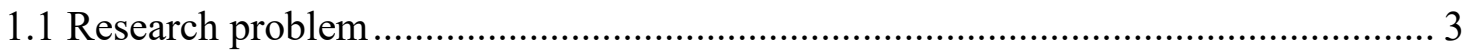

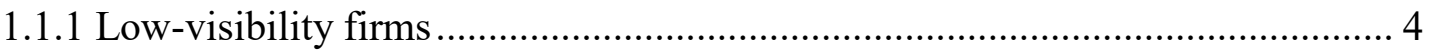

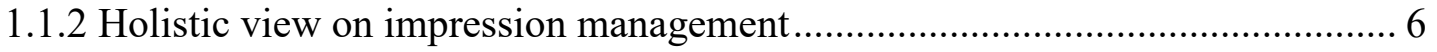

1.1.3 Direct impact of impression management .................................................. 7

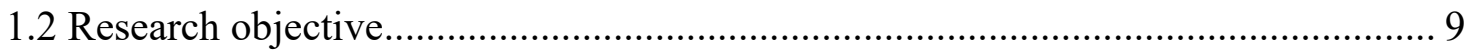

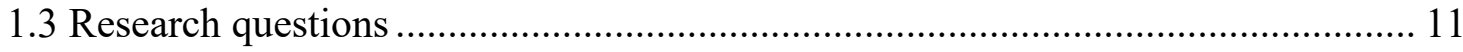

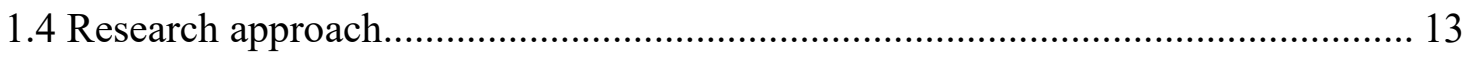

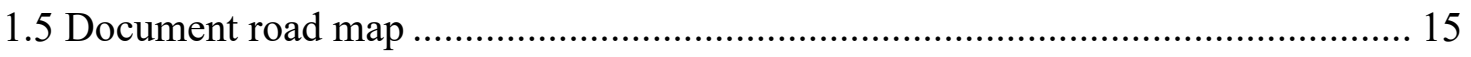

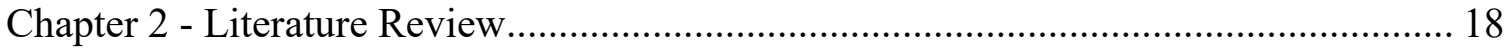

2.1 Voluntary disclosure motivations and disclosure management .......................... 19

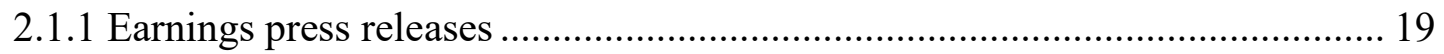

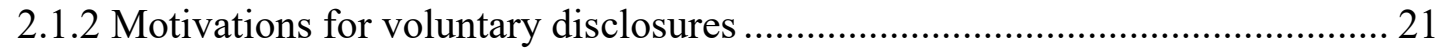

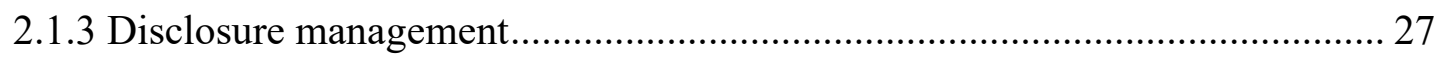

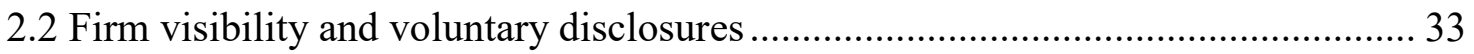

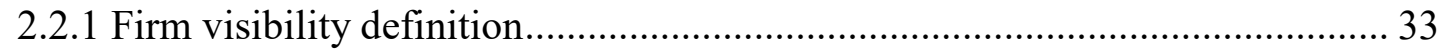

2.2.2 Firm visibility and voluntary disclosure motivations .................................. 39

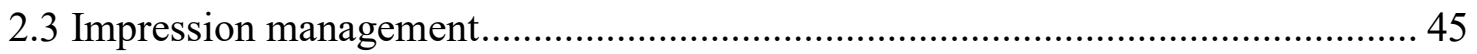

2.3.1 Impression management definition ....................................................... 45

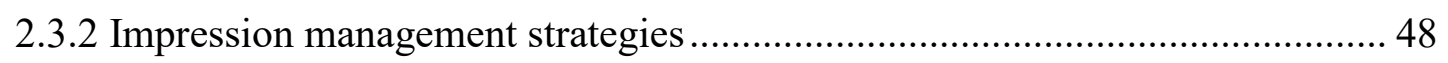

2.3.2.1 Thematic Manipulation (tone management) ......................................... 48

2.3.2.2 Reading ease manipulation (readability manipulation) ............................50

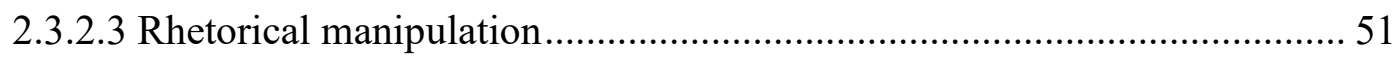

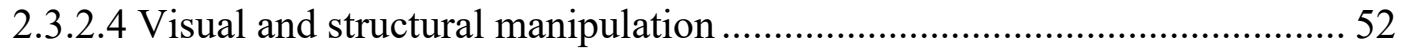

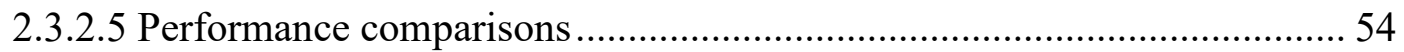

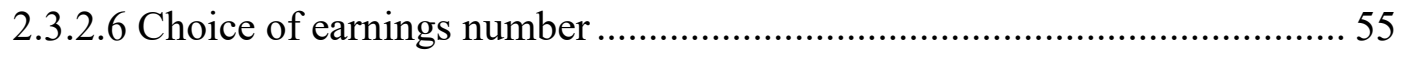

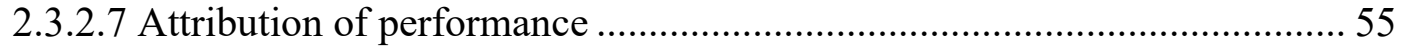


2.3.3 Manual versus computer-based content analysis methods ............................. 56

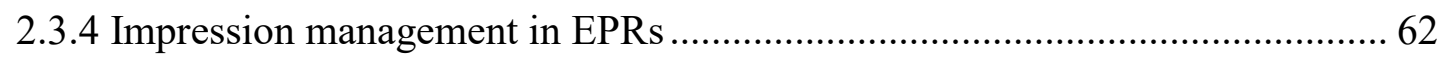

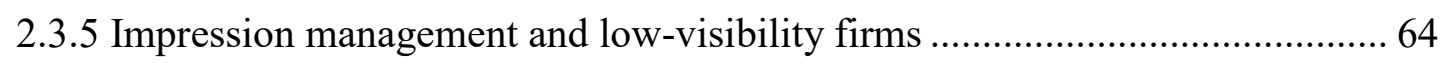

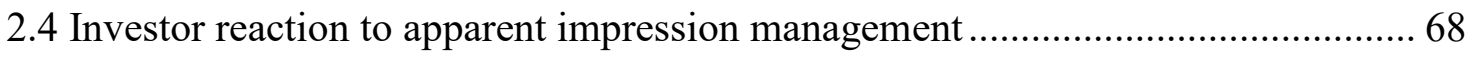

2.4.1 Stock market reaction to apparent impression management ........................... 70

2.4.2 Online discussion board activity and stock market returns ........................... 76

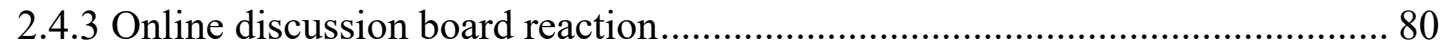

2.5 Other important factors affecting impression management and investor reaction.. 83

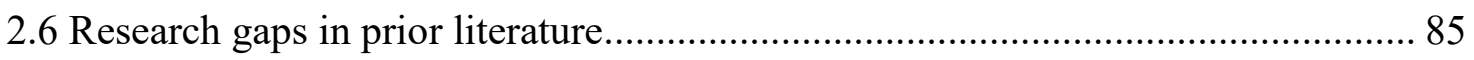

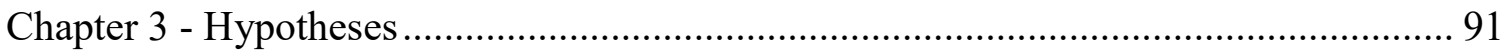

3.1 Impression management in EPRs - firm perspective....................................... 92

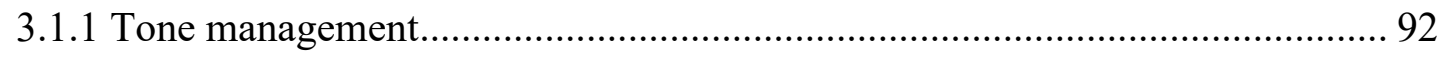

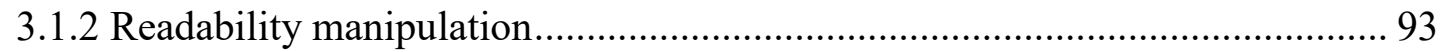

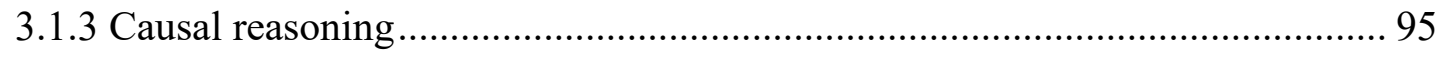

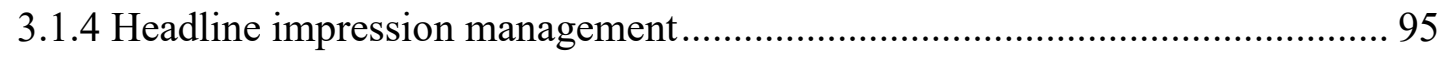

3.2 Stock market reaction to apparent impression management - investor perspective97

3.2.1 Abnormal tone and cumulative abnormal return ......................................... 97

3.2.2 Reading complexity and cumulative abnormal return ................................ 98

3.2.3 Causal reasoning intensity and cumulative abnormal return ......................... 99

3.2.4 Headline impression management and cumulative abnormal return............... 99

3.3 Online discussion board reaction to apparent impression management - investor

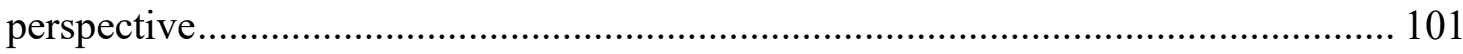

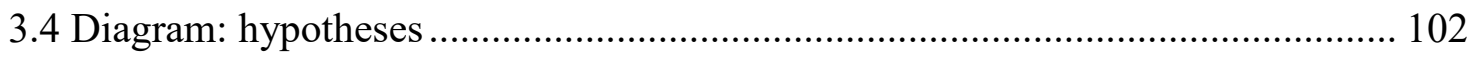

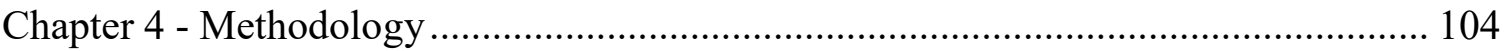

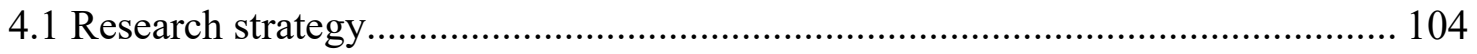

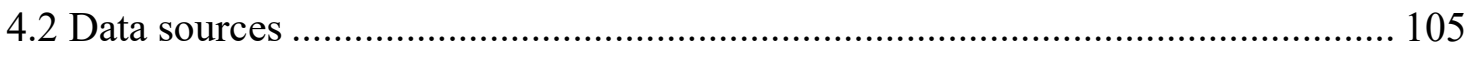

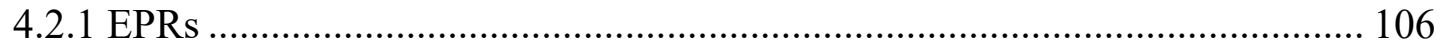

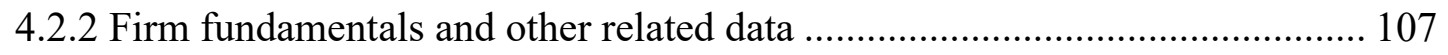

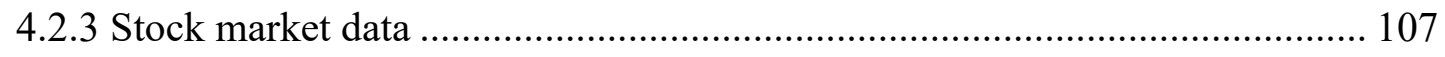

4.2.4 Online investment discussion board data .................................................. 107

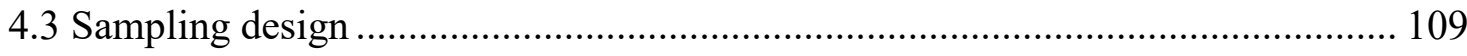




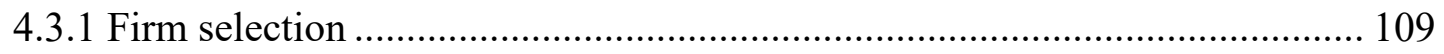

4.3.2 Selection of impression management strategies ............................................ 115

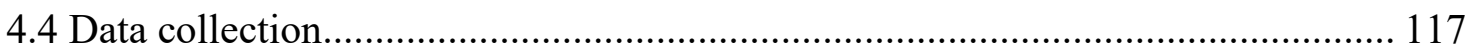

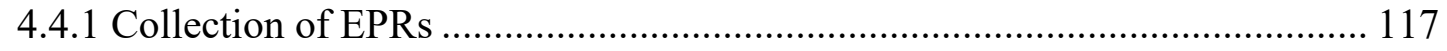

4.4.2 Collection of firm fundamentals data and stock market data ......................... 119

4.4.3 Collection of online investments discussion board posts ................................ 119

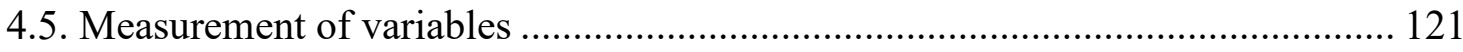

4.5.1 Measuring firm performance and other important factors................................ 121

4.5.2 Measuring impression management in EPRs .................................................. 123

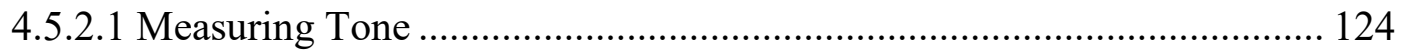

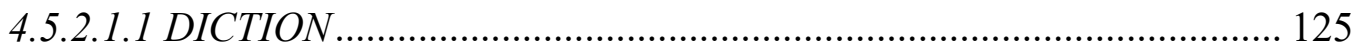

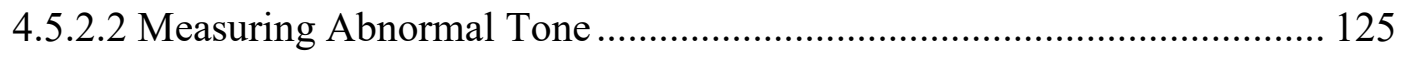

4.5.2.3 Measuring causal reasoning intensity ..................................................... 127

4.5.2.4 Measuring Headline Impression Management in EPR ............................ 128

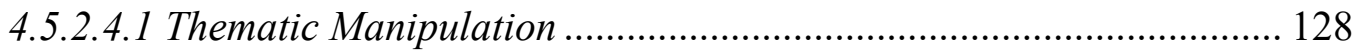

4.5.2.4.2 Emphasis by repetition and reinforcement ....................................... 129

4.5.2.4.3 Composite Score and Measure of Headline Impression Management

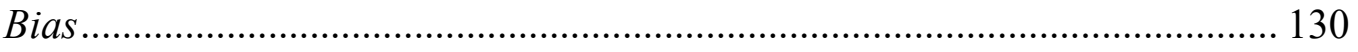

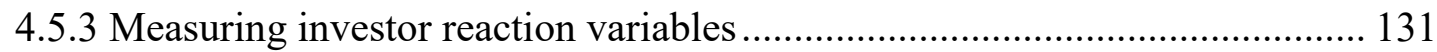

4.5.3.1 Cumulative Abnormal Return (CAR) ...................................................... 132

4.5.3.2 Discussion volume and discussion sentiment ........................................ 132

4.5.4 Summary of variables and measurements ................................................... 133

4.6 Data analysis approach................................................................................ 136

4.6.1 Firm performance and impression management ........................................... 137

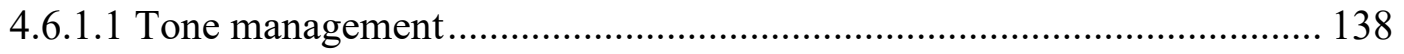

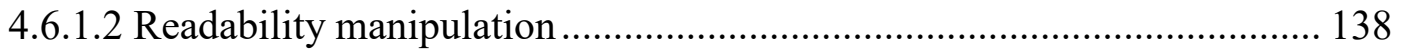

4.6.1.3 Causal reasoning ................................................................................. 139

4.6.1.4 Headline Impression Management .......................................................... 139

4.6.2 Investor reaction to apparent impression management ................................. 140

4.6.2.1 Stock market reaction .......................................................................... 140

4.6.2.2 Investment discussion board reaction ..................................................... 141 
4.6.3 Summary of data analysis approach …………............................................. 143

Chapter 5 - Descriptive Statistics and Regression Results .............................................. 146

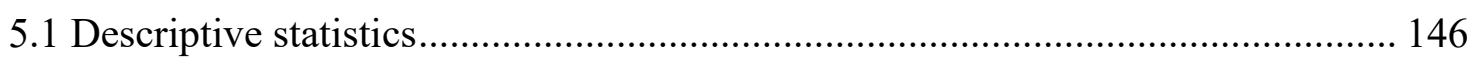

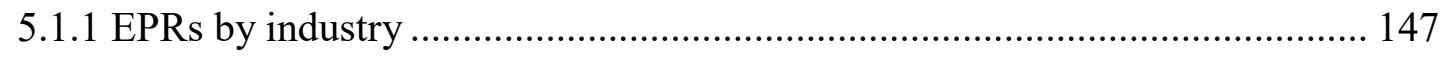

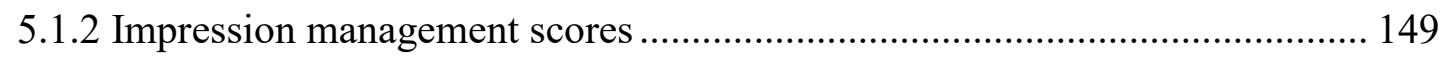

5.1.3 Stockhouse posts on EPR-issuing firms …………….................................... 154

5.1.4 Firm fundamentals and stock data ............................................................. 159

5.1.5 Correlations among main variables ……………………………………..... 162

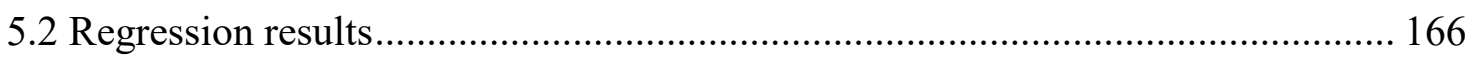

5.2.1 Firm performance and impression management ............................................ 167

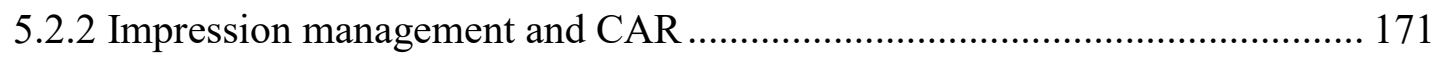

5.2.3 Impression management and online user reaction........................................ 172

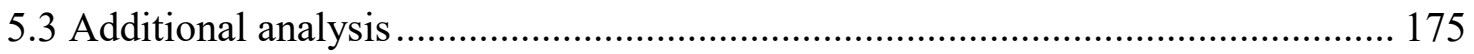

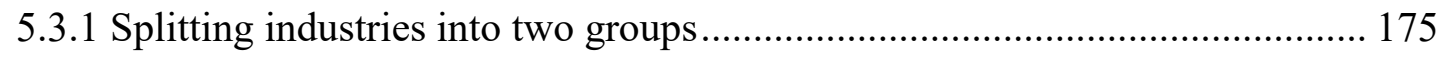

5.3.2 Logistic regression on headline impression management ............................. 179

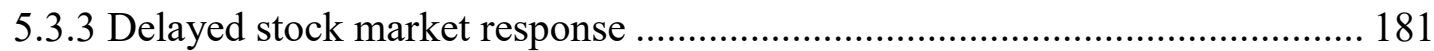

5.3.4 Delayed online discussion board volume reaction ......................................... 183

5.3.5 Online discussion views as an alternative to discussion volume..................... 185

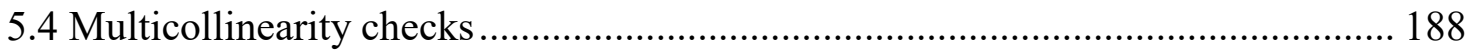

Chapter 6 - Discussion and Conclusion ..................................................................... 189

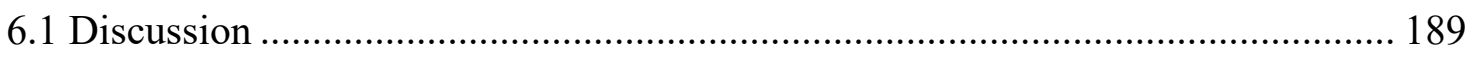

6.1.1 Findings on the firm perspective ………................................................... 189

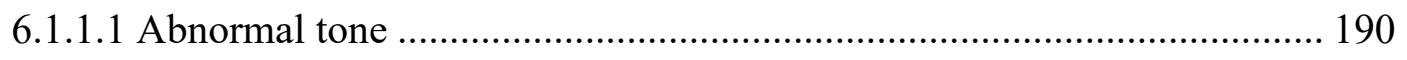

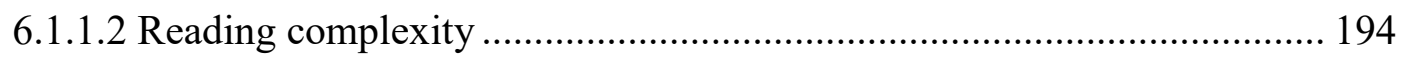

6.1.1.3 Causal reasoning intensity ................................................................... 196

6.1.1.4 Headline impression management bias....................................................... 196

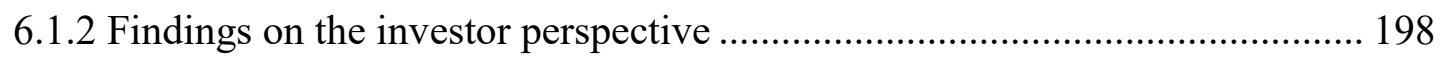

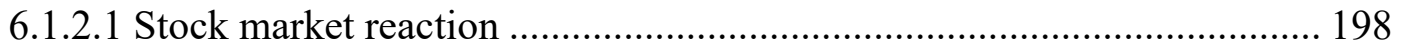

6.1.2.2 Online discussion volume and sentiment reaction.................................. 202

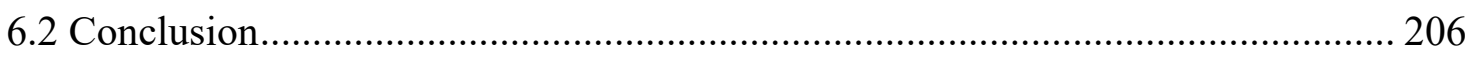

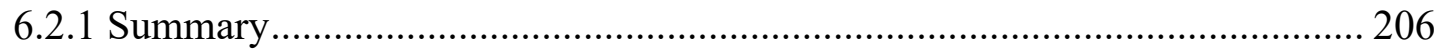


6.2.1.1 Firm perspective.................................................................................... 206

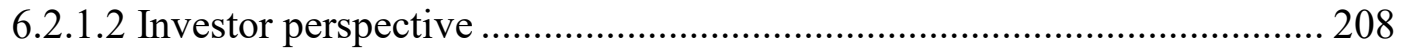

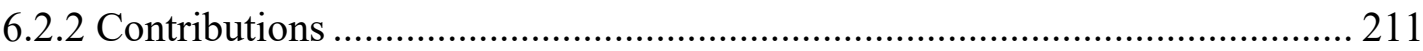

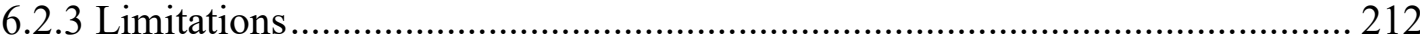

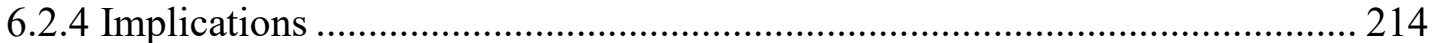

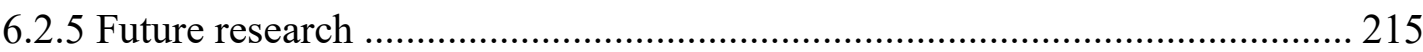

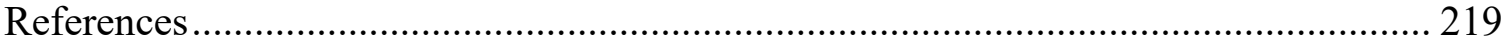

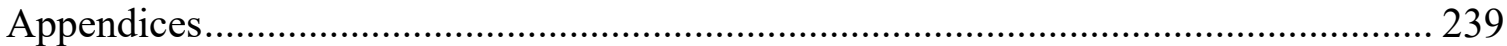




\section{List of Tables}

Table 1.1 Research theme, problem, objective, questions, and approach 15

Table 2.1. Disclosure management categories and disclosure documents 31

Table 2.2. Firm visibility proxies in prior literature 38

Table 2.3. Main strategies and content analysis methods in impression management research 59

Table 2.4. Investor reaction to apparent impression management. 75

Table 4.1. The Number of posts (including replies) in June 2018 for the top five and bottom five S\&P/TSX Venture Index constituents (based on the initial 409 firms) ...... 109

Table 4.2. Firm sample selection process

Table 4.3. Industry representation of issuing and non-issuing firms in the initial sample (sorted by the number of firms in the initial sample) .............................................. 112

Table 4.4. Sample Selection Process by Industry

Table 4.5. EPR-issuing by the number of EPRs issued and industry representation (sorted by the number of firms issuing earning press releases). 115

Table 4.6. Impression management strategies investigated in this study 116

Table 4.7. EPRs issued by the final sample of firms (EPR-issuers with three or more EPRs) broken down by the number of EPRs and industry representation (sorted by the number of total EPRs). 118

Table 4.8. Summary of measures 134

Table 5.1. Descriptive statistics on the number of EPRs by industry 148

Table 5.2. Descriptive statistics on impression management strategies in the body and the headline of EPRs 150

Table 5.3. Stockhouse post deciles for the sample firms with at least one post 155

Table 5.4. Posts by industry for EPR-issuing and EPR-non-issuing firms from Jan 1, 2016 to July 1, 2018 (sorted by the average number of posts per firm) 157 
Table 5.5. Daily posts per firm by industry for EPR-issuing firms in the event window (three-day) and pre-event window (60-day) (sorted by average number of posts in the event period)

Table 5.6. Descriptive statistics on firm fundamentals and stock price related information

Table 5.7. Descriptive statistics for operating income and operating income change after the removal of an extreme outlier 161

Table 5.8 Correlations among Main Variables 165

Table 5.9. Firm performance on tone and abnormal tone. 168

Table 5.10. Firm performance on readability, causal reasoning intensity, and headline impression management. 170

Table 5.11. Impression management strategies on three-day CAR. 172

Table 5.12. Impression management strategies on abnormal discussion volume 173

Table 5.13. Impression management strategies on abnormal discussion sentiment 174

Table 5.14. Tone and abnormal tone regression results with the new industry grouping

Table 5.15. Readability, causal reasoning, and headline impression management regression results with the new industry grouping

Table 5.16. Three-day CAR regression results with the new industry grouping.... 178

Table 5.17. Abnormal discussion volume and abnormal discussion sentiment regression results with the new industry grouping

Table 5.18. Firm performance on headline impression management (Logistic regression)

Table 5.19. Impression management strategies on longer-term CAR. 183

Table 5.20. Impression management strategies on 60-day abnormal discussion volume 185

Table 5.21. Impression management strategies on abnormal discussion views 187

Table 6.1. Main findings for each hypothesis. 192 


\section{List of Figures}

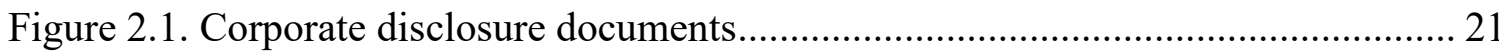

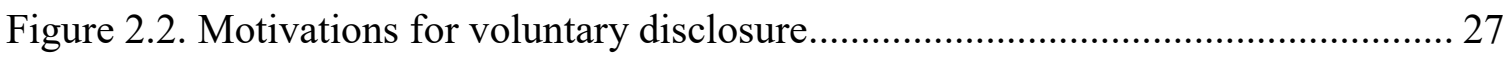

Figure 2.3. Disclosure management categories .................................................... 29

Figure 2.4. Motivations for voluntary disclosure and disclosure management .............. 33

Figure 2.5. Firm visibility proxies and factors effecting firm visibility ........................ 39

Figure 2.6. Firm visibility, low-visibility firms and impression management ................ 67

Figure 2.7. Investor Reaction to apparent impression management................................. 69

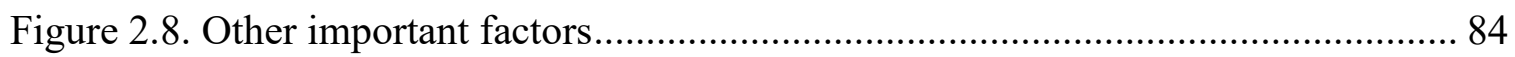

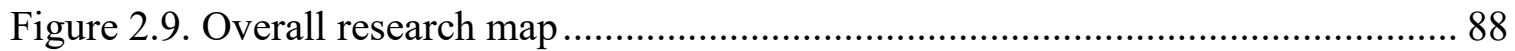

Figure 3.1. Hypotheses and the main research areas ............................................ 103

Figure 4.1. Impression management strategies................................................. 116

Figure 4.2. Connections between measurements, analyses, and hypotheses................ 144 


\section{List of Appendices}

Appendix A. Comparisons of firm visibility proxies between S\&P/TSX Venture and $\mathrm{S} \& \mathrm{P} / \mathrm{TSX}$ indices

Appendix B. An example of a discussion board page of a firm on Stockhouse.com -

Snipp Interactive Inc

Appendix C. An example of an online post from a Stockhouse.com user - digitel ....... 241

Appendix D. The body of an EPR issued by C-Com Satellite Systems Inc. on July 18, 2017

Appendix E. Descriptive statistics on firm fundamentals and stock related data

Appendix F. Variance inflation factors (VIFs) for regression models and predictors.... 245

Appendix G. List of abbreviations 246 


\section{Chapter 1 - Introduction}

Firms use various voluntary disclosure documents to signal or communicate valuable incremental information to their investors about the firm's current and future performance (Abrahamson and Amir, 1996; Baginski et al., 2000; Botosan and Plumlee, 2002; Matsumoto et al., 2006). Firms also use these documents opportunistically to manage or influence the perceptions and decisions of investors (Guillamon- Saorin, 2006; Henry, 2006; Davis et al., 2007). This opportunistic behavior of firms in their disclosure documents is referred to as impression management which is a rapidly growing field of research in accounting.

First conceptualized by Goffman (1959), impression management is often described as a self-presentation process to appeal to target audiences and to manage others' perceptions (Goffman, 1959; Schlenker, 1980; Riess et al., 1981; Schneider, 1982). As a widely used concept in social psychology, impression management is a strategy, or a set of strategies, used by individuals to influence how others view them to achieve a desired presentation (Kaplan et al., 1990; Hooghiemstra, 2000). Similarly, in the organizational context, impression management is defined as firms' actions to control or manipulate investors' perceptions to create more favorable images about financial performance than is warranted (Smith and Taffler, 2000; Rutherford, 2005; GuillamonSaorin et al., 2012). There is recent increased interest from academics in investigating ways corporate disclosures are used to convey firms' view of financial performance. Many studies are finding that firms are increasingly using their corporate disclosure documents opportunistically to engage in various impression management strategies (Yuthas et al., 2002; Clatworthy and Jones, 2003; Lee et al., 2004; Henry, 2008; Brennan 
et al., 2009; Aerts and Cheng, 2011; Davis and Tama-Sweet, 2012; Guillamon-Saorin et al., 2012; Huang et al., 2014; Arslan-Ayaydin et al., 2016; Aerts and Yan, 2017; Sandulescu and Albu, 2018). This study focuses on earnings press releases (EPRs), which are voluntary disclosure documents, to study impression management.

EPRs are characterized as voluntary disclosure mechanisms in terms of both issuance and content that are easily accessible to investors (Bowen et al., 2005; Davis et al., 2012). Voluntary disclosure refers to the disclosing of proprietary information in addition to the minimum disclosures mandated by financial regulators (Diamond, 1985). Despite their voluntary nature, EPRs are an important element of a firm's overall disclosure strategy (Davis et al., 2006) revealing a package of information to investors (Francis et al., 2002). Moreover, the information content, especially narrative content, of EPRs has increased significantly over time (Kross and Kim 2000; Lo and Lys 2000; Francis et al., 2002; Landsman and Maydew, 2002; Collins et al., 2009), and has been accompanied by a corresponding increase in press release length.

Growing acceptance of EPRs among firms coupled with an increasing preference for more qualitative content in EPRs have caught the attention of researchers who are intrigued by studying motives behind such discretionary disclosures (Bushman and Smith, 2001; Francis et al., 2002; Lang and Lundholm, 2000). Several studies provide strong evidence for firms' use of impression management in EPRs (Bowen et al., 2005; Henry, 2008; Davis and Tama-Sweet, 2012; Guillamon-Saorin et al., 2012). This study choses EPRs among other types of voluntary disclosures because EPRs are widely used by firms (Francis et al., 2002; Collins et al., 2009) and they are easily accessible (Bowen 
et al., 2005). The importance of these two characteristics of EPRs becomes more pronounced in the context of low-visibility firms which this study explores.

The concept of firm visibility is often determined by various proxies including analyst following (Arbel and Strebel, 1983; Bushee and Miller, 2012) and institutional ownership (Kadlec and McConnell, 1994; Abarbanell et al., 2003). Based on theories such as neglected firms (Arbel and Strebel, 1982; Arbel et al., 1983; Arbel, 1985) and the investor recognition hypothesis (Merton, 1987), prior research finds that firm visibility is affected by firm size (Coval and Moskowitz, 2001; Abarbanell et al., 2003), exchange prominence (Lehavy and Sloan, 2008), and investor relations programs (Bushee and Miller, 2012). Disclosure effects are more pronounced for less-visible firms (Bhushan, 1989; Lang and Lundholm, 1996; Botosan, 1997; Brockman et al., 2017), as measured by the extent of analyst following and institutional ownership. These effects create opportunities for impression management by less visible firms (Davis and Tama-Sweet, 2012; Blankespoor et al., 2013; Hamrouni et al., 2015; Bhagwat and Burch, 2016). This research studies TSX Venture firms to explore impression management practices of lowvisibility firms and the consequences of these practices for investors.

\subsection{Research problem}

A growing body of research has investigated impression management from both firm (Merkl-Davies and Brennan, 2007; Loughran and McDonald, 2011; Davis and Tama-Sweet, 2012; Aerts and Cheng, 2012; Aerts and Yan, 2017) and investor perspectives (Henry 2008; Huang et al., 2014; Arslan-Ayaydin et al., 2016). Yet, research gaps remain in both perspectives. In general, the research problem arises from three major gaps in the existing impression management literature: lack of research on low- 
visibility firms, limited research on the holistic view of impression management, and the absence of research investigating the direct impact of impression management on investors. The following subsections discuss each research gap in more detail.

\subsubsection{Low-visibility firms}

There has been a lack of research to understand impression management practices of exclusively low-visibility firms. Several studies conclude that less visible firms are more likely to take advantage of private information since there is generally insufficient information available to investors to monitor firms' actions (Elliott et al., 1984; Schipper, 1989; Wareld et al., 1995; Merkl-Davies and Brennan, 2011). Therefore, less visible firms can more successfully influence the perceptions of the readers of their disclosure documents (Short and Palmer, 2003; Merkl-Davies and Brennan, 2007; Blankespoor et al, 2013; Bhagwat and Burch, 2016; Bartov, 2017). Some existing impression management studies have included some firms with low-visibility characteristics in their samples, but these studies do not provide generalizable findings on impression management practices of low-visibility firms (Bowen et al., 2005; Davis et al., 2012; Kimbrough and Wang, 2014; Benson et al., 2015; Kim et al., 2016). As a result, there is little known on impression management practices of specifically low-visibility firms. This study uses a sample of TSX Venture firms to explore impression management by exclusively low-visibility firms in their EPRs. TSX Venture Exchange firms play an important role in the Canadian economy but they have mostly been ignored by accounting or finance researchers so far.

Canada's natural resources are responsible for a significant portion (16\%) of the country's GDP and account for 1.74 million Canadian jobs directly and indirectly 
(Statistics Canada, 2017). While Canadian mining and energy firms play a crucial role in the process of extracting economic value from the country's vast natural resources, these firms largely depend on Canadian stock exchanges to finance their operations. With nearly $60 \%$ of global mining financing and over $\$ 18$ billion in equity capital raised for energy firms, the TSX Venture Exchange and the TSX stock exchange are global leaders in providing access to capital for natural resource firms (TMX Group, 2018). In terms of the number of issuers, the TSX Venture Exchange accounts for over $80 \%$ of overall mining companies and more than $62 \%$ of energy companies that are listed on the two Canadian exchanges (TMX Group, 2018).

Therefore, studying the disclosure practices of TSX Venture firms and motivations for such disclosures creates knowledge that can benefit investors, regulators, and firms leading to better utilization of Canada's natural resources. Although it has over 1,600 listed companies and \$51 billion market value (TMX Group, 2017), the TSX Venture Exchange has not yet received significant attention from academic scholars. The exchange is one of the leaders in providing opportunities to raise equity capital for emerging, small and less visible companies from 14 sectors of the economy. It is estimated that the average market capitalization of listed companies on the TSX Venture exchange is $\$ 30.7$ million (TMX Group, 2017). Therefore, TSX Venture firms can be classified as less visible firms as the firms exhibit the main characteristics of less visible firms - small market capitalization, low liquidity, low analyst following, and listed on less prominent exchanges (Bushee and Miller, 2012). Such characteristics of TSX Venture firms make them a valuable venue of research to study impression management and investor reaction to it. 
This study uses the phrase 'apparent impression management' when referring to investor reaction because the study investigates investors' reactions to impression management measures rather than impression management. The objective in the investor perspective is to explore how investors respond when they are presented with various degrees of impression management measures in EPRs. The distinction between impression management measures and impression management is discussed in the investigation of the firm perspective (Section 4.6).

\subsubsection{Holistic view on impression management}

There is limited research that explores a holistic view of impression management practices and their consequences. The holistic view used in this context signifies providing an overall understanding of impression management practices of firms, as opposed to selectively choosing one or two impression management practices for investigation. While existing literature has examined several impression management strategies (Subramanian et al., 1993; Smith and Taffler, 2000; Yuthas et al., 2002; Courtis, 2004; Bowen et al., 2005; Rutherford, 2005; Brennan et al., 2009; Li, 2010; Loughran and McDonald, 2011; Davis and Tama-Sweet, 2012; Aerts and Cheng, 2012; Rennekamp, 2012; Patelli and Pedrini, 2013; Huang et al., 2014; Allee and DeAngelis, 2014; Kimbrough and Wang, 2014; Arslan-Ayaydin et al., 2016; Sandulescu and Albu, 2018), most studies have focused on solely tone management and a very limited number of studies (Davison, 2008; Henry, 2008; Richards, 2011; Guillamon-Saorin et al., 2012) have looked at more than one impression management strategy in the same study. Differences in the disclosure document investigated, the characteristics of sample firms, and other research design specifics may limit the generalizability of findings regarding 
firms' impression management practices across many firms. Therefore, to better understand the overall impression management practices of firms in their disclosures, it is important to examine several impression management strategies in the same sample of firms. Using computer-based content analysis methods, this research examines six (discussed in Chapter 2) of the seven impression management strategies ${ }^{1}$ identified by Merkl-Davies and Brennan (2007). Studying several impression management strategies simultaneously helps better understand firms' engagement in impression management practices and investor reaction to identified impression management.

Moreover, unlike most prior impression management studies, the present study offers the investigation of both firm and investor perspectives on impression management. There are two main benefits of investigating both perspectives together. First, findings are more robust when firm and other control variables remain unchanged in measuring impression management and investor reaction. Second, since several impression management strategies are investigated together, incorporating investor reaction allows us to observe whether investors are influenced more strongly by those strategies which are stressed by firms.

\subsubsection{Direct impact of impression management}

From the investor perspective, there is limited research that explores the direct impact of impression management on investors' perceptions. Prior research has mainly investigated stock market reaction in response to some impression management strategies (Henry, 2008; Feldman et al., 2010; Aerts and Cheng, 2011; Huang et al., 2014;

\footnotetext{
${ }^{1}$ One of the seven impression management strategies is not examined due to challenges of measuring it using computer-based methods. More in-detail discussion is provided in Section 2.3 of this study.
} 
Wisniewski and Yekini, 2015, Arslan-Ayaydin et al., 2016). Measuring investor reaction to apparent impression management by analyzing stock price assumes that, if there is impression management, then investors have paid attention to it. Investigating users' direct reactions to apparent impression management in a disclosure adds value to our understanding of how impression management is perceived among investors. This investigation can provide valuable findings regarding retail investors' attention (to apparent impression management) which may be timelier than stock price reaction. Prior research that investigated the perceptions of impression management was limited to experiments (Rennekamp, 2012). While online investment discussion boards offer a great opportunity for analyzing investors' perceptions of impression management, there has been no research that uses this data source for this purpose. This study extends investor reaction literature by analyzing users' discussions from online investment boards. More specifically, it uses several hundred thousand discussion board posts to investigate how individual investor respond to apparent impression management in the EPRs of TSX Venture Exchange firms.

An online discussion board, also known as a forum, is an internet community which connects individuals who interact to share their opinions and seek information (Wasko and Faraj, 2005; Figer, 2014; Park et al., 2014; Seethamraju, 2014). Recent shifts in online communication, coupled with the growth of online stock trading, have fueled the popularity of investment- and stock-related discussion boards over the last few years. Academic researchers have used online investment discussion data from a wide range of free online investment boards such as Yahoo! Finance, SeekingAlpha, Raging Bull, HotCopper, TheLion.com (Antweiler and Frank, 2004; Das and Chen, 2007; Sabherwal 
et al., 2011; Chen et al. 2014; Leung and Ton, 2015; Lerman, 2017). The use of online investment discussion boards is not a new source of data in disclosure research. Prior research has mainly used this data to investigate how collective discussions can explain stock behavior around various corporate disclosure events (Tumarkin and Whitelaw, 2001; Sabherwal et al., 2008; Hu et al., 2013; Blankespoor et al., 2013; Prokofieva, 2015). Researchers have also studied the association between disclosures and aggregate discussion metrics such as overall volume and sentiment (Antweiler and Frank, 2005; Das and Chen, 2007; Sprenger et al., 2014). However, there has been no study that investigates users' reaction to apparent impression management using online investment discussion board data. This creates a unique research opportunity that can greatly benefit existing impression management research.

\subsection{Research objective}

The objective of this study is to explore the extent and nature of both impression management by low-visibility firms and its impact on investors. Understanding impression management practices of low-visibility firms and investor reaction to apparent impression management has implications for financial regulators, individual investors, and firms issuing voluntary disclosure documents. Financial regulators such as Canadian Securities Administrators (CSA) may want to determine whether impression management in EPRs is widespread among low-visibility firms and what are the prevalent impression management strategies. Also, the ramifications of investor reaction to apparent impression management is another aspect that may be of concern to the CSA. Better understanding the consequences of impression management can help determine whether disclosure practices in EPRs should be regulated by standardizing the presentation of 
information in these voluntary disclosure documents. Financial regulators can also benefit from evidence on various factors that affect firms' motivations for impression management. Overall, findings of this study can assist with approaches or methods for designing effective disclosure policy regulations.

Since low-visibility firms are characterized by having a small institutional ownership percentage (Arbel, 1985; Coval and Moskowitz, 2001; Abarbanell et al., 2003, Bushee and Miller, 2012), TSX Venture Exchange firms are mostly owned by individual investors (discussed in Chapter 2). Individual investors are more susceptible than analysts and institutional investors to opportunistic disclosures in EPRs because individual investors rely more on public sources of information (Bhattacharya et al. 2007). Moreover, since disclosure effects are more pronounced for smaller and less-visible firms (Bushan, 1989; Lang and Lundholm, 1996; Botosan, 1997; Brockman et al., 2017), individual investors should be aware of opportunistic disclosure strategies in EPRs. Therefore, better understanding various types and effects of impression management in corporate disclosure documents benefits individual investors who base their investment decisions on information from EPRs.

Firms can also benefit from this research as it provides insights on both firm and investor perspectives, which may help firms determine optimal disclosure strategies. Firms may want to be aware of the short-term and longer-term stock market reactions to apparent impression management. Knowledge of stock price consequences of impression management can, and should, be an important element of management's decision making. Moreover, firms may also be interested in investors' more direct reactions to apparent impression management from online investment discussion boards. For 
example, can investors see through various impression management strategies in voluntary disclosures? More specifically, does impression management lead to higher discussion volume or a particular sentiment in online investment discussion boards? Collectively answers to these questions can generate important insights that firms may want to consider when crafting their voluntary disclosure policies.

\subsection{Research questions}

Overall, there are two general questions this study aims to answer on the firm and investor perspectives on impression management.

RQ A. What, if any, impression management practices do low-visibility firms use in their EPRs?

RQ B. What is investors' reaction to apparent impression management?

The first general research question (RQ A) is regarding the firm perspective on impression management. By addressing this question, this study aims to shed light onto impression management practices of low-visibility firms. In particular, it helps determine whether, and how (using which strategies), TSX Venture firms opportunistically manage the presentation of information in their EPRs based on financial performance. This study also provides findings on the characteristics (e.g., industry, firm size) of firms that engage in various impression management practices. More specific questions on the firm perspective are as follows:

RQ A1. Does firm performance affect the likelihood of engagement in impression management strategies by TSX Venture firms?

RQ A2. What are prevalent impression management strategies used in the EPRs of TSX Venture firms? 
RQ A3. What are the characteristics of TSX Venture firms that use certain impression management strategies?

The second general research question (RQ B) is on the investor perspective, which explores the consequences of impression management for investors. This study investigates both stock market reaction and online investment discussion board reaction to apparent impression management. For stock market reaction, it examines the associations between various impression management strategies and stock price behavior. More specifically, research questions on stock market reaction can be expressed as follows:

RQ B1. Is there relationship between impression management strategies and stock returns?

RQ B2. How do certain impression management strategies impact stock returns?

This study provides answers to these questions which help better understand capital market implications of impression management by TSX Venture firms. Additionally, this study explores questions regarding online investment board reaction as an alternative way of understanding investor reaction. This exploration can provide supplementary findings on investor reaction that can increase overall understanding of the consequences of impression management. More specific research questions regarding online investment board reaction can be expressed as follows:

RQ B3. Is there an association between impression management and online user reaction, as measured by discussion volume?

RQ B4. Is there an association between impression management and online user reaction, as measured by discussion sentiment? 
Finding answers to these questions helps better understand individual investor behavior in response to apparent impression management.

\subsection{Research approach}

Drawing from the extant literature on disclosure and impression management, this study employs a deductive approach for empirically investigating the firm and investor perspectives on impression management. Therefore, in general, it relies on a positivist epistemology directed at testing relationships formulated in hypotheses (see Chapter 3) by statistical analysis of collected data. The data used to test these relationships is diverse and includes EPRs, firm fundamentals (e.g., operating income, total assets, market capitalization), stock market (e.g., stock prices and returns), and investment discussion board messages (volume and content). Although the data used is both qualitative and quantitative in nature, this study applies a quantitative approach by employing regression analyses. This is achieved by quantifying the content of qualitative data and applying a computerized analysis approach.

This study employs two major methodologies to examine firm and investor perspectives on impression management. First, to examine impression management from the firm perspective, this study employs an innovative methodology which is based on constructing impression management measures using computer-assisted content analysis methods and testing the associations of these measures with firm performance. The process of constructing impression management measures is mainly adopted from prior literature which primarily uses manual content analysis methods (Kohut and Segars, 1992; Lee et al., 2004; Baginski et al., 2004; Brennan et al., 2009; Aerts and Cheng, 2012; Guillamon-Saorin et al., 2012; Kimbrough and Wang, 2014). This study also 
replicates the existing literature which uses computer-assisted ways of measuring tone (Davis et al., 2007; Henry, 2008; Loughran and McDonald, 2011; Davis and TamaSweet, 2012; Arslan-Ayaydin et al., 2016) and readability (Li, 2008; Richards, 2011; Lee, 2012) of disclosure documents. Then, the association between each constructed impression management measure and firm performance is tested using a regression analysis.

Second, to examine impression management from the investor perspective, this study uses the event study methodology which is widely used in capital markets research. Regression analysis is performed to analyze the impact of impression management on investor reaction by testing the association between each investor reaction measure and the constructed impression management measures. Investor reaction measures represent stock market reaction through abnormal returns and online investment discussion board reaction through abnormal discussion volume and sentiment. Chapter 4 discusses the overall methodology and methods in detail.

Table 1.1 summarizes some of the main points discussed this far in Chapter 1. It provides a brief outline of the research theme, problem, purpose, questions, and approach. 
Table 1.1 Research theme, problem, objective, questions, and approach

\begin{tabular}{|c|c|}
\hline Research theme & $\begin{array}{l}\text { The study of impression management in the EPRs of low- } \\
\text { visibility firms and its consequences }\end{array}$ \\
\hline Research problem & $\begin{array}{l}\text { Limited or lack of research on low-visibility firms, a holistic view } \\
\text { of impression management, and the direct impact of impression } \\
\text { management on investors }\end{array}$ \\
\hline Research objective & $\begin{array}{l}\text { To explore the extent and nature of impression management by } \\
\text { low-visibility firms and its impact on investors }\end{array}$ \\
\hline $\begin{array}{l}\text { Research questions } \\
\text { (general) }\end{array}$ & $\begin{array}{l}\text { A. What, if any, impression management practices do low- } \\
\text { visibility firms use in their EPRs? } \\
\text { B. What is investors' reaction to apparent impression } \\
\text { management? }\end{array}$ \\
\hline $\begin{array}{l}\text { Research questions } \\
\text { (specific) }\end{array}$ & $\begin{array}{l}\text { A1. Does firm performance affect the likelihood of engagement } \\
\text { in impression management strategies by TSX Venture firms? } \\
\text { A2. What are prevalent impression management strategies used } \\
\text { in the EPRs of TSX Venture firms? } \\
\text { A3. What are the characteristics of TSX Venture firms that use } \\
\text { certain impression strategies? } \\
\text { B1. Is there relationship between impression management } \\
\text { strategies and stock returns? } \\
\text { B2. How do certain impression management strategies impact } \\
\text { stock returns? } \\
\text { B3. Is there an association between impression management and } \\
\text { online user reaction, as measured by discussion volume? } \\
\text { B4. Is there an association between impression management and } \\
\text { online user reaction, as measured by discussion sentiment? }\end{array}$ \\
\hline Research approach & $\begin{array}{l}\text { An empirical approach that quantitatively tests a set of } \\
\text { formulated hypotheses by analyzing collected data based on } \\
\text { content analysis and event study methodologies }\end{array}$ \\
\hline
\end{tabular}

\subsection{Document road map}

The rest of this document is organized as follows. Chapter 2 provides a review of existing literature on disclosure management, firm visibility, and investor reaction to disclosure management. These areas of research represent founding blocks for this study, and the connections between these areas are discussed throughout the chapter. The final 
section of Chapter 2 discusses research gaps in the existing literature and presents a research map that connects the dots for this study.

Chapter 3 identifies the epistemology underlying this research and develops specific research hypotheses to be tested. For the firm perspective, the formulation of hypotheses is based on how firm performance relates to each impression management measure. Hypothesis development for the investor perspective is twofold as it seeks to investigate both stock market reaction and online investment discussion board reaction. Stock market reaction hypotheses are designed to test relationships between abnormal stock returns and the impression management measures. Online investment discussion board reaction to apparent impression management is tested using two hypotheses which are aimed at testing relationships between the impression management measures and abnormal discussion volume or abnormal discussion sentiment.

Chapter 4 discusses the research methodology. It starts with defining a research strategy which provides an overview of the overall approach. Next, the chapter identifies data sources, develops the sampling design, discusses the data collection process, provides details on the measurement of variables, and explains the data analysis approach.

Chapter 5 provides descriptive statistics for main variables and presents regression results. It also discusses other possible scenarios for both firm and investor perspectives and performs additional regression analyses. Moreover, Chapter 5 also includes correlation analysis and multicollinearity checks to ensure that there are no major statistical issues in the relationships between variables. 
Finally, Chapter 6 comprises two major parts: discussion and conclusion. The discussion section reflects on the regression results and explains the findings in reference to the formulated hypotheses, research propositions, and existing impression management literature. The conclusion section concludes this study by summarizing main findings and outlining contributions and implications. The last section also discusses limitations of this research and identifies possibilities for future research. 


\section{Chapter 2 - Literature Review}

This study builds on research from several interconnected areas of accounting and finance literature: voluntary disclosures, disclosure management, impression management, firm visibility, and reaction to apparent impression management. The first section of this chapter reviews extant voluntary disclosure and disclosure management literature. Also, it summarizes motivations for, and consequences of, voluntary disclosures as well as provides findings from several disclosure management studies. The second section discusses prior work to define the construct of firm visibility and to show the effects of firm visibility on voluntary disclosure motivations. It also includes the discussion of factors affecting the visibility of firms and low-visibility firms. The third section reviews existing impression management literature. It defines impression management, discusses major impression management strategies, and reviews content analysis methods used in prior literature to examine impression management. The third section also includes a review of research that investigated impression management in EPRs and the discussion of the implications of firm visibility for impression management. The fourth section introduces research on investor reaction to apparent impression management. It also draws on growing empirical work on individual investor attention and studies using data from online investment discussion boards to set the stage for the current study. The fifth section discusses other important factors that affect impression management and its consequences. Finally, the sixth section concludes the literature review by summarizing existing research gaps and presents a research framework for this study. 


\subsection{Voluntary disclosure motivations and disclosure management}

Corporate disclosure can be grouped into two broad categories: mandatory disclosure and voluntary disclosure. Mandatory or compulsory disclosure, which includes such disclosure documents as financial statements, material change forms, and insider trading reports, is required by financial regulators to satisfy investors' informational needs. Financial regulators have specific requirements for when and how mandatory disclosure documents must be filed to help investors make informed investment decisions (Ontario Securities Commission, 2018).

Voluntary or discretionary disclosure, on the other hand, generally refers to the disclosing of proprietary information in addition to minimum disclosures mandated by market regulators (Diamond, 1985). It entails voluntary communication of information through various disclosure mechanisms such as management forecasts, management's discussion and analysis (MD\&A), analysts' presentations and conference calls, press releases, internet sites, and other corporate reports (Healy and Palepu, 2001). This section starts with the introduction of EPRs which are voluntary disclosure documents. Next, the section proceeds with an explanation of why firms are motivated to publish voluntary disclosures, as articulated in the extant voluntary disclosure literature. Finally, the section discusses the disclosure management literature to show how firms manage various aspects of their disclosures.

\subsubsection{Earnings press releases}

Many public firms issue earnings press releases (EPRs) several weeks after the end of each quarter to inform investors about their performance for the quarter (Henry, 
2008). EPR disclosure falls under the category of voluntary disclosure as this disclosure document is not required to be issued by regulators (see Figure 2.1). These disclosure documents allow firms substantial discretion in the interpretation of their quarterly or annual performance results in addition to complete discretion regarding whether they issue EPRs (Bowen et al., 2005; Kimbrough and Wang, 2014). Despite their voluntary nature, EPRs comprise an important element of a firm's overall disclosure strategy (Davis et al., 2006) revealing a package of information to investors (Francis et al., 2002). Therefore, prior literature has investigated not only why firms issue this disclosure document but also how they disclose it in terms of the disclosure channel and the information content.

The information content of EPRs has increased significantly over time (Kross and Kim 2000; Lo and Lys 2001; Francis et al., 2002; Landsman and Maydew, 2002; Collins et al., 2009) and has been accompanied by a corresponding increase in press release length. More importantly, there has been a significant increase in the number of words used in these discretionary disclosure materials (Francis et al. 2002). Collins et al. (2009) argue that the increase in the content of EPRs is associated with increased informativeness of earnings announcements. They also find that the increased information content of EPRs leads to investors' intensified reaction to earnings surprises. These findings are consistent with Landsman and Maydew (2002) and Brown and Sivakumar (2003), who reach similar conclusions regarding the impact of an increase in the informativeness of EPRs on stock price and trading volume behaviors.

An important element of the increasing qualitative and quantitative information content of EPRs is how firms present their results, potentially influencing the perceptions 
of investors (Bowen et al., 2005). Prior research finds that firms manage various features of EPRs such as tone, visual and structural presentation, readability, and other rhetorical aspects (Henry, 2008; Guillamon-Saorin et al., 2012; Kimbrough and Wang, 2014;

Arslan-Ayaydin et al., 2016). Therefore, firms view EPRs as an unregulated communication channel to inform investors about performance as well as influence their perceptions of firm performance (Guillamon-Saorin et al., 2012).

\section{Figure 2.1. Corporate disclosure documents}

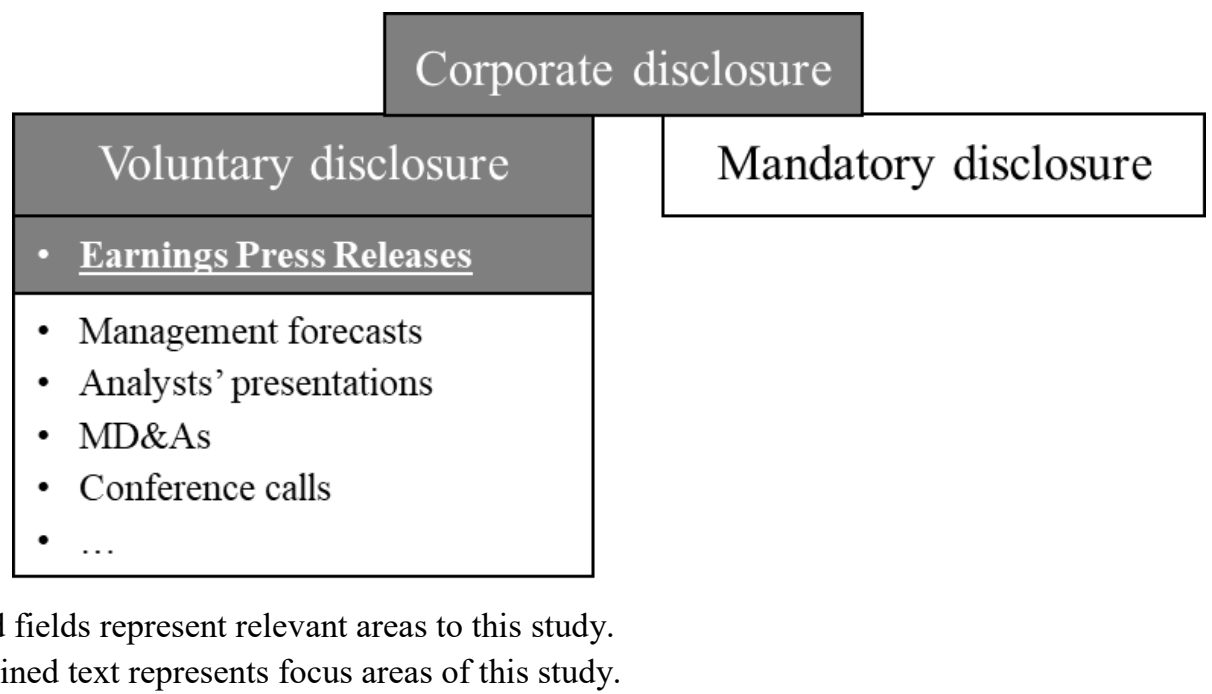

\subsubsection{Motivations for voluntary disclosures}

A number of theoretical and empirical studies have examined firms' motivations for issuing voluntary disclosure documents or EPRs, in particular. In their review of previous voluntary disclosure literature, Healy and Palepu (2001) identify improved stock liquidity, reduced cost of capital, and increased information intermediation as three main consequences of expanded voluntary disclosure (see Figure 2.2). Diamond (1985) argues that firms are motivated to disclose more information than prescribed by regulators in order to reduce information asymmetry with their investors. He uses a general 
equilibrium model with endogenous information collection to show an optimal public information release policy which can benefit all security holders. In a similar analytical study, Diamond and Verrecchia (1991) also develop an equilibrium model of liquidity to show theoretically that greater disclosure improves stock liquidity by reducing information asymmetries in the firm's capital markets. They also note that expanded disclosure leads to increased interest from institutional investors. In addition, their model predicts that reduced information asymmetry, as a result of higher levels of disclosure, will decrease a firm's cost of capital.

While voluntary disclosure research generally explains the association between disclosure and cost of capital with reference to market liquidity, Lambert et al. (2006) propose a novel model that establishes a direct link between disclosure quality and cost of capital, with no reference to liquidity. They show that the quality of disclosure by a firm about its future cash flow directly affects market participants' perceptions about the distribution of future cash flows. Based on this premise, Lambert et al. (2006) argue that higher disclosure quality and volume can reduce a firm's cost of capital.

Extant empirical literature has also provided evidence for both improved stock liquidity and reduced cost of capital consequences of voluntary disclosures. In his review of empirical studies on voluntary corporate disclosures, Lev (1992) concludes that voluntary disclosures not only influence stock prices and volumes, but they also impact stock volatility and bid-ask spreads, thus affecting the liquidity of securities. He provides evidence from studies investigating various voluntary disclosures such as managerial earnings forecasts (Lev and Penman, 1990), management's discussion and analysis (Hoskin et al., 1986), announcement of acquisition programs (Schipper and Thompson, 
1983) and justifying dividend decreases (Woolridge and Ghosh, 1985) to show how the level of voluntary disclosure is negatively associated with stock market liquidity.

Welker (1995) uses analysts' ratings of firms' disclosures as a proxy for firm disclosure policy to explore the association between market liquidity and disclosure policy. He finds that market liquidity, as measured with bid-ask spreads, is significantly higher for firms with higher disclosure rankings than firms with lower disclosure rankings. Analysts' disclosure rankings in his study are based on weighted scores from both mandatory and voluntary disclosure materials for each firm in the sample.

Following Welker (1995), Sengupta (1998) also uses firm disclosure rankings given by financial analysts and finds evidence that firms with high disclosure quality ratings enjoy a lower cost of debt capital. He also finds that the disclosure effect is more significant in situations where there is a greater market uncertainty surrounding the firm as measured by the variance of stock returns. The results of Sengupta's (1998) study indicate that a higher disclosure quality impacts bond yields and interest costs in addition to the cost of equity capital.

Unlike Welker (1995) and Sengupta (1998), Botosan (1997) designs and validates a self-constructed disclosure index that considers an aggregate disclosure score based on items disclosed in the annual reports of 122 machinery firms. She uses these disclosure scores to investigate the association between disclosure level and a firm's cost of equity capital. The results of her study indicate a negative association between the disclosure measure and the cost of equity capital for firms with low analyst following, but the results did not extend to firms with high analyst following. 
More recently, following Botosan (1997), Francis et al. (2008) have also developed a self-constructed measure of firms' voluntary disclosures to examine the association between voluntary disclosure and the overall cost of capital. They find that more voluntary disclosure is associated with a lower cost of capital. Francis et al. (2008) test this association on disclosures of 677 firms representing multiple industries for the period of 1991-2001. Francis et al. (2008) provide strong evidence for the impact of voluntary disclosure volume on the cost of capital in terms of the generalizability of their findings.

Another consequence of expanded voluntary disclosure is increased information intermediation resulting from the impact of disclosures on analyst following. Both theoretical and empirical studies have provided evidence that a higher level of disclosure leads to a lower cost of information acquisition for analysts and thus increases the supply of analyst services (Glosten and Milgrom, 1985; Diamond and Verrecchia, 1991; Lang and Lundholm, 1996; Botosan, 1997; Francis et al., 2008). In addition, researchers find that voluntary disclosure improves the quality of analysts' earnings forecasts and the accuracy of their recommendations (Lang and Lundholm, 1996; Lakhal, 2009; Dhaliwal et al., 2012). Bhushan (1989) develops an analytical model to examine the effect of various firm characteristics on the amount of information collected on the firm. He argues that firm size influences the cost of information acquisition because large firms have more sources of information than small firms, thereby larger firms make more public disclosures.

More recently, Hamrouni et al. (2017) studied the relationship between the extent of voluntary disclosure in annual reports and the level of analyst following for 155 
French firms listed on the Euronet Paris stock exchange. The authors find a statistically significant relationship between voluntary disclosure level and the number of analysts covering the firm. Their results indicate that voluntary information may reduce the cost of information collection for analysts, motivating analysts to increase their service offerings. Based on these findings, Hamrouni et al. (2017) suggest that voluntarily disclosed information may serve as a financial marketing technique for enticing analysts and influencing their behavior.

Consequences of voluntary disclosure help explain why firms may be motivated to voluntarily disclose information. Researchers have provided evidence that improved stock liquidity and reduced cost of capital can explain some of the reasons for voluntary disclosure. Most of these studies are based on the premise that disclosure reduces uncertainty about the firm by lowering information asymmetry between firms and investors. This premise stems from the theoretical studies of Barry and Brown (1985, 1986) and Merton (1987), who argue that investors demand a higher risk premium for bearing risk when there is a higher level of information asymmetry. Therefore, voluntary disclosure is viewed as a means of communicating proprietary information to external investors in order to create better financing and investing opportunities for the firm. Healy and Palepu (1993) argue that voluntary disclosures provide a potentially important means of delivering proprietary information to outside investors, even if capital markets are efficient. However, researchers have identified certain tradeoffs that have to be considered when making a decision regarding voluntary disclosures.

A sizable literature has used economic theory to establish tradeoffs between providing voluntary disclosure to reduce information asymmetry for a firm's stock and 
certain economic consequences of voluntary disclosure. More specifically, those tradeoffs compare the benefits in the reduction of information asymmetry with certain costs such as proprietary costs (Verrecchia, 1983), direct costs of disclosure (Gray et al., 1990), and litigation costs (Skinner, 1994). Firms carefully analyze these costs associated with voluntary disclosure, which only occurs if the benefits of disclosing outweigh the costs. Verrecchia (1983) proposes an analytical model that uses a notion of proprietary costs, which he interprets as the cost of revealing any information that may negatively affect a firm's future cash flows. His explanation of the rationale for voluntary disclosure is based on the premise that, due to proprietary costs associated with disclosure, only firms with news above a certain cost threshold will disclose information. Therefore, Verrecchia (1983) states that firms compare the benefits of voluntarily providing information with withholding information to maximize the firm's product market advantage.

In empirical work which investigates cost constraints on voluntary disclosure, Gray et al. (1990) examine various costs involved in the voluntarily disclosure of information. They argue that a firm's incentive to disclose information voluntarily is also constrained by direct costs such as data collection, processing, production, and auditing. Skinner's (1994) explanation for the motivations for voluntary disclosure is also based on Gray et al.'s (1990) empirical study of voluntary earnings-related disclosures of a sample of NASDAQ firms. Skinner (1994) suggests that firms voluntarily disclose bad news to avoid or reduce litigation costs which may result from large stock price declines on earnings announcement days. He also finds that firms provide precise quantitative earnings estimates when disclosing good news disclosures and less precise qualitative 
estimates when disclosing bad news. This subjectivity in the disclosure behavior of firms is an indication of disclosure management, which has been extensively studied in the prior literature (discussed in Section 2.3). Disclosure management is shaded in Figure 2.2 because it is one of the fields of research relevant to the present study.

\section{Figure 2.2. Motivations for voluntary disclosure}

\section{Motivations for voluntary disclosure}

- Improved stock liquidity

- Reduced cost of capital

- Increased information intermediation

- Disclosure management opportunity

*Shaded fields represent relevant areas to this study.

\subsubsection{Disclosure management}

Opportunity for disclosure management may serve as another motivation for disclosing information voluntarily (Gibbins et al., 1990; Merkl-Davies and Brennan, 2007). Disclosure management can be defined as a set of activities by the firm that include deliberately chosen strategies impacting what is released (Gibbins et al., 1990). As discussed in the previous section, the first three motivations have been extensively studied in previous literature as primary motives for disclosing information voluntarily. Although opportunity for disclosure management is not widely viewed as one of the motivations for voluntary disclosure, growing accounting literature provides evidence that firms are incentivized to influence investors by strategically managing their disclosures (Carslaw, 1988; Baker and Kare, 1992; Courtis, 1996; Kasznik, 1999; Bujaki and McConomy, 2002; Elliott, 2006; Davis and Tama-Sweet, 2012; Jackson et al., 2014; 
Arslan-Ayaydin et al., 2016). Therefore, disclosure management opportunity is included in overall disclosure management motivations which affect voluntary disclosure. In Figure 2.2, disclosure management opportunity is shaded because it is one of the areas that is relevant to this study.

In their review of disclosure management literature, Gibbins et al. (1990) observe that firms can manage their financial disclosures in several ways based on the method and the source of disclosure management representing separate dimensions of disclosure management. More specifically, Gibbins et al. (1990) identify eight categories of disclosure management that shape disclosure in various aspects including disclosure content and secondary features. They view data content, data organization, prior or concurrent interpretations by the discloser, redundancy, and subsequent interpretation by the discloser as categories for managing disclosure content. In addition, the authors state that firms can carry out disclosure management by manipulating secondary features such as medium, timing, and credibility. Figure 2.3 lists the disclosure management categories defined by Gibbins et al. (1990). The disclosure management categories in the shaded region of the figure are associated with impression management strategies explored in this study. These associations are discussed later in this subsection.

Empirical disclosure management literature provides mounting evidence for the impact of each of disclosure management category on the way corporate disclosures are prepared (Briloff, 1972; Hofstedt and Hughes, 1977; Gibbins, 1982; Watts and Zimmerman, 1986; Thompson et al., 1987; Jones, 1988; Schipper, 1989; Atiase et al., 1989; D’Aveni and MacMillan, 1990; Roberts, 1990). Table 2.1 summarizes some empirical disclosure management studies entailing managing content or secondary 
features of various voluntary and mandatory disclosure documents. The selection of papers, which cover a period from late 1980s to 2019, is based on the attempt to provide information on various disclosure management categories and strategies in a wide range of disclosure documents.

\section{Figure 2.3. Disclosure management categories}

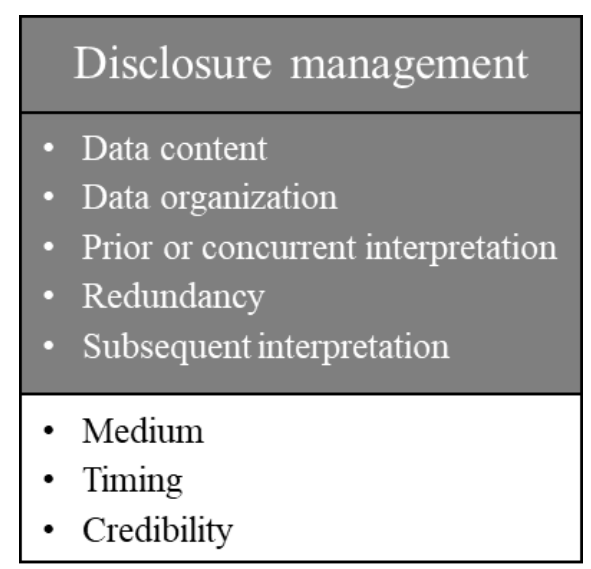

*Shaded fields represent relevant areas to this study.

A closely related field to disclosure management is impression management which is one of the focuses of this research (discussed in detail in the third section of this chapter). As a part of disclosure management, impression management involves managing content related aspects of voluntary narrative disclosures such as narrative content, organization, and rhetorical features (Merkl-Davies and Brennan, 2007). Therefore, impression management research falls under the content management category of disclosure management and focuses on disclosure management in narrative discretionary disclosures (Merkl-Davies and Brennan, 2007). As highlighted in Figure 2.3, data content, prior or concurrent interpretation by discloser, data organization, redundancy and subsequent interpretation by the discloser categories of disclosure management are in the shaded section of the box as these disclosure management 
categories are related to impression management. These five categories entail managing content rather than secondary features of disclosure documents.

Table 2.1 illustrates that prior research has investigated firms' use of disclosure management strategies by analyzing the content and secondary features of mandatory disclosures, voluntary disclosures, and voluntary disclosures in mandatory disclosure documents. Moreover, the table provides information on how some impression management strategies outlined by Merkl-Davies and Brennan (2007) fit under three of the content management categories of disclosure management described by Gibbins et al. (1990). For example, studies by Baker and Kare (1992) and Davis and Tama-Sweet (2012) examine such impression management strategies as reading ease manipulation and tone management, respectively, and fall under interpretation by the discloser category of disclosure management. Other examples include Ogden and Clarke (2005), Larcker and Zakolyukina (2012), and Bujaki and McConomy (2012) who study such impression management strategies as performance attribution, deception, and use of metaphors, respectively. These studies fall under data content management of disclosure management. Similarly, Elliott (2006), Riedl and Srinivasan (2010) investigate impression management by manipulating the placing or positioning of certain information in disclosure content, and, therefore, fall under data organization category of disclosure management.

Unlike studies that analyze disclosure management in the content of disclosure documents, studies that focus on secondary features of disclosure documents explore disclosure management, rather than impression management. As Table 2.1 shows 
disclosure management categories such as medium (Bujaki and McConomy, 2002), timing (Sengupta, 2004; Jackson et al., 2014), and credibility (Mercer, 2004) involve managing secondary features of disclosure documents, and do not investigate impression management. The focus of this study is impression management which is discussed in detail later in this chapter.

Table 2.1. Disclosure management categories and disclosure documents

\begin{tabular}{|c|c|c|c|}
\hline $\begin{array}{c}\text { Disclosure } \\
\text { management } \\
\text { category }\end{array}$ & Study & $\begin{array}{l}\text { Disclosure } \\
\text { document }\end{array}$ & $\begin{array}{c}\text { Content vs } \\
\text { Secondary } \\
\text { features }\end{array}$ \\
\hline \multirow[t]{11}{*}{ Data content } & Carslaw (1988) & Financial statements & Content \\
\hline & $\begin{array}{l}\text { Hooghiemstra } \\
\text { (2001) }\end{array}$ & $\begin{array}{l}\text { CEO's letter to } \\
\text { shareholders }\end{array}$ & Content \\
\hline & $\begin{array}{l}\text { Ogden and } \\
\text { Clarke (2005) }\end{array}$ & $\begin{array}{l}\text { Voluntary disclosure } \\
\text { in annual reports }\end{array}$ & Content \\
\hline & $\begin{array}{l}\text { Guillamon-Saorin } \\
\text { (2006) }\end{array}$ & EPRs & Content \\
\hline & $\begin{array}{l}\text { Larcker and Zakolyukina } \\
\text { (2012) }\end{array}$ & Conference calls & Content \\
\hline & $\begin{array}{l}\text { Bujaki and McConomy } \\
\text { (2012) }\end{array}$ & $\begin{array}{l}\text { Letters to } \\
\text { shareholders }\end{array}$ & Content \\
\hline & $\begin{array}{l}\text { Guillamon-Saorin et al } \\
\text { (2012) }\end{array}$ & EPRs & Content \\
\hline & Benson et al. (2015) & IPO document & Content \\
\hline & Kim et al. (2016) & $10-\mathrm{K}$ reports & Content \\
\hline & Sandulescu and Albu (2018) & $\begin{array}{l}\text { Letters to } \\
\text { shareholders }\end{array}$ & Content \\
\hline & Yan et al. (2019) & CEO letters & Content \\
\hline \multirow{3}{*}{$\begin{array}{c}\text { Data } \\
\text { organization }\end{array}$} & Bowen et al. (2005) & EPRs & Content \\
\hline & Elliott (2006) & EPRs & Content \\
\hline & Riedl and Srinivasan (2010) & Financial statements & Content \\
\hline \multirow[t]{2}{*}{$\begin{array}{l}\text { Interpretation } \\
\text { by the discloser }\end{array}$} & $\begin{array}{l}\text { Baker and Kare } \\
(1992)\end{array}$ & $\begin{array}{l}\text { President's } \\
\text { letter }\end{array}$ & Content \\
\hline & Li (2008) & Annual statements & Content \\
\hline
\end{tabular}




\begin{tabular}{|c|l|l|l|}
\hline $\begin{array}{c}\text { Disclosure } \\
\text { management } \\
\text { category }\end{array}$ & \multicolumn{1}{|c|}{ Study } & \multicolumn{1}{|c|}{$\begin{array}{c}\text { Disclosure } \\
\text { document }\end{array}$} & $\begin{array}{l}\text { Content vs } \\
\text { Secondary } \\
\text { features }\end{array}$ \\
\hline \multirow{2}{*}{ Redundancy } & $\begin{array}{l}\text { Davis and Tama-Sweet } \\
(2012)\end{array}$ & EPRs and MD\&As & Content \\
\hline Medium & $\begin{array}{l}\text { Courtis (1996) } \\
(2002)\end{array}$ & $\begin{array}{l}\text { Voluntary disclosure } \\
\text { in annual reports }\end{array}$ & Content \\
\hline Disclosure \\
timing & Sengupta (2004) & $\begin{array}{l}\text { Voluntary disclosure } \\
\text { documents }\end{array}$ & $\begin{array}{l}\text { Secondary } \\
\text { features }\end{array}$ \\
\cline { 2 - 5 } & Jackson et al. (2014) & $\begin{array}{l}\text { Quarterly reports } \\
\text { earnings forecasts } \\
\text { (MFEs) }\end{array}$ & $\begin{array}{l}\text { Secondary } \\
\text { features }\end{array}$ \\
\hline Credibility & Mercer (2004) & $\begin{array}{l}\text { Management } \\
\text { disclosures }\end{array}$ & $\begin{array}{l}\text { Secondary } \\
\text { features }\end{array}$ \\
\hline
\end{tabular}

Figure 2.4 illustrates the relationships between corporate disclosure, voluntary disclosure, motivations for voluntary disclosure, disclosure management, and impression management. All shaded fields represent areas relevant to this research while underlined text represents the focus areas of this study. As the figure shows, EPRs fall under voluntary disclosure documents which are impacted by certain benefits that motivate firms to provide voluntary disclosure. The impact of voluntary disclosure motivations on firms' decision to issue voluntary disclosure is shown by arrow \#1. One of the motivations for providing voluntary disclosure is the opportunity for disclosure management which is linked with disclosure management categories comprised of various disclosure management categories as outlined by Gibbins et al. (1990). Hence the dashed line \#3 which connects motivations for voluntary disclosure and disclosure management. As discussed, disclosure management also affects the way disclosure documents are prepared. Arrow \#2 illustrates this relationship. Moreover, as shown in Table 2.1, disclosure management is associated with content management categories 
which are shaded in the shaded region of disclosure management. Dashed line \#5 illustrates this association between disclosure management and impression management. Finally, similar to disclosure management, impression management also influences the way voluntary disclosure documents are prepared. This impact of impression management is shown by arrow \#4. Section 3 of this chapter discusses impression management more in detail.

\section{Figure 2.4. Motivations for voluntary disclosure and disclosure management}

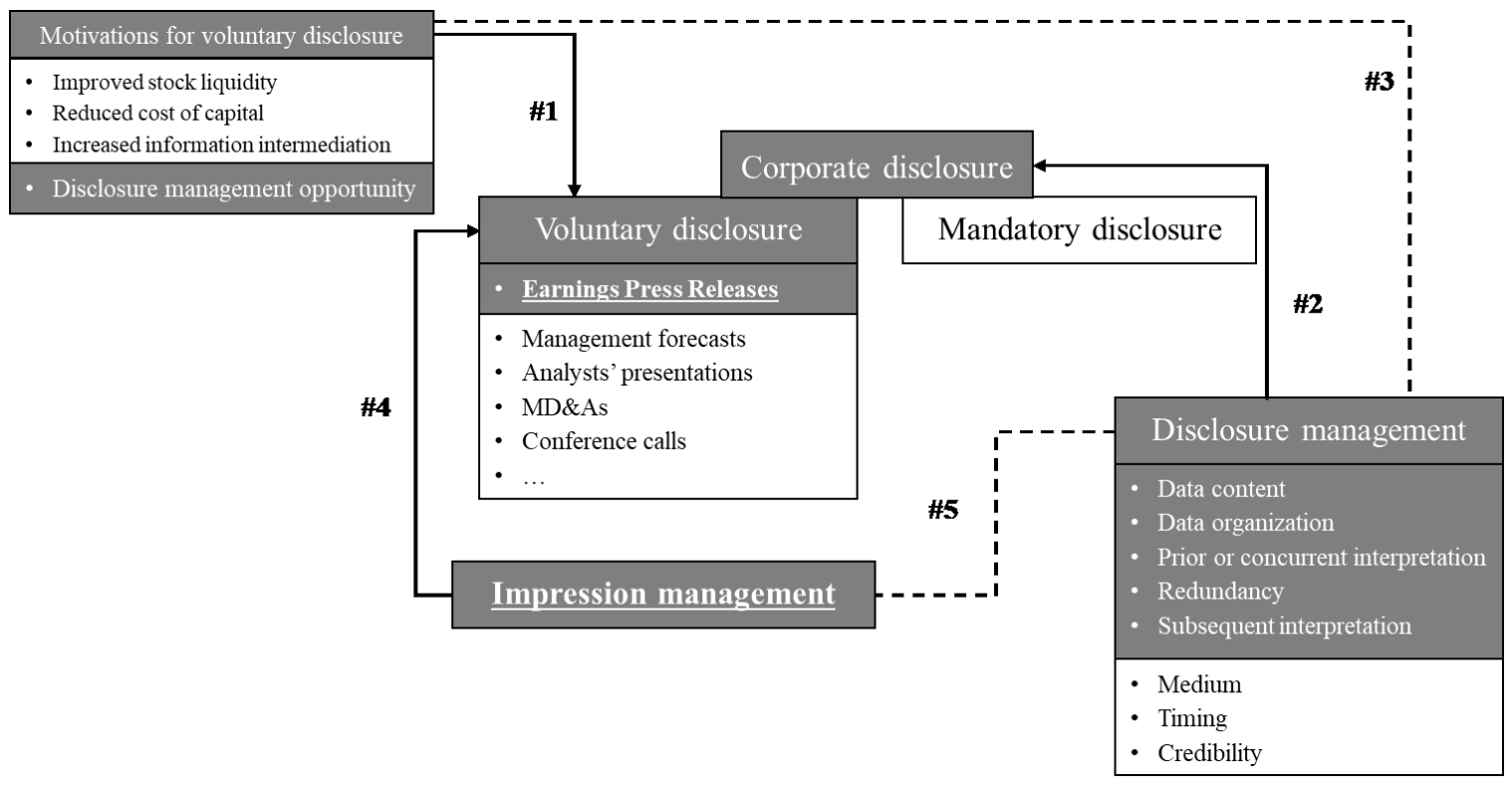

* Shaded fields represent relevant areas to this study.

*Underlined text represents focus areas of this study.

\subsection{Firm visibility and voluntary disclosures}

\subsubsection{Firm visibility definition}

The theoretical roots of the firm visibility concept stem from the theory of 'neglected' firms (Arbel and Strebel, 1982; Arbel et al., 1983; Arbel, 1985) and the 
investor recognition hypothesis (Merton, 1987). The theory of neglected firms is based on the idea that certain firms neglected by analysts and institutions are sold at discount due to the low quality of information available on those firms. Based on this premise, several studies have put forward the "neglected-firms effect" as an empirical exception to the Capital Asset Pricing Model (CAPM). Those studies find premium returns for certain securities which attract minimal interest from financial institutions and analysts. For example, in their empirical examination of 510 firms over a 10-year period Arbel et al. (1983) find that investors expect higher returns when investing in the securities of firms which are overlooked by analysts and institutions. They explain that certain firms, especially small capitalization firms, do not meet the investing requirements of institutions, and, therefore, are generally ignored by analysts. Consistent with Arbel et al. (1983), Abarbanell et al. (2003) confirm the effect of firm size on investing preferences of institutions. They find lower institutional ownership for firms with small market capitalization due to the higher information processing and search costs associated with small firms.

Similar to the neglected firms effect, Merton's (1987) investor recognition hypothesis (IRH) also extends CAPM by proposing a model of capital market equilibrium with incomplete information. Merton's model uses the number of investors who are familiar with a firm as a level of 'investor recognition' for the security of that firm. However, given the difficulty of measuring the number of people who know about a security, Lehavy and Sloan (2008) propose ownership of a security as an empirical proxy to measure investor recognition. Simply, IRH postulates that investors buy and hold only those securities about which they have enough information. One of the main premises in 
the model is that gathering information on stocks requires resources and, therefore, investors, having limited amounts of such resources, save these resources by following only stocks of which they are aware. This leads Merton (1987) to conclude that investors expect higher returns from firms they know less about, and finds that this effect is more pronounced for small firms.

Several studies have provided empirical support for the importance of firm visibility in determining a firm's stock returns. In their investigation of investor recognition of a firm's stock, Lehavy and Sloan (2008) empirically test Merton's (1987) model of capital market equilibrium under incomplete information. They prove that Merton's (1987) theoretical analysis holds in practice and suggest that firm visibility, as proxied by institutional ownership, affects stock price even more than firm fundamentals such as cash flow or return on assets. More specifically, their analysis of 23 -year period institutional data shows that investor recognition affects contemporaneous stock returns more than earnings news. These studies show the importance of firm visibility to both investors and firm managers who are concerned with firm valuation.

Firm managers are also concerned with the visibility of their firms. Managers are interested in greater dissemination of information to reduce uncertainty about their firms. Consequently, reduced risk, as a result of more available information, helps attract the investment community (Barry and Brown, 1987). In an extension of his model, Merton (1987) shows that changes in investor recognition are positively correlated with corporate financing and investing activities. Consistent with Merton (1987), Lehavy and Sloan (2008) find changes in investor recognition are strongly related to contemporaneous and future corporate financing and investing activities. Another benefit of higher firm 
visibility is enhanced efficiency of the trading market in the stock by reducing information asymmetries (Baker et al., 1999). Therefore, the concept of firm visibility has attracted widespread interest from researchers who have investigated the impact of various visibility enhancing measures (i.e., listing on prominent exchange, investor relations programs, etc.).

Both the theory of neglected firms and IRH provide theoretical frameworks for studying the impact of various firm characteristics on firm visibility. While the former explains risk-premiums associated with neglected firms from the perspective of analysts and institutions, the latter uses a more direct measure - investor recognition - to show the variation in returns. Both theories show the importance of firm visibility in defining the security prices of firms. Following these theories, several studies have started using analyst coverage, institutional ownership, and investor base as measures of firm visibility. Building on Merton's (1987) IRH, Kadlec and McConnell (1994) find empirical support for the effect of NYSE listing on firms' visibility among individual and institutional shareholders. Their finding provides support for investor recognition as a result of listing on a prominent exchange which increases both stock liquidity and the number of shareholders following the stock.

However, Baker et al. (1999), who also examine how listing on the NYSE impacts firm visibility, find that increase in firm visibility is primarily associated with increase in firm size, as measured by market capitalization, not with NYSE listing per se. In their definition, firm visibility is the extent to which institutions own, and analysts cover, a firm's stock. More recently, Bushee and Miller (2012) define firm visibility more broadly to investigate firms' motivations for engaging in investor relations (IR) programs 
in the context of small, low-visibility firms. They examine institutional ownership, analyst following, media coverage, and market valuations to empirically study how investor relations activities may help attract investors and information intermediaries. Their findings show that improvements (both in quality and quantity) in corporate disclosure practices as a result of investor relations activities attract wider interest from institutional investors and increase both the breadth and intensity of analyst and media coverage.

Table 2.2 summarizes the findings of prior research regarding firm visibility proxies and factors affecting firm visibility. Analyst coverage, defined as the number of analysts covering the firms, and institutional ownership, defined as the percentage of shares held by institutional investors, are the two most common visibility proxies used in the prior literature. As shown in Table 2.2, many studies find that firm size, which is defined as the total market capitalization of the firm, affects analyst following and institutional ownership. Prominent exchange listing and IR programs have also been found to affect firm visibility proxies. Although there is no commonly accepted measure of exchange prominence, researchers have considered the ability of an exchange to create greater media coverage, offer investor-relation services, forums for securities analysts, and industry conferences (Baker et al., 1999). As for IR programs, Bushee and Miller (2012) define IR programs as a firm's initiation of an IR strategy by hiring an outside IR firm. 
Table 2.2. Firm visibility proxies in prior literature

\begin{tabular}{|c|c|c|c|}
\hline Visibility proxy & Paper & $\begin{array}{l}\text { Factors affecting } \\
\text { firm visibility }\end{array}$ & Underlying theory \\
\hline \multirow{9}{*}{$\begin{array}{l}\text { Analyst coverage } \\
\text { and/or institutional } \\
\text { ownership }\end{array}$} & $\begin{array}{l}\text { Arbel and Strebel } \\
(1982,1983)\end{array}$ & Firm size & Neglected firm effect \\
\hline & Arbel et al. (1983) & Firm size & Neglected firm effect \\
\hline & Arbel (1985) & Firm size & Neglected firm effect \\
\hline & $\begin{array}{l}\text { Kadlec and } \\
\text { McConnell (1994) }\end{array}$ & $\begin{array}{l}\text { Prominent } \\
\text { exchange listing }\end{array}$ & Investor recognition \\
\hline & Baker et al. (1999) & $\begin{array}{l}\text { Prominent } \\
\text { exchange listing }\end{array}$ & $\begin{array}{l}\text { Investor recognition \& } \\
\text { neglected firm effect }\end{array}$ \\
\hline & $\begin{array}{l}\text { Coval and } \\
\text { Moskowitz (2001) }\end{array}$ & Firm size & Investor recognition \\
\hline & $\begin{array}{l}\text { Abarbanell et al. } \\
(2003)\end{array}$ & Firm size & Neglected firm effect \\
\hline & $\begin{array}{l}\text { Lehavy and Sloan } \\
(2008)\end{array}$ & $\begin{array}{l}\text { Prominent } \\
\text { exchange listing }\end{array}$ & Investor recognition \\
\hline & Han et al. (2017) & Firm size & Investor recognition \\
\hline \multirow[t]{2}{*}{$\begin{array}{l}\text { Number of } \\
\text { shareholders }\end{array}$} & $\begin{array}{l}\text { Barry and Brown } \\
\text { (1986) }\end{array}$ & Firm size & Investor recognition \\
\hline & $\begin{array}{l}\text { Becker-Blease and } \\
\text { Paul (2003) }\end{array}$ & Firm size & Investor recognition \\
\hline \multirow{2}{*}{$\begin{array}{l}\text { Analyst coverage } \\
\text { and/or institutional } \\
\text { ownership, and media } \\
\text { coverage }\end{array}$} & $\begin{array}{l}\text { Bushee and Miller } \\
(2012)\end{array}$ & IR programs & Investor recognition \\
\hline & Prokofieva (2015) & Firm size & Investor recognition \\
\hline
\end{tabular}

Figure 2.5 illustrates the relationships between visibility proxies and factors

affecting firm visibility as summarized in Table 2.2. As the arrow \#8 in Figure 2.5 shows, analyst coverage and institutional ownership are affected by firm size, exchange prominence, and IR programs. Following Baker et al. (1999) this research uses analyst coverage, measured by the number of analysts issuing a price target for the firm's stock price, and institutional ownership, measured by the percentage of shares held by institutional investors, as firm visibility proxies. These two proxies of firm visibility are 
interrelated through customer/supplier relationship between institutions and brokers (O’Brien and Bushan, 1990). Institutional demand for information about the firm drives analysts' motivations to follow that firm. Therefore, because of this reciprocal relationship between analysts and institutions, it is important to consider both in investigations of firm visibility.

\section{Figure 2.5. Firm visibility proxies and factors effecting firm visibility}

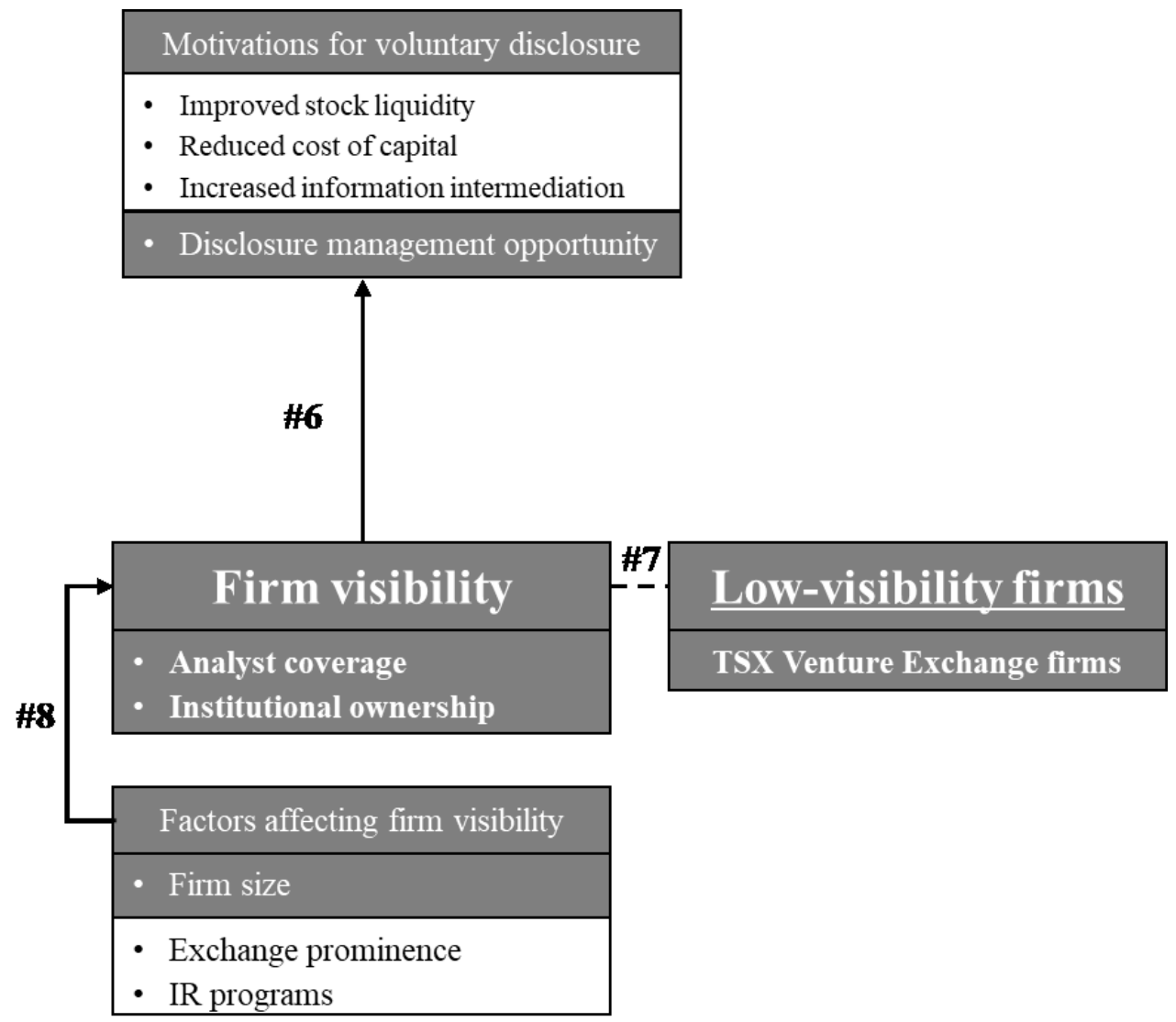

\subsubsection{Firm visibility and voluntary disclosure motivations}

Existing literature has largely studied the association between voluntary disclosure and firm visibility, which affects firms' stock behavior, and ultimately firms' financing opportunities. Those prior studies are based on the premise that a greater level of voluntary disclosure reduces information asymmetry between firms and investors, thus 
leading to lower cost of capital. Theoretically, two streams of research explain this association between disclosure level and cost of capital. The first stream is based on the idea that voluntary disclosure increases the liquidity of the market for a firm's securities by reducing information asymmetry or by reducing bid-ask spread (Copeland and Galai, 1983; Glosten and Milgrom, 1985; Amihud and Mendelson, 1986; Diamond and Verecchia, 1991). While reduced information asymmetry encourages large investors to take larger positions in the firm's securities, a reduced bid-ask spread attracts investors by lowering transaction costs. As a result, increased liquidity of the firm's stock leads to a lower cost of capital for the firm.

The proponents of the second stream argue that voluntary disclosure leads to a lower cost of capital due to reduction in estimation risk (Barry and Brown, 1985; Handa and Linn, 1993; and Coles et al., 1995). 'Estimation risk' refers to additional risk arising from investors' uncertainty about the parameters of the return or cashflow process (Botosan, 2006). Researchers in this stream agree that the estimation risk cannot be diversified, since investors generally attribute more systemic risk to firms with low information than firms with high information. Therefore, in general, a higher level of disclosure increases available information which consequently improves investors' confidence in the information set they have about a firm. On the other hand, a low disclosure level leads to little available information about the firm, and as a result, investors feel uncertain about their estimations of the firm's future performance.

On the empirical front, several studies have provided mounting evidence for a negative relationship between disclosure quality and information asymmetry. This research has also served as the basis for the study of the relationship between the degree 
of voluntary disclosure and firm visibility, as studies have established links between information asymmetry and firm visibility based on the investor recognition hypothesis and the theory of neglected firm. That is, improved disclosure quality reduces costs associated with processing firm specific information and increases firm's visibility among analysts and investors by encouraging more trading.

Lang and Lundholm (1996) investigate informativeness of a firm's discretionary disclosures in relation to information asymmetries and analyst coverage. Using data from FA Report (1985-89), which is a comprehensive evaluation of the complete range of a firm's disclosures by analysts, the authors estimate whether the informativeness of the firm's disclosures, along with other variables for firm characteristics, can explain the number of analysts following the firm. They find that the overall disclosure quality is negatively associated with information asymmetry. Their findings also indicate a positive and significant effect of firm size on the number of analysts following the firm. This last finding is consistent with Bushan (1989) who suggests that small firms are less attractive to investors than large firms, and therefore, are followed by fewer analysts.

In the same vein of research, Hamrouni et al. (2015) test the relationship between voluntary disclosure level and analyst coverage in an international context for a sample of non-financial firms listed on the Euronext Paris stock exchange and members of the SBF 250 index. The authors find a positive and statistically significant relationship between the extent of voluntary disclosure in annual reports and analyst coverage. Their regression results also indicate that the financial analysts are more attracted to large French firms. These findings are consistent with prior theoretical and empirical work on the relationship between disclosure level and firm visibility. 
In another early empirical work Botosan (1997) studies how the level of voluntary disclosure affects information asymmetry, and ultimately the cost of capital. The results indicate a negative association between a firm's disclosure quality and the cost of capital. She measures firm visibility with analyst coverage for a sample which is comprised of 122 manufacturing firms that provided voluntary disclosures in their 1990 annual reports. To test the effect of voluntary disclosure, Botosan (1997) designs separate samples for firms with low and high analyst coverage. She finds strong evidence for the association between a higher level of voluntary disclosure and a lower cost of capital for the sample of firms with low analyst coverage. However, for the sample of firms with high analyst coverage, this association does not exist. This is an important finding that illustrates a distinct effect of voluntary disclosure in the context of low-visibility firms.

In a recent study, Brockman et al. (2017) study the influence of investor conferences on firms' stock liquidity for low and high visibility firms. They find that managerial presentations at investor conferences - a form of voluntary disclosure reduce information asymmetry among investors, increase stock liquidity, and ultimately improve firm visibility (measured by institutional ownership and analyst coverage). More importantly, confirming prior research on the association between firm visibility and disclosure effect, the authors find that less visible firms achieve greater improvements in stock liquidity than more visible firms. Consistent with Botosan (1997), they show that these improvements in liquidity (reduction in bid-ask spread) are negatively associated with the cost of equity. Interestingly, the results of their analysis also indicate that firms with high visibility and a large investor base can experience a decrease in stock liquidity 
as a result of conference participation, suggesting that investor conferences can also increase information asymmetry among investors.

Because voluntary disclosure effects are more pronounced when firms are less visible, firms may also take advantage of such strong effects when releasing new information. In their investigation of the association between information asymmetry and voluntary disclosure, Elliott et al. (1984) study insider trading based on private information and find that insider trading is more prevalent among small firms. They conclude that because fewer analysts follow small firms, those firms can more successfully use private information. Their sample of small firms comprises firms with an average market value of equity under \$100 million in the years 1976 through 1978. Several other studies also conclude that smaller firms carry out more disclosure management, or are more likely to take advantage of private information, when there is insufficient information available to investors to monitor firms' actions (Schipper, 1989; Wareld et al., 1995; Merkl-Davies and Brennan, 2011).

A number of contemporary studies have also found significant differences between disclosure management motivations of less visible and more visible firms. Notably, an increasing number of present-day studies investigating disclosure communication and reaction to disclosure are using data from social media platforms, online discussion boards or other online sources due to the rapid rise of the internet. For example, Blankespoor et al. (2013) investigate whether firms can reduce information asymmetry by voluntarily disclosing information on Twitter. They find that providing market participants with links to press releases via Twitter is associated with lower abnormal bid-ask spreads and greater abnormal depths (an indication of higher number of 
buy and sell orders at each price level), leading to a reduction in information asymmetry. More importantly, while this relationship holds for less visible firms, it is muted for high visibility firms, which already receive broad coverage, confirming a distinct effect of disclosure for less visible firms. Blankespoor et al. (2013) use size (measured by the market value of equity), the number of shareholders, and institutional ownership as proxies for firm visibility.

In a similar study, Bhagwat and Burch (2016) study firms' voluntary disclosure of earnings news on social media and market reaction to it. Using analyst coverage and firm size as firm visibility measures, they find evidence that less visible firms are more likely to strategically disclose financial information on Twitter. More specifically, they find that tweeting of financial information by a firm, especially when the firm is less visible, increases during and after announcement of earnings results with positive surprises. The authors conclude that firms are aware of the effects of strategic disclosure of financial information. The study by Bhagwat and Burch (2016) demonstrates that firms involved in disclosure management use such approaches as choice of medium and timing, redundant disclosure, and subsequent interpretation of information, as outlined by Gibbins et al. (1990).

The relationship between firm visibility and incentives for issuing voluntary disclosures, including EPRs, is illustrated with the arrow \#6 in Figure 2.5. This link summarizes the findings of above reviewed studies which find that firm visibility proxies such as analyst coverage and institutional ownership influence the motivations for voluntary disclosure. The prior literature documents that less visible firms can achieve certain benefits such as improved stock liquidity, reduced cost of capital, and increased 
stock intermediation by providing voluntary disclosure. Moreover, the prior literature finds that the effect of voluntary disclosure on those benefits is more significant for less visible firms (Bushan, 1989; Lang and Lundholm, 1996; Botosan, 1997; Brockman et al., 2017). This pronounced effect of voluntary disclosure also creates motivations for disclosure management by less visible firms (Davis and Tama-Sweet, 2012; Blankespoor et al., 2013; Hamrouni et al., 2015; Bhagwat and Burch, 2016).

\subsection{Impression management}

This section defines impression management and reviews impression management strategies identified in prior literature. Section 2.3.3 provides an overview of content analysis methods employed to study impression management. Section 2.3.4 reviews prior literature that used EPRs to investigate impression management. Finally, Section 2.3.5 discusses impression management for low-visibility firms.

\subsubsection{Impression management definition}

The origins of impression management research stem from the social psychology literature where impression management is defined as how individuals present themselves to others to be perceived favorably (Schlenker, 1980; Riess et al., 1981; Schneider, 1982). Goffman (1959) notes that in any situation, when a person appears or performs before others, he or she is motivated to control the impressions of what others perceive of the situation. This impression management is accomplished by employing common communication techniques that help impact others' opinions about the individual or their performance (Goffman, 1959). Similar to individuals, organizations engage in impression management in their disclosures as a strategy to change the public's 
perceptions about their legitimacy (Hooghiemstra, 2000). This view is largely based on legitimacy theory which states that organization strive to operate within the bounds and norms of society in order to survive (Brown and Deegan, 1998). Frank and Ferris (1998) argue that impression management is a more effective means of providing information than reliance on observations alone because the consumers of information interpret observations in the context of their perceptions of information rather than the information itself. Therefore, the study of impression management has largely borrowed from social psychology which explains impression management from social and behavioral interactions perspectives.

In a corporate reporting context, the majority of studies explain motives for impression management based on established theories such as agency theory, legitimacy theory, and signaling theory (Merkl-Davies and Brennan, 2007). These studies find that firms try to take advantage of proprietary information they possess by altering or obfuscating negative performance results (Abrahamson and Park, 1994; Courtis, 2004; Li, 2006), by signaling good performance (Smith and Taffer, 1992; Rutherford, 2003), or by changing the perceptions about the legitimacy of the firm (Hooghiemstra, 2000).

Mounting empirical literature has investigated a wide range of accounting narrative documents to study how firms engage in impression management. Those studies have provided evidence that, in their disclosure documents, firms emphasize the positive aspects of their performance (Clatworthy and Jones, 2003), emphasize certain themes (Kohut and Segars, 1992), use metaphors (Bujaki and McConomy, 2012), construct linguistic styles such as assertive, defensive, and logic-based cognitive impression management (Aerts and Yan, 2017), manage the tone of words (Arslan-Ayaydin et al., 
2016), include or omit certain items of information from discretionary narrative documents (Leung et al., 2015), and rhetorically manipulate narrative disclosures (Aerts and Yan, 2017). Thus, based on prior literature, impression management can be defined as managing disclosure documents in a way that manipulates or distorts investors' perceptions of the firm's financial performance (Neu, 1991; Neu et al., 1998; Osma and Guillamon-Saorin, 2011) or organizational outcomes (Smith and Taffler, 2000; Rutherford, 2005; Davison, 2008).

In their attempts to control the impression conveyed to users of accounting information (Clatworthy and Jones, 2001) and strategically manipulate the perceptions of stakeholders (Yuthas et al., 2002), firms use various corporate disclosure documents. In their review of impression management literature, Merkl-Davies and Brennan (2007) summarize extensive literature examining corporate narratives such as management discussion and analyses, interim reports, presidents' letters, chairmen's reports, letters to stockholders, financial statement footnotes, prospectuses, and EPRs as impression management vehicles. Each of these corporate disclosure documents provides a varying level of opportunity for the use of impression management. For example, while voluntary disclosure documents such as presidents' letters allow for the use of impression management with great flexibility regarding content and organization, mandatory reports such as annual financial statements restrict the use of impression management to certain sections such as footnotes. Unlike voluntary disclosures, mandated disclosures such as financial statements are audited and are regulated by governing financial bodies in terms of both content and structure of information contained in such documents (Healy and 
Palepu, 2001). Therefore, impression management is more likely to occur in voluntary disclosures rather than mandatory financial reporting documents.

\subsubsection{Impression management strategies}

Merkl-Davies and Brennan (2007) identify seven major impression management strategies in the impression management literature that can be classified into concealment and attribution strategies used by firms. They indicate that concealment strategies are generally achieved by either manipulating verbal information (by reading ease manipulation or rhetorical manipulation) or emphasizing good news (by thematic manipulation, visual and structural manipulation, performance comparisons, and choice of earnings number). Attribution strategies, on the other hand, involve interpreting organizational events with a tendency to claim more responsibility for successes than for failures (Merkl-Davies and Brennan, 2007). Attribution strategy is the only one of the seven impression management strategies that is not examined in this study. Prior literature has provided strong evidence for all seven impression management strategies that are classified as either concealment or attribution strategies by Merkl-Davies and Brennan (2007). Next, this section reviews the prior literature on the seven impression management strategies and approaches for analyzing those strategies.

\subsubsection{Thematic Manipulation (tone management)}

Thematic manipulation strategy can be defined as firms' actions to conceal information from readers of disclosure documents by not reporting bad news to the same extent as good news (Merkl-Davies and Brennan, 2007) or emphasizing positive performance or organizational outcomes and affecting the tone of disclosure documents 
(Smith and Taffler, 2000; Rutherford, 2005; Guillamon-Saorin, 2006). Thematic manipulation (also known as tone management) studies are prevalent in the empirical impression management literature. These studies investigate various outcomes related to tone in the narrative disclosures and vary by the approach for measuring tone and the disclosure medium. Several studies have used a "bag-of-words" approach, which generally is based on the frequency of occurrence of each classified word, to measure tone in disclosures (Henry, 2008; Kothari et al., 2009; Loughran and McDonald, 2011; Davis and Tama-Sweet, 2012; Huang et al., 2014). While some of these studies use general words lists (for positive and negative words) in commonly used content analysis software packages such as the Linguistic Inquiry and Word Count (LIWC) (Aerts and Yan, 2017), General Inquirer (Tetlock, 2007, Kothari et al., 2009) and DICTION (Davis and Tama-Sweet, 2012) to quantify tone, others create custom word lists that are more suitable for describing tone in financial communication (Loughran and McDonald, 2011; Huang et al., 2014).

In a novel study, $\mathrm{Li}(2010)$ uses a naïve Bayesian machine algorithm to calculate tone in forward-looking statements (FLS) of MD\&A documents. To train the algorithm the author manually classifies 30,000 sentences from randomly selected FLS in MD\&A documents into positive and negative tone. She also tests the accuracy of commonly used dictionaries such as DICTION, General Inquirer, and LIWC. Li (2010) then measures the success rate of each dictionary in classifying tone by comparing classification results to those made by the human coder. Her results indicate that of all three dictionaries, DICTION has the highest success rate (48.5\%). Li (2010) explains that the higher accuracy rate of DICTION compared to the other two dictionaries is due to the fact that 
DICTION has a section for "corporate financial reports", unlike General Inquirer and LIWC, which are general purpose dictionaries. However, the naïve Bayes algorithm performed significantly better than all three dictionaries (67\% accurate classification).

Allee and DeAngelis (2014) apply a more rigorous technique which considers the underlying narrative structure in which tone words are present in conference call transcripts. Following rhetoric and communication theory (Kintsch and Yarbrough, 1982; Spivey, 1990) and related applications in computational linguistics (Kostoff et al., 1997) the authors argue that tone dispersion is important as it captures the extent to which good or bad news is spread across different sections of conference call transcripts. Therefore, they use a measure of linguistic dispersion from the computational linguistics literature to measure how evenly tone words are distributed throughout the document. Allee and DeAngelis (2014) find significant variation in tone dispersion across firms but little timeseries variation within firms. Overall, their findings indicate that managers deliberately construct tone as part of their impression management in narrative documents.

\subsubsection{Reading ease manipulation (readability manipulation)}

A second impression management strategy is reading ease manipulation (readability manipulation) which entails managing the reading complexity of disclosures by increasing the complexity of text in disclosures or obfuscating firm performance (Courtis, 1998; Merkl-Davies and Brennan, 2007). The Fog index, Flesch index, and Smog index are widely used readability measures which consider metrics such as sentence length, number of complex words per sentence, and some measure of verbal complexity such as syllables per word (Li, 2008). A sizeable literature has found that 
poorly performing firms obfuscate their disclosures using textual complexity

(Subramanian et al., 1993; Courtis, 2004; Li, 2006; Richards, 2011). However, other researchers have argued that this relationship between readability and firm performance does not exist (Smith and Taffler, 1992; Clatworthy and Jones, 2001; Rutherford, 2003).

\subsubsection{Rhetorical manipulation}

Studies on rhetorical manipulation mainly investigate how firms manage rhetorical features such as communication style, narration, and verbal structure in narrative portions of their disclosure documents (Jameson, 2000; Yuthas et al., 2002; Aerts and Yan, 2017). Brennan et al. (2009) study how firms rhetorically reinforce sentences using qualifiers to emphasize arguments in hostile takeover defense documents. They manually analyze the narrative content of the disclosures to examine the use of qualifiers in sentences that attack the bidding firm and sentences that defend the target firm. They argue that it is not possible to derive contextual meaning based on keywords or statements analysis, which can be achieved by computer assisted methods. Brennan et al. (2009) examine a small sample of narrative documents comprising ten disclosures which made the manual content analysis feasible.

Using a similar approach, Guillamon-Saorin et al. (2012) manually analyze both qualitative and quantitative information in press release headlines to show that firms stress good news and downplay bad news. They examine the reinforcement of keywords and performance comparisons using qualifiers as an emphasis strategy. Guillamon-Saorin et al. (2012) adopt manual content analysis due to its reliability over computerized coding (Sydserff and Weetman 2002) as well as its greater flexibility allowing for more detailed 
and sophisticated analysis (Linderman 2001; Conway 2007). Jameson (2000) combines manual reading with computer analysis in his investigation of narration in the shareholder reports of 100 mixed-return and 100 top-return mutual funds. For example, he measures the directness of investment story by manually locating initial statements of the absolute and relative returns and using computer analysis to count the number of words between those statements.

The use of computer programs is widely accepted among researchers investigating rhetorical features of disclosure documents. These researchers generally use commonly used content analysis software packages such as DICTION (Sydserff and Weetman, 2002; Yuthas et al., 2002; Patelli and Pedrini, 2013), and LIWC (Aerts and Yan, 2017) to thematically analyze narrative disclosure based on scores given by the program for several variables representing various linguistic dimensions. Most of these studies examine strategic use of the differences in rhetorical features of narratives when releasing 'good' performance as opposed to 'bad' performance. In a notable study, Aerts and Yan (2017) use LIWC's "causal reasoning" style category to measure the relative presence of causal connectors in the letter to shareholders. Although their study does not address performance attribution as an impression management strategy, their method of identifying sentences with causal reasoning using computer software can add efficiency in the process of obtaining sentences where cause is mentioned, rather than performing this process manually.

\subsubsection{Visual and structural manipulation}

Firms engage in impression management through visual and structural manipulation with the primary purpose of emphasizing organizational outcomes 
(Davison, 2008). This impression management strategy involves placement and repetition of words, phrases, and statements in narrative disclosure documents with the goal of attracting readers' attention to specific information (Lothian, 1976; Courtis 1996; Guillamon-Saorin 2006; Nelson and Pritchard 2007; Davison, 2008; Guillamon-Saorin et al., 2012; Soobaroyen and Ntim 2013; Pesci et al., 2015). These studies focus on the investigation of impression management within a single disclosure, and they apply manual content analysis to identify impression management by repetition and placement of information. For example, Osma and Guillamon-Saorin (2006) examine how firms may manipulate impressions by repeating positive outcomes and placing positive outcomes in a prominent location in annual results press releases. In their manual coding process, the authors score positive and negative keywords in terms of location and repetition in each press release and compute separate composite scores for emphasis through repetition and placement.

Later, Guillamon-Saorin et al. (2012) perform a manual content analysis to investigate several impression management strategies by focusing on the headlines of press release disclosures. They argue that the analysis of press release headlines, which are of high prominence and relevance due to their location in the document, helps uncover tactics that firms apply to create a good first impression to potential readers. Davison (2008) also manually examines repetition of words, key phrases, and lists in the annual reviews of British Telecommunications (BT) plc. While Davison's study does not consider the repetition to emphasize positive outcomes, its findings (based on simple word counts) indicate that repetition in BT's annual reviews is predominantly used to 
emphasize the company's intangible assets and its corporate identity and its participation in the "dot.com" era.

More recently, Pesci et al. (2015) also perform a quantitative manual content analysis while considering the level of intensity of repetition. More specifically, the authors examine identical, similar, and accumulated repetition strategies which, the authors argue, have low, higher and the most intensive effect to create an impression, respectively. Pesci et al. (2015) admit the manual analysis is time-consuming, however, they argue that the inductive nature of identifying similar and accumulated repetition requires a more detailed and sophisticated analysis which can be achieved only by manual content analysis.

\subsubsection{Performance comparisons}

Performance comparisons as an impression management strategy involves the use of numerical performance comparisons such as benchmark earnings numbers and previous performance referents that show the firm's current performance in the best possible way (Merkl-Davies and Brennan, 2007). Performance comparison in disclosure documents has also been examined by researchers as a sign of emphasis in the form of reinforcement (Guillamon-Saorin, 2006; Guillamon-Saorin et al., 2012). For example, Guillamon-Saorin et al. (2012) investigate a performance comparison strategy in the headlines of EPRs. Their approach for identifying reinforcement involves manual coding of EPR headlines in which performance figures are accompanied by a benchmark. The benchmark can be percentage change from the prior period's amount or prior period's number. After identifying a performance comparison strategy, Guillamon-Saorin et al. 
(2012) assign +1 point for a positive comparison (improved performance relative to prior period performance) and -1 for negative comparison (decreased performance relative to prior period performance). Guillamon-Saorin et al. (2012) find that firms only use positive performance comparisons in the headlines of their EPRs.

\subsubsection{Choice of earnings number}

Choice of earnings number as an impression management strategy entails selecting or emphasizing certain earnings figures and omitting others to portray firm performance (Merkl-Davies and Brennan, 2007; Guillamon-Saorin, 2006). GuillamonSaorin et al. (2012) examine the degree of selectivity of earnings numbers in the headlines of earnings press releases from the face of the profit and loss statement. They use a manual coding approach that involves coding quantitative items in the profit and loss account and matching those items with earnings numbers included in the headlines of EPRs. Consistent with prior research (Aerts, 2005; Bowen et al., 2005), GuillamonSaorin et al. (2012) find that firms emphasize positive performance by highlighting the most favorable earnings numbers.

\subsubsection{Attribution of performance}

Several studies have documented strong evidence that firms engage in impression management by attributing positive performance to internal factors and negative performance to external factors (Staw et al., 1983; Salancik and Meindl, 1984; Aerts, 2001; Hooghiemstra, 2001; Tsang, 2002; Clatworthy and Jones, 2003; Kimbrough and Wang, 2014; Aerts and Yan, 2017). A sizeable literature applies content analysis techniques to examine whether, and how, firms attribute positive/negative organizational 
outcomes to their own actions/external factors. Most of these studies rely on manual coding to identify positive and negative outcomes and classify attributions to identified outcomes (Clatworthy and Jones, 2003; Lee et al., 2004; Aerts and Cheng, 2012; Kimbrough and Wang, 2014). For example, Kimbrough and Wang (2014) read EPRs to identify statements explaining current period performance. Then, they code the cause in each sentence as having either favorable or unfavorable impact on performance, as cited by a disclosing firm. Finally, the authors classify the sentences to be attributed, by the firm, as either an internal or external cause. Other studies using manual content analysis perform similar analyses to this approach. To date there has been no study that uses computer-based methods to determine performance attribution in disclosure documents.

\subsubsection{Manual versus computer-based content analysis methods}

The use of either computer-based or manual approaches to analyze impression management strategies in the content of various disclosure documents is also determined by the strategy being analyzed. For example, most tone management studies have used software tools such as DICTION, General Inquirer, or LIWC (Linguistic Inquiry and Word Count), whereas most studies on causal reasoning and emphasis have performed manual content analysis. Also, a few researchers have developed custom algorithms or software tools to investigate tone management $(\mathrm{Li}, 2007)$ and reading ease manipulation (Li, 2008; Lee, 2012) in disclosure documents.

Early content analysis literature examining impression management in voluntary corporate disclosures used rather simplistic techniques based on manual and computerbased methods. For example, Clatworthy and Jones (2003) use a mixture of computer and manual coding procedures to classify news into good, bad, and neutral categories based 
on coding the number of words in a sentence, and, also counting keywords. Kohut and Segars (1992) manually code to classify sentences into themes and derive the themes emphasized in the presidents' letters. In a similar fashion, Baginski et al. (2004) manually classify causal sentences with performance attributions as either internal or external based on a list of identified keywords. Clatworthy and Jones (2006) perform a more involved analysis by examining multiple characteristics such as numerical performance figures, personal references, passive sentences, and future-orientated sentences in disclosures.

Bujaki and Mcconomy (2012) use a combination of qualitative and quantitative approaches to assess and evaluate the use of metaphors in the letters to shareholders in Nortel's annual reports. Following Gibson (2004), they apply a selective reading approach to identify metaphors in the annual reports in the qualitative analysis aspect of their study. In the quantitative stage, the authors perform a series of sorting and frequency counting procedures to determine the extent of metaphor usage in each annual report. The selective reading approach used by Bujaki and Mcconomy (2012) illustrates how manual reading may be superior to computer assisted tools when the detection of certain textual elements is entirely dependent on the contextual meaning of a narrative. According to Lakoff and Johnson (1980), metaphors are cognitive mappings of concepts from one domain to another. Analyzing cognitive meanings of text requires human-level natural language understanding which poses certain challenges for computer models, resulting in lower accuracy in the interpretations of meanings (McShane, 2017). Therefore, while it can be more time-consuming, a selective reading approach is a reliable way of accurately deriving meanings in narrative disclosure documents. 
More recent studies implement more comprehensive approaches which involve the use of several content analysis techniques simultaneously. For example, Aerts and Yan (2017) applied a rhetorical perspective that builds on metadiscourse to investigate impression management in CEO's letters to shareholders. They identify assertive, defensive and cognition-based style profiles which "underpin the persuasiveness and interpersonal effect of the message but represent distinct self-presentational logics" (Aerts and Yan, 2017, p. 405). The authors find the cognition-based style, which they also name the logic-based rationalizing style, is observed more for firms with higher information asymmetry, thus being responsive to information needs of investors. One of the important contributions of their study is that they combine multiple rhetorical style features to investigate how they co-exist in the shareholder letter. This increases the practicality of their study since it is expected that companies exercise many linguistic styles in combination, rather than separately, to deliver their point (Gillaerts and Van de Velde, 2010). In addition to the overall interpretation of financial performance, many firms include CEO comments in the quotation sections of EPRs. Therefore, the present study can also benefit from the existing literature, such as Aerts and Yan (2017), that investigates impression management in such corporate disclosure materials. Table 2.3 identifies main impression management strategies by the method of analysis (computerassisted and manual), indicates which content analysis techniques have been used to assess the strategy, and identifies empirical studies that have used the various techniques. 
Table 2.3. Main strategies and content analysis methods in impression management research

\begin{tabular}{|c|c|c|c|}
\hline Method & Strategy & Content analysis technique & Empirical study \\
\hline \multirow[t]{8}{*}{$\begin{array}{l}\text { Computer- } \\
\text { assisted }\end{array}$} & \multirow[t]{8}{*}{$\begin{array}{l}\text { Thematic } \\
\text { manipulation }\end{array}$} & $\begin{array}{l}\text { Tone is calculated using } \\
\text { Diction, General Inquirer and } \\
\text { LIWC dictionaries as well as a } \\
\text { naïve Bayes algorithm }\end{array}$ & Li (2007) \\
\hline & & $\begin{array}{l}\text { DICTION word list is used for } \\
\text { frequency counts }\end{array}$ & Henry (2008) \\
\hline & & $\begin{array}{l}\text { General Inquirer is used to } \\
\text { classify and generate the } \\
\text { counts of tone words }\end{array}$ & $\begin{array}{l}\text { Kothari et al. } \\
(2009)\end{array}$ \\
\hline & & $\begin{array}{l}\text { DICTION software is used to } \\
\text { construct a measure of net } \\
\text { optimistic language }\end{array}$ & $\begin{array}{l}\text { Davis et al. } \\
\text { (2012) }\end{array}$ \\
\hline & & $\begin{array}{l}\text { Tone dispersion as the degree } \\
\text { to which tone is spread evenly } \\
\text { throughout a disclosure } \\
\text { narrative }\end{array}$ & $\begin{array}{l}\text { Allee and } \\
\text { DeAngelis (2014) }\end{array}$ \\
\hline & & $\begin{array}{l}\text { Abnormal tone is measured } \\
\text { using a word list compiled by } \\
\text { Loughran and McDonald } \\
\text { (2011) to classify optimistic } \\
\text { and pessimistic words }\end{array}$ & $\begin{array}{l}\text { Huang et al. } \\
\text { (2014) }\end{array}$ \\
\hline & & $\begin{array}{l}\text { LIWC's "positive/negative } \\
\text { emotion words and net } \\
\text { affective" style category is } \\
\text { used to calculate relative } \\
\text { occurrences of tone words }\end{array}$ & $\begin{array}{l}\text { Aerts and Yan } \\
\text { (2017) }\end{array}$ \\
\hline & & $\begin{array}{l}\text { DICTION is used to obtain } \\
\text { standardized scores on } \\
\text { semantic variables of rhetorical } \\
\text { dimensions }\end{array}$ & $\begin{array}{l}\text { Yuthas et al. } \\
\text { (2002) }\end{array}$ \\
\hline
\end{tabular}




\begin{tabular}{|c|c|c|c|}
\hline Method & Strategy & Content analysis technique & Empirical study \\
\hline & \multirow[t]{3}{*}{$\begin{array}{l}\text { Reading ease } \\
\text { manipulation }\end{array}$} & $\begin{array}{l}\text { Perl }^{2} \text { program is used to } \\
\text { calculate Fog index of } \\
\text { disclosures }\end{array}$ & Li (2008) \\
\hline & & $\begin{array}{l}\text { Fog, Flesch, and Smog } \\
\text { readability scores are extracted } \\
\text { from Readability Calculations }{ }^{3} \\
\text { software }\end{array}$ & Richards (2011) \\
\hline & & $\begin{array}{l}\text { Lingua-EN-Fathom package of } \\
\text { Perl is used to calculate Fog } \\
\text { index from raw documents }\end{array}$ & Lee (2012) \\
\hline & \multirow[t]{3}{*}{$\begin{array}{l}\text { Rhetorical } \\
\text { manipulation }\end{array}$} & $\begin{array}{l}\text { LIWC is used to identify and } \\
\text { measure linguistic style }\end{array}$ & Yan et al. (2019) \\
\hline & & $\begin{array}{l}\text { DICTION is used for rhetorical } \\
\text { analysis as the authors replicate } \\
\text { Yuthas et al. (2012) }\end{array}$ & $\begin{array}{l}\text { Patelli and } \\
\text { Pedrini (2013) }\end{array}$ \\
\hline & & $\begin{array}{l}\text { LIWC's linguistic style } \\
\text { categories are used to analyze } \\
\text { cognitive marking mechanisms } \\
\text { and personalization }\end{array}$ & $\begin{array}{l}\text { Aerts and Yan } \\
\text { (2017) }\end{array}$ \\
\hline \multirow[t]{4}{*}{ Manual } & \multirow[t]{4}{*}{$\begin{array}{l}\text { Visual and } \\
\text { structural } \\
\text { manipulation }\end{array}$} & $\begin{array}{l}\text { Manual analysis of redundant } \\
\text { disclosure containing a defined } \\
\text { checklist of } 91 \text { items }\end{array}$ & Courtis (1996) \\
\hline & & $\begin{array}{l}\text { Repetition and placing of } \\
\text { positive outcomes are analyzed } \\
\text { by manual coding }\end{array}$ & $\begin{array}{l}\text { Guillamon-Saorin } \\
\text { (2006) }\end{array}$ \\
\hline & & $\begin{array}{l}\text { Word, phrase, list frequencies } \\
\text { are manually extracted }\end{array}$ & Davison (2008) \\
\hline & & $\begin{array}{l}\text { Manual content analysis is } \\
\text { performed to identify identical, } \\
\text { similar, and accumulated } \\
\text { repetition }\end{array}$ & Pesci et al. (2015) \\
\hline
\end{tabular}

\footnotetext{
${ }^{2}$ A general-purpose programming language (https://www.perl.org/).
}

${ }^{3}$ A computational linguistics software by Micro Power \& Light. 


\begin{tabular}{|c|c|c|c|}
\hline Method & Strategy & Content analysis technique & Empirical study \\
\hline & \multirow[t]{3}{*}{$\begin{array}{l}\text { Performance } \\
\text { comparisons }\end{array}$} & $\begin{array}{l}\text { Manual analysis of prior period } \\
\text { benchmark comparisons of } \\
\text { earnings }\end{array}$ & Krische (2005) \\
\hline & & $\begin{array}{l}\text { Manual scoring process is } \\
\text { employed to examine the use } \\
\text { of benchmarks }\end{array}$ & $\begin{array}{l}\text { Brennan et al. } \\
(2009)\end{array}$ \\
\hline & & $\begin{array}{l}\text { Reinforcement of keywords } \\
\text { and performance comparisons } \\
\text { is analyzed based on manual } \\
\text { analysis of qualifiers }\end{array}$ & $\begin{array}{l}\text { Guillamon-Saorin } \\
\text { et al. (2012) }\end{array}$ \\
\hline & \multirow[t]{3}{*}{$\begin{array}{l}\text { Choice of } \\
\text { earnings } \\
\text { number }\end{array}$} & $\begin{array}{l}\text { Manual analysis of the use of } \\
\text { pro-forma earnings versus } \\
\text { GAAP earnings }\end{array}$ & $\begin{array}{l}\text { Bowen et al. } \\
(2005)\end{array}$ \\
\hline & & $\begin{array}{l}\text { Manual scoring process is used } \\
\text { to analyze the selectivity of } \\
\text { quantitative amounts }\end{array}$ & $\begin{array}{l}\text { Brennan et al. } \\
(2009)\end{array}$ \\
\hline & & $\begin{array}{l}\text { Selectivity of performance } \\
\text { numbers is examined through a } \\
\text { manual coding process }\end{array}$ & $\begin{array}{l}\text { Guillamon-Saorin } \\
\text { et al. (2012) }\end{array}$ \\
\hline & \multirow[t]{3}{*}{$\begin{array}{l}\text { Performance } \\
\text { attribution }\end{array}$} & $\begin{array}{l}\text { Manual coding of attributions } \\
\text { is performed based on } \\
\text { causation phrases in attribution } \\
\text { statements }\end{array}$ & Lee et al. (2004) \\
\hline & & $\begin{array}{l}\text { Manual coding was performed } \\
\text { to identify implicit and explicit } \\
\text { causal relationships from } \\
\text { causal attributional statements }\end{array}$ & $\begin{array}{l}\text { Aerts and Cheng } \\
(2011)\end{array}$ \\
\hline & & $\begin{array}{l}\text { Manual coding is used to } \\
\text { classify attributions }\end{array}$ & $\begin{array}{l}\text { Kimbrough and } \\
\text { Wang (2014) }\end{array}$ \\
\hline & $\begin{array}{c}\text { Rhetorical } \\
\text { manipulation }\end{array}$ & $\begin{array}{l}\text { The analysis is based on } \\
\text { reading as well as computer } \\
\text { analysis to gather data about } \\
\text { the reports' linguistic, stylistic, } \\
\text { and structural features }\end{array}$ & Jameson (2000) \\
\hline
\end{tabular}




\begin{tabular}{|c|c|l|l|}
\hline Method & Strategy & Content analysis technique & Empirical study \\
\hline $\begin{array}{c}\text { Both computer- } \\
\text { assisted and } \\
\text { manual }\end{array}$ & $\begin{array}{c}\text { Rhetorical } \\
\text { manipulation }\end{array}$ & $\begin{array}{l}\text { LIWC's “causal reasoning" } \\
\text { style category is used to } \\
\text { measure the relative presence } \\
\text { of causal connectors }\end{array}$ & $\begin{array}{l}\text { Aerts and Yan } \\
(2017)\end{array}$ \\
\cline { 2 - 5 } & $\begin{array}{c}\text { Performance } \\
\text { attribution }\end{array}$ & $\begin{array}{l}\text { Computer analysis is used to } \\
\text { collect the frequency data, and } \\
\text { manual analysis is used for the } \\
\text { semantic coding of news and } \\
\text { attribution analysis. }\end{array}$ & $\begin{array}{l}\text { Clatworthy and } \\
\text { Jones (2003) }\end{array}$ \\
\hline
\end{tabular}

\subsubsection{Impression management in EPRs}

Because the unregulated and discretionary content of EPRs creates opportunities for impression management, researchers have explored various impression management strategies used by firms in EPRs. For example, Bowen et al. (2005) study whether firms deliberately emphasize pro forma earnings as opposed to GAAP earnings within EPRs. More specifically, Bowen et al. (2005) measure the level of emphasis by analyzing how firms present performance measures by placing them in prominent places such the headline and the first or second paragraph of the EPR. The authors find that firms deliberately emphasize the metric that gives a perception of better performance to influence investors. This strategy, which involves emphasizing certain earnings or performance numbers, is similar to the choice of earnings number strategy as defined by Brennan et al. (2007). Their results also indicate that there is a stronger market reaction to EPRs with greater emphasis on favorable performance metrics. Henry (2006) also examines investor reaction to various rhetorical features such as the readability, numerical intensity, length and the tone of the EPR. Henry (2006) concludes that firms 
use EPRs for the purpose of both providing information and managing impressions of investors.

Guillamon-Saorin et al. (2012) focus on the headlines of annual EPRs to examine how Spanish listed firms engage in impression management. Guillamon-Saorin et al., (2012) argue that headlines provide many opportunities for impression management because headlines are 'eye-catching' and play an important role to create positive 'first impressions'. They find that firms use thematic manipulation, performance comparisons, choice of earnings number, and reading ease manipulation (or ambiguity manipulation) strategies to give positive impressions about firm performance and mask negative performance. Consistent with Elliott (2006), Guillamon-Saorin et al., (2012) conclude that firms avoid including negative results in the headlines because investors tend to form their judgements first from performance results presented.

In a more recent study, Arslan-Ayaydin et al. (2016) use a sample of 26,000 EPRs of large, medium, and small firms traded on the U.S. exchanges to investigate how equity-based incentives motivate firm managers to engage in tone management in EPRs. Their results indicate managerial self-serving behavior, as firm managers with equity incentives are more likely to opportunistically inflate the tone of the narrative section of EPRs. One of the important features of the present study is inflated or abnormal tone calculation, the strategy which Arslan-Ayaydin et al. (2016) use following Huang et al. (2014). Since the tone of EPRs can be correlated with a number of factors arising from firm performance and firm characteristics, it is important to capture the abnormal part of the overall tone in order to measure impression management. Therefore, Arslan-Ayaydin 
et al. (2016) derive abnormal tone by controlling for many variables that are attributable to firm fundamentals and other firm characteristics.

Similar to Bowen et al. (2005), the current study investigates impression management both in the headlines and in the body of EPRs. As the studies investigating impression management in earning press releases demonstrate, certain impression management strategies such as choice of earnings number and performance comparison are applicable to the headline portion of EPRs, while other strategies such as rhetorical manipulation and reading ease manipulation can be better performed in the body section of EPRs due to the greater latitude for presenting narrative content. Moreover, unlike the above studies which study impression management in the context of firms with varying levels of visibility, this study concentrates on low-visibility firms to study impression management.

\subsubsection{Impression management and low-visibility firms}

As discussed in section 2.2.2, voluntary disclosure benefits (see motivations for voluntary disclosure) are more pronounced for visible firms (Bushan, 1989; Lang and Lundholm, 1996; Botosan, 1997; Brockman et al., 2017) which creates motivations for impression management by less visible firms (Davis and Tama-Sweet, 2012; Blankespoor et al., 2013; Hamrouni et al., 2015; Bhagwat and Burch, 2016). However, despite the growing impression management literature, there has been limited research that focuses on firms with low-visibility. Studying impression management from the perspective of firm visibility has also been limited as there is little or no research on the association between firm visibility and firm engagement in impression management. 
Some previous impression management studies have considered firm size, often measured by market capitalization, to determine whether firm size has an impact on impression management. For example, Baker and Kare (1992) find that smaller firms are more likely to engage in reading ease manipulation. Davis and Tama-Sweet (2012) study market reaction to language disclosed in EPRs compared to MD\&A disclosure releases for high-growth firms and conclude that managers of these firms also face greater strategic reporting incentives. Their findings also indicate that managers of small firms are more incentivized to omit pessimistic language from their EPRs. While both Baker and Kare (1992) and Davis and Tama-Sweet (2012) find that smaller firms are more likely to engage in impression management, a few other studies document the opposite impression management is more likely for larger firms (Baginski et al., 2004; MerklDavies, 2007). These contradictory findings regarding the impact of firm size on the engagement in impression management demonstrate that firm size alone may not help answer the question whether low-visibility firms are more likely to engage in impression management.

As discussed in section 2.2.1, firm size has been found to affect visibility proxies such as institutional ownership and analyst coverage, however, it alone is insufficient to capture overall firm visibility, thus limiting the generalizability of findings in the context of firm visibility. Therefore, to better understand the effect of firm visibility on firm motivations for impression management, it is important to consider widely used firm visibility proxies - institutional ownership and analyst coverage.

The current study investigates relationships between firm visibility and impression management by exclusively focusing on low-visibility firms, which 
significantly differ from benchmark firms regarding analyst coverage and institutional ownership. More specifically, the study uses the S\&P/TSX Venture Index constituent firms which can be considered as significantly less visible than their counterparts in the S\&P/TSX index (Appendix A). Since prior research has found an impact of exchange prominence on firm visibility (Kadlec and McConnell, 1994; Baker et al., 1999; Lehavy and Sloan, 2008), prior studies may have been missing unique insights that can be obtained by studying less visible firms listed on lesser known exchanges.

As Appendix A shows, Venture Exchange firms have not only significantly lower levels of institutional ownership and analyst coverage, visibility proxies, but also firm size, a factor affecting firm visibility, than those of TSX firms. These significant differences in the visibility metrics indicate that Venture Exchange firms are lowvisibility firms compared to firms listed on main exchanges such as the TSX Exchange. This is a pioneering study in impression management in terms of using visibility proxies which have such low values to investigate low-visibility firms specifically. Therefore, since there is a negative association between disclosure effects and firm visibility, using S\&P/TSX Venture index constituents as low-visibility firms can generate valuable findings that can benefit the study of firm visibility. 


\section{Figure 2.6. Firm visibility, low-visibility firms and impression management}
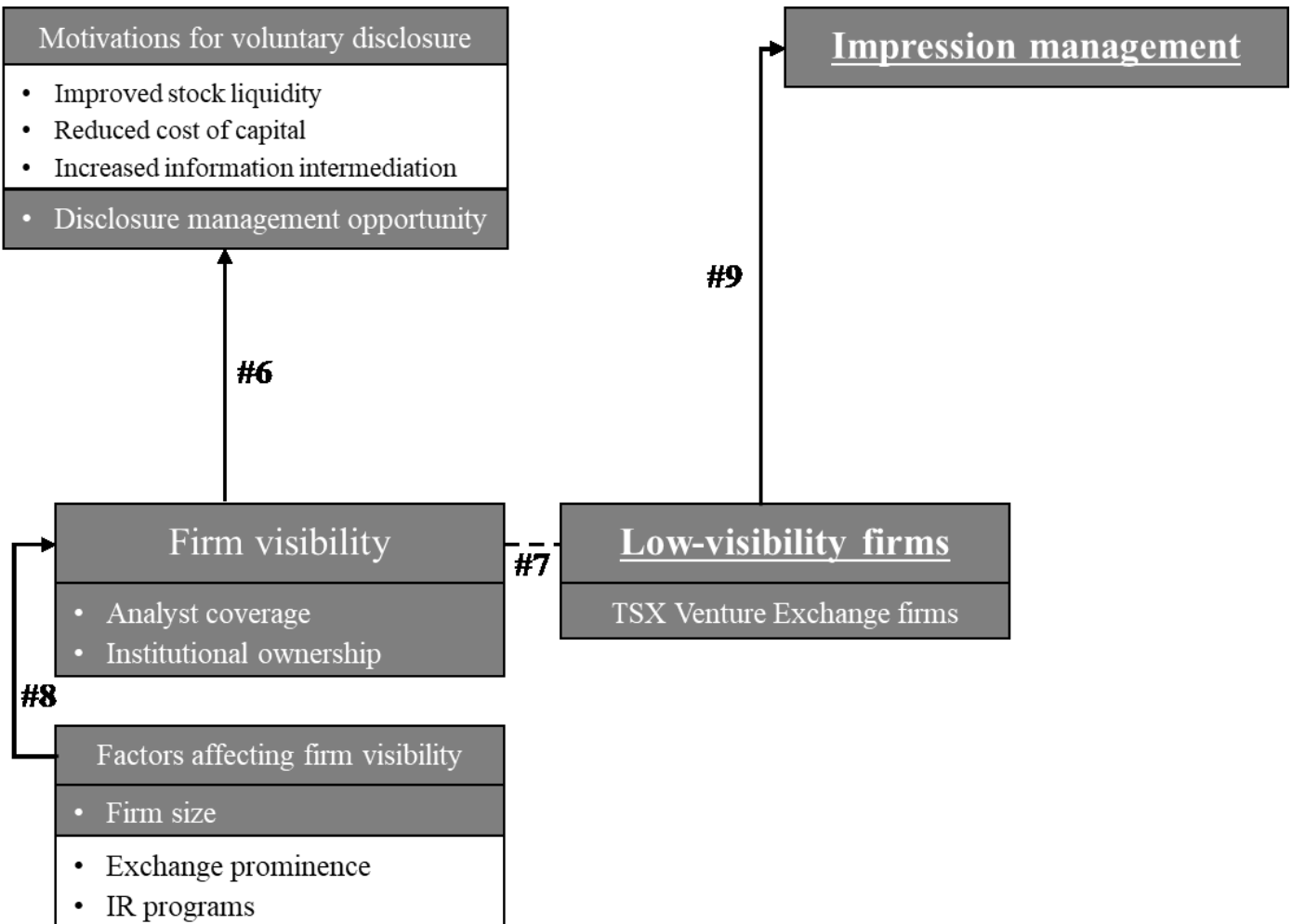

The association between firm visibility and TSX Venture firms, which this research identifies as low-visibility firms as measured by analyst coverage and institutional ownership, is described in the dashed line \#7 of Figure 2.6. As Table 2.5 shows, sampled by S\&P/TSX Venture Index, TSX Venture firms have noticeably lower analyst coverage and institutional ownership compared to TSX firms, sampled by S\&P/TSX Index. Both the median and mean numbers for the S\&P/TSX Venture Index sample are several multiple times smaller than those of the S\&P/TSX Index sample.

The arrow \#9, which is one of the relationships that this study is builds on, describes the association between low-visibility firms and impression management. The arrow \#9 is based on the findings of prior studies regarding the impact of firm visibility, often proxied by firm size, on motivations for impression management. Those studies 
have found that lower visibility firms are more motivated to engage in impression management than higher visibility firms (Davis and Tama-Sweet, 2012; Blankespoor et al., 2013; Hamrouni et al., 2015; Bhagwat and Burch, 2016).

\subsection{Investor reaction to apparent impression management}

A growing body of research has examined individual investor reaction to various impression management strategies in disclosure documents. Prior research has studied this relationship largely from the perspective of stock price behavior, while a very few studies have used experiments. Studying individual investor reaction by analyzing stock price behavior has also been the focus of a rapidly growing body of literature that uses data from online discussion boards. This literature has mainly investigated the predictive power of aggregate changes in discussion volume and sentiment in response to various corporate disclosures and events (Tumarkin and Whitelaw, 2001; Antweiler and Frank, 2004; Das and Chen, 2007; Sprenger et al., 2014). One common feature of these studies is that they tend to focus on overall style features such as tone (in disclosure document) and sentiment (in online discussions), rather than the content of disclosures and online discussions.

An online discussion board, also known as a forum, is an internet community which connects individuals who interact to share their opinions and seek information (Wasko and Faraj, 2005; Park et al., 2014; Seethamraju, 2014; Figer, 2014). Recent shifts in online communication, coupled with the growth of online stock trading, have fueled the popularity of investment- and stock-related discussion boards over the last few years. Academic researchers have used online investment discussion data from a wide range of free online investment boards such as SeekingAlpha, Yahoo! Finance, Raging Bull, 
HotCopper, and TheLion.com (Antweiler and Frank, 2004; Das and Chen, 2007;

Sabherwal et al., 2011; Chen et al.,2014; Leung and Ton, 2015; Lerman, 2017). Despite growing research on the association between online discussion board reaction and stock market reaction, there is very limited research that uses online discussion board reaction to investigate investor reaction to apparent impression management. A few studies have examined how online discussion boards facilitate disclosure dissemination (Blankespoor et al., 2013; Prokofieva, 2015) or how discussion volume changes in response to various disclosures (Wysocki, 2000; Lerman, 2017), however, no study has investigated how online discussion volume or sentiment varies in response to various impression management strategies used in disclosure documents.

\section{Figure 2.7. Investor Reaction to apparent impression management}

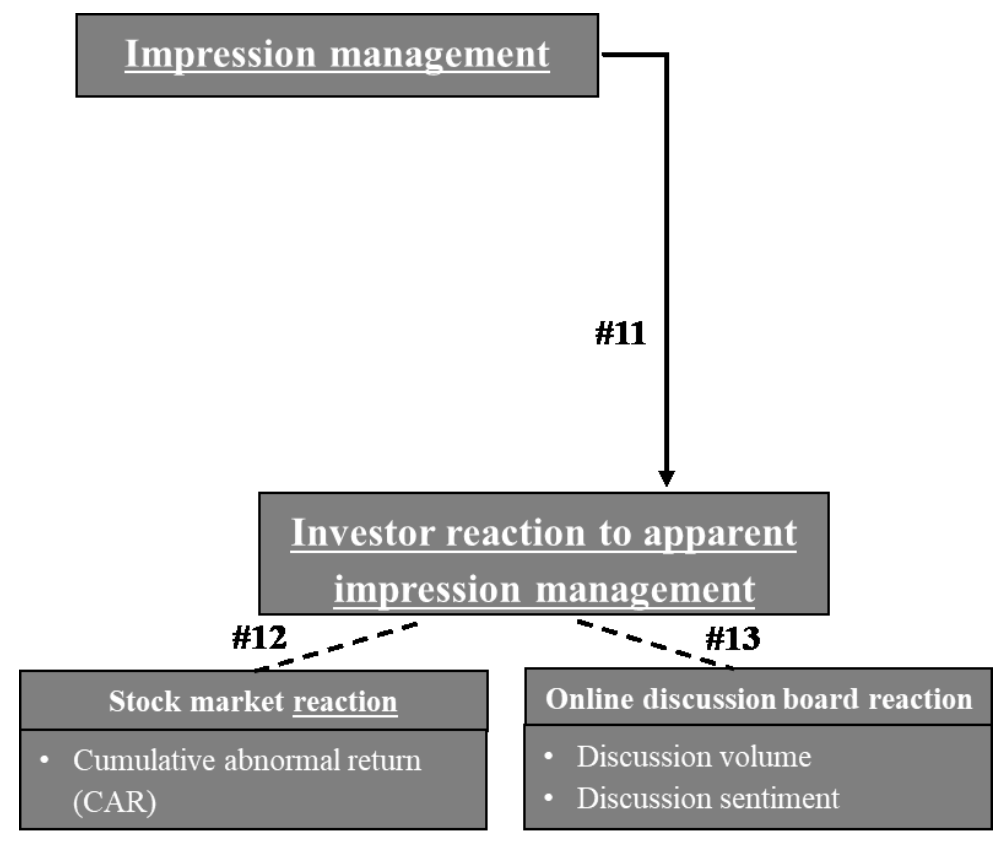

This study examines investor reaction to apparent impression management in two related components: stock market reaction and online discussion board reaction. These two reaction types are described with dashed lines \#12 and \#13 of Figure 2.7. The 
remainder of this section introduces prior literature on stock market reaction to apparent impression management as well as the association between online discussion board activity and stock price behavior. The section then draws on existing research that uses discussion boards to understand how online discussion board data can help understand investor reaction to apparent impression management.

\subsubsection{Stock market reaction to apparent impression management}

A sizeable literature has established a relationship between tone in narrative disclosures and stock market reaction. Feldman et al. (2009) measure tone change in the management discussion and analysis (MD\&A) section of mandatory financial reports and find strong immediate market reactions to tone change in MD\&A documents. More specifically, the results of their study indicate that optimism or pessimism of the information embedded in disclosures can explain contemporaneous stock returns. Based on their results, the authors argue that market participants consider nonfinancial information from MD\&A disclosures in their investing decisions. Using a similar approach to classify tone into optimistic and pessimistic words, Davis and Tama-Sweet (2012) examine tone in managers' comments in a large sample of EPRs. They argue that managers use language in EPRs to signal future expectations in addition to the actual earnings numbers. Moreover, they find a significant market response, as measured by three-day cumulative abnormal return (CAR), to these linguistic signals.

Huang et al. (2014) also study how investors react to the management of tone in EPRs. Consistent with both Feldman et al. (2009) and Davis et al. (2012), Huang et al. (2014) find that abnormally positive tone creates an excessively optimistic short window 
stock response. Overall, they conclude that the tone of EPRs influences investors' judgement regarding the firm's value in the short run. One of the important contributions of Huang et al. (2014) is the decomposition of tone into non-discretionary and discretionary components. While non-discretionary tone results from incremental information based on economic fundamentals, discretionary tone reflects managerial motivation to opportunistically interpret a firm's performance. These and many other studies clearly demonstrate that investors react to strategic disclosures involving tone management in voluntary corporate disclosures.

While the majority of prior studies seem to have investigated the effect of tone management on stock behavior, some researchers have also established a relationship between other impression management strategies and the stock market. For example, Lee et al. (2004) manually analyze attributional statements in corporate annual reports to determine causal attributions for positive and negative events. They find firms that make internal and controllable attributions for negative events, that are self-disserving attributions, have higher stock prices one year later. Contrary to many findings regarding performance attributions (i.e., Aerts and Cheng, 2012), Lee et al. (2004) argue that firms can create more positive impressions by claiming personal responsibility for negative events, making the firms appear more in control. More recently, Aerts and Cheng (2011) study self-serving causal disclosures regarding earnings related outcomes in the prospectuses of Chinese IPO firms. They find that assertive causal disclosures regarding positive outcomes are associated with higher IPO price valuation. Conversely, their results indicate that defensive causal disclosures regarding negative outcomes, such as excuses, justification and causality denials, are negatively related to IPO price. They 
argue that firms can effectively shape perceptions of investors by providing self-serving explanations of positive earnings outcomes.

Benson et al. (2015) focus on IPO documents to examine firms' use of overly complex, technical language - management obfuscation or camouflage - to make the documents less transparent. Using a bag-of-words linguistic approach, the authors construct a measure for camouflage that helps capture the nature of both the interpretative and structural features of IPO documents. The authors also include the tone of narrative document in their measure of camouflage. Their results indicate that IPO offerings with more camouflaged text raise more funds, providing evidence that investors are influenced by this impression management strategy. Benson et al. (2015) also find that firms are less likely to camouflage their documents when there is greater analyst coverage, which is one of the measures of firm visibility (Arbel and Strebel 1983; Baker et al., 1999; Bushee and Miller, 2012). This finding is consistent with the literature that finds higher motivation for impression management by less visible firms due to insufficient information available to investors to monitor firms' actions (Schipper, 1989; Wareld et al., 1995; Merkl-Davies and Brennan, 2011; Aerts, 2005; Leary and Kowalski, 1990; Li, 2010).

Henry (2008) examines how investors are influenced by impression management strategies in a rhetorical analysis of the genre of EPRs. More specifically, her study explores the association between the tone, length, numerical intensity, and verbal complexity of EPRs and market reaction. She finds that the tone of EPRs influences investors as more positive tone leads to higher three-day abnormal stock returns. As for the stylistic attributes of EPRs, the results indicate that lengthier and more numerically intensive press releases diminish the impact of unexpected earnings. Based on these 
findings, Henry (2008) argues that firms use EPRs to both communicate information and influence investors. One of the contributions of Henry's (2008) study is that it links prospect theory (Tversky and Kahneman, 1981, 1986), which states that framing financial performance in positive terms causes investors to think about the results in terms of increases relative to reference points, to the study of impression management consequences.

As mentioned earlier, a very few studies conduct experiments to study how investors react to impression management in disclosure documents. In an experimental study, Rennekamp (2012) investigates an investor's reaction to apparent impression management that involves manipulating the readability of press releases by firms. Based on the results of her controlled experiment, Rennekamp (2012) finds that investors' judgements are affected by the readability of corporate documents. More specifically, her results indicate that investors react more strongly to more readable documents. That is, investors' judgements are more positive when news is good and more negative when news is bad. Also, Rennekamp (2012) argues that investors' reliance on documents increases when disclosure documents are more readable. Given that there are limited experimental studies exploring the effects of disclosure styles on investor reaction coupled with the suitability of experiments to study such relationships, Rennekamp's (2012) study greatly contributes to the understanding of investor reactions from the behavioral perspective, as opposed to stock behavior.

In a more recent study, Chen et al. (2016) conduct experiments to investigate how investors react when a firm attributes negative earnings guidance to external factors and positive earnings guidance to internal factors. In their experiment, the authors ask 
participants, 119 Master of Finance students, to read background information, followed by earnings guidance where internal and external attributions are made. The results indicate that investors are more pessimistic about future earnings when external rather than internal attributions are used in management guidance, while internal attributions for positive outcomes affect investors' judgement more strongly. Moreover, they find firms can positively impact investors' earnings judgements when information about outcome controllability is provided to investors. Since Chen et al. (2016) test the effect of attribution on investor reaction in one specific setting using a management guidance document for one company, they suggest that future research investigate the generalizability of their findings using other disclosure documents such as actual earnings announcements.

As Table 2.4 illustrates, a well-developed body of recent research has examined stock market reaction to apparent impression management strategies in corporate narrative disclosures. From the table, it is clear that tone studies dominate this literature as researchers have provided strong evidence for market reaction in response to the tone of disclosures. Moreover, while there are a few studies that demonstrate longer term impact of tone management on investors, it seems that immediate (commonly up to three days) market reaction is observed in most studies. Finally, the investigation of investor reaction to apparent impression management by observing stock price response shows that firms engage in various impression management tactics to influence investor perceptions of disclosure information. However, these studies assume that investors are paying attention to the narrative content of disclosures and making decisions based on their perceptions of the disclosure content. 
Table 2.4. Investor reaction to apparent impression management

\begin{tabular}{|c|c|c|c|c|}
\hline $\begin{array}{c}\text { Impression } \\
\text { management } \\
\text { strategy }\end{array}$ & $\begin{array}{l}\text { Disclosure } \\
\text { document }\end{array}$ & Study & $\begin{array}{c}\text { Investor reaction to } \\
\text { apparent } \\
\text { impression } \\
\text { management }\end{array}$ & $\begin{array}{c}\text { Reaction } \\
\text { time }\end{array}$ \\
\hline \multirow[t]{6}{*}{$\begin{array}{l}\text { Tone } \\
\text { management }\end{array}$} & \multirow[t]{3}{*}{ EPRs } & Henry (2008) & $\begin{array}{l}\text { Investors are } \\
\text { influenced by tone. }\end{array}$ & $\begin{array}{l}\text { three-day } \\
\text { window }\end{array}$ \\
\hline & & $\begin{array}{l}\text { Huang et al. } \\
\text { (2014) }\end{array}$ & $\begin{array}{l}\text { Abnormal tone has a } \\
\text { positive stock return } \\
\text { effect at the earnings } \\
\text { announcement. }\end{array}$ & $\begin{array}{l}\text { three-day } \\
\text { window }\end{array}$ \\
\hline & & $\begin{array}{l}\text { Arslan- } \\
\text { Ayaydin et al. } \\
(2016)\end{array}$ & $\begin{array}{l}\text { Investors respond } \\
\text { positively to } \\
\text { abnormal tone in } \\
\text { EPRs in the short- } \\
\text { term. }\end{array}$ & $\begin{array}{l}\text { three-day } \\
\text { window }\end{array}$ \\
\hline & MD\&A & $\begin{array}{l}\text { Feldman et al. } \\
\text { (2010) }\end{array}$ & $\begin{array}{l}\text { Market reactions } \\
\text { around the SEC } \\
\text { filing are } \\
\text { significantly } \\
\text { associated with the } \\
\text { tone change. }\end{array}$ & $\begin{array}{l}\text { three-day } \\
\text { window }\end{array}$ \\
\hline & $\begin{array}{l}\text { Conference } \\
\text { calls }\end{array}$ & $\begin{array}{l}\text { Price et al. } \\
(2012)\end{array}$ & $\begin{array}{l}\text { Conference call tone } \\
\text { is a significant } \\
\text { predictor of } \\
\text { abnormal returns and } \\
\text { trading volume. }\end{array}$ & $\begin{array}{l}\text { three-day and } \\
60 \text {-day } \\
\text { windows }\end{array}$ \\
\hline & $\begin{array}{l}10-\mathrm{K}, 10-\mathrm{Q}, \\
\text { and } \\
\text { conference } \\
\text { calls }\end{array}$ & $\begin{array}{l}\text { Jiang et al. } \\
\text { (2019) }\end{array}$ & $\begin{array}{l}\text { Tone is a negative } \\
\text { predictor of stock } \\
\text { returns. }\end{array}$ & $\begin{array}{l}\text { four-day } \\
\text { window }\end{array}$ \\
\hline \multirow[t]{2}{*}{$\begin{array}{l}\text { Readability } \\
\text { manipulation }\end{array}$} & EPRs & $\begin{array}{l}\text { Rennekamp } \\
(2012)\end{array}$ & $\begin{array}{l}\text { Investor's judgement } \\
\text { is affected by the } \\
\text { readability of } \\
\text { corporate } \\
\text { documents. }\end{array}$ & $\begin{array}{l}\text { Immediate } \\
\text { (experiment) }\end{array}$ \\
\hline & $\begin{array}{l}\text { Annual } \\
\text { reports }\end{array}$ & $\begin{array}{l}\text { Wisniewski } \\
\text { and Yekini } \\
(2015)\end{array}$ & $\begin{array}{l}\text { Variables capturing } \\
\text { activity and realism } \\
\text { are positively and } \\
\text { significantly }\end{array}$ & 1 to 250 days \\
\hline
\end{tabular}




\begin{tabular}{|c|c|c|c|c|}
\hline $\begin{array}{c}\text { Impression } \\
\text { management } \\
\text { strategy }\end{array}$ & $\begin{array}{l}\text { Disclosure } \\
\text { document }\end{array}$ & Study & $\begin{array}{c}\text { Investor reaction to } \\
\text { apparent } \\
\text { impression } \\
\text { management }\end{array}$ & $\begin{array}{l}\text { Reaction } \\
\text { time }\end{array}$ \\
\hline & & & $\begin{array}{l}\text { associated with } \\
\text { future price changes. }\end{array}$ & \\
\hline & $\begin{array}{l}\text { Analyst } \\
\text { reports }\end{array}$ & $\begin{array}{l}\text { Hsieh et al. } \\
\text { (2016) }\end{array}$ & $\begin{array}{l}\text { Stock market } \\
\text { responds more } \\
\text { positively to reports } \\
\text { with less reading } \\
\text { complexity. }\end{array}$ & $\begin{array}{l}\text { three-day } \\
\text { window }\end{array}$ \\
\hline & $\begin{array}{l}\text { IPO } \\
\text { documents }\end{array}$ & $\begin{array}{l}\text { Benson et al. } \\
(2015)\end{array}$ & $\begin{array}{l}\text { Investors are } \\
\text { affected by } \\
\text { camouflage in IPO } \\
\text { documents. }\end{array}$ & Short term \\
\hline & & $\begin{array}{l}\text { Aerts and } \\
\text { Cheng (2011) }\end{array}$ & $\begin{array}{l}\text { Assertive (defensive) } \\
\text { causal performance } \\
\text { attributions have } \\
\text { positive (negative) } \\
\text { impact on IPO } \\
\text { pricing. }\end{array}$ & $\begin{array}{l}\text { Same day and } \\
\text { subsequent } \\
\text { day }\end{array}$ \\
\hline $\begin{array}{l}\text { Performance } \\
\text { attribution }\end{array}$ & $\begin{array}{l}\text { Management } \\
\text { guidance }\end{array}$ & $\begin{array}{l}\text { Chen et al. } \\
(2016)\end{array}$ & $\begin{array}{l}\text { Investors' earnings- } \\
\text { related judgements } \\
\text { are affected by } \\
\text { performance } \\
\text { attributions and } \\
\text { outcome } \\
\text { controllability. }\end{array}$ & $\begin{array}{l}\text { Immediate } \\
\text { (experiment) }\end{array}$ \\
\hline
\end{tabular}

\subsubsection{Online discussion board activity and stock market returns}

Prior research also has also investigated the association between message board posting activity and short window stock returns. In order to show that individual investors are primary participants of online investment discussion boards, researchers have analyzed how overall posting activity is related to the percentage of individual shareholders or institutional shareholders. For examples, Wysocki (1999) finds that a 
$10 \%$ increase in institutional ownership is associated with a $1 \%$ decrease in the number of postings, while a $10 \%$ increase in the number of individual investors explains a $1 \%$ increase in the number postings. Da et al. (2011) argue that institutional investors have access to more sophisticated information services, therefore, people who search Google are more likely to be individual investors. They provide direct evidence that an increase in investor attention, as measured by Search Volume Index (SVI), is associated with an increase in trading by individual investors. More recently, Lerman (2017) also provides evidence for strong negative association between institutional ownership and posting activity on Yahoo! Finance message boards, suggesting that individual investors are the primary participants of message boards.

Wysocki (1999) finds that changes in overnight posting activity contain valuable information and that increases in overnight posting volume generally predict next day trading volume and abnormal stock returns. Wysocki argues that online investment board participants focus on firms with high levels of information asymmetry and poor information environments, therefore investors are motivated to gather more information by actively engaging in conversations with other participants. Tumarkin and Whitelaw (2001) examine the relationship between RagingBull.com message board activity and abnormal stock returns, as well as trading volume for Internet stocks. They find that change in investor opinion is correlated with contemporaneous, same day and second day, abnormal industry-adjusted returns. However, consistent with the efficient market hypothesis, the authors did not find any association between message board posting activity and stock returns and trading volume. Another possible explanation for no causal relationship between message board activity and stock behavior is that the Internet firms 
selected in the study are not, on average, firms with high information asymmetry and low visibility as the median market capitalization of selected firms is $\$ 1.12$ billion (Tumarkin and Whitelaw, 2001). Prior research has found that firm size, as measured by market capitalization, is negatively related to information asymmetry and firm visibility (Baker et al., 1999; Barry and Brown, 1986; Abarbanell, 2003). Therefore, no association between posting activity and stock behavior for firms with low information asymmetry is somewhat consistent with Wysocki (1999), who argues that investors of firms with high information asymmetry have higher individual investor motivation to gather and spread information on message boards.

Sabherwal et al. (2008) focus on stocks that are most actively discussed by online posters to investigate whether messages posted about these stocks have any stock price consequences. Consistent with prior findings, Sabherwal et al. (2008) find that the number of messages posted about a stock on a given day is not only positively related with the stock's abnormal return on that day, but it also positively predicts the next day's abnormal return. The authors also find that online posters prefer thinly traded micro-cap stocks. Therefore, as one of the main implications of their research, the authors state it would be interesting to examine if the investor sentiment expressed in online messages has predictive power for micro-cap stocks.

Considerable extant literature has investigated how aggregate sentiment in online discussions can predict stock price and volume behavior. Researchers report mixed results regarding the predictive power of sentiment. For example, Sprenger et al. (2014) use computational linguistics to analyze the sentiment (bullishness) of stock-related messages (tweets) on Twitter. They find a significant association between bullishness and 
contemporaneous stock returns. Das and Chen (2007) also analyze sentiment for a sample of 24 tech-sector stocks, present in the Morgan Stanley High-Tech Index (MSH), and find a weak relationship between aggregate message board sentiment and contemporaneous stock index returns. They call for more research that can achieve greater accuracy in extracting sentiment given the noisy and nonuniform content of messages. Das and Chen (2007) also find that message volume explains stock volatility, confirming Antweiler and Frank (2004). In another study that also analyzes both volume and sentiment of messages, Antweiler and Frank (2005) examine messages posted on Yahoo! Finance and Raging Bull for 45 firms in the Dow Jones Industrial Average and the Dow Jones Internet Index. Using computational linguistics methods to measure bullishness in posts, the authors find that stock messages on Yahoo! Finance help predict market volatility. Their results indicate that an abnormal increase in message board posting leads to negative returns on the next day, while disagreement among the posted messages is associated with increased trading volume.

As the studies reviewed show, while prior research has no conclusive evidence on the causal effect of online investment discussion activity and sentiment on stock price stock market and volume behavior, mounting literature has investigated this relationship using information from various online discussion boards. The majority of these studies provide strong evidence for the relationship between contemporaneous, usually threeday, stock behavior and posting activity such as volume and sentiment. 


\subsubsection{Online discussion board reaction}

Researchers have measured investor attention in response to various informational events indirectly with such proxies as extreme returns (Barber and Odean, 2007), trading volume (Barber and Odean, 2008; Gervais et al, 2001; Hou et al., 2008), and price limits (Seasholes and $\mathrm{Wu}, 2007)$. One of the biggest assumptions in using these proxies to measure aggregate investor attention is that if a stock's return or turnover (stock liquidity) was extreme, or its name was mentioned in the news media, then investors should have paid attention to it. In response to this limitation, Da et al. (2011) propose a novel approach using Google Search Volume Index (SVI) to directly assess investor attention. They measure investor attention for a sample of Russell $3000^{4}$ stocks and conclude that SVI: (1) is correlated with, but different from, existing proxies of investor attention; (2) captures investor attention in a timelier fashion, and (3) likely measures the attention of retail investors. Ding and Hou (2015) also use the same proxy for investor attention and conclude that retail investor attention, reflected by the level and change in SVI, significantly enlarges the shareholder base and improves stock liquidity.

More recently, Chen (2017) also uses Google search volume as a direct measure of investor attention toward global benchmark indices and empirically examines its impact on stock returns. The author documents a significant decrease in index returns following an increase in investor attention. As these studies find, search volume can serve as a direct measure of investor attention and it can even impact stock liquidity and price movement. However, search volume measure is solely based on the number of searches

\footnotetext{
4 A market capitalization-weighted index tracking the performance 3000 largest US stocks, which represent approximately $98 \%$ of the US public equity market (Nasdaq, 2018).
} 
and is unable to provide details of investor reaction (e.g., investor sentiment) to disclosure or an event. Moreover, it is impossible to determine whether search volume change is caused by mostly repeat searches from a very few investors or searches by many unique investors. Understanding investor reaction in response to impression management in voluntary disclosure documents requires a more detailed source of information that includes more than just investor attention in terms of search volume. Therefore, online discussion boards would be a more appropriate source of data for investor reaction.

Research linking online discussion boards and corporate disclosure is not new. Previous research has studied the role of internet message boards and blogs in disclosure dissemination for firms with low visibility and high information asymmetry. For example, Blankespoor et al. (2013) investigate whether firms can reduce information asymmetry by using Twitter to send market participants links to press releases. Using firm market value, the number of shareholders, and the number of institutional investors as proxies for visibility, the authors find that information dissemination on Twitter is associated with event window lower bid-ask spread, greater market depth, and higher liquidity for firms that are not highly visible. Blankespoor et al. (2013) contribute to the disclosure literature by providing empirical evidence that firms, especially ones with low visibility, can effectively reach a broader set of investors using internet communication channels such as Twitter.

In another study that investigates the effect of dissemination of corporate disclosure via Twitter on firm visibility, Prokofieva (2015) provides empirical evidence for the Investor Recognition Hypothesis for 109 firms listed on the Australian Stock 
Exchange (ASX). She finds a negative association between the abnormal bid-ask spread (a proxy for information asymmetry) and dissemination of corporate announcements via Twitter. The results of her study indicate that the effect of dissemination is stronger for less visible firms which have a lower degree of recognition, as measured by analyst coverage and business press coverage. Prokofieva (2015) argues that secondary dissemination of information on Twitter broadens firms' investor recognition and contributes to the reduction of information asymmetry, consistent with the Investor Recognition Hypothesis. Blankespoor et al. (2013) and Prokofieva (2015) use the threeday window as the event period in their studies to show the effect of information dissemination on information asymmetry for less visible firms.

In another related study, Hu et al. (2013) show the importance of Internet blogs in information dissemination. They find that stocks with high blog exposure earn lower returns than stocks with low blog exposure. Their results are more pronounced among stocks with lower institutional ownership, which is one of the characteristics of firms with low visibility (Arbel et al., 1983; Kadlec and McConnell, 1994; Lehavy and Sloan, 2008). Hu et al. (2013) use a limited attention hypothesis to interpret their findings. They argue that blogs are a positively biased disclosure channel, and that investors selectively interpret the biased disclosure by giving preference to stocks with an absence of news i.e., low blog exposure stocks. Overall, this and other similar research adds to the disclosure literature the insight that broader dissemination of information on the Internet can lead to real market consequences, especially for less visible firms. These studies find that secondary dissemination of corporate disclosures on online message boards both by 
disclosing firms and message board participants, negatively affects information asymmetry, especially for firms with low visibility.

This study uses a number of advanced text mining approaches to extract and analyze information from one of the most prominent online investment discussion boards in the North America. The data provides valuable insights regarding investors' reactions to disclosure. Since, to my knowledge, there has been no study that uses online investment board data to investigate individual investor reaction to apparent impression management by analyzing the content of messages, the approach is one of the major contributions of this study to the existing literature.

\subsection{Other important factors affecting impression management and investor reaction}

Throughout the previous sections of this chapter, it became evident that firm performance is one of the important factors affecting firms' decisions to engage in impression management. As discussed earlier, extant impression management literature finds that in their disclosure documents firm obfuscate negative performance results (Subramanian et al., 1993; Abrahamson and Park, 1994; Courtis, 2004; Li, 2006; Richards, 2011) and emphasize positive aspects of performance (Clatworthy and Jones, 2003; Bowen et al., 2005; Brennan et al., 2009; Guillamon-Saorin et al., 2012) using various strategies. Some impression management strategies involve firm performance directly (performance comparisons, choice of earnings number, attribution of performance), while others do so indirectly (tone management, readability manipulation, rhetorical manipulation, visual and structural manipulation). The impact of firm performance on impression management is illustrated by arrow \#15 in Figure 2.8. 
Besides firm performance, there are other important factors such as firm size and industry that influence firms' decision to engage in impression management. The role of firm size was discussed in section on firm-visibility (Section 2.2).

Industry is another important factor affecting impression management because several studies find industry characteristics are significant in explaining impression management (Davis et al., 2012; Kimbrough and Wang, 2014; Aerts and Yan, 2017; Aerts et al., 2018). Industry is frequently used as a control variable in most impression management studies (Smith and Taffler, 2000; Yuthas et al., 2002; Rutherford, 2005; Li, 2007; Henry, 2008; Loughran and McDonald, 2011; Davis et al., 2012; Kimbrough and Wang, 2014; Aerts and Yan, 2017; Aerts et al., 2018). Moreover, the impact of industry may be even stronger for low-visibility firms as an outcome of mimetic isomorphism. Mimetic isomorphism postulates that firms try to adopt the practices of bigger and successful firms within their industries (Dimaggio and Powell, 1983; Haveman, 1993). Therefore, industry is considered as one of the main factors likely to affect impression management in this study.

\section{Figure 2.8. Other important factors}

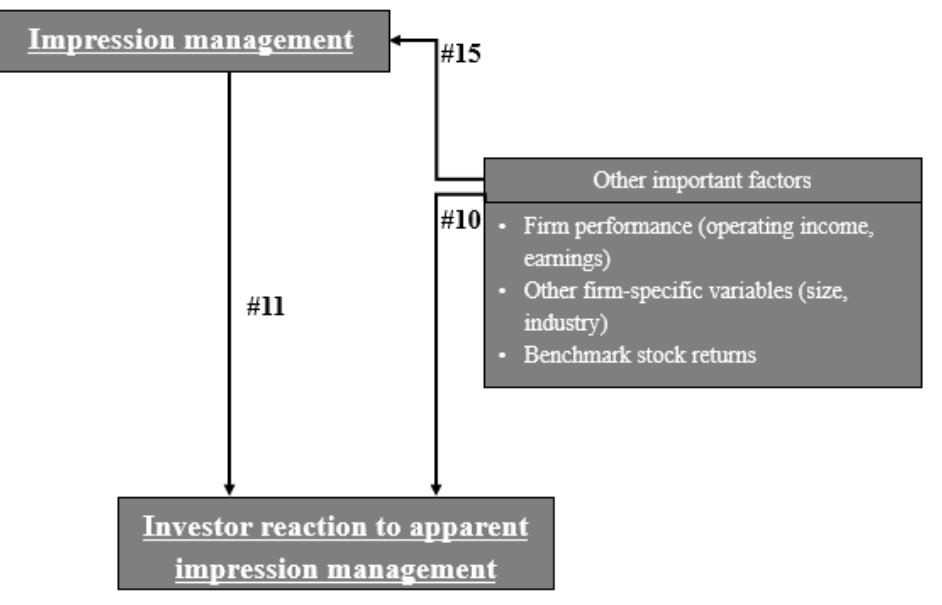


Other important factors shown in Figure 2.8 also affect investor reaction to apparent impression management. This relationship is illustrated by arrow \#10. For example, investors react to incremental information about firms' current and future performance contained in disclosure documents (Abrahamson and Amir, 1996; Baginski et al., 2000; Botosan and Plumlee, 2002; Matsumoto et al., 2006). Therefore, firm performance is controlled for in most studies that investigate investor reaction to apparent impression management (Henry et al., 2008; Huang et al., 2014; Feldman et al., 2010; Aerts and Cheng, 2011; Davis et al., 2012; Blankespoor et al., 2013; Prokofieva, 2015; Wisniewski and Yekini, 2015; Arslan-Ayaydin et al., 2016). These studies also consider benchmark stock returns, firm size, and industry as important variables that influence investor reaction by including them as control variables in their analyses.

\subsection{Research gaps in prior literature}

As previously stated, the overall research question seeks to answer whether (and how) low-visibility firms engage in impression management strategies in their EPRs, and if yes, what is investor reaction to these strategies? The first part of this question covers the firm perspective, while the second part covers the investor perspective on impression management. Figure 2.9, which is the overall research map, highlights each perspective by surrounding them with rounded rectangles. Figure 2.9 also shows connections between research areas relevant to this study based on previous literature. The literature review chapter reveals three major research gaps in prior impression management literature.

First, there is limited impression management research that focuses on firm visibility, particularly low-visibility firms. Prior research documents stronger effects of 
voluntary disclosure on disclosure benefits such as improved stock liquidity, reduced cost of capital, and increased information intermediation for less visible firms (Bushan, 1989; Lang and Lundholm, 1996; Botosan, 1997; Brockman et al., 2017). Stronger disclosure impact also creates stronger motivations for disclosure management for firms with lowvisibility which is often measured by the level of analyst coverage and institutional ownership (Davis and Tama-Sweet, 2012; Blankespoor et al., 2013; Hamrouni et al., 2015; Bhagwat and Burch, 2016). This relationship between firm visibility and motivations for voluntary disclosure is described by the arrow \#6 in Figure 2.9. This relationship also shows a gap in existing impression management studies which have not examined impression management in the context of low-visibility firms. Therefore, by focusing exclusively on low-visibility firms, this research seeks to examine the impression management practices of low-visibility firms and their impact on investor reaction.

Understanding firms' impression management practices requires broad examination of several impression management strategies. While existing literature has examined several impression management strategies, a very limited number of studies have looked at more than one impression management strategy in the same study. Differences in disclosure document investigated, the characteristics of sample firms, and other research design specifics may limit the generalizability of findings regarding firms' impression management practices across many firms. For example, Kimbrough and Wang (2014) study performance attribution in EPRs of 94 randomly selected US firms, whereas Bowen et al. (2005) randomly select the quarterly EPRs of 550 firms which reported pro forma earnings metrics between April 7 and June 7 in 2001 to investigate 
emphasis. While both studies find that firms engage in the respective impression management strategies, it would be impossible to determine whether the same firms engage both in performance attribution and emphasis. Therefore, in order to identify impression management practices of firms, it is important to examine several impression management strategies in the same sample of firms. As highlighted in the central box of Figure 2.9, this research examines six of the seven impression management strategies identified by Merkl-Davies and Brennan (2007). Studying several impression management strategies simultaneously helps better understand firms' impression management practices and investor reaction to identified impression management.

As discussed in the review of literature on investor reaction to apparent impression management, prior literature has focused on only stock market reaction (Feldman et al., 2009; Davis et al., 2012; Huang et al., 2014; Benson et al., 2015). Given that several studies find online discussion board activity to have predictive power in determining stock market behavior (Tumarkin and Whitelaw, 2001; Antweiler and Frank, 2004; Das and Chen, 2007; Sprenger et al., 2014), it would be of value to establish a link, if any, between impression management and investor reaction from online investment discussion boards. As the arrow \#13 in Figure 2.9 shows, this research investigates discussion volume and sentiment reaction from online discussion board data in addition to investigating stock market reaction to apparent impression management (arrow \#12).

The research map (Figure 2.9) brings together all previous figures discussed in the literature review chapter by connecting the main research areas in the study with arrows and dashed lines. Those main research areas are the focus of this study, therefore they are highlighted in bold in Figure 2.9. The figure describes the findings in the literature review 
chapter which starts with the discussion of corporate disclosure with an emphasis on voluntary disclosure which includes EPRs - the focus of this study. Voluntary disclosure motivations such as improved stock liquidity, reduced cost of capital, increased information intermediation, and disclosure management opportunity influence firms' decisions to disclose information voluntarily.

\section{Figure 2.9. Overall research map}

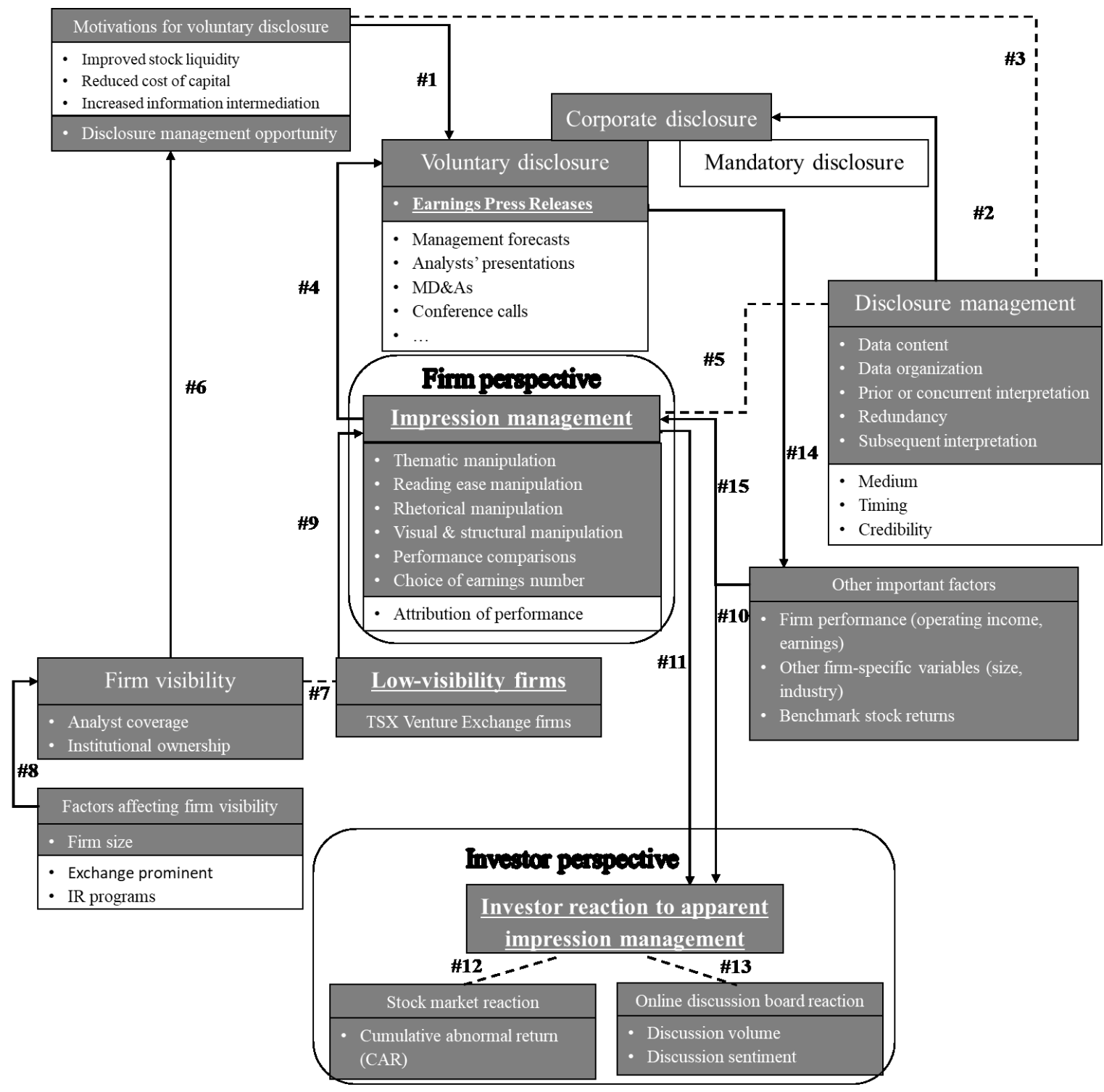


Although in their review of the prior disclosure literature Healy and Palepu (2001) do not explicitly include disclosure management as one of the motivations for voluntary disclosure, an increasing body of research provides evidence that the opportunity of managing disclosure incentivizes firms to voluntarily disclose information. Therefore, dashed line \#3 connects motivations for voluntary disclosure with seven disclosure management categories summarized by Gibbins et al (1990). Next, dashed line \#5 connects content management categories of disclosure management with impression management - another focus of this study. Impression management is the central topic in this research and it covers six of the seven impression management strategies outlined by Merkl-Davies and Brennan (2007). Arrow \#4 shows that impression management influences how voluntary disclosure documents are prepared, as discussed in 2.3.1.

Another area of focus for this research is firm visibility - the level of analyst coverage and institutional ownership - which is affected by such factors as firm size and exchange prominence. As illustrated by arrow \#6, firm visibility affects firms' motivations for voluntary disclosure as discussed in section 2.2. Since this research studies impression management in the context of low-visibility firms, proxied by TSX Venture Index constituents, dashed arrow \#7 shows this focus of the research. Moreover, as discussed in section 2.3.5, motivations of low-visibility firms to engage in various impression management strategies is shown by arrow \#9. Also, as discussed in the literature review section, firms' engagement in impression management is also affected by other factors such as firm performance, firm size, industry, benchmark stock returns, etc. This association between impression management and these factors is illustrated by arrow \#15. 
Finally, this research studies reaction to apparent impression management by examining both stock market reaction and online discussion board reaction to apparent impression management as discussed in section 2.4. As arrows \#10 and \#11 show, investors react to both impression management and other important factors such as firm performance, industry, and benchmark stock returns. Arrows \#12 and \#13 illustrate the two areas of investor reaction that this study investigates: stock market reaction and online investment discussion board reaction.

Having mapped out the connections between all key research concepts, the next chapter identifies the epistemological approach underlying this research and develops specific research hypotheses to be tested. 


\section{Chapter 3 - Hypotheses}

As the literature review chapter demonstrates, motivations for impression management and its consequences can be explained primarily by agency and legitimacy theories. By investigating impression management in the context of low-visibility firms, this study adds another perspective from such theories as neglected firms and investor recognition hypothesis. These affiliations with the mentioned theories, which are methodologically rooted in the positivist paradigm, have influenced this study and most impression management studies (through the affiliations with the agency and legitimacy theories) to take a positivist approach. The positivist paradigm postulates that objective reality can be understood through research which employs an empirical approach (Neurath, 1973; Fadhel, 2002). In other words, positivism is based on an empirical epistemology that explains the nature of relationships by collecting and analyzing data to test formulated hypotheses. Similarly, this study employs an empirical approach which relies on testing formulated hypotheses using collected data, statistical analysis, and deductive logic to arrive to conclusions about relationships. Two main relationships investigated in this study are the association between firm performance and impression management (for the firm perspective) and the association between impression management and investor reaction (for the investor perspective). Next sections and chapters follow the above defined positivist epistemology by formulating hypotheses regarding the two relationships, designing a methodology, and performing statistical tests leading to the generalization of results.

The remainder of this chapter identifies hypotheses for the firm and the investor perspectives on impression management. The firm perspective hypotheses are intended to 
investigate the associations between impression management and firm performance. The investor perspective is studied by formulating hypotheses on stock market reaction and online investment discussion board reaction to apparent impression management..

\subsection{Impression management in EPRs - firm perspective}

\subsubsection{Tone management}

In their summary of the impression management literature, Merkl-Davies and Brennan (2007) report that firms obfuscate performance results through various concealment strategies by manipulating tone, readability, and rhetorical features of narrative disclosures. As discussed in the literature review section of this research, prior literature finds that as a means of thematic manipulation, firms opportunistically engage in tone management depending on their performance results (Smith and Taffler, 2000; Rutherford, 2005; Henry, 2008; Kothari et al., 2009; Loughran and McDonald, 2011; Davis and Tama-Sweet, 2012; Huang et al., 2014). Key performance results include profitability, performance against prior period results, analysts' expectations, and managerial incentives (Graham et al., 2005; Matsumoto et al., 2006; Henry, 2006, Davis and Tama-Sweet, 2007; Davies and Tama-Sweet, 2012). Using abnormal positive tone as an indicator of impression management, Huang et al. (2014) find that abnormal tone predicts negative future earnings and cash flows. This finding leads the authors to the conclusion that firms use tone management to mask poor financial performance and misinform investors about future performance. Abnormal positive tone in Huang et al. (2014) is estimated from residuals of a tone model that controls for firm fundamentals such as performance and risk. The present study follows Huang et al. (2014) in deriving abnormal tone (defined in Chapter 4) from a tone model to investigate the association 
between positive abnormal tone and future firm performance. However, since the TSX Venture Exchange hosts small and early-stage firms, most of these firms have not achieved profitability yet (TMX Group, 2017). Therefore, unlike Huang et al. (2014), this research uses change in operating income (defined in Chapter 4) as a key performance indicator that may affect firms' motivations for impression management. More specifically, for the first hypothesis, the change in operating income measures future performance which is obtained by subtracting the current quarter operating income from operating income in the same quarter of the following year. A high level of positive abnormal tone and a negative or no change in future performance would indicate tone management since abnormally high, positive tone which is obtained after controlling for firm fundamentals does not lead to increase in performance, indicating impression management. Thus, the null hypothesis regarding tone management is formulated as follows:

Hypothesis 1 (H1): Future firm performance is not associated with abnormal tone in EPRs.

\subsubsection{Readability manipulation}

As discussed in Chapter 2 the association between readability and firm performance has been studied extensively in previous literature. Several studies find that the readability (or reading ease) of disclosures is positively associated with firm performance as firms with lower profitability (against prior performance and other benchmarks) have less readable annual reports, while firms with higher profitability issue more readable disclosures (Courtis, 2004; Li, 2008; Rennekamp 2012). However, some researchers have argued that this relationship between readability and firm performance 
does not exist (Smith and Taffler, 1992; Clatworthy and Jones, 2001; Rutherford, 2003). Moreover, this relationship between readability and firm performance has not been studied in the context of low visibility firms. Also, the majority of previous studies on readability address mandatory disclosure documents such as annual reports (Subramanian et al., 1993; You and Zhang, 2009; Miller, 2010; Lawrence, 2013; Kim et al., 2016) and very few examine voluntary disclosures such as new press releases (Henry, 2008; Rennekamp, 2012) and corporate social responsibility reports (Richard, 2011).

Therefore, by following previous literature which tested the association between readability and firm performance, this study attempts to find an association between readability and firm performance in the context of low-visibility firms. Manipulation of readability occurs when there is a negative relationship between readability and current firm performance which is measured as the difference between the current quarter operating income and operating income for the same quarter of previous year. Using the Gunning Fog Index, a widespread readability measure in the prior literature, this study regards reading complexity (defined in Chapter 4) as an opposite concept to readability (or reading ease). Then the study investigates impression management by reading complexity manipulation (increasing reading complexity or decreasing readability) through the following null hypothesis:

Hypothesis 2 (H2): Firm performance is not associated with the reading complexity of EPRs. 


\subsubsection{Causal reasoning}

As discussed in section 2.3.2, causal reasoning is a form of rhetorical manipulation which entails the manipulation of rhetorical features of disclosure documents. Studies on rhetorical manipulation have investigated how firms manage rhetorical features of such as usage of qualifiers, communication style, narration, and verbal structure in narrative portions of their disclosure documents (Jameson, 2000; Yuthas et al., 2002; Brennan et al. 2009; Aerts and Yan, 2017). Causal reasoning, as the name implies, is the usage of causal words to explain firm performance (i.e., attributing negative performance to external events) (Merkl-Davies and Brennan, 2007).

Causal reasoning is related to readability as causal words and phrases add more meaning making sentences longer and more complex (Aerts and Yan, 2017). Moreover, causal reasoning intensity, which is measured by the relative frequency of causal words or phrases in a document, affects disclosure understandability and readability (Zhang et al., 2018). Therefore, similar to $\mathrm{H} 2$, this study tests the relationship between causal reasoning intensity (defined in Chapter 4) and firm performance. That is, this hypothesis seeks to investigate the association, if any, between firm performance and causal reasoning intensity in EPRs. Thus, the null hypothesis for $\mathrm{H} 3$ is formulated as follows:

Hypothesis 3 (H3): Firm performance is not associated with causal reasoning intensity.

\subsubsection{Headline impression management}

Impression management in the headline of EPRs covers two of the seven impression management strategies (see Merkl-Davies and Brennan, 2007) - visual and structural manipulation and choice of earnings numbers. Previous literature on visual and 
structural manipulation strategy finds that firms emphasize positive performance by strategically placing and repeating words, phrases, numbers and statements in narrative disclosure documents with the goal of attracting reader's attention to specific information (Lothian, 1976; Courtis 1996; Guillamon-Saorin 2006; Nelson and Pritchard 2007;

Davison, 2008; Guillamon-Saorin et al., 2012; Soobaroyen and Ntim 2013; Pesci et al., 2015). Similarly, the choice of earnings number strategy entails selecting or emphasizing certain earnings figures to highlight positive firm performance (Merkl-Davies and Brennan, 2007; Guillamon-Saorin, 2006). For example, Guillamon-Saorin et al. (2012) examine the degree of selectivity of earnings numbers in the headlines of earnings press releases from the face of the profit and loss account releases. Consistent with prior research (Aerts, 2005; Bowen et al., 2005), Guillamon-Saorin et al. (2012) find that firms emphasize positive performance by highlighting the most favorable earnings numbers. They argue that firms try to affect the "first impressions" of readers positively, rather than negatively, by emphasizing good, rather than bad, performance in the headlines of EPRs. Therefore, by extending previous literature on visual and structural manipulation strategy and choice of earnings numbers strategy, this study formulates a hypothesis regarding impression management in the headlines of EPRs. A measure of impression management bias in the headline of EPRs is constructed (defined in Chapter 4) following Guillamon-Saorin et al. (2012) to investigate the relationship between impression management in the headline of EPRs and firm performance. This investigation is based on the premise that firms try to emphasize positive performance by repetition, emphasis, and thematic manipulation strategies. More specifically, the null hypothesis for $\mathrm{H} 4$ is formulated in the following way: 
Hypothesis 4 (H4): Firm performance is not associated with impression management bias in the headline of EPRs.

\subsection{Stock market reaction to apparent impression management - investor perspective}

Most capital markets studies have investigated short-term stock market reaction to earnings because approaches using this period are more reliable and have fewer statistical limitations than long-term approaches (Barber and Lyon, 1997; Kothari and Warner, 2006; Henry, 2008). Moreover, impression management strategies studies conclude that impression management strategies in disclosure documents are likely to create an optimistic short-window stock response. Most of these studies find evidence for a significantly positive one-day to three-day cumulative abnormal return reaction to apparent impression management (Henry, 2008; Feldman et al., 2010; Aerts and Cheng, 2011; Davis and Tama-Sweet, 2012; Huang et al., 2014). Therefore, following capital market research and impression management studies that investigate short-horizon stock response to disclosures, this study uses three-day cumulative abnormal return to investigate investor reaction to apparent impression management strategies.

\subsubsection{Abnormal tone and cumulative abnormal return}

Previous studies have documented positive and significant association between the tone of EPRs and short-term cumulative abnormal return around the earnings announcement date (Henry, 2008; Davis et al., 2012; Huang et al., 2014; Arslan-Ayaydin et al., 2016). However, this relationship between tone and cumulative abnormal return may be mainly due to firm performance that explains positive tone. Since this study examines impression management in tone, the focus of this study is the portion of tone in 
EPRs that cannot be explained with performance. Huang et al. (2014) and ArslanAyaydin et al. (2016) argue that various firm related factors including firm performance may drive the tone of EPRs. Therefore, both studies control for incremental information about firms' current and expected future performance by measuring only the abnormal tone portion of the overall tone. Both Huang (2014) and Arslan-Ayaydin et al. (2016) find that investors positively react to abnormal tone in EPRs. The current research replicates Huang et al. (2014) and Arslan-Ayaydin et al. (2016) in measuring abnormal tone (see $\varepsilon_{i, q, t}$ in Eq. 2) and tests the association between abnormal tone in EPR and short-term (three-day) cumulative abnormal return (defined in Chapter 4). Following the above two studies, this study tests whether the impact of abnormal tone holds for lowvisibility firms.

Hypothesis 5 (H5): There is no association between abnormal tone in EPRs and shortterm cumulative abnormal return.

\subsubsection{Reading complexity and cumulative abnormal return}

Prior literature finds that there is more investor interest and trading activity for shares of firms with shorter, clearer, and more readable disclosures (You and Zhang, 2009; Lawrence, 2013). There is no strong evidence for the impact of readability on short-term stock returns. Kim et al. (2016) provide evidence that 10-K reports with more difficult readability are more likely to cause stock crashes, however, their findings are limited to specific events (stock crashes). Henry (2008) tests the association between the reading complexity of EPRs and short-term stock returns and concludes that reading complexity does not affects market reaction. Therefore, this study investigates the impact of EPR readability on short-term CAR by formulating the following hypothesis regarding 
investor reaction to readability of EPRs by TSX Venture Exchange firms. In line with many previous studies (Courtis, 1986; Subramanian et al., 1993; Li 2008; Miller, 2010; Lawrence, 2013; Loughran and McDonald, 2014) this study uses the Gunning Fog Index as the measure of reading complexity and tests the following null hypothesis.

Hypothesis 6 (H6): There is no association between reading complexity of EPRs and short-term cumulative abnormal return.

\subsubsection{Causal reasoning intensity and cumulative abnormal return}

As discussed above, causal reasoning intensity affects readability since the usage of causal words leads to more complex disclosure documents (Aerts and Yan, 2017; Zhang et al., 2018). Therefore, similar to the previous hypothesis on reading complexity and cumulative abnormal return, this research tests the relationship between causal reasoning in EPRs and cumulative abnormal return. The null hypothesis on the association between causal reasoning intensity (defined in Chapter 4) and short-term cumulative abnormal return is formulated as follows.

Hypothesis 7 (H7): There is no association between causal reasoning intensity and shortterm cumulative abnormal return.

\subsubsection{Headline impression management and cumulative abnormal return}

Earlier in this chapter, $\mathrm{H} 4$ was formulated based on previous research findings that firms try to emphasize positive performance by various selection, emphasis, and thematic manipulation strategies. On the investor reaction side, this study also tests the relationship between headline impression management and short-term investor reaction. Although many prior studies find that firms engage in impression management by placing good news in more prominent sections or headlines of disclosure documents (Baird and 
Zelin, 2000; Bowen et al., 2005; Kelton, 2006; Davison, 2008; Gordon et al., 2010; Guillamon-Saorin et al., 2012), there are a limited number of studies that tested the association between this impression management strategy and investor reaction.

In an experimental design study, Baird and Zelin (2000) test the effect of information order while presenting positive and negative information in the president's letter. They conclude that investors are more influenced by information that they read first in disclosure documents. Since the headlines of EPRs are first to capture investors' attention, it can be argued that investors are influenced by impression management in the headlines. Moreover, as discussed in the previous chapter, prior literature finds that firms engage in biased reporting by repeating, reinforcing, and emphasizing good performance or good news more than bad ones (Bowen et al., 2005; Guillamon-Saorin, 2006; Brennan et al., 2009; Guillamon-Saorin et al., 2012). Therefore, similar to the hypothesis regarding the association between abnormal tone, which positively affects short-term investor reaction according to previous literature, this study predicts that headline impression management also leads to a higher cumulative abnormal return. Headline impression management bias (defined in Chapter 4), which includes emphasis of positive performance by thematic manipulation, reinforcement, and repetition, will be used to test this association. The following null hypothesis tests the association between headline impression management bias and short-term cumulative abnormal return. Hypothesis 8 (H8): There is no association between headline impression management bias and short-term cumulative abnormal return. 


\subsection{Online discussion board reaction to apparent impression management - investor perspective}

Since the majority of online investment board participants are individual investors (Wysocki, 1999; Lerman, 2017), it may be expected that online discussion board users' reactions to the tone of EPRs is similar to those of investors. For example, in line with previous research on the association between abnormal tone in EPRs and short-term stock response (Henry, 2008; Davis et al., 2012; Huang et al., 2014; Arslan-Ayaydin et al., 2016), abnormal positive tone may also lead to abnormal positive sentiment (defined in Chapter 4) in online investment discussion. Or, since better EPR readability is associated with more pronounced (Miller, 2010; Lee, 2012; Henry, 2008; Lawrence, 2013; Kim et al., 2016) investor reaction, better readability may also be associated with higher abnormal discussion volume (defined in Chapter 4) in online investment discussion posts. Similar to H4, lower causal reasoning intensity, which is inversely related with better readability, may also be related with higher online discussion volume. However, since there is no previous research that investigates online discussion board reaction to apparent impression management, this study examines retail investors' reaction or attention to apparent impression management by formulating two null hypotheses. More specifically, the following $\mathrm{H} 9$ and $\mathrm{H} 10$ help explore whether there are discussion volume and discussion sentiment responses to apparent impression management in EPRs, respectively.

H9: There is no association between impression management and online user reaction, as measured by discussion volume.

H10: There is no association between impression management and online user reaction, as measured by discussion sentiment. 


\subsection{Diagram: hypotheses}

Figure 3.1, which is based on the main research map (Figure 2.9), illustrates where in the main research areas the formulated hypotheses fit. As shown in Figure 3.1, earnings press releases, impression management, and other factors affecting investor reaction make up the area for the firm perspective. Other factors affecting investor reaction include such variables as firm performance (e.g., operating income, net earnings), firm-specific control variables (e.g., firm size, industry) and benchmark stock returns (contemporaneous annual TSX Venture stock returns). This variable, although in the area for the firm perspective, also affects the investor perspective similar to impression management. The investor perspective on impression management includes investor reaction, which comprises of stock market reaction and online discussion board reaction. Each arrow connecting the boxes are discussed in detail in Chapter 2.

Hypotheses $\mathrm{H} 1-\mathrm{H} 4$ are in the firm perspective area as they help understand impression management strategies by firms. The analysis required to test these four hypotheses uses data from all three boxes that belong to the area: EPRs, impression management strategies which are obtained from EPRs, and other factors affecting investor reaction. Next, findings from the firm perspective on each of the four broadly defined categories of impression management strategies are used to test hypotheses and explore research propositions on the investor perspective. Stock market reaction is tested with hypotheses $\mathrm{H} 5-\mathrm{H} 8$, while online discussion board reaction is explored with hypotheses $\mathrm{H} 9$ and H10. Chapter 4 presents additional detail on the research approach and methodology used to test these hypotheses and explore the research propositions. 
Figure 3.1. Hypotheses and the main research areas

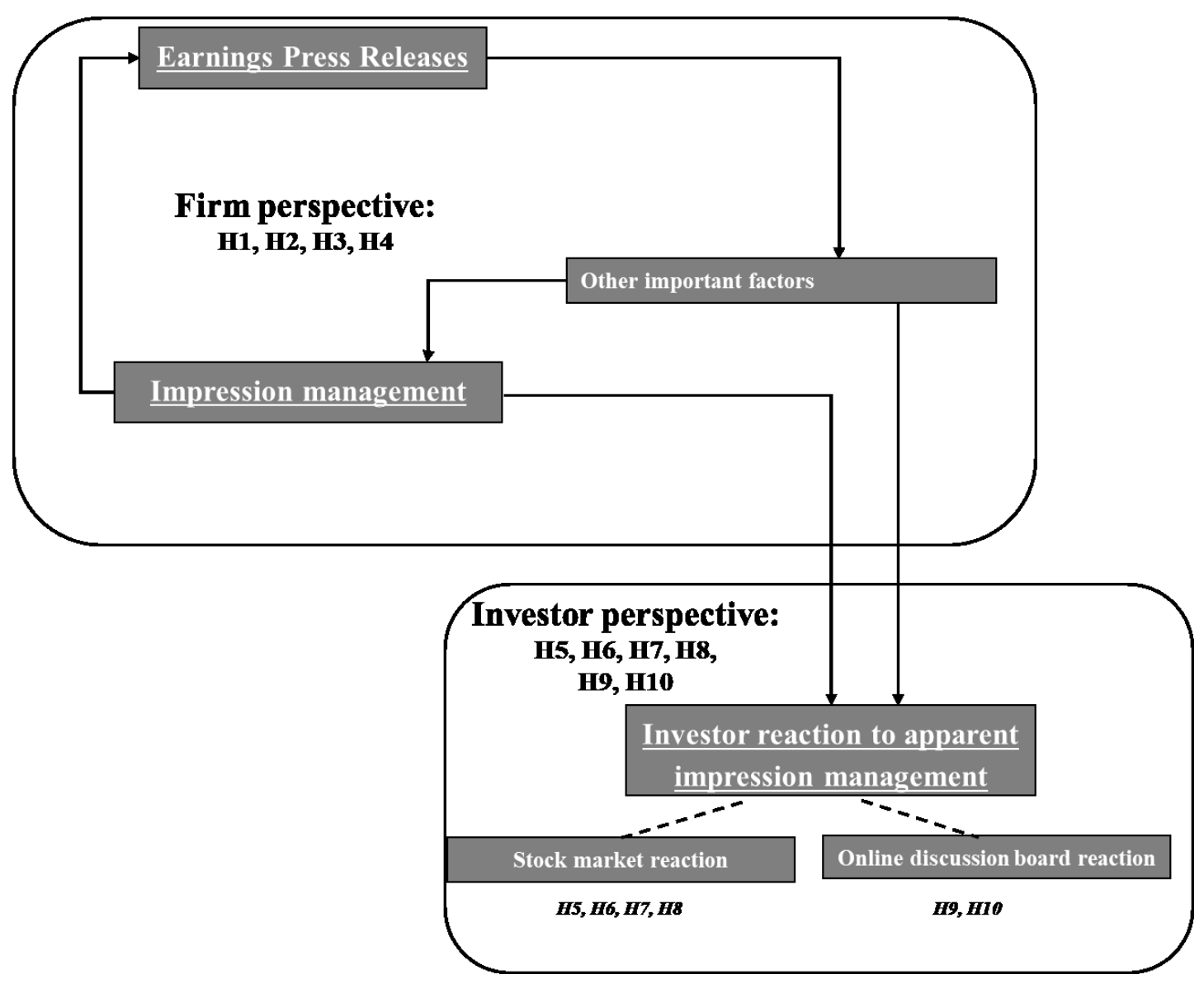




\section{Chapter 4 - Methodology}

This chapter explains the approach for investigating impression management and its consequences based on the hypotheses and research propositions formulated in the previous chapter. First, the chapter introduces the research strategy which provides a brief overview on the methodology for investigating both firm and investor perspectives on impression management. Next, sections on data sources, sampling design, and data collection describe the overall process of obtaining data that is used for further analysis. Finally, sections on variable measurement and data analysis discuss the methods and methodologies used to explore impression management and its consequences for investors.

\subsection{Research strategy}

In short, the research strategy involves performing a quantitative analysis to identify impression management in EPRs and examine its impact on investors. This entails multiple steps from collecting required data, which is both qualitative (e.g., EPRs, online investment discussions board messages) and quantitative (e.g., operating income, market capitalization, stock market data), to testing specific relationships between variables. Given the fact that this study examines both quantitative and qualitative data, a major reason for using quantitative analyses, as opposed a mixed method, is to be able to apply computerized content analysis techniques by quantifying the content of EPRs and investment discussion board messages. At a high level, there are two main relationships that this study investigates to explore the firm and investor perspectives on impression management. 
First, the methodology employed for investigating the firm perspective is based on measuring impression management and analyzing the relationship between impression management and firm performance. The process of measuring impression management uses computer-based content analysis methods to analyze the narrative content of EPRs. This study collects EPR disclosures of TSX Venture Exchange firms to examine impression management by these low-visibility firms.

Second, the investor perspective on impression management is investigated based on the event study methodology which is a widely used approach in capital markets research. As discussed in previous chapters, there are two components in the investor perspective that explores how investors react to impression management: (1) stock market reaction which uses CAR as the dependent variable and (2) online investment discussion board reaction which uses volume (number of posts) and sentiment as the dependent variables. Similar to the concept of CAR, the investigation of online investment discussion board reaction involves calculating abnormal volume and sentiment. In addition to EPRs, stock data, and online discussion board data, this study uses firm fundamentals data such as operating income, net earnings, total assets, and market capitalization as dependent variables. Industry classification is used as a control variable. The following sections of this chapter discuss each step described in the research strategy in detail starting from identifying data sources.

\subsection{Data sources}

This section identifies various data sources for qualitative and quantitative data used in this study. There are four broad categories of data: EPRs, firm fundamentals and other important factors, stock market data, online investment discussion board messages. 
All data is obtained for TSX Venture Exchange firms identified in the sample design process which is described in Section 4.3 of this chapter.

\subsubsection{EPRs}

There are several sources available for obtaining EPRs. These sources include corporate websites, SEDAR, and financial information networks such as GlobeNewswire. This study considers all three sources for collecting EPRs of TSX Venture Exchange firms. Data collection process and the justification of the source selection for EPRs is described in Section 4.4 of this chapter.

EPRs of many firms are accessible through the Investor Relations page of corporate websites. However, since making EPRs available on corporate websites is completely voluntary, there is no guarantee that all issued EPRs can be found on corporate websites. Another source for obtaining EPRs is SEDAR. SEDAR (the System for Electronic Document Analysis and Retrieval) is an electronic portal used for filing most securities related information with the Canadian securities regulatory bodies ${ }^{5}$. Finally, EPRs can also be obtained from online financial networks. This study also explores the option of collecting EPRs from GlobeNewswire. GlobeNewswire is a prominent Nasdaq company which specializes in the delivery of corporate press releases, financial disclosures and multimedia content to the media, investment community, individual investors, and the general public ${ }^{6}$.

\footnotetext{
${ }^{5} \mathrm{https}: / /$ sedar.com/sedar/background_on_sedar_en.htm

${ }^{6}$ https://globenewswire.com/Index
} 


\subsubsection{Firm fundamentals and other related data}

Firm fundamentals data include operating income, net earnings, total assets, market capitalization, and book-to-market (BTM) ratio. This study uses Bloomberg database (Bloomberg) as the source for firm fundamentals data. Bloomberg is one of the leading financial data and analytics providers covering over 129 countries and 250 exchanges ${ }^{7}$. It offers quarterly financial statements data as well as daily information on market capitalization, total assets, BMT, which are used in this study.

To identify a sample of TSX Venture firms and their industry affiliations, this study uses information from the TMX Money website. It is an official website of TMX Group which operates Canadian exchanges such as the TSX, TSX Venture, TSX Alpha and others ${ }^{8}$. The website provides up-to-date information on the TSX Venture Index and its constituents. The relevance of the TSX Venture Index to this study is discussed in the data collection section.

\subsubsection{Stock market data}

This study uses stock market data that includes daily opening price, daily closing price, daily closing bid-ask spread, daily average bid-ask spread. The source for this data is Blomberg. Moreover, this study also uses TSX Venture Index returns data which is obtained from the TMX Money website.

\subsubsection{Online investment discussion board data}

\footnotetext{
${ }^{7}$ https://www.bloomberg.com/professional/solution/bloomberg-terminal/

${ }^{8}$ https://www.tmx.com/tmx-group/tmx-group-companies
} 
This study obtains individual investor discussions data from Stockhouse.com Canada's top financial portal and one of North America's largest small cap investor communities. Every month, over one million unique users visit the website to exchange ideas and gain information about stocks of their interest (Stockhouse.com, 2018). The reason for using Stockhouse is that this source is by far the most visited and largest (by the volume of posts) online stock discussion board for Canadian TSX Venture firms based on the investigation of relevant online investment discussion boards. Other relevant online discussion boards were identified by searching multiple keywords in Google which is responsible for about $90 \%$ of the overall global search engine market share (Statista, 2016). The Google search results yielded four most popular online discussion boards: Stockhouse, Yahoo! Finance, Investors Hub, The Motley Fool. Furthermore, to determine the relative popularity of each of the four selected online discussion boards, the number of posts for the top five and bottom five constituents of the S\&P/TSX Venture Index constituents by market capitalization was identified. As Table 4.1 illustrates, the number of posts from Stockhouse is significantly higher than those from Yahoo! Finance, Investors Hub, and The Motley Fool.

Stockhouse offers stock-related discussion boards, where individuals engage in discussions with other participants and share their thoughts about stocks and firms that they are interested in learning about for investment and other purposes ${ }^{9}$. While only registered users can post messages, discussants can quasi-anonymously select usernames to register or use their Facebook, Google, LinkedIn, or Twitter accounts to log in. In addition to registered users, there are also unregistered readers who have only read access

\footnotetext{
${ }^{9}$ http://www.stockhouse.com/corporate/about-us
} 
to the contents of discussions. Stockhouse discussion boards follow a post rating system in which posters are rewarded by earning credit from other users for sharing valuable opinions. This system helps minimize the problem stated in Vilardo (2004) that the same user may post under multiple usernames.

Table 4.1. The Number of posts (including replies) in June 2018 for the top five and bottom five S\&P/TSX Venture Index constituents (based on the initial 409 firms)

\begin{tabular}{|l|c|c|c|c|}
\hline & Stockhouse & $\begin{array}{c}\text { Yahoo! } \\
\text { Finance }\end{array}$ & $\begin{array}{c}\text { Investors } \\
\text { Hub }\end{array}$ & $\begin{array}{c}\text { The Motley } \\
\text { Fool }\end{array}$ \\
\hline \multicolumn{7}{|c|}{ Top five firms (by market cap) } \\
\hline Storagevault Canada Inc & 4 & 0 & 0 & 0 \\
\hline Cobalt 27 Capital Corp & 24 & 3 & 0 & 0 \\
\hline Novo Resources Corp & 1,632 & 6 & 0 & 0 \\
\hline Organigram Holdings Inc & 636 & 5 & 332 & 0 \\
\hline Auxly Cannabis Group Inc & 1,292 & 293 & 0 & 0 \\
\hline \multicolumn{7}{|c|}{ Bottom five firms (by market cap) } \\
\hline Majestic Gold Corp & 6 & 0 & 0 & 0 \\
\hline Falco Resources Ltd & 56 & 0 & 0 & 0 \\
\hline Eco Atlantic Oil and Gas & 28 & 0 & 0 & 0 \\
Ltd & 257 & 0 & 0 & 0 \\
\hline Bonterra Resources Inc & 2 & 0 & 0 & 0 \\
\hline Mirasol Resources Ltd &
\end{tabular}

Source: Stockhouse, Yahoo! Finance, Investors Hub, The Motley Fool, Google, 2018

\subsection{Sampling design}

This section provides information on the process of sample selections for lowvisibility firms that are investigated in this study. This sample selection determines the data collection criteria for all data categories discussed earlier. This section also discusses the selection of impression management strategies which this study explores.

\subsubsection{Firm selection}

Sections 2.2 and 2.3 of Chapter 2 provided justifications why TSX Venture firms can be considered as low-visibility firms. As the starting point of the sample selection 
process for low-visibility firms, this study uses the entire list of S\&P/TSX Venture Composite Index constituents, 409 firms, as of January 2016. The S\&P/TSX Venture Composite Index is a broad market capitalization-based index which is designed to measure the performance of securities listed on the TSX Venture Exchange ${ }^{10}$. The index constituents list is reviewed at the end of every calendar quarter and announced within the first two weeks of the following quarter. To be included in the list, firms must satisfy several requirements including market capitalization of at least $0.05 \%$ of the total capitalization of the index and incorporation under Canadian federal, provincial, or territorial jurisdictions (McGraw Hill Financial, 2015).

Some prior studies have used two years of data to investigate impression management (Bowen et al., 2005; Guillamon-Saorin et al., 2012). This research collects EPRs for the study period of 2.5 years from January $1^{\text {st }}, 2016$ to July $1^{\text {st }}, 2018$. This period covering 10 quarters is expected to provide sufficient data for generalizability of findings. Firms that do not remain in the TSX Venture Exchange throughout the study period are removed from the sample.

Table 4.2 describes the sample selection process which consists of seven steps. As the table illustrates, the first step starts with all 409 firms which make up the S\&P/TSX Venture Index as of January $1^{\text {st }}, 2016$. In the second step, firms that did not stay in the TSX Venture exchange throughout the study period are removed. Among the initial 409 firms, 82 did not remain in the TSX Venture Exchange by July $1^{\text {st }}$, 2018. Throughout the study period, of these 82 firms, 35 (43\%) graduated to the TSX Exchange, 29 (or 35\%)

\footnotetext{
${ }^{10}$ See https://web.tmxmoney.com/assets/docs/indices/JX/Methodology_JX.pdf for the methodology of selecting TSX Venture Index constituents.
} 
were acquired or privatized, 18 (or 22\%) were delisted from the TSX Venture Exchange or re-listed on other exchanges. This distribution shows that only $22 \%$ of the 82 firms that were excluded from the sample (step-2 of Table 4.2) were delisted or re-listed due to not satisfying the requirements of the TSX Venture Exchange. The main causes of delisting or re-listing from the TSX Venture Exchange are insufficient amount of assets, working capital, and market capitalization, which directly and indirectly impact firm visibility as discussed in Chapter 2 (TMX Group, 2017). This limits the effect of a survival bias because less than a quarter (18) of the excluded (82) firms may potentially be firms with much lower visibility than selected firms. In other words, the high percentage of graduated, acquired or privatized firms shows that the exclusion of firms in step-2 (Table 2) is not biased towards firms that are more likely to be less visible than remaining firms.

Table 4.2. Firm sample selection process

\begin{tabular}{|l|l|c|c|}
\hline Steps & \multicolumn{1}{|c|}{ Process } & $\begin{array}{c}\text { Number } \\
\text { of firms }\end{array}$ & $\begin{array}{c}\text { Percent of } \\
\text { remaining* }\end{array}$ \\
\hline Step 1 & S\&P/TSX Venture Index constituents are identified & $\mathbf{4 0 9}$ & $\mathbf{1 0 0 \%}$ \\
\hline Step 2 & $\begin{array}{l}\text { Firms that did not remain in the TSX Venture Exchange } \\
\text { throughout the study period are dropped }\end{array}$ & $(82)$ & $20.0 \%$ \\
\hline Step 3 & Surviving firms are determined - initial sample & $\mathbf{3 2 7}$ & $\mathbf{8 0 . 0 \%}$ \\
\hline Step 4 & Firms that did not issue any EPRs are dropped & $(156)$ & $47.7 \%$ \\
\hline Step 5 & Firms that issued one or more EPRs are determined & $\mathbf{1 7 1}$ & $\mathbf{5 2 . 3 \%}$ \\
\hline Step 6 & Firms that issued only one or two EPRs are dropped & $(26)$ & $15.2 \%$ \\
\hline Step 7 & The final sample of firms is determined & $\mathbf{1 4 5}$ & $\mathbf{8 4 . 8 \%}$ \\
\hline
\end{tabular}

Source: TMX Group, 2016

*Percentage values are calculated based on the number in the previous step

Next, after the removal of 82 firms from the initial 409 firms, surviving firms are determined - these firms make up the initial sample. As shown in the third step, 327 or $80.0 \%$ of all TSX Venture Index constituents remained in the TSX Venture Exchange by July $1^{\text {st }}, 2018$. 
Since the disclosure of EPRs is voluntary, it would be surprising if all of the surviving 327 firms in the initial sample issued such disclosures. This study investigates impression management in EPRs, therefore, the next step (step 4) of the sample selection process is to drop firms that did not issue any EPRs in the period from January $1^{\text {st }}, 2016$ to July $1^{\text {st }}, 2018$. The process of identifying the number of EPRs issued by each firm in the sample of surviving firms is provided in Section 4.4.1 of this chapter. Table 4.3 displays the number and percentage of EPR-issuing (firms that issued at least one EPR in the study period) and non-EPR-issuing firms (firms that did not issue any EPRs in the study period) by industry.

Table 4.3. Industry representation of issuing and non-issuing firms in the initial sample (sorted by the number of firms in the initial sample).

\begin{tabular}{|l|c|c|c|c|c|c|}
\hline & \multicolumn{2}{|c|}{ Initial sample } & \multicolumn{2}{c|}{$\begin{array}{l}\text { EPR-Issuing } \\
\text { firms }\end{array}$} & \multicolumn{2}{c|}{$\begin{array}{c}\text { Non-EPR- } \\
\text { Issuing firms }\end{array}$} \\
\hline \multicolumn{1}{|c}{ Industry } & $\#$ & $\%$ & $\#$ & $\%$ & $\#$ & $\%$ \\
\hline Metals \& Mining & $\mathbf{1 4 6}$ & $100 \%$ & 36 & $25 \%$ & 110 & $75 \%$ \\
\hline Oil \& Gas & $\mathbf{3 5}$ & $100 \%$ & 27 & $77 \%$ & 8 & $23 \%$ \\
\hline Biotechnology & $\mathbf{3 2}$ & $100 \%$ & 15 & $47 \%$ & 17 & $53 \%$ \\
\hline Application Software & $\mathbf{2 6}$ & $100 \%$ & 23 & $88 \%$ & 3 & $12 \%$ \\
\hline Industrial Products \& Manufacturing & $\mathbf{2 6}$ & $100 \%$ & 22 & $85 \%$ & 4 & $15 \%$ \\
\hline Other Industries & $\mathbf{2 3}$ & $100 \%$ & 15 & $65 \%$ & 8 & $35 \%$ \\
\hline Consulting \& Business Services & $\mathbf{2 0}$ & $100 \%$ & 17 & $85 \%$ & 3 & $15 \%$ \\
\hline Communication Equipment & $\mathbf{1 9}$ & $100 \%$ & 16 & $84 \%$ & 3 & $16 \%$ \\
\hline Total & $\mathbf{3 2 7}$ & $\mathbf{1 0 0 \%}$ & $\mathbf{1 7 1}$ & $\mathbf{5 2 \%}$ & $\mathbf{1 5 6}$ & $\mathbf{4 8 \%}$ \\
\hline
\end{tabular}

Source: TMX Group, 2016; SEDAR

As Table 4.3 shows, 156 of the surviving firms are non-EPR-issuing firms which are dropped ${ }^{11}$ from the sample of the surviving 327 firms. Therefore, the step 4 in Table

\footnotetext{
${ }^{11}$ Excluding non-EPR-issuing firms introduces a potential selection bias which may limit the applicability of findings only to EPR-issuing firms.
} 
4.2 shows 156 which is subtracted from 327 resulting in 171 firms (or $52 \%$ of 327 )

which disclosed one or more EPRs in the study period. The number 171 for EPR-issuing firms corresponds to the number provided in the fifth step in Table 4.2.

Table 4.4. Sample Selection Process by Industry

\begin{tabular}{|c|c|c|c|c|c|c|c|c|c|c|}
\hline \multirow{2}{*}{$\begin{array}{l}\quad \begin{array}{l}\text { Sample } \\
\text { selection }\end{array} \\
\text { Metals \& } \\
\text { Mining }\end{array}$} & \multicolumn{2}{|c|}{$\begin{array}{l}\text { Initial sample } \\
\text { (surviving } \\
\text { firms) }\end{array}$} & \multicolumn{2}{|c|}{$\begin{array}{l}\text { Less firms } \\
\text { that did not } \\
\text { issue any } \\
\text { EPRs in the } \\
\text { study } \\
\text { period }\end{array}$} & \multicolumn{2}{|c|}{$\begin{array}{l}\text { Firms that } \\
\text { issued one } \\
\text { or more } \\
\text { EPRs }\end{array}$} & \multicolumn{2}{|c|}{$\begin{array}{l}\text { Less firms } \\
\text { with only } \\
\text { one or two } \\
\text { EPRs in the } \\
\text { study period }\end{array}$} & \multicolumn{2}{|c|}{$\begin{array}{l}\text { Final sample } \\
\text { (firms with } \\
\text { three or } \\
\text { more EPRs } \\
\text { in the study } \\
\text { period) }\end{array}$} \\
\hline & 146 & $100 \%$ & 110 & $75 \%$ & 36 & $25 \%$ & 14 & $10 \%$ & 22 & $15 \%$ \\
\hline Oil \& Gas & 35 & $100 \%$ & 8 & $23 \%$ & 27 & $77 \%$ & 4 & $11 \%$ & 23 & $66 \%$ \\
\hline Biotechnology & 32 & $100 \%$ & 17 & $53 \%$ & 15 & $47 \%$ & 0 & $0 \%$ & 15 & $47 \%$ \\
\hline $\begin{array}{l}\text { Application } \\
\text { Software }\end{array}$ & 26 & $100 \%$ & 3 & $12 \%$ & 23 & $88 \%$ & 0 & $0 \%$ & 23 & $88 \%$ \\
\hline $\begin{array}{l}\text { Industrial } \\
\text { Products \& } \\
\text { Manufacturing }\end{array}$ & 26 & $100 \%$ & 4 & $15 \%$ & 22 & $85 \%$ & 4 & $15 \%$ & 18 & $69 \%$ \\
\hline $\begin{array}{l}\text { Consulting \& } \\
\text { Business } \\
\text { Services } \\
\end{array}$ & 20 & $100 \%$ & 3 & $15 \%$ & 17 & $85 \%$ & 0 & $0 \%$ & 17 & $85 \%$ \\
\hline $\begin{array}{l}\text { Communication } \\
\text { Equipment }\end{array}$ & 19 & $100 \%$ & 3 & $16 \%$ & 16 & $84 \%$ & 3 & $16 \%$ & 13 & $68 \%$ \\
\hline $\begin{array}{l}\text { Other } \\
\text { Industries }\end{array}$ & 23 & $100 \%$ & 8 & $35 \%$ & 15 & $65 \%$ & 1 & $4 \%$ & 14 & $61 \%$ \\
\hline Total & 327 & $100 \%$ & 156 & $48 \%$ & 171 & $52 \%$ & 26 & $8 \%$ & 145 & $44 \%$ \\
\hline
\end{tabular}

As shown in Table 4.4, of the 156 non-EPR-issuing firms, the majority (118 firms or 76\%) are in the two natural resource industries - Metals \& Mining (110 firms) and Oil $\&$ Gas (8 firms). The operations of these predominantly junior miners are mainly targeted at the exploration of precious metals, oil and gas; therefore, in general these firms have not achieved any operating income or net earnings. Instead, a manual examination of SEDAR shows that most firms in the Metals \& Mining and Oil \& Gas industries issue 
news releases informing investors about such events as financing deals and drilling results. Thus, for these firms, EPRs are replaced by news releases that better fit their life cycle and the nature of their business.

Firms are not required to issue EPRs each quarter due to the voluntary nature of EPRs. Table 4.5 displays the number and percentage of EPR-issuing firms by the number (brackets) of EPRs and by industry. The table shows that 124 (or 72\%) of EPR-issuing firms released 8-10 EPRs, while 21 (or 13\%) of EPR-issuing firms provided 3-7 EPRs in the study period. Of EPR-issuing firms $26^{12}$ (or $15 \%$ ) disclosed only 1 or 2 EPRs in the study period. Moreover, a manual examination of the 26 EPRs by firms with only 1 or 2 disclosures show that press releases in this group mainly comprise only annual EPRs.

Patterns of impression management are less likely to be evident among these disclosers due to insufficient data and irregular disclosing behavior. Therefore, earnings press releases of this group are dropped from the sample as shown in the step 6 in Table 4.2. Thus, the final sample consists of 145 firms of EPR-issuing firms that issued three or more EPRs in the period from January $1^{\text {st }}, 2016$ to July $1^{\text {st }}, 2018$. The final step (step 7) in Table 4.2 determines these 145 firms which are the focus of this study. Table 4.4 illustrates the sample selection process by providing information on the number and percentage of firms by industry.

\footnotetext{
12 82\% (18) of these (26) non-frequent EPR-issuers are in the Metals \& Mining and Oil \& Gas industries which are mostly junior mining firms who may not view EPRs as valuable as other releases such as exploration results or financing deals. Nevertheless, it should be noted that excluding these non-frequent issuers (relative to firms issuing three or more EPRs) from the final sample introduces additional bias which restricts findings to be applicable only to frequent EPR-issuers.
} 
Table 4.5. EPR-issuing by the number of EPRs issued and industry representation.

\begin{tabular}{|c|c|c|c|c|c|c|c|c|}
\hline \multirow[b]{3}{*}{ Industry } & & & & & \multicolumn{4}{|c|}{ Final sample of firms } \\
\hline & \multicolumn{2}{|c|}{$\begin{array}{l}\text { EPR-Issuing } \\
\text { firms }\end{array}$} & \multicolumn{2}{|c|}{$\begin{array}{l}\text { Firms with 1-2 } \\
\text { releases }\end{array}$} & \multicolumn{2}{|c|}{$\begin{array}{l}\text { Firms with 3-7 } \\
\text { releases }\end{array}$} & \multicolumn{2}{|c|}{$\begin{array}{l}\text { Firms with } 8- \\
10 \text { releases }\end{array}$} \\
\hline & \# & $\%$ & \# & $\%$ & \# & $\%$ & \# & $\%$ \\
\hline Metals \& Mining & 36 & $100 \%$ & 14 & $39 \%$ & 6 & $17 \%$ & 16 & $44 \%$ \\
\hline Oil \& Gas & 27 & $100 \%$ & 4 & $15 \%$ & 4 & $15 \%$ & 19 & $70 \%$ \\
\hline $\begin{array}{l}\text { Application } \\
\text { Software }\end{array}$ & 23 & $100 \%$ & 0 & $0 \%$ & 2 & $9 \%$ & 21 & $91 \%$ \\
\hline $\begin{array}{l}\text { Industrial Products } \\
\& \text { Manufacturing }\end{array}$ & 22 & $100 \%$ & 4 & $18 \%$ & 0 & $0 \%$ & 18 & $82 \%$ \\
\hline $\begin{array}{l}\text { Consulting \& } \\
\text { Business Services }\end{array}$ & 17 & $100 \%$ & 0 & $0 \%$ & 3 & $18 \%$ & 14 & $82 \%$ \\
\hline $\begin{array}{l}\text { Communication } \\
\text { Equipment }\end{array}$ & 16 & $100 \%$ & 3 & $24 \%$ & 1 & $12 \%$ & 12 & $65 \%$ \\
\hline Biotechnology & 15 & $100 \%$ & 0 & $6 \%$ & 3 & $19 \%$ & 12 & $75 \%$ \\
\hline Other Industries & 15 & $100 \%$ & 1 & $7 \%$ & 2 & $13 \%$ & 12 & $80 \%$ \\
\hline Total & 171 & $100 \%$ & 26 & $15 \%$ & 21 & $13 \%$ & 124 & $72 \%$ \\
\hline
\end{tabular}

Source: TMX Group, 2016; SEDAR

\subsubsection{Selection of impression management strategies}

As mentioned previously, this study covers six of the seven impression management strategies introduced in Subsection 2.3.2. Namely, it examines the firms' use of thematic manipulation, reading ease manipulation, rhetorical manipulation, visual and structural manipulation, performance comparison, and choice of earnings number strategies (see shaded region in Figure 4.1). Performance attribution strategy is not included because, as the prior literature shows, this impression management strategy requires manual analysis of disclosure documents (Clatworthy and Jones, 2003; Lee et al., 2004; Aerts and Cheng, 2012; Kimbrough and Wang, 2014). Therefore, since this research uses computer-based methods to determine impression management, the performance attribution impression management strategy is not included in the scope of 
this research. As Table 4.6 illustrates, firms engage in various impression management strategies, therefore, the investigation of six impression management strategies, rather than one or two strategies, provides a more complete view of firms' involvement in impression management.

Figure 4.1. Impression management strategies.

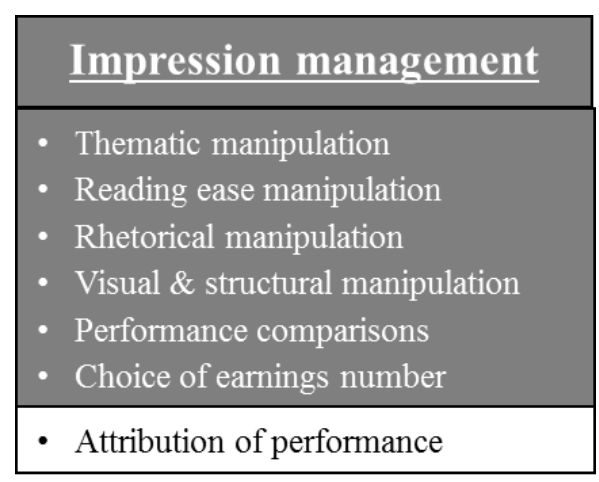

Table 4.6 contains information on the impression management strategies and measures used in this study to investigate six of the impression management strategies described in Subsection 2.3.2. It shows the name of each impression management strategy (as defined in this study) as well measures that each strategy is associated with.

Subsection 4.5.2 discusses each impression management measure in more detail.

Table 4.6. Impression management strategies investigated in this study

\begin{tabular}{|l|l|l|}
\hline $\begin{array}{c}\text { Strategy name in Merkl- } \\
\text { Davies and Brennan (2007) }\end{array}$ & \multicolumn{1}{|c|}{$\begin{array}{c}\text { Strategy name in this } \\
\text { study }\end{array}$} & \multicolumn{1}{|c|}{ Measure used in this study } \\
\hline Thematic manipulation & Tone management & $\begin{array}{l}\text { Tone, Abnormal tone, thematic } \\
\text { manipulation in EPR headlines }\end{array}$ \\
\hline Reading ease manipulation & Readability manipulation & Reading complexity \\
\hline Rhetorical manipulation & Causal reasoning & Causal reasoning intensity \\
\hline $\begin{array}{l}\text { Visual \& structural } \\
\text { manipulation }\end{array}$ & $\begin{array}{l}\text { Headline impression } \\
\text { management }\end{array}$ & $\begin{array}{l}\text { Headline impression } \\
\text { management bias }\end{array}$ \\
\hline Performance comparisons & $\begin{array}{l}\text { Headline impression } \\
\text { management }\end{array}$ & Emphasis by reinforcement \\
\hline Choice of earnings number & $\begin{array}{l}\text { Headline impression } \\
\text { management }\end{array}$ & Emphasis by repetition \\
\hline
\end{tabular}




\subsection{Data collection}

As discussed earlier, data used in this research includes EPRs, firm fundamentals and other important factors, stock market data, and online investment discussion board messages. This section provides some detail on the data collection process from the sources identified earlier.

\subsubsection{Collection of EPRs}

The collection of EPRs is performed manually by examining multiple reputable sources such as the corporate websites of sample firms, GlobeNewswire, and SEDAR to collect, if available, EPRs disclosed in the selected study period. Although GlobeNewswire provides many press releases issued by all TSX Venture firms, it does not contain all EPRs of a very few selected firms as verified by SEDAR and company websites.

SEDAR also contains most of the disclosed press releases by TSX Venture firms, however, a very few firms may choose not to file their EPRs on SEDAR due to the voluntary nature of such documents. To further ensure that all available data is collected, company websites are also manually examined to collect EPRs. The search results indicate that SEDAR included all EPRs available on company websites and GlobeNewswire, thus making SEDAR a complete source of EPRs. Therefore, all EPRs were downloaded from SEDAR. The complementary analysis of the two alternative sources was performed to ensure that all disclosed EPRs are collected. Moreover, the purpose for obtaining these disclosures from corporate websites is to document firms' 
disclosure channels since it is possible that not all firms issue their EPRs on their websites.

Table 4.7 shows the number and percentage of EPRs by industry for consistent issuers - sample firms that issued three or more EPRs in the study period. Among these consistent issuers selected in the final sample, Metals \& Mining (84\%), Biotechnology (86\%), and Oil \& Gas (88\%) firms are comparatively less consistent issuers than firms in the other industries (all above 90\%) selected in the final sample. The majority (91\%) of firms in the final sample issued EPRs very consistently with 8-10 EPRs in the 10 quarters covered by this study. Also, the Application Software industry has the highest representation in the sample with 217 releases while Other industries has the lowest number of EPRs with 126 releases. Overall, the final sample includes 1317 EPRs issued by 145 firms.

Table 4.7. EPRs issued by the final sample of firms (EPR-issuers with three or more EPRs) broken down by the number of EPRs and industry representation (sorted by the number of total EPRs).

\begin{tabular}{|l|c|c|c|c|c|c|}
\hline & \multicolumn{2}{|c|}{ Total releases } & \multicolumn{2}{c|}{$3-7$ releases } & \multicolumn{2}{c|}{$\mathbf{8 - 1 0}$ releases } \\
\hline \multicolumn{1}{|c|}{ Industry } & $\begin{array}{l}\text { \# of } \\
\text { releases }\end{array}$ & $\begin{array}{l}\% \text { releases } \\
\text { refle }\end{array}$ & $\begin{array}{l}\text { \# of } \\
\text { releases }\end{array}$ & $\begin{array}{l}\% \text { of } \\
\text { releases }\end{array}$ & $\begin{array}{l}\text { \# of } \\
\text { releases }\end{array}$ & $\begin{array}{l}\% \text { of } \\
\text { releases }\end{array}$ \\
\hline Application Software & 198 & $100 \%$ & 10 & $5 \%$ & 207 & $95 \%$ \\
\hline Oil \& Gas & 190 & $100 \%$ & 24 & $12 \%$ & 174 & $88 \%$ \\
\hline Metals \& Mining & 175 & $100 \%$ & 0 & $16 \%$ & 159 & $84 \%$ \\
\hline $\begin{array}{l}\text { Industrial Products \& } \\
\text { Manufacturing }\end{array}$ & 152 & $100 \%$ & 14 & $9 \%$ & 175 & $100 \%$ \\
\hline Consulting \& Business Services & 131 & $100 \%$ & 18 & $14 \%$ & 113 & $91 \%$ \\
\hline Biotechnology & 128 & $100 \%$ & 8 & $6 \%$ & 120 & $94 \%$ \\
\hline Communication Equipment & 126 & $100 \%$ & 13 & $10 \%$ & 113 & $90 \%$ \\
\hline Other Industries & 1317 & $100 \%$ & 118 & $9 \%$ & 1194 & $91 \%$ \\
\hline Total & & & & & & \\
\hline
\end{tabular}

Source: TMX Group, 2016; SEDAR 


\subsubsection{Collection of firm fundamentals data and stock market data}

As discussed earlier, firm fundamentals and stock market data is collected from Bloomberg and the TMX Money website for the period of January 1st, 2016 - January 1st, 2019. This data collection period exceeds the period for collecting EPRs because this is needed to measure future firm financial performance and investor reactions that extend beyond the date of EPR issuance.

Firm fundamentals data such as operating income, total assets, market capitalization is collected from Bloomberg. Industry information on the sample firms is obtained from the TMX Money website.

Stock market data for the final sample of 145 firms is obtained from Bloomberg ${ }^{13}$. This data includes daily opening price, closing price, closing bid-ask spread, and average bid-ask spread. Stock price information is primarily used to calculate abnormal stock return which is measured as the actual return on firm i's stock on day t minus the return on S\&P/TSX Venture Index on day t. Bid-ask spread data is used to calculate spread which is used in examining stock market reaction to apparent impression management. Book to Market ratio is also calculated from Bloomberg data. Benchmark returns data is collected from the TMX Money website.

\subsubsection{Collection of online investments discussion board posts}

As discussed in Subsection 4.2.4, the source for online investment discussion board data is Stockhouse. On Stockhouse, each firm has a discussion board page which organizes posts by their posted date and time (see an example in Appendix B). If a post

\footnotetext{
${ }^{13}$ Bloomberg stock market data is dividend-adjusted.
} 
has been posted as a reply to another post, the post title reflects that information by showing "RE" at the beginning of the title. Each post includes information on post id, post title, post time, post author, post text, post rating, author's username, author's overall rating, and the number of views obtained by the post (see an example in Appendix C). All these details are obtained for each firm among the final sample of 145 TSX Venture firms for the study period from January $1^{\text {st }}, 2016$ to January $1^{\text {st }}, 2019$ using a custom-made Python $^{14}$ scraper. This data collection period exceeds the period for collecting EPRs because this is needed to measure investor reactions that extend beyond the date of EPR issuance. It should be mentioned also that the volume of post data varies considerably by firm, depending on how actively users discuss a firm and its stock. Discussions cover various topics such as opinions on corporate disclosures, stock performance, future performance predictions, news coverage, etc.

It is possible that some firms themselves may participate as posters on Stockhouse to try to influence ongoing discussions or initiate discussions that may benefit these firms in certain ways. To determine if any of the sample firms are participating in discussions, firm names were matched with online usernames. This matching process did not return any results indicating that no firm name was found among the usernames of collected Stockhouse posts. However, it should be noted, there is no reliable way of ensuring that firms are not participating in online discussions as the process of registering a username does not require an official or an identifiable name.

\footnotetext{
${ }^{14}$ Python is an open-source programming language with applications in web development, database access, scientific research, network programming, and other areas (https://www.python.org/about/).
} 


\subsection{Measurement of variables}

This section provides details on the measurement of the variables used to investigate impression management and its consequences. More specifically, it discusses the measurement of firm performance and other important factors, impression management strategies, and investor reaction. These measurements serve as a basis for the data analysis process discussed in the next subsection.

\subsubsection{Measuring firm performance and other important factors}

As discussed in Chapter 3, firm performance is one of the central variables used in the investigation of impression management from the firm perspective. In other words, firm performance helps test whether or not a certain impression management strategy is present in EPRs. Most impression management studies use net earnings as a measure of firm performance (Henry 2008; Huang et al., 2014; Arslan-Ayaydin et al., 2016). However, the use of net earnings may not be as applicable for low-visibility firms. Since the TSX Venture Exchange hosts small and early-stage firms, most of these firms have not achieved profitability yet (TMX Group, 2017). Therefore, unlike prior studies, this research uses change in operating income as a key performance indicator that may affect firms' motivations for impression management.

Firm performance is calculated for current performance and future performance. The subsequent sections of this chapter discuss the use of each performance figures. Current firm performance is measured as the change in current operating income from the same quarter of previous year. Similarly, future firm performance is measured by subtracting current operating income from operating income for the same quarter of the 
following year. Both current and future performance numbers are scaled by total assets (in the corresponding quarter) to account for differences in the size of firms.

As discussed in Section 2.5, this study uses a number of other important factors as control variables. The control variables include earnings, firm size, BTM (book-tomarket ratio), benchmark stock returns, and industry. The earnings variable is used as a dummy variable that shows whether earnings are positive (1) or not positive (0) for a particular quarter. This variable is important because, as discussed earlier, most TSX Venture firms may not have achieved profitability. Therefore, whether earnings are positive or not may prove to be a significant factor in the study of impression management.

The firm size (market capitalization), BTM, and benchmark stock returns (contemporaneous benchmark annual stock returns) variables are used in the present study following prior impression management literature (Henry et al., 2008; Demers and Vega, 2010; Price et al., 2012; Huang et al., 2014; Aerts and Cheng, 2011; Davis et al., 2012).

Industry is also included as one of the control variables because it is an important factor in the investigation of impression management and investor reaction to apparent impression management (Davis et al., 2012; Kimbrough and Wang, 2014; Aerts and Yan, 2017; Aerts et al., 2018). An industry dummy variable is frequently used as a control variable in most impression management studies (Smith and Taffler, 2000; Yuthas et al., 2002; Rutherford, 2005; Li, 2007; Henry, 2008; Loughran and McDonald, 2011; Davis et al., 2012; Kimbrough and Wang, 2014; Aerts and Yan, 2017; Aerts et al., 2018). As 
discussed previously, the industry effect may be even stronger for low-visibility firms as an outcome of mimetic isomorphism.

In this study industry is a categorical control variable containing 8 groups: Application Software, Biotechnology, Communication Equipment, Consulting \& Business Services, Industrial Products \& Manufacturing, Metals \& Mining, Oil \& Gas, and other ${ }^{15}$ industries. These industry groups represent all industries that are available on the TSX Venture Exchange.

\subsubsection{Measuring impression management in EPRs}

This study analyzes the content of both the body ${ }^{16}$ and the headline (or title) of EPRs to investigate six impression management strategies described in Chapter 2. Following the existing impression management literature, the analysis of impression management is performed in the narrative content of EPRs that excludes tables, company logos, pictures, and recurring sections such as "About the Company" and "Forward Looking Statements". Therefore, each EPR goes through a computerized pre-processing step which helps obtain EPR headline and narrative portions in the body of EPRs. The pre-processing step uses a custom-designed Python script that splits EPRs into processed headline and body sections which are free from tables, company logos, pictures, and recurring sections. The procedure for identifying EPR headlines is based on a logic which seeks the place (city) and date of EPRs that start at the beginning of the body part in each

\footnotetext{
${ }^{15}$ Industries with fewer than 10 firms in the initial sample of 327 firms are grouped under the 'other industries' category.

${ }^{16}$ Body is the part of an EPR starting with the place and time of the EPR issue. Also, it is the part which follows the title and subtitles in the EPR.
} 
EPR. Based on this logic, the designed Python script classifies titles and subtitles of EPRs as EPR headlines, while the remaining content is classified as the body part.

The analysis of the processed EPR body entails measuring tone, abnormal tone, reading complexity, and causal reasoning intensity in the narrative content. The analysis of the processed EPR headline includes the examination of both qualitative and quantitative information to measure such impression management strategies as emphasis by thematic manipulation, emphasis by repetition, and emphasis by reinforcement. Following Brennan et al. (2009) and Guillamon-Saorin et al. (2012), a composite score (headline impression management bias) is computed for headline impression management.

\subsubsection{Measuring Tone}

Following prior literature (Davis and Tama-Sweet, 2012; Davis et al., 2012; Patelli and Pedrini, 2013; Huang et al., 2014; Arslan-Ayaydin et al., 2016), this study measures EPR tone based on the difference between the count of positive and the count of negative words scaled by total words in the document:

$$
\text { Tone }_{i, q, t}=100 * \frac{\operatorname{PosW}_{i, q, t}-\mathrm{NegW}_{i, q, t}}{\operatorname{TotW}_{i, q, t}},
$$

where $\mathrm{Pos} \mathrm{W}_{\mathrm{i}, \mathrm{q}, \mathrm{t}}$ is the number of positive words, $\mathrm{NegW}_{\mathrm{i}, \mathrm{q}, \mathrm{t}}$ is the number of negative words, and Tot $\mathrm{W}_{\mathrm{i}, \mathrm{q}, \mathrm{t}}$ is the total number of words in an EPR of firm $\mathrm{i}$, in quarter q of year t.

To label positive and negative words, researchers have used custom-built word dictionaries (Clatworthy and Jones 2003; Henry, 2008; Loughran and McDonald, 2011) 
and lists from dictionary-based programs such as DICTION (Yuthas et al., 2002; Davis et al., 2012; Patelli and Pedrini, 2013), and the combination of both (Arslan-Ayaydin et al., 2016). In order to ensure the suitability and completeness of words lists, DICTION's optimism-increasing and optimism-decreasing word lists are supplemented with specifically designed financial disclosure-related dictionaries by Henry (2008) and Loughran and McDonald (2011) to measure the tone of EPRs.

\subsection{DICTION}

This study uses DICTION 7.0 to calculate tone. DICTION (available from dictionsoftware.com) is a computer-assisted textual-analysis program for determining tone. It uses a series of dictionaries to determine semantic features (e.g., Activity, Optimism, Certainty, Realism, Commonality) and sub-features of a document (DICTION, 2018). Most importantly, DICTION allows researchers to use user-defined word lists for performing frequency counts and other analyses. Perhaps, due to this feature, the program is widely used in impression management studies (Sydserff and Weetman, 2002; Yuthas et al., 2002; Henry, 2008; Davis et al., 2012; Patelli and Pedrini, 2013).

\subsubsection{Measuring Abnormal Tone}

Since disclosure tone can reflect actual or expected financial performance (Miller, 2002), it is important to capture abnormal tone by controlling for incremental information contained in EPRs (Huang et al., 2014). Therefore, similar to Huang et al. (2014) and Arslan-Ayaydin et al. (2016), abnormal tone (AB_TONE $\left.{ }_{i, q, t}\right)$ is measured as the residual $\left(\varepsilon_{i, q, t}\right)$ of the following OLS regression which takes into consideration firm performance and other control variables such as firm size, total assets, and industry: 


$$
\begin{aligned}
& \text { TONE }_{i, q, t}=\alpha+\beta_{0} \Delta \mathrm{OI}_{i, q, t}+\beta_{1} \mathrm{POS}_{-} \mathrm{EAR}_{i, q, t}+\beta_{2} \operatorname{lnMV}_{i, q, t}+\beta_{3} \mathrm{BTM}_{i, q, t}+\beta_{4} \mathrm{M}_{-} \mathrm{RET}_{i, q, t}+ \\
& +\beta_{5} \mathrm{IND}_{i, q, t}+\varepsilon_{i, q, t}
\end{aligned}
$$

where:

TONE $=$ Tone in EPR (excluding the headline) of firm $\mathrm{i}$ in quarter $\mathrm{q}$ of year $\mathrm{t}$;

$\Delta \mathrm{OI}=$ change in operating income (compared to the same quarter of previous year) scaled by total assets in the corresponding quarter;

POS_EAR $=$ dummy variable for positive earnings ( 0 if net earnings are negative or zero and 1 if net earnings are positive);

$\operatorname{lnMV}=$ natural logarithm of total market capitalization at announcement date;

$\mathrm{BTM}=$ Book-to-market ratio (calculated as total market capitalization over total book value);

M_RET $=$ contemporaneous benchmark annual stock returns;

$\mathrm{IND}=$ dummy variable for industry;

Thus, AB_TONE $E_{i, q, t}\left(\right.$ abnormal tone), which is the residual $\left(\varepsilon_{i, q, t}\right)$ of the above regression (2), is used to evaluate impression management by tone management.

\subsubsection{Measuring Reading Complexity}

Extant literature on disclosure readability has measured reading ease (readability) using the Fog Index (Courtis, 1986; Subramanian et al., 1993; Li 2008; Miller, 2010; Lawrence, 2013; Loughran and McDonald, 2014). This readability measure, also known as the Gunning Fog Index, is one of the most popular readability measures in academic research and is the measure of choice among finance and accounting scholars (Loughran 
and McDonald, 2014). The Fog Index ${ }^{17}$, considers the number of complex words and the average sentence length to provide a readability test of documents (Readability Formulas, 2018). Therefore, the greater the Fog Index the more difficult it is to read the document. Based on this direct relationship, this study uses the Fog Index to define reading complexity. Thus, the reading complexity of an EPR is equal to the EPR's Fog Index.

\subsubsection{Measuring causal reasoning intensity}

Following Aerts and Cheng (2011) and Aerts and Yan (2017), this research measures the relative frequency of causation words to determine the level of causal reasoning, also referred to as causal reasoning intensity (Zhang et al., 2018), in an EPR. More specifically, the methodology uses DICTION's causal reasoning style category which contains such causation words or connectors as 'hence', 'therefore', 'cause', 'as a result', etc. The level of causal reasoning in each EPR is determined by the sum of total sentences including causation words scaled by the number of total sentences in the document:

$$
C A U S \_R_{i, q, t}=100 * \frac{\operatorname{CausS}_{i, q, t}}{\operatorname{TotS}_{i, q, t}}
$$

where:

$C A U S_{-} R_{i, q, t}=$ the level of causal reasoning in EPR of firm $\mathrm{i}$ in quarter q of year $\mathrm{t}$;

$\operatorname{CausS}_{i, q, t}=$ the number of sentences with causal words or connectors in an EPR of firm $\mathrm{i}$, in quarter q of year $\mathrm{t}$;

${ }^{17}$ The Gunning Fog Index formula: 0.4 * ((average sentence length) + (percentage of Hard Words)) 
$\operatorname{TotS}_{i, q, t}=$ the total number of sentences in an EPR of firm $\mathrm{i}$, in quarter q of year $\mathrm{t}$.

\subsubsection{Measuring Headline Impression Management in EPR}

Several studies have investigated how firms manipulate the order or physical location of information in a disclosure document to affect readers' attention (Baird and Zelin, 2000; Bowen et al., 2005; Kelton, 2006; Davison, 2008; Gordon et al. 2010), however only Guillamon-Saorin et al. (2012) focus on the headline portion of disclosure by studying EPR headlines. Guillamon-Saorin et al. (2012) argue that the study of headlines yields valuable insights on firms' impression management strategies because headlines are a key portion of financial communication. Moreover, headlines set the agenda for the reader (Mahoney, 1991), attract the attention of the reader (Bell, 1991), and create a lasting impression (Bernstein and Garst 1982). Therefore, given their strategic importance and location, EPR headlines are a valuable research object for studying impression management.

\subsection{Thematic Manipulation}

Thematic manipulation entails emphasizing positive organizational performance by using positive and optimistic words rather than negative and pessimistic words (Brennan et al., 2007; Davis et al., 2007; Brennan et al., 2010). For example, in the following press release headlines, the highlighted words are used to emphasize positive performance using words with positive connotations:

1. "Excellent operating and financial results for elder mine for the three-month and nine-month periods ended March 31, 2018” (Abcourt Mines, EPR headline 2018 Q1). 
2. "AnalytixInsight posts strong quarterly results driven by the increased demand for its content" (AnalytixInsight, EPR headline 2016 Q2)

Using the supplemented list of positives and negative keywords described earlier, the number of positive and negative words per each EPR headline is summed up. These individual scores (totals) are then used in the computation of a composite impression management score which is described following sections.

\subsection{Emphasis by repetition and reinforcement}

Existing impression management research has studied how firms emphasize good news by repeating, reinforcing, and placing information in disclosure documents (Baird and Zelin, 2000; Bowen et al., 2005; Elliott, 2006; Files et al., 2009, Guillamon-Saorin et al., 2012). The present study investigates two types of emphasis in the headlines of EPRs: repetition of performance figures and reinforcement of performance comparisons. Below are examples of each type of emphasis studied in this paper:

1. Emphasis by repetition - "ATN reports a net income of $\$ 1,862,841$ on revenues of $\$ 26,102,683$ for the 12 months ended December 31, 2015” (ATN, 2015 Q4)

2. Reinforcement of performance comparisons - "AcuityAds Reports First Quarter Financial Results - Q1 Revenue Increased 71\% Year over Year" (AcuityAds, 2016 Q2)

In the first example, ATN is emphasizing the net income and revenue figures by presenting them in the headline of their EPR. Therefore, to measure the level of emphasis by repetition, a score of 1 is given for each performance figure mentioned in an EPR 
headline. Emphasis by repetition is counted as positive if no negative word is used to describe the repeated number. Negative words are identified using combined word lists from Henry (2008) and Loughran and McDonald (2011), and DICTION's optimismdecreasing dictionaries. In the second example, AcuityAds is reinforcing the fact that their revenue grew by $71 \%$ compared to the same quarter last year. Similar to measuring emphasis by repetition, reinforcement of performance comparisons is measured by giving a score of 1 for each comparison figure in the headline of each EPR. However, if a performance comparison is negative, -1 point is added. No points are awarded when there is no emphasis by repetition or reinforcement of performance comparisons in the headline. The level of overall emphasis is calculated by summing scores for both impression management strategies.

\subsection{Composite Score and Measure of Headline Impression Management Bias}

Next, an aggregate impression management score is computed for the headlines portion of EPRs. Following Brennan et al. (2009) and Guillamon-Saorin et al. (2012), composite scores for both positive and negative impression management are calculated by summing the individual scores for each impression management strategy per EPR headline as follows:

PosIMScore $=$ Pos_TM + Pos_Rein + Pos_Rep

NegIMScore $=$ Neg_TM + Neg_Rein + Neg_Rep

where: 
PosIMScore $=$ total positive impression management score for an EPR headline;

NegIMScore $=$ total negative impression management score for an EPR headline;

Pos_TM = total positive thematic manipulation score;

Neg_TM = total negative thematic manipulation score;

Pos_Rep $=$ total positive repetition score;

Pos_Rep $=$ total negative repetition score;

Pos_Rein $=$ total positive reinforcement score;

Neg_Rein $=$ total negative reinforcement score;

Brennan et al. (2009) also propose a method to measure impression management bias using the totals of positive and negative composite impression management scores. Following Brennan et al. (2009), a headline impression management bias score $\left(H E A D_{-} B\right)$ is computed as the difference between total positive and negative impression management scores scaled by the sum of the two total scores:

$$
\text { HEAD_B }=\frac{\text { PosIMScore- } \text { NegIMScore }}{\text { PosIMScore+NegIMScore }}
$$

A positive impression management score indicates that a firm is biased toward emphasizing good news in the headline of its EPR.

\subsubsection{Measuring investor reaction variables}

This subsection discusses the variables used to investigate investor reaction to apparent impression management. More specifically, it provides information on how 
stock market reaction and online investment discussion board reaction variables are measured.

\subsubsection{Cumulative Abnormal Return (CAR)}

This study defines CAR as cumulative returns in excess of benchmark performance during the period around the issuance of EPRs. Benchmark performance is measured using TSX Venture Exchange Index returns for the same period. The TSX Venture Exchange Index is used as the benchmark because the index constituents represent the population from where the sample for this study is obtained. This allows for an efficient calculation of CAR while controlling for factors external to this particular index.

\subsubsection{Discussion volume and discussion sentiment}

Online participants' reaction is measured by analyzing abnormal volume and abnormal sentiment from online discussions. The calculation of discussion volume is based on counting the number of discussion posts around the issuance of EPRs. Similar to the concept of CAR, abnormal discussion volume is measured as the average discussion volume for three days following the issue of EPR less the average discussion volume for the 60 days preceding the day before the EPR date. By choosing the preceding 60 days (as opposed to 90,120 , or 360 days, for example) it may be possible to avoid some other major interfering events such as previous earnings announcements while covering the preceding two months period which can give a reasonable timeframe to capture the information on usual discussion volume. 
The calculation of discussion sentiment uses the same dictionary (DICTION's optimism-increasing and optimism-decreasing word lists supplemented with specifically designed financial disclosure-related dictionaries by Henry (2008) and Loughran and McDonald (2011)) as used in the measurement of EPR tone, while the calculation of discussion volume considers the number of posts. DICTION's optimism-increasing and optimism-decreasing word lists ${ }^{18}$ can better capture sentiment from lexicon used in everyday communication (between online discussants), whereas financial disclosurerelated dictionaries (Henry (2008) and Loughran and McDonald (2011)) are more suitable for capturing sentiment from accounting and finance lexicon. In combination, these merged word lists can help derive sentiment from online discussions which can be both financial and non-financial in nature.

Similar to the calculation of abnormal discussion volume, abnormal discussion sentiment is measured as the average discussion sentiment for three days following the issue of EPR less the average discussion sentiment for the 60 days preceding the day before the EPR date. The reason for choosing the 60-day period is the same as the reason given for abnormal discussion volume.

\subsubsection{Summary of variables and measurements}

Section 4.5 of this chapter describes the measurement of variables used in this study. Table 4.8 summarizes all measurements by providing brief definitions for them.

\footnotetext{
${ }^{18}$ The optimism-increasing word lists in DICTION track words associated with 'praise', 'satisfaction' and 'inspiration', while the optimism-decreasing word list includes words describing 'blame', 'hardship' and 'denial'.
} 
Moreover, the third column (Related concept) in the table links each measure with a research area from the overall research map (see Figure 2.9).

Table 4.8. Summary of measures

\begin{tabular}{|c|c|c|}
\hline Measure & Measure definition & Related concept \\
\hline PosW & The number of positive words in an EPR & $\begin{array}{l}\text { Impression management - } \\
\text { Tone management }\end{array}$ \\
\hline $\mathrm{NegW}$ & The number of negative words in an EPR & $\begin{array}{l}\text { Impression management - } \\
\text { Tone management }\end{array}$ \\
\hline TotW & The total number of words in an EPR & $\begin{array}{l}\text { Impression management - } \\
\text { Tone management }\end{array}$ \\
\hline TONE & Tone in an EPR (measured in Eq. 1) & $\begin{array}{l}\text { Impression management - } \\
\text { Tone management }\end{array}$ \\
\hline AB_TONE & $\begin{array}{l}\text { Abnormal tone in an EPR (measured in Eq. } 1 \text { and } \\
\text { Eq. 7) }\end{array}$ & $\begin{array}{l}\text { Impression management - } \\
\text { Tone management }\end{array}$ \\
\hline READ & $\begin{array}{l}\text { The reading complexity of an EPR as } \\
\text { measured by the Gunning Fog index (measured } \\
\text { in Eq. 8) }\end{array}$ & $\begin{array}{l}\text { Impression management - } \\
\text { Readability manipulation }\end{array}$ \\
\hline CausS & $\begin{array}{l}\text { The number of sentences with causal words or } \\
\text { connectors in an EPR (measured in Eq. 3) }\end{array}$ & $\begin{array}{l}\text { Impression management - } \\
\text { Causal reasoning }\end{array}$ \\
\hline TotS & The total number of sentences in an EPR & $\begin{array}{l}\text { Impression management - } \\
\text { Causal reasoning }\end{array}$ \\
\hline CAUS_R & $\begin{array}{l}\text { Causal reasoning intensity in an EPR (measured } \\
\text { in Eq. } 3 \text { and Eq. 9) }\end{array}$ & $\begin{array}{l}\text { Impression management - } \\
\text { Causal reasoning }\end{array}$ \\
\hline Pos_TM & $\begin{array}{l}\text { Total positive thematic manipulation score in an } \\
\text { EPR headline }\end{array}$ & $\begin{array}{l}\text { Impression management - } \\
\text { Headline impression } \\
\text { management }\end{array}$ \\
\hline Neg_TM & $\begin{array}{l}\text { Total negative thematic manipulation score in an } \\
\text { EPR headline }\end{array}$ & $\begin{array}{l}\text { Impression management - } \\
\text { Headline impression } \\
\text { management }\end{array}$ \\
\hline Pos_Rep & Positive repetition score & $\begin{array}{l}\text { Impression management - } \\
\text { Headline impression } \\
\text { management }\end{array}$ \\
\hline Neg_Rep & Negative repetition score & $\begin{array}{l}\text { Impression management - } \\
\text { Headline impression } \\
\text { management }\end{array}$ \\
\hline Pos_Rein & Total positive reinforcement score & $\begin{array}{l}\text { Impression management - } \\
\text { Headline impression } \\
\text { management }\end{array}$ \\
\hline Neg_Rein & Total negative reinforcement score & $\begin{array}{l}\text { Impression management - } \\
\text { Headline impression } \\
\text { management }\end{array}$ \\
\hline
\end{tabular}




\begin{tabular}{|c|c|c|}
\hline Measure & Measure definition & Related concept \\
\hline PosIMScore & $\begin{array}{l}\text { Total positive impression management score for } \\
\text { an EPR headline (measured in Eq. 4) }\end{array}$ & $\begin{array}{l}\text { Impression management - } \\
\text { Headline impression } \\
\text { management }\end{array}$ \\
\hline NegIMScore & $\begin{array}{l}\text { Total negative impression management score for } \\
\text { an EPR headline (measured in Eq. 5) }\end{array}$ & $\begin{array}{l}\text { Impression management - } \\
\text { Headline impression } \\
\text { management }\end{array}$ \\
\hline HEAD_B & $\begin{array}{l}\text { Headline impression management bias score } \\
\text { (measured in Eq. } 6 \text { and Eq. 10) }\end{array}$ & $\begin{array}{l}\text { Impression management - } \\
\text { Headline impression } \\
\text { management }\end{array}$ \\
\hline$\Delta$ FUT_OI & $\begin{array}{l}\text { Future operating income change measured by } \\
\text { subtracting current quarter operating income } \\
\text { from operating income of the same quarter in the } \\
\text { following year. Values are scaled by total assets } \\
\text { in the corresponding quarter. }\end{array}$ & Other important factors \\
\hline$\Delta \mathrm{OI}$ & $\begin{array}{l}\text { Change in operating income (compared to the } \\
\text { same quarter of previous year). Values are scaled } \\
\text { by total assets in the corresponding quarter. }\end{array}$ & Other important factors \\
\hline POS_EAR & Dummy variable for positive earnings & Other important factors \\
\hline $\operatorname{lnMV}$ & $\begin{array}{l}\text { Natural logarithm of total market capitalization at } \\
\text { announcement date }\end{array}$ & Other important factors \\
\hline BTM & Book-to-market ratio & Other important factors \\
\hline M_RET & Contemporaneous benchmark stock returns & Other important factors \\
\hline IND & Dummy variable for industry & Other important factors \\
\hline SPREAD & $\begin{array}{l}\text { Daily average bid-ask spread divided by the } \\
\text { midpoint of bid and ask prices }\end{array}$ & Stock market reaction \\
\hline CAR & $\begin{array}{l}\text { Cumulative abnormal return (measured in Eq. } \\
\text { 11) }\end{array}$ & Stock market reaction \\
\hline AB_DVOL & $\begin{array}{l}\text { Abnormal discussion volume measured as the } \\
\text { average number of posts for three days following } \\
\text { the issue of EPR minus the average number of } \\
\text { posts for the } 60 \text { days preceding the day before } \\
\text { the EPR date (measured in Eq. 12) }\end{array}$ & $\begin{array}{l}\text { Online discussion board } \\
\text { reaction }\end{array}$ \\
\hline D_WEEK & Dummy variable for day of week & $\begin{array}{l}\text { Online discussion board } \\
\text { reaction }\end{array}$ \\
\hline AB_DSEN & $\begin{array}{l}\text { Abnormal discussion sentiment measured as the } \\
\text { average discussion sentiment for three days } \\
\text { following the issue of EPR minus the average } \\
\text { discussion sentiment for the } 60 \text { days preceding } \\
\text { the day before the EPR date (measured in Eq. 13) }\end{array}$ & $\begin{array}{l}\text { Online discussion board } \\
\text { reaction }\end{array}$ \\
\hline IND_AS & Industry group - Application Software & Other important factors \\
\hline IND_Bio & Industry group - Biotechnology & Other important factors \\
\hline IND_C_BS & Industry group - Consulting \& Business Services & Other important factors \\
\hline
\end{tabular}




\begin{tabular}{|l|l|l|}
\hline \multicolumn{1}{|c|}{ Measure } & \multicolumn{1}{|c|}{ Measure definition } & \multicolumn{1}{c|}{ Related concept } \\
\hline IND_CE & Industry group - Communication Equipment & Other important factors \\
\hline IND_IP_M & $\begin{array}{l}\text { Industry group - Industrial Products \& } \\
\text { Manufacturing }\end{array}$ & Other important factors \\
\hline IND_M_M & Industry group - Metals \& Mining & Other important factors \\
\hline IND_OTHER & Industry group - Other industries & Other important factors \\
\hline INDUSTRY & $\begin{array}{l}\text { Industry group - includes all industries except } \\
\text { for the Oil \& Gas and Metals \& Mining } \\
\text { industries }\end{array}$ & Other important factors \\
\hline AB_DVIEW & $\begin{array}{l}\text { Abnormal discussion views measured as the } \\
\text { average number of discussion views in the first 3 } \\
\text { days after the issuance of the EPR minus the } \\
\text { average number of discussion views in the 60 } \\
\text { days preceding the issuance of an EPR from }\end{array}$ & $\begin{array}{l}\text { Online discussion board } \\
\text { reaction }\end{array}$ \\
\hline
\end{tabular}

* The measures are listed in the order of their appearance in this study.

\subsection{Data analysis approach}

The data analysis approach involves a quantitative analysis aimed at examining the relationships formulated in the hypotheses and research propositions. The study employs regression analysis which is a widespread method used both in impression management and capital markets research. This method fits the purpose of this analysis as the method allows for testing the effect of one or more independent variables on the dependent variable. Moreover, regression analysis is appropriate because the set of variables used in this study comprise both continuous and categorical data. More specifically, this study employs Least Squares method for obtaining parameter estimates to fit a function to a set of data. Ordinary Least Squares (OLS) technique is one of the most popular regression techniques for its mathematical tractability and simplicity. As a prerequisite for using an OLS regression analysis, all assumptions of linear regression such as linear relationship, multivariate normality, no multicollinearity, uncorrelated errors, and homoscedasticity are checked in the observations. When the assumptions of linear regression is violated (e.g., autocorrelation, heteroscedasticity), Generalized Least 
Squares (GLS) can be applied for obtaining parameter estimates, especially when the data is pooled.

The methodology for investigating the firm perspective on impression management is based on testing the association between firm performance and each impression management measure (see Subsection 4.5.2) using an OLS regression analysis method. Testing this association helps determine whether firms manage impression management measures based on their performance results.

On the investor perspective, methodologies for investigating stock market reaction and online discussion board reaction are similar. The methodology for examining stock market reaction to apparent impression management employs OLS regression analysis to test the relationship between CAR and the studied impression management measures. In a similar way, the methodology for examining online investment discussion board reaction also employs OLS regression analysis to test the relationship between the abnormal discussion volume measure or the abnormal discussion tone measures and the studied impression management measures.

\subsubsection{Firm performance and impression management}

This subsection describes how the firm perspective on impression management is explored by examining the relationship between firm performance (or future firm performance in the case of tone management) and each of the studied impression management strategies. The identified impression management measures may also indicate opportunism by firms to 'seek firm-specific advantages' by behaving in a particular way when disclosing their EPRs (Gibbins et al., 1990, pp. 72). However, the 
focus of this study is impression management which can be revealed by examining the relationship between firm performance ${ }^{19}$ and the identified impression management measures using a large sample of EPRs.

\subsubsection{Tone management}

Tone management strategy is investigated by testing the relationship between future firm performance and the abnormal tone measure. Based on Hypothesis 1, the following equation regresses abnormal tone on the future firm performance ( $\Delta$ FUT_OI future operating income change) measure and control variables.

$$
\begin{aligned}
& \text { AB_TONE }_{i, q, t}=\alpha+\beta_{1} \Delta \mathrm{FUT}_{-} \mathrm{OI}_{i, q, t}+\beta_{2} \mathrm{POS}_{-} \mathrm{EAR}_{i, q, t}+ \\
& +\beta_{3} \operatorname{InMV}_{i, q, t}+\beta_{4} \mathrm{BTM}_{i, q, t}+\beta_{5} \mathrm{M}_{-} \mathrm{RET}_{i, q, t}+\beta_{6} \mathrm{IND}_{i, q, t}+\varepsilon_{i, q, t}
\end{aligned}
$$

AB_TONE $=$ abnormal tone in an EPR (see Eq. 2);

$\Delta$ FUT_OI $=$ future operating income change (measured by subtracting current quarter operating income from operating income of the same quarter in the following year) scaled by total assets in the corresponding quarter; POS_EAR, InMV, BTM, M_RET, IND are as defined in Eq. 2.

\subsubsection{Readability manipulation}

Readability manipulation strategy is investigated by testing the relationship between current firm performance and the reading complexity measure. Based on Hypothesis 2, the following equation regresses reading complexity on the firm performance (operating income change) measure and control variables:

\footnotetext{
${ }^{19}$ See Section 2.5 for more discussion of the relevance of firm performance in studying impression management.
} 
$\operatorname{READ}_{i, q, t}=\alpha+\beta_{1} \Delta \mathrm{OI}_{i, q, t}+\beta_{2}$ POS_EAR $_{i, q, t}+\beta_{3} \operatorname{lnMV}_{i, q, t}+\beta_{4} \mathrm{BTM}_{i, q, t}+\beta_{5} \mathrm{M}_{-} \mathrm{RET}_{i, q, t}+$ $\beta_{6} \mathrm{IND}_{i, q, t}+\varepsilon_{i, q, t}$

$\mathrm{READ}=$ the reading complexity of an EPR as measured by the Fog Index;

$\Delta$ OI, POS_EAR, lnMV, BTM, M_RET, IND are as defined in Eq. 2.

\subsubsection{Causal reasoning}

Causal reasoning strategy is investigated by testing the relationship between current firm performance and the causal reasoning intensity measure. Based on Hypothesis 3, the following equation regresses causal reasoning intensity on current firm performance (operating income change) and control variables:

CAUS_R $_{i, q, t}=\alpha+\beta_{1} \Delta \mathrm{OI}_{i, q, t}+\beta_{2} \mathrm{POS}_{-} \mathrm{EAR}_{i, q, t}+\beta_{3} \operatorname{lnMV}_{i, q, t}+\beta_{4} \mathrm{BTM}_{i, q, t}+\beta_{5} \mathrm{M} \_\mathrm{RET}_{i, q, t}+$ $\beta_{6} \operatorname{IND}_{i, q, t}+\varepsilon_{i, q, t}$

CAUS_R = the level of causal reasoning in an EPR (See Eq. 3);

$\triangle O$ I, POS_EAR, lnMV, BTM, M_RET, IND are as defined in Eq. 2.

\subsubsection{Headline Impression Management}

Headline impression management strategy is investigated by testing the relationship between current firm performance and the headline impression management bias measure. Based on Hypothesis 4, the following equation regresses headline impression management bias on current firm performance (operating income change) and control variables:

$\mathrm{HEAD}_{-} \mathrm{B}_{i, q, t}=\alpha+\beta_{1} \Delta \mathrm{OI}_{i, q, t}+\beta_{2} \mathrm{POS}_{-} \mathrm{EAR}_{i, q, t}+\beta_{3} \operatorname{lnMV}_{i, q, t}+\beta_{4} \mathrm{BTM}_{i, q, t}+\beta_{5} \mathrm{M}_{-} \mathrm{RET}_{i, q, t}+$ $\beta_{6} \operatorname{IND}_{i, q, t}++\varepsilon_{i, q, t}$

HEAD_B = impression management bias in the headline of an EPR (see Eq. 6);

$\triangle O \mathrm{OI}, \mathrm{POS} \_\mathrm{EAR}, \operatorname{lnMV}, \mathrm{BTM}, \mathrm{M} \_$RET, IND are as defined in Eq. 2. 


\subsubsection{Investor reaction to apparent impression management}

This research also investigates investor reaction to impression management measures defined in Subsection 4.5.2. This investigation focuses on individual investor reaction both in terms of stock price behavior and the reaction of online investment board participants.

As discussed, several studies find short-term, usually three-day, effects of impression management on stock price (Henry, 2008; Feldman et al., 2009; Davis et al., 2012; Rennekamp, 2012; Aerts and Cheng, 2012; Huang et al., 2014; Benson et al., 2015; Chen et al., 2016; Arslan-Ayaydin et al., 2016). In their review of impression management studies Brennan et al., (2007) state that an impression management interpretation of disclosure management is based on a weak form of market efficiency which assumes that investors are unable to assess managerial bias in the short term. Therefore, following many prior studies, the present study investigates the effect of impression management on three-day stock price reaction. Similarly, a three-day window is used to also investigate an online investment discussion board participants' reaction to apparent impression management.

\subsubsection{Stock market reaction}

Stock market reaction uses the measure of CAR (as defined Subsection 4.5.3) to tests hypotheses 5, 6, 7, and 8. Following Henry (2008), Davis et al. (2012), and ArslanAyaydin et al. (2016), this study estimates the following linear-based model to measure the effect of impression management on three-day CAR: 
$\operatorname{CAR}[-1,+1]_{i, q, t}=\alpha+\beta_{0} \mathrm{AB}_{-} \mathrm{TONE}_{i, q, t}+\beta_{1} \mathrm{READ}_{i, q, t}+\beta_{2} \mathrm{CAUS}_{-} \mathrm{R}_{i, q, t}+\beta_{3} \mathrm{HEAD}_{-} \mathrm{B}_{i, q, t}+\beta_{4} \Delta \mathrm{OI} \mathrm{I}_{i, q, t}+$ $+\beta_{5}$ POS_EAR $_{i, q, t}+\beta_{6} \operatorname{lnMV}_{i, q, t}+\beta_{7} \mathrm{BTM}_{i, q, t}+\beta_{8} \mathrm{M} \_R E T_{i, q, t}+\beta_{9} \operatorname{IND}_{i, q, t}+\beta_{10} \operatorname{SPREAD}_{i, q, t}+\varepsilon_{i, q, t}$

where:

$\operatorname{CAR}[-1,+1]$ three-trading-days cumulative abnormal return surrounding the issue of EPRs;

AB_TONE $=$ abnormal tone in EPR (see Eq. 2);

$\mathrm{READ}=$ the Fog Index score of an EPR

CAUS_R $=$ the level of causal reasoning in an EPR (See Eq. 3);

HEAD_B = impression management bias in the headline of an EPR (see Eq. 6);

SPREAD = daily average bid-ask spread divided by the midpoint of bid and ask prices;

$\triangle \mathrm{OI}, \mathrm{POS} \_\mathrm{EAR}, \operatorname{lnMV}, \mathrm{BTM}, \mathrm{M} \_\mathrm{RET}$, IND are as defined in Eq. 2.

Due to the low liquidity of TSX Venture Exchange firms, the timing of the closing price and end of day bid-ask spread could be asynchronous. As a generally accepted practice in the event methodology, this study uses the closing price in the calculation of returns while controlling for daily average bid-ask spread. Alternatively, the measurement of returns could be based on the closing bid-ask when using the end of day bid-ask spread.

\subsubsection{Investment discussion board reaction}

Investment discussion board reaction uses the abnormal discussion volume, as measured by the number of posts, and sentiment measures (as defined Subsection 4.5.3) to investigate the research propositions 1 and 2. Similar to the regression for evaluating stock price reaction, this research estimates the following two regressions to measure 
abnormal discussion volume (Eq. 12) and abnormal discussion sentiment (Eq. 13) in response to impression management:

$$
\begin{aligned}
& \text { AB_DVOL }[-1,+1]_{[i, q, \mathrm{t}]}=\alpha+\beta_{0} \mathrm{AB}_{-} \mathrm{TONE}_{\mathrm{i}, \mathrm{q}, \mathrm{t}}+\beta_{1} \operatorname{READ}_{\mathrm{i}, \mathrm{q}, \mathrm{t}}+\beta_{2} \mathrm{CAUS}_{-} \mathrm{R}_{\mathrm{i}, \mathrm{q}, \mathrm{t}}+
\end{aligned}
$$

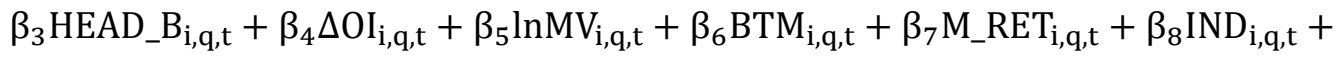

$$
\begin{aligned}
& \beta_{9} D_{-} \text {WEEK }+\varepsilon_{\mathrm{i}, \mathrm{q}, \mathrm{t}}, \\
& \mathrm{AB}_{-} \mathrm{DSEN}[-1,+1]_{i, q, t}=\alpha+\beta_{0} \mathrm{AB}_{-} \mathrm{TONE}_{i, q, t}+\beta_{1} \mathrm{READ}_{i, q, t}+\beta_{2} \mathrm{CAUS}_{-} \mathrm{R}_{i, q, t}+ \\
& +\beta_{3} \mathrm{HEAD}_{-} \mathrm{B}_{i, q, t}+\beta_{4} \Delta \mathrm{OI}_{i, q, t}+\beta_{5} \operatorname{lnMV}_{i, q, t}+\beta_{6} \mathrm{BTM}_{i, q, t}+\beta_{7} \mathrm{M} \_R E T_{\mathrm{i}, \mathrm{q}, \mathrm{t}}+\beta_{8} \mathrm{IND}_{\mathrm{i}, \mathrm{q}, \mathrm{t}}+ \\
& \varepsilon_{\mathrm{i}, \mathrm{q}, \mathrm{t}},
\end{aligned}
$$

where:

AB_DVOL $[-1,+1]_{[i, q, t]}=$ the average number of posts for three days surrounding the issue of EPR minus the average number of posts for the 60 days preceding the day before the EPR date;

AB_DSEN $[-1,+1]_{[i, q, t]}=$ the average discussion sentiment for three days surrounding the issue of EPR minus the average discussion sentiment for the 60 days preceding the day before the EPR date;

Day of week (D_WEEK) - is a dummy variable for the day of the week, which is included in the abnormal discussion volume equation as it may have impact on the number of discussions (Lerman, 2017);

AB_TONE, $\triangle \mathrm{OI}$, lnMV, BTM, M_RET, and IND are as defined in Eq. 2;

READ, CAUS_R, and HEAD_B are as defined in Eq. 7.

It is possible that there may be multicollinearity among certain variables in the above equations. Evidence of any significant multicollinearity can be identified by 
examining a correlation matrix and evaluating variance inflation factors. If significant multicollinearity is evident, it may be necessary to remove some variables from the model or to use regression methods that are designed for highly correlated variables. Detailed analysis of multicollinearity is performed in Chapter 5 .

\subsubsection{Summary of data analysis approach}

Data analysis approach described the statistical methods for investigating the firm and investors perspectives on impression management. As discussed, the regression equations designed to test hypotheses and propositions regarding both firm and investor perspectives use variable measures from Section 4.5 of this chapter. Section 4.5 described the methods which are based on scoring and measuring impression management using computer-assisted content analysis methods. The process of scoring impression management measures is mainly adopted from prior literature which primarily uses manual content analysis methods (Kohut and Segars, 1992; Lee et al., 2004; Baginski et al., 2004; Brennan et al., 2009; Aerts and Cheng, 2012; Guillamon-Saorin et al., 2012;Kimbrough and Wang, 2014). This study also replicates the existing literature which uses computer-assisted ways of measuring tone (Davis et al., 2007; Henry, 2008; Loughran and McDonald, 2011; Davis and Tama-Sweet, 2012; Arslan-Ayaydin et al., 2016) and readability (Li, 2008; Richards, 2011; Lee, 2012) of disclosure documents. 
Figure 4.2. Connections between measurements, analyses, and hypotheses

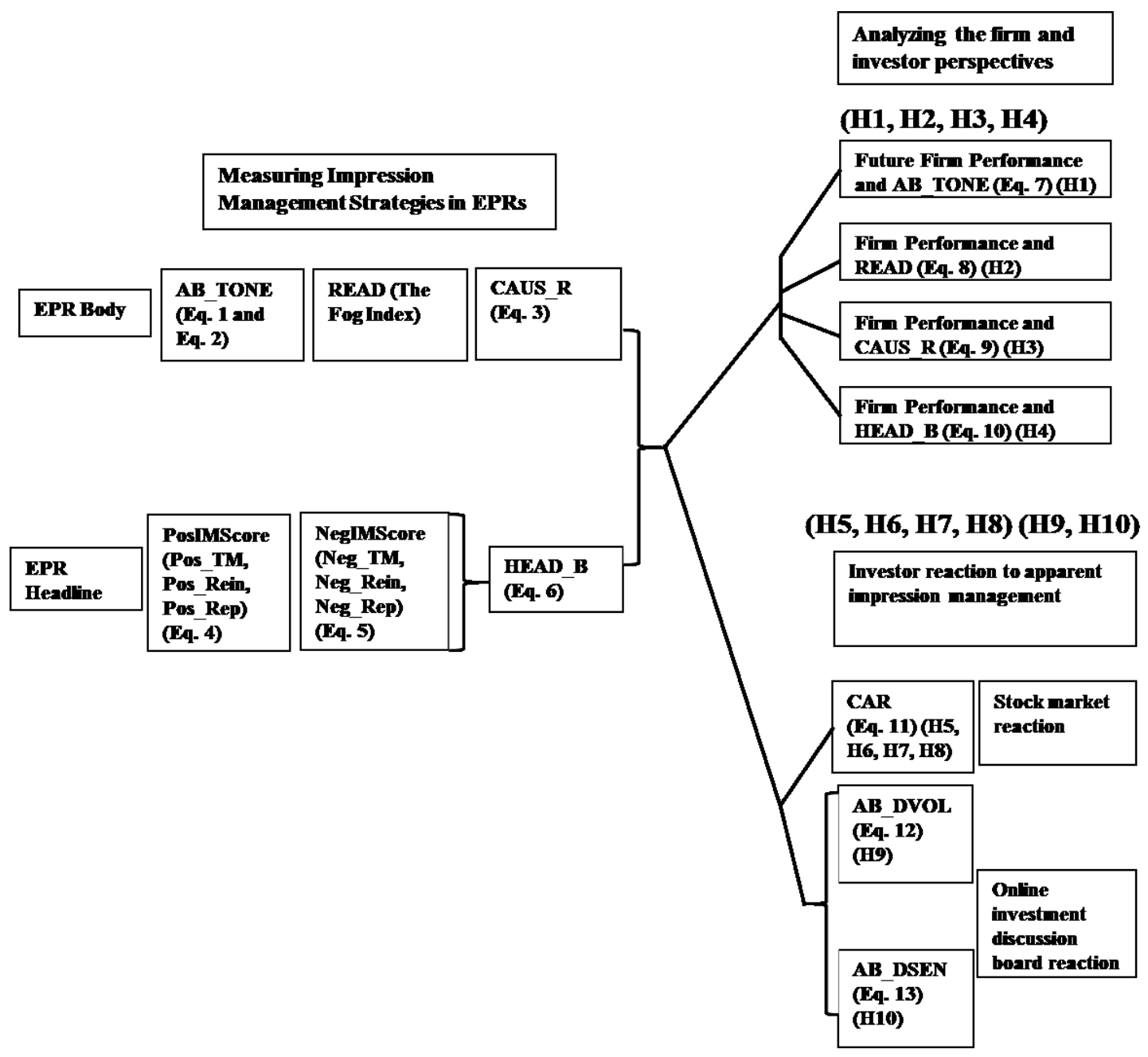

Figure 4.2 illustrates the entire process of variable measurement and data analysis.

It also maps out the relationships among measures, equations and hypotheses. As shown in the figure, impression management measures are computed for the body (abnormal tone, reading complexity, causal reasoning intensity) and headline (thematic manipulation and emphasis) of EPRs using the equations shown in parentheses. The impression management measures are then used to investigate both the firm perspective (firm performance and impression management) and the investor perspective (investor reaction to apparent impression management) on impression management. The process of 
measuring impression management (Section 4.5) is described on the left side of the figure, while the process of analyzing (Section 4.6) the firm and investor perspectives is described on the right side of the figure. 


\section{Chapter 5 - Descriptive Statistics and Regression Results}

This chapter introduces descriptive statistics on the data discussed in the preceding chapter. Tables are presented to better understand aggregate data on both the firm perspective and investor perspectives. Then, the chapter proceeds with the presentation of regression results which are discussed in detail. Finally, additional analyses are performed to ensure robustness checks and examine few other possible scenarios.

\subsection{Descriptive statistics}

This part of the chapter is concerned with better understanding overall data on all three components of this research as defined in Figure 4.1: EPRs, stock market data, and online investment discussion board data. First, overall descriptive statistics for EPRs are discussed. The EPR statistics are grouped by industry to show comparative numbers for analysis. Second, descriptive statistics on impression management scores are computed and discussed. This discussion includes a detailed explanation of how scores on the impression management strategies examined are obtained. The next section proceeds with shedding light into the investor perspective by introducing statistics on the online discussion board data which is obtained from Stockhouse.com. Overall information on the number of posts (messages on firm pages), unique posters (posts by unique users), daily posts, and other information is analyzed. Finally, firm data concludes descriptive statistics on the investor perspective. In that section, overall numbers on stock prices of sample firms and benchmark returns are analyzed, in addition to the discussion of firm 
fundamentals data such as market capitalization, operating income, and book to market information.

\subsubsection{EPRs by industry}

Chapter 4 discussed the sample selection process for the firms that are investigated in this study. This sample selection process is also described in Appendix A which illustrates that out of 327 firms in the initial sample $171(52 \%)$ firms issued at least one EPR in the study period from January $1^{\text {st }}, 2016$ to July $1^{\text {st }}, 2018$. However, since only consistent EPR-issuers (firms with three or more EPRs in the study period) are selected in the final sample, the final sample comprises 145 firms which represents $44 \%$ of the initial sample. However, there is a noticeable difference in the percentage of firms selected in the final sample among industries. For example, in the Metals \& Mining industry only $15 \%$ of firms in the initial sample are consistent EPR-issuers that are selected in the final sample while $88 \%$ of firms in the Application Software industry are selected in the final sample. Consulting \& Business Services (85\%) and Application Software $(88 \%)$ are the top two industries in terms of the percentage of consistent issuers while Metals \& Mining $(15 \%)$ and Biotechnology (47\%) are the bottom two. This difference may be explained by direct cost constraints such as data collection, processing, production, and auditing costs, which are considered by firms when releasing voluntary information (Gray et al., 1990). Moreover, Biotechnology and Metals \& Mining firms may be characterized as non-news intensive firms due to more long-term projects than firms in other industries in general. Therefore, biotechnology and mining firms may be less likely to issue EPRs due to no revenue in some quarters in their income statements. Overall, the industry concentration of firms in the final sample (145 firms) ranges from 13 firms (Communication 
Equipment) to 23 firms (Application Software or Oil \& Gas). This industry concentration of the final sample firms is much more evenly distributed than the industry concentration in the initial sample (327 firms) where the range is 19 firms (Communication Equipment) - 146 firms (Metals \& Mining).

Table 5.1 provides descriptive statistics on the number of EPRs by industry for the final sample of 1317 EPRs. Overall, as confirmed by the median number of EPRs, most firms issued 10 EPRs in this period (i.e. one each for quarter under review). On average each firm in the final sample issued slightly over nine (9.08) EPRs in the ten quarters from January $1^{\text {st }}, 2016$ to July $1^{\text {st }}, 2018$. The highest average number of EPRs were issued by Communication Equipment industry firms (9.85) while Oil \& Gas firms (8.61) have the lowest average number of EPRs. The Metals \& Mining industry (2.19) shows the highest degree of standard deviation which is noticeably above the standard deviation for the entire final sample of firms (1.59). Moreover, as Table 5.1 shows, although the Application Software industry has the most representation in the final sample of EPRs, each industry is well represented in the final sample.

Table 5.1. Descriptive statistics on the number of EPRs by industry

\begin{tabular}{|l|c|c|c|c|c|c|}
\hline \multicolumn{1}{|c|}{ Industry } & Count & Mean & Std & Min & Median & Max \\
\hline Application Software & 217 & 9.43 & 1.44 & 4 & 10.00 & 10 \\
\hline Oil \& Gas & 198 & 8.61 & 1.45 & 5 & 9.00 & 10 \\
\hline Metals \& Mining & 190 & 8.64 & 2.19 & 4 & 10.00 & 10 \\
\hline Industrial Products \& Manufacturing & 175 & 9.72 & 0.65 & 8 & 10.00 & 10 \\
\hline Consulting \& Business Services & 152 & 8.94 & 2.01 & 4 & 10.00 & 10 \\
\hline Biotechnology & 131 & 8.73 & 1.53 & 5 & 9.00 & 10 \\
\hline Communication Equipment & 128 & 9.85 & 0.53 & 6 & 10.00 & 10 \\
\hline Other Industries & 126 & 9.00 & 1.25 & 6 & 9.50 & 10 \\
\hline \multicolumn{1}{|c|}{ Total } & $\mathbf{1 3 1 7}$ & $\mathbf{9 . 0 8}$ & $\mathbf{1 . 5 9}$ & $\mathbf{4}$ & $\mathbf{1 0 . 0 0}$ & $\mathbf{1 0}$ \\
\hline
\end{tabular}




\subsubsection{Impression management scores}

This part of the chapter presents descriptive statistics on the impression management scores studied and provides further details on the calculation of scores. As Table 5.2 illustrates, impression management strategies are measured both in the body, which includes processed ${ }^{20}$ EPR text excluding the title and subtitles, and the headline, which includes the title and subtitles, of EPRs.

The top part of Table 5.2 provides statistics on tone, reading complexity, and causal reasoning intensity in the body of EPRs. Since these three impression management strategies can be measured in all EPRs, the total number of observations (Count) for each strategy is 1,317 which is equal to the number of EPRs in the final sample. Tone is measured as defined in Eq. 1 which uses specifically designed financial disclosure-related dictionaries by Henry (2008) and Loughran and McDonald (2011) as well as optimismincreasing and optimism-decreasing words lists in DICTION. Reading complexity is obtained using the Gunning Fog Index formula ${ }^{21}$ which considers average sentence length and percentage of Hard Words ${ }^{22}$ in EPRs. Finally, causal reasoning intensity is measured as defined in Eq. 3 which uses DICTION's causal words lists. Chapter 4 provides more details on the calculation of these impression management measures. Table 5.2 shows that there is a high level of variability in all three impression management strategies, with noticeably higher variability in tone and causal reasoning intensity than reading complexity.

\footnotetext{
${ }^{20}$ As described in Section 4.5.2, pre-processing entails obtaining headlines and narrative portions of EPRs by removing tables and recurring parts such as "About the Company" and "Forward Looking Statements" using a specifically designed Python script.

${ }^{21}$ Gunning Fog Index formula is $0.4 *$ ((average sentence length) + (percentage of Hard Words)).

${ }^{22}$ Hard words are words with more than two syllables.
} 
Table 5.2. Descriptive statistics on impression management strategies in the body and the headline of EPRs

\begin{tabular}{|c|c|c|c|c|c|c|c|c|c|}
\hline & IM Strategies & Count & Mean & Std & Min & $25 \%$ & $50 \%$ & $75 \%$ & Max \\
\hline \multirow{3}{*}{ 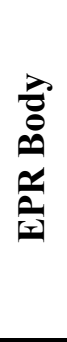 } & Tone & 1317 & 3.60 & 1.60 & 0.36 & 2.46 & 3.36 & 4.54 & 9.42 \\
\hline & $\begin{array}{l}\text { Reading } \\
\text { Complexity }\end{array}$ & 1317 & 18.67 & 3.15 & 10.25 & 16.70 & 18.29 & 20.13 & 43.88 \\
\hline & $\begin{array}{c}\text { Causal } \\
\text { Reasoning } \\
\text { Intensity }\end{array}$ & 1317 & 16.21 & 7.67 & 0 & 11.1 & 15.8 & 20.04 & 50.00 \\
\hline \multirow{7}{*}{ 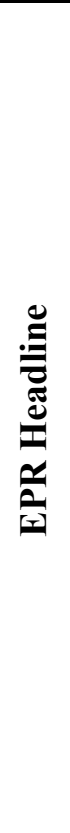 } & $\begin{array}{c}\text { Positive } \\
\text { Thematic } \\
\text { Manipulation }\end{array}$ & 515 & 2.65 & 1.79 & 1 & 1 & 2 & 4 & 13 \\
\hline & $\begin{array}{c}\text { Negative } \\
\text { Thematic } \\
\text { Manipulation }\end{array}$ & 25 & 1.08 & 0.28 & 1 & 1 & 1 & 1 & 2 \\
\hline & $\begin{array}{c}\text { Positive } \\
\text { Reinforcement }\end{array}$ & 212 & 1.80 & 1.15 & 1 & 1 & 1 & 2 & 9 \\
\hline & $\begin{array}{c}\text { Negative } \\
\text { Reinforcement }\end{array}$ & 2 & 1.00 & 0.00 & 1 & 1 & 1 & 1 & 1 \\
\hline & $\begin{array}{l}\text { Positive } \\
\text { Repetition }\end{array}$ & 150 & 2.22 & 1.99 & 1 & 1 & 2 & 2 & 12 \\
\hline & $\begin{array}{l}\text { Negative } \\
\text { Repetition }\end{array}$ & 0 & 0 & 0 & 0 & 0 & 0 & 0 & 0 \\
\hline & $\begin{array}{c}\text { Headline IM } \\
\text { Bias }\end{array}$ & 586 & 0.96 & 0.25 & -1 & 1 & 1 & 1 & 1 \\
\hline
\end{tabular}

To illustrate the calculation of tone, reading complexity, and causal reasoning intensity, an example is provided in Appendix D which shows the body of an EPR issued by C-Com Satellite Systems Inc. (C-COM) on July 18, 2017. Since each EPR in the sample is processed to obtain the body part which does not contain any general information such as "About the Company" and "Forward Looking Statements", the analysis of impression management strategies in the EPR body is performed on the processed body part as shown in Appendix D. 
As mentioned earlier, reading complexity is calculated based on the Gunning Fog Index formula which considers the average length of sentences as well as hard words as measured by the number of syllables. In C-COM's case the average sentence length is 26.33 words as measured by dividing the total number of words (400) by the total number of sentences (15). Also, the percentage of hard words is 20 which is obtained by dividing the number of words with three or more syllables (80) by the total number of words (400). Therefore, the reading complexity score of this EPR body is $18.53(0.4 *(26.33+$ 20)) which is right around the average reading complexity score (18.67) of the overall sample.

Tone in EPR body is obtained using Eq. 1 which divides the difference between positive and negative words by the total number of words. This tone measure is then multiplied by 100 to convert it to a percentage tone figure that is used in the analysis. In the C-COM's example (Appendix D) there are 19 positive words and 4 negative words that are found in the overall dictionary list that includes dictionaries by Henry (2008) and Loughran and McDonald (2011) and optimism-increasing and optimism-decreasing words lists in DICTION. Since the total number of words in this body of EPR is 400 , the tone can be calculated by dividing 15 (19 minus 4) by 400. Therefore, the final tone score of the body of this EPR is 3.75 which is obtained by multiplying $0.0375(15 / 400)$ by 100 . This tone score is slightly higher than the average tone score of the entire sample (3.61) since C-COM's EPR provided in this example (Appendix D) exhibits generally positive sentiment.

Causal reasoning intensity is calculated using Eq. 3 which determines the ratio of the number of sentences that contain causal words over the total number of sentences in 
the body of an EPR. In C-COM's example (Appendix D) the total number of sentences is 15 and there is only one sentence containing causal words. The following sentence contains two causal words from the causal words dictionary used in this study: "The large increase in research and development expense and resulting lower net after tax profit in Q2 is almost entirely attributable to the payments made to the University." More specifically, this sentence contains such causal words and phrases as "resulting" and "attributable to". However, since both causal words or phrases appear in the same sentence, the number of sentences with causal words in this EPR body is only one. Therefore, the causal reasoning intensity score is 6.67 which is the result of dividing 1 (the number of sentences containing causal words) by 15 (total number of sentences) and multiplying the division by 100 . This causal reasoning score is noticeably lower than the average causal reasoning score for the sample (15.21) since this C-COM's earning press release is presenting mostly positive performance which frequently results in little or no usage of causal words and phrases.

Unlike strategies in the body of EPRs, for which the extent of impression management is measured using formula and ratios, impression management strategies in the headline of EPRs are measured based on the occurrence of certain words, numbers, and percentages in the headline of EPRs. Therefore, the bottom part of Table 5.2 contains descriptive statistics only for the EPRs whose headlines contain certain occurrences indicating the existence of impression management. For example, in the case of repetition, out of 1,317 press releases only 150 have headlines which highlight certain performance numbers by repeating what is contained in the EPR body. Positive thematic 
manipulation, which is calculated based on the occurrence of positive keywords ${ }^{23}$, is observed in 515 press release headlines. However, only 25 press release headlines contain one or more negative keywords. Similarly, positive reinforcement, which measures the number of times EPR headlines reinforce improved performance by including percentage comparisons to prior periods, is observed in 212 EPR headlines which contains 1.8 reinforcements on average. Not surprisingly, the reinforcement of declines in performance (negative reinforcement) occurs in only two EPR headlines, indicating that firms very rarely emphasize or highlight negative performance. Following GuillamonSaorin (2012), this study measures impression management bias in the headlines of EPRs as defined in Eq. 6 which considers positive repetition, negative repetition, positive thematic manipulation, negative thematic manipulation, positive reinforcement, and negative reinforcement in the calculation of scores. Impression management bias is observed in $586(44.55 \%)$ of all press releases in the final sample of EPR headlines. EPR headlines have an average bias score of 0.96 (on a scale of 1.0 for positive bias to -1.0 for negative bias) which is an indication of a very high impression management level resulting from the highlighting of positive performance.

The following EPR headlines illustrate how the headline impression management bias score is calculated based on repetition, thematic manipulation, and reinforcement scores. Omni-Lite's EPR dated October 20, 2016 has the following headline "Omni-Lite Industries Reports Strong Third Quarter: Q3 Cash Flow Up 44\%; Q3 Adjusted EBITDA Up 30\%; Q3 Earnings per share Up 48\%". In this example, the keyword "strong" is a

\footnotetext{
${ }^{23}$ Positive keywords are from specifically designed financial disclosure-related dictionaries by Henry (2008) and Loughran and McDonald (2011) as well as optimism-increasing and optimism-decreasing words lists in DICTION
} 
positive thematic manipulation, while percentage increases $(44 \%, 30 \%$, and $48 \%)$ are positive reinforcements. Since there is no negative thematic manipulation, no negative reinforcement, and no repetition, in this example the headline impression management bias score is 1 which is the result of four divided by four (the sum of three for positive reinforcement and one for positive thematic manipulation). In another example, Chanfeng's EPR (March 31, 2017) headline reads “Chanfeng Announces Revenue Up 16\%, Gross Profit Up 4\% and Net Income Dropped 41\% For Year Ended December 31, 2016 ". In this example, the headline impression management bias score is 0.33 which is the result of one (two positive reinforcements minus one negative reinforcement) divided by three (total number of impression management strategies used). On August 24, 2017 Pediapharm Inc. published its EPR with the following title: "PEDIAPHARM ANNOUNCES Q1 RECORD REVENUE OF \$2.5M (2.8X LAST YEAR)”. This title has a headline impression management bias score of one because the only impression management used in the title is the repetition of the revenue number ( $\$ 2.5$ million) which is emphasized in the headline, in addition to being mentioned in the press release body.

\subsubsection{Stockhouse posts on EPR-issuing firms}

As discussed in previous chapters, this study uses online discussion board data from Stockhouse.com (Stockhouse) to investigate investor reaction to apparent impression management in EPRs. This data includes details on the posts (online messages by users on the Stockhouse discussion board designated for each company) and posting (writing a message on a discussion board) behavior including the number and frequency of posts by posters (users who write messages on discussion boards). Table 5.3 contains information on the number of posts and posting behavior by both non-EPR- 
issuing firms (firms that did not issue any EPR in the study period) and EPR-issuing firms that had at least one post on their discussion board in the study period. Overall, there is no visible difference in the number and frequency of posts, as well as in the number of unique posters between EPR-issuing and non-EPR-issuing firms. Therefore, both groups have almost similar increases across all provided (in the table) metrics when shifting up gradually from the lowest to the highest decile based on the number of posts.

Table 5.3. Stockhouse post deciles for the sample firms with at least one post

\begin{tabular}{|c|c|c|c|c|c|c|}
\hline \multicolumn{7}{|c|}{ For firms that issued EPRs in the study period (Jan 1, 2016- July 1, 2018) } \\
\hline Deciles & $\begin{array}{l}\text { Number } \\
\text { of Posts }\end{array}$ & $\begin{array}{c}\text { Number } \\
\text { of Unique } \\
\text { Posters } \\
\end{array}$ & $\begin{array}{c}\text { Average } \\
\text { Post per } \\
\text { Poster } \\
\end{array}$ & $\begin{array}{c}\text { Number of } \\
\text { Days* with at } \\
\text { Least One Post }\end{array}$ & $\begin{array}{l}\text { Average } \\
\text { Daily } \\
\text { Posts** }\end{array}$ & $\begin{array}{c}\text { Average } \\
\text { Daily } \\
\text { Views** }\end{array}$ \\
\hline $1^{\text {st }}$ & 69.8 & 19.8 & 3.5 & 26.2 & 2.1 & 135.1 \\
\hline $2^{\text {nd }}$ & 114.2 & 27.0 & 4.2 & 67.0 & 2.3 & 192.7 \\
\hline $3^{\text {rd }}$ & 238.2 & 47.0 & 5.1 & 131.6 & 2.6 & 221.8 \\
\hline $4^{\text {th }}$ & 486.0 & 70.0 & 6.9 & 210.0 & 3.7 & 260.1 \\
\hline $5^{\text {th }}$ & 715.0 & 93.0 & 7.7 & 316.0 & 3.9 & 276.6 \\
\hline $6^{\text {th }}$ & 1222.6 & 120.8 & 10.1 & 434.6 & 4.3 & 296.8 \\
\hline $7^{\text {th }}$ & 1941.8 & 149.6 & 13.0 & 626.2 & 6.0 & 331.3 \\
\hline $8^{\text {th }}$ & 3884.2 & 241.0 & 16.1 & 753.6 & 7.5 & 371.7 \\
\hline $9^{\text {th }}$ & 7007.4 & 382.8 & 18.3 & 905.7 & 13.6 & 437.8 \\
\hline $10^{\text {th }}$ & 39929 & 991 & 40.3 & 912 & 119.7 & 953.5 \\
\hline \multicolumn{7}{|c|}{ For firms that did not issue EPRs in the study period (Jan 1, 2016 - July 1, 2018) } \\
\hline Deciles & $\begin{array}{l}\text { Number } \\
\text { of Posts }\end{array}$ & $\begin{array}{c}\text { Number } \\
\text { of Unique } \\
\text { Posters } \\
\end{array}$ & $\begin{array}{c}\text { Average } \\
\text { Post per } \\
\text { Poster } \\
\end{array}$ & $\begin{array}{c}\text { Number of } \\
\text { Days* with at } \\
\text { Least One Post }\end{array}$ & $\begin{array}{l}\text { Average } \\
\text { Daily } \\
\text { Posts** }\end{array}$ & $\begin{array}{c}\text { Average } \\
\text { Daily } \\
\text { Views** }\end{array}$ \\
\hline $1^{\text {st }}$ & 53.8 & 22.0 & 2.4 & 35.3 & 2.1 & 146.6 \\
\hline $2^{\text {nd }}$ & 105.2 & 31.4 & 3.4 & 67.2 & 2.4 & 186.9 \\
\hline $3^{\text {rd }}$ & 230.3 & 49.1 & 4.7 & 123.8 & 2.5 & 215.1 \\
\hline $4^{\text {th }}$ & 461.0 & 67.2 & 6.9 & 212.0 & 3.7 & 248.3 \\
\hline $5^{\text {th }}$ & 723.0 & 93.0 & 7.8 & 325.5 & 4.0 & 277.7 \\
\hline $6^{\text {th }}$ & 1081.4 & 126.0 & 8.6 & 414.8 & 4.4 & 306.5 \\
\hline $7^{\text {th }}$ & 1857.0 & 180.0 & 10.3 & 563.6 & 5.7 & 341.8 \\
\hline $8^{\text {th }}$ & 3878.0 & 235.2 & 16.5 & 799.4 & 7.7 & 364.9 \\
\hline $9^{\text {th }}$ & 6653.4 & 399.4 & 16.7 & 903.3 & 14.9 & 441.4 \\
\hline $10^{\text {th }}$ & 13273 & 602 & 22.1 & 912 & 21.3 & 562.6 \\
\hline
\end{tabular}

*Out of 912 days in the study period

**For days with at least one post 
Table 5.3 also shows that there is a noticeable difference in the number of posts and overall posting behavior between firms in the lower deciles and higher deciles. For example, for EPR-issuing firms, a firm with the highest number of posts in the bottom 20 percent of firms has only 114 posts which is over 60 times smaller than 7007 - the number of posts for the firm in the 9th decile. There is a noticeable difference between 10th decile for the top and bottom parts of the table, as the most discussed firm that issued EPRs has received much more attention from online investment board participants than the most discussed firm that did not issue any EPR in the study period.

In the group of EPR-issuing firms, the highest number of posts $(39,929)$ is on the discussion board of Theralase Technologies Inc. (Theralase) which belong to the Biotechnology industry. In a manner uncharacteristic of many other members of its industry, Theralase very frequently and regularly issues news press releases and EPRs to keep investors and potential investors up to date with all developments in the company. This also may explain the big gap between the number of posts available for Theralase $(39,929)$ and the average number of posts for the Biotechnology industry $(7,729.8)$ (see Table 5.4).

Unlike firms in the Biotechnology industry, the Communication Equipment industry firms are more evenly discussed on Stockhouse. The top two highly discussed firms in the Communication Equipment industry are Edgewater Wireless Systems Inc. and Poet Technologies Inc. with 18,087 and 11,976 discussion board posts, respectively. These two firms also rank second and third among all the EPR-issuing firms in the sample in terms of the number of posts available in the study period. Although these numbers are higher than the industry average (10357.9), the difference is not as 
pronounced as it is in the case of the Biotechnology industry. Overall, the Biotechnology industry leads the average number of posts while the Application Software industry has the lowest average. Besides showing the number of posts and firms by industry, Table 5.4 displays information on the average number of posts per firm and number of posters. As shown in the table, the total of $901,330(551,599+349,731)$ posts from $53,275(30,075+$ $23,200)$ Stockhouse users are collected, however, only the posts $(551,599)$ for EPRissuing firms in the final sample of 145 firms are selected for analysis.

Table 5.4. Posts by industry for EPR-issuing and EPR-non-issuing firms from Jan 1, 2016 to July 1, 2018 (sorted by the average number of posts per firm)

\begin{tabular}{|c|c|c|c|c|}
\hline \multicolumn{5}{|c|}{ For firms that issued EPRs in the study period* } \\
\hline Industry & $\begin{array}{l}\text { Number } \\
\text { of posts }\end{array}$ & $\begin{array}{l}\text { Number of } \\
\text { firms }\end{array}$ & $\begin{array}{l}\text { Avg. number } \\
\text { of posts per } \\
\text { firm }\end{array}$ & $\begin{array}{l}\text { Number } \\
\text { of posters }\end{array}$ \\
\hline Communication Equipment & 134653 & 13 & 10357.9 & 5384 \\
\hline Biotechnology & 115947 & 15 & 7729.8 & 6722 \\
\hline Industrial Products \& Manufacturing & 80401 & 18 & 4466.7 & 3794 \\
\hline Metals \& Mining & 60872 & 22 & 2766.9 & 5229 \\
\hline Consulting \& Business Services & 45648 & 17 & 2685.2 & 1724 \\
\hline Oil \& Gas & 53493 & 23 & 2325.8 & 4143 \\
\hline Other Industries & 23554 & 14 & 1682.4 & 492 \\
\hline Application Software & 37031 & 23 & 1610.0 & 2587 \\
\hline Total/Average & 551599 & 145 & 3804.1 & 30075 \\
\hline \multicolumn{5}{|c|}{ For firms that did not issue EPRs in the study period** } \\
\hline Industry & $\begin{array}{c}\text { Number } \\
\text { of posts }\end{array}$ & $\begin{array}{l}\text { Number of } \\
\text { firms }\end{array}$ & $\begin{array}{l}\text { Avg. number } \\
\text { of posts per } \\
\text { firm }\end{array}$ & $\begin{array}{l}\text { Number } \\
\text { of posters }\end{array}$ \\
\hline Application Software & 24432 & 3 & 8144.0 & 901 \\
\hline Biotechnology & 74399 & 16 & 4649.9 & 5176 \\
\hline Consulting \& Business Services & 7212 & 2 & 3606.0 & 803 \\
\hline Oil \& Gas & 25970 & 8 & 3246.3 & 1043 \\
\hline Communication Equipment & 5410 & 2 & 2705.0 & 343 \\
\hline Metals \& Mining & 205811 & 103 & 1998.2 & 14280 \\
\hline Other Industries & 4203 & 7 & 600.4 & 383 \\
\hline Industrial Products \& Manufacturing & 2294 & 6 & 382.3 & 271 \\
\hline Total/Average & 349731 & 147 & 3166.5 & 23200 \\
\hline
\end{tabular}

* 7 firms among issuing firms did not have any post in the study period

** 9 firms among non-issuing firms did not have any post in the study period 
Table 5.5 presents descriptive statistics on daily posts for EPR three-day event window and 60-day pre-event window by industry as defined in Chapter 4 . There is a visibly higher posting activity in the three-day event window following an EPR, than the 60-day pre-event window across all industries as confirmed by the mean and median number of posts. However, the posting activity in the event windows also shows a high level of variance (standard deviation) which is not unexpected given higher means than medians. The higher volume in the event window is also not surprising since numerous studies have found evidence for increased online discussion volume in social media immediately after earnings announcement (Sabherwal et al., 2011; Chen et al., 2014; Leung and Ton, 2015; Gabrovsek et al., 2017; Lerman, 2017).

Table 5.5. Daily posts per firm by industry for EPR-issuing firms in the event window (three-day) and pre-event window (60-day) (sorted by average number of posts in the event period)

\begin{tabular}{|l|c|c|c|c|c|c|}
\cline { 2 - 8 } \multicolumn{1}{c|}{} & \multicolumn{3}{c|}{$\begin{array}{c}\text { three-day post-event } \\
\text { window }\end{array}$} & \multicolumn{3}{c|}{$\begin{array}{c}\text { 60-day pre-event } \\
\text { window }\end{array}$} \\
\hline \multicolumn{1}{|c|}{ Industry } & Mean & Std & Median & Mean & Std & Median \\
\hline Communication Equipment & 15.58 & 15.32 & 5.67 & 5.58 & 12.11 & 0.80 \\
\hline Consulting \& Business Services & 8.09 & 17.18 & 2.50 & 1.90 & 5.06 & 0.23 \\
\hline $\begin{array}{l}\text { Industrial Products \& } \\
\text { Manufacturing }\end{array}$ & & & & & & \\
\hline Biotechnology & 7.70 & 13.18 & 2.67 & 2.50 & 5.37 & 0.37 \\
\hline Application Software & 7.45 & 14.68 & 3.86 & 2.89 & 4.18 & 0.97 \\
\hline Oil \& Gas & 4.37 & 5.17 & 2.00 & 1.31 & 2.52 & 0.29 \\
\hline Other Industries & 3.90 & 6.89 & 1.33 & 1.29 & 3.35 & 0.25 \\
\hline Metals \& Mining & 3.66 & 6.69 & 1.33 & 0.96 & 2.52 & 0.05 \\
\hline
\end{tabular}

In general, Table 5.5 also shows that among the EPR-issuing firms, Communication Equipment firms are the most actively discussed on Stockhouse, while Metals \& Mining industry firms are least actively discussed in the event window. This is 
somewhat consistent with Tables 5.1 and 5.3, which show that the Metals \& Mining industry is one of the least active industries in terms of issuing press releases while the Communication \& Equipment industry is among the most active industries. Perhaps, though in general terms, this relationship between online discussion volume and the propensity of firms to release EPRs could be explained by the investor recognition hypothesis (Merton, 1987). That is, the familiarity of investors with a firm is affected by how much information (including information made available through EPRs) is available on the firm. Hence, firms in an industry that is less likely to release EPRs are less known to the public, which includes Stockhouse posters who are responsible for creating volume on the social media platform.

Table 5.5 also shows that there is a high degree of variance in the number of average daily posts among firms, as seen in the standard deviation and median figures. Given the ratio of standard deviation over mean (coefficient of variation or CV), it appears that the Communication Equipment industry has the lowest level of variation in the number of daily posts $(\mathrm{CV}=0.98)$. Consulting \& Business Services $(\mathrm{CV}=2.12)$ and Biotechnology $(\mathrm{CV}=1.97)$ are the top two industries in terms of variance in the number of daily posts in the three-day event window.

\subsubsection{Firm fundamentals and stock data}

This part of the chapter summarizes some of the firm fundamentals and stock price related information. More specifically, Table 5.6 contains descriptive statistics on operating income, operating income change (change from the same quarter of previous year), firm's market capitalization (Market Cap), book-to-market (BTM) ratio, three-day cumulative abnormal return, and average effective spread (Spread). Since multiple press 
releases are obtained for each firm in the final sample throughout the study period, statistics in this table represent data points at the time of each EPR issue. For example, Acasti Pharma Inc. (Acasti) issued 10 EPRs in the study period from January 1, 2016 to July 1, 2018, therefore, this table considers Acasti's fundamental and stock data corresponding to the date of each EPR.

Table 5.6. Descriptive statistics on firm fundamentals and stock price related information

\begin{tabular}{|c|c|c|c|c|c|c|c|c|}
\hline & Count & Mean & Std & Min & 0.25 & 0.50 & 0.75 & Max \\
\hline $\begin{array}{l}\text { Operating } \\
\text { income* }\end{array}$ & 1317 & -1.087 & 8.388 & -245.200 & -1.293 & -0.446 & 0.261 & 51.384 \\
\hline $\begin{array}{l}\text { Operating } \\
\text { Income change* }\end{array}$ & 1317 & -0.080 & 11.201 & -244.761 & -0.440 & 0.060 & 0.589 & 244.327 \\
\hline Total assets* & 1317 & 62.933 & 87.186 & 0.152 & 8.67 & 26.696 & 78.718 & 895.496 \\
\hline Market Cap* & 1317 & 58.987 & 96.704 & 1.216 & 16.546 & 31.589 & 65.651 & 1545.307 \\
\hline BTM & 1317 & 0.769 & 1.450 & -11.086 & 0.142 & 0.468 & 1.046 & 14.144 \\
\hline three-day CAR & 1317 & -0.002 & 0.114 & -0.549 & -0.053 & -0.002 & 0.039 & 0.985 \\
\hline Spread & 1317 & 0.041 & 0.062 & 0.002 & 0.008 & 0.019 & 0.040 & 0.456 \\
\hline
\end{tabular}

Both the mean and median $\left(50^{\text {th }}\right.$ percentile) numbers show that operating income is mostly negative. This is not surprising since most of the Venture Exchange firms are emerging firms which may have not achieved positive operating income or profitability. Moreover, despite the fact the minimum and maximum operating income numbers are noticeably different than the average and median operating income, there are only a very few such extreme operating income figures, as can be judged from the $25^{\text {th }}$ and $50^{\text {th }}$ percentiles. As for the extreme operating income numbers, they usually result from rare non-recurring items on the Income Statement. To illustrate, ShaMaran Petroleum Corp. which reported negative $\$ 245.2 \mathrm{mln}$ operating income in the fourth quarter of 2015 , states the following in its press release issued on March 16, 2016: 
"The Company reports a net loss of \$252.9 million in 2015 which was primarily driven by a non cash impairment loss on the Company's oil and gas assets as well as by routine general and administrative expenses, share based payment expenses and finance cost, the substantial portion of which was expensed borrowing costs on the Company's senior secured bonds" (ShaMaran Petroleum Corp., 2016).

Since operating income change is based on operating income figures from current (at the time of release) and previous years, operating income change is also affected twice by the same extreme outlier in operating income. Table 5.7 shows how descriptive statistics for operating income and operating income change look after removing the extreme outlier (-245.200).

Table 5.7. Descriptive statistics for operating income and operating income change after the removal of an extreme outlier

\begin{tabular}{|l|c|c|c|c|c|c|c|c|}
\cline { 2 - 8 } \multicolumn{1}{c|}{} & Count & Mean & Std & Min & $\mathbf{0 . 2 5}$ & $\mathbf{0 . 5 0}$ & $\mathbf{0 . 7 5}$ & Max \\
\hline $\begin{array}{l}\text { Operating } \\
\text { income }\end{array}$ & 1315 & -0.902 & 5.009 & -80.626 & -1.291 & -0.444 & 0.264 & 51.384 \\
\hline $\begin{array}{l}\text { Operating } \\
\text { Income change }\end{array}$ & 1315 & -0.080 & 5.885 & -89.511 & -0.440 & 0.060 & 0.584 & 82.267 \\
\hline
\end{tabular}

The exclusion of the extreme outlier noticeably impacted standard deviation for both operating income and operating income change. Moreover, the average operating income is now -0.902 as opposed to -1.087 before. Therefore, such obvious extreme outliers are carefully treated in the analysis. Overall, the standard deviation numbers in Table 5.6 indicate that there is a high level of variation in the fundamental and stock related data of the final sample firms. However, by observing the quartile numbers, one can conclude that some or most of this variation may be caused by a very few extreme figures in each variable.

Appendix E provides descriptive statistics by industry. Based on the median numbers, Metals \& Mining and Oil \& Gas are the two largest industries by the market capitalization of firms in these industries. This is expected as the TSX Venture Exchange 
is a global leader for providing equity capital to natural resource companies and primarily finances emerging companies in the Metals \& Mining and Oil \& Gas industries (TMX Group, 2018). The Biotechnology industry can be characterized as having the highest variation in the size of firms judged by the range between the $25^{\text {th }}$ and $75^{\text {th }}$ percentiles, as well as the standard deviation. High variation in market size of biotechnology firms can be explained by the nature of biotechnology firms which are characterized as being financially riskier than firms in other industries, leading to higher volatility in the market size and book value of biotechnology firms (Golec and Vernon, 2007). The indication of higher financial risk is also reflected in the higher spread than other industries in terms of mean and standard deviation.

Appendix E also provides descriptive statistics for cumulative abnormal return (CAR) by industry. In general, based on the mean and median numbers, the Consulting \& Business Services and Biotechnology industries have the lowest CARs in the short window after the issuance of EPRs. By contrast, the Industrial Products \& Manufacturing and Other industries have higher CARs than other industries, in general. In terms of variation in CAR, the returns of Communication Equipment and Application Software industry firms deviate from the average CAR to a greater extent than other industries.

\subsubsection{Correlations among main variables}

Table 5.8 provides a correlation matrix for impression management variables (READ, CAUS_R, HEAD_B, TONE, AB_TONE), investor reaction variables (CAR, AB_DVOL, AB_DSEN), and independent variables such as operating income change $(\Delta \mathrm{OI})$, future operating income change ( $\Delta$ FUT_OI), earnings sign (POS_EAR), firm market value (lnMV), book-to-market (BTM), spread (SPREAD), and contemporary 
market returns (M_RET). Spearman correlations are presented above the diagonal and Pearson correlations are shown below the diagonal. Two-tailed $p$ values are displayed in parentheses.

Among the impression management variables, reading complexity (READ) and causal reasoning intensity (CAUS_R) are positively correlated at the greatest level with significant (at the $1 \%$ level) Spearman $(0.327)$ and Pearson $(0.309)$ correlations. This is expected as causal reasoning intensity increases complexity of documents by making them more difficult to read (Aerts and Yan, 2017; Zhang et al., 2018). However, the correlation coefficient between reading complexity and causal reasoning intensity is not dramatically high as they measure two related but separate features of EPRs (see Section 4.1 for details). Another pair of impression management variables with strong (significance at the $1 \%$ level) positive correlation are tone (TONE) and headline impression management (HEAD_B), which have Spearman and Pearson correlations of 0.179 and 0.157 , respectively.

A similar relationship exists between abnormal tone (AB_TONE) and headline impression management with significant (at the 1\% level) Spearman (0.149) and Pearson (0.120) correlations. These relationships between headline impression management bias and tone variables is also somewhat expected. Since headline impression management bias is higher when firms emphasize good performance by highlighting it in the headlines of EPRs, firms may also inflate tone in the body of EPRs. As discussed in previous chapters, the emphasis of good performance is accomplished by such strategies as thematic manipulation (tone management), repetition, and reinforcement (Lothian, 1976; Courtis 1996; Guillamon-Saorin 2006; Nelson and Pritchard 2007; Davison, 2008; 
Guillamon-Saorin et al., 2012; Soobaroyen and Ntim, 2013; Pesci et al., 2015) which are all captured by headline impression management. 
Table 5.8 Correlations among Main Variables

\begin{tabular}{|c|c|c|c|c|c|c|c|c|c|c|c|c|c|c|c|}
\hline & READ & CAUS_R & HEAD_B & TONE & AB_TONE & $\Delta \mathrm{OI}$ & $\Delta \mathrm{FUT} \_\mathrm{OI}$ & POS_EAR & $\operatorname{lnMV}$ & BTM & M_RET & SPREAD & CAR & AB_DVOL & AB_DSEN \\
\hline READ & & $\begin{array}{c}0.327 \\
(0.000)\end{array}$ & $\begin{array}{c}-0.009 \\
(0.749) \\
\end{array}$ & $\begin{array}{c}0.191 \\
(0.000)\end{array}$ & $\begin{array}{c}0.044 \\
(0.107)\end{array}$ & $\begin{array}{l}-0.304 \\
(0.000)\end{array}$ & $\begin{array}{c}-0.024 \\
(0.383) \\
\end{array}$ & $\begin{array}{l}-0.114 \\
(0.000) \\
\end{array}$ & $\begin{array}{c}0.001 \\
(0.962)\end{array}$ & $\begin{array}{l}-0.156 \\
(0.000)\end{array}$ & $\begin{array}{l}-0.013 \\
(0.634)\end{array}$ & $\begin{array}{c}0.023 \\
(0.414)\end{array}$ & $\begin{array}{l}-0.073 \\
(0.008)\end{array}$ & $\begin{array}{c}0.026 \\
(0.338) \\
\end{array}$ & $\begin{array}{c}0.072 \\
(0.009)\end{array}$ \\
\hline CAUS_R & $\begin{array}{c}0.309 \\
(0.000)\end{array}$ & & $\begin{array}{c}0.064 \\
(0.020)\end{array}$ & $\begin{array}{c}0.081 \\
(0.003)\end{array}$ & $\begin{array}{l}-0.029 \\
(0.290)\end{array}$ & $\begin{array}{l}-0.171 \\
(0.000)\end{array}$ & $\begin{array}{l}-0.006 \\
(0.819)\end{array}$ & $\begin{array}{l}-0.089 \\
(0.001)\end{array}$ & $\begin{array}{l}-0.035 \\
(0.210)\end{array}$ & $\begin{array}{l}-0.066 \\
(0.016)\end{array}$ & $\begin{array}{l}-0.016 \\
(0.555)\end{array}$ & $\begin{array}{c}0.053 \\
(0.056)\end{array}$ & $\begin{array}{l}-0.019 \\
(0.486)\end{array}$ & $\begin{array}{l}-0.022 \\
(0.435)\end{array}$ & $\begin{array}{c}0.038 \\
(0.169)\end{array}$ \\
\hline HEAD_B & $\begin{array}{l}-0.026 \\
(0.337)\end{array}$ & $\begin{array}{c}0.071 \\
(0.010)\end{array}$ & & $\begin{array}{c}0.179 \\
(0.000)\end{array}$ & $\begin{array}{c}0.149 \\
(0.000)\end{array}$ & $\begin{array}{c}0.073 \\
(0.008)\end{array}$ & $\begin{array}{c}-0.085 \\
(0.002)\end{array}$ & $\begin{array}{c}0.214 \\
(0.000)\end{array}$ & $\begin{array}{c}0.045 \\
(0.104)\end{array}$ & $\begin{array}{l}-0.062 \\
(0.026)\end{array}$ & $\begin{array}{l}-0.013 \\
(0.638)\end{array}$ & $\begin{array}{c}0.102 \\
(0.000)\end{array}$ & $\begin{array}{c}0.107 \\
(0.000)\end{array}$ & $\begin{array}{c}0.234 \\
(0.000)\end{array}$ & $\begin{array}{c}0.109 \\
(0.000)\end{array}$ \\
\hline TONE & $\begin{array}{c}0.155 \\
(0.000) \\
\end{array}$ & $\begin{array}{c}0.064 \\
(0.020) \\
\end{array}$ & $\begin{array}{c}0.157 \\
(0.000) \\
\end{array}$ & & $\begin{array}{c}0.178 \\
(0.000) \\
\end{array}$ & $\begin{array}{c}0.246 \\
(0.000) \\
\end{array}$ & $\begin{array}{l}-0.171 \\
(0.000) \\
\end{array}$ & $\begin{array}{c}0.087 \\
(0.001) \\
\end{array}$ & $\begin{array}{l}-0.133 \\
(0.000) \\
\end{array}$ & $\begin{array}{l}-0.183 \\
(0.000) \\
\end{array}$ & $\begin{array}{c}0.002 \\
(0.955) \\
\end{array}$ & $\begin{array}{c}0.107 \\
(0.000) \\
\end{array}$ & $\begin{array}{c}0.082 \\
(0.003) \\
\end{array}$ & $\begin{array}{c}0.128 \\
(0.000) \\
\end{array}$ & $\begin{array}{c}0.120 \\
(0.000) \\
\end{array}$ \\
\hline AB_TONE & $\begin{array}{c}0.016 \\
(0.559)\end{array}$ & $\begin{array}{l}-0.042 \\
(0.131)\end{array}$ & $\begin{array}{c}0.120 \\
(0.000)\end{array}$ & $\begin{array}{c}0.155 \\
(0.000)\end{array}$ & & $\begin{array}{c}0.182 \\
(0.000)\end{array}$ & $\begin{array}{c}-0.228 \\
(0.000)\end{array}$ & $\begin{array}{c}0.039 \\
(0.156)\end{array}$ & $\begin{array}{c}-0.032 \\
(0.251)\end{array}$ & $\begin{array}{l}-0.137 \\
(0.000)\end{array}$ & $\begin{array}{c}0.020 \\
(0.472)\end{array}$ & $\begin{array}{c}0.119 \\
(0.000) \\
\end{array}$ & $\begin{array}{c}0.123 \\
(0.000) \\
\end{array}$ & $\begin{array}{c}0.120 \\
(0.000) \\
\end{array}$ & $\begin{array}{c}0.110 \\
(0.000) \\
\end{array}$ \\
\hline$\Delta \mathrm{OI}$ & $\begin{array}{l}-0.056 \\
(0.042) \\
\end{array}$ & $\begin{array}{l}-0.046 \\
(0.098) \\
\end{array}$ & $\begin{array}{c}0.016 \\
(0.572) \\
\end{array}$ & $\begin{array}{c}0.044 \\
(0.108) \\
\end{array}$ & $\begin{array}{c}0.019 \\
(0.480) \\
\end{array}$ & & $\begin{array}{c}-0.192 \\
(0.000) \\
\end{array}$ & $\begin{array}{c}0.194 \\
(0.000) \\
\end{array}$ & $\begin{array}{c}0.031 \\
(0.268) \\
\end{array}$ & $\begin{array}{c}0.035 \\
(0.208) \\
\end{array}$ & $\begin{array}{l}-0.002 \\
(0.928) \\
\end{array}$ & $\begin{array}{c}0.002 \\
(0.953) \\
\end{array}$ & $\begin{array}{c}0.129 \\
(0.000) \\
\end{array}$ & $\begin{array}{c}0.047 \\
(0.088) \\
\end{array}$ & $\begin{array}{l}-0.014 \\
(0.609) \\
\end{array}$ \\
\hline$\Delta$ FUT_OI & $\begin{array}{c}0.008 \\
(0.773)\end{array}$ & $\begin{array}{c}0.012 \\
(0.661)\end{array}$ & $\begin{array}{l}-0.033 \\
(0.225)\end{array}$ & $\begin{array}{l}-0.065 \\
(0.018)\end{array}$ & $\begin{array}{l}-0.100 \\
(0.000)\end{array}$ & $\begin{array}{l}-0.370 \\
(0.000)\end{array}$ & & $\begin{array}{l}-0.073 \\
(0.008)\end{array}$ & $\begin{array}{c}0.125 \\
(0.000)\end{array}$ & $\begin{array}{c}0.094 \\
(0.000)\end{array}$ & $\begin{array}{l}-0.100 \\
(0.000)\end{array}$ & $\begin{array}{l}-0.045 \\
(0.105)\end{array}$ & $\begin{array}{l}-0.040 \\
(0.144)\end{array}$ & $\begin{array}{l}-0.015 \\
(0.583)\end{array}$ & $\begin{array}{l}-0.040 \\
(0.151)\end{array}$ \\
\hline POS_EAR & $\begin{array}{l}-0.121 \\
(0.000)\end{array}$ & $\begin{array}{l}-0.097 \\
(0.000)\end{array}$ & $\begin{array}{c}0.213 \\
(0.000)\end{array}$ & $\begin{array}{c}0.078 \\
(0.005)\end{array}$ & $\begin{array}{c}0.024 \\
(0.379)\end{array}$ & $\begin{array}{c}0.063 \\
(0.022) \\
\end{array}$ & $\begin{array}{l}-0.052 \\
(0.058)\end{array}$ & & $\begin{array}{c}0.127 \\
(0.000)\end{array}$ & $\begin{array}{c}0.127 \\
(0.000)\end{array}$ & $\begin{array}{l}-0.021 \\
(0.456)\end{array}$ & $\begin{array}{c}0.154 \\
(0.000)\end{array}$ & $\begin{array}{c}0.094 \\
(0.001)\end{array}$ & $\begin{array}{c}0.033 \\
(0.232)\end{array}$ & $\begin{array}{c}-0.018 \\
(0.507)\end{array}$ \\
\hline $\ln M V$ & $\begin{array}{c}0.010 \\
(0.724)\end{array}$ & $\begin{array}{l}-0.022 \\
(0.432)\end{array}$ & $\begin{array}{c}0.061 \\
(0.026)\end{array}$ & $\begin{array}{c}-0.131 \\
(0.000)\end{array}$ & $\begin{array}{c}-0.040 \\
(0.149)\end{array}$ & $\begin{array}{c}0.003 \\
(0.923)\end{array}$ & $\begin{array}{c}0.075 \\
(0.007)\end{array}$ & $\begin{array}{c}0.132 \\
(0.000)\end{array}$ & & $\begin{array}{c}-0.078 \\
(0.000)\end{array}$ & $\begin{array}{c}0.021 \\
(0.441)\end{array}$ & $\begin{array}{c}0.254 \\
(0.000)\end{array}$ & $\begin{array}{c}0.037 \\
(0.174)\end{array}$ & $\begin{array}{c}0.047 \\
(0.088)\end{array}$ & $\begin{array}{c}0.010 \\
(0.712)\end{array}$ \\
\hline BTM & $\begin{array}{c}-0.111 \\
(0.000)\end{array}$ & $\begin{array}{c}-0.088 \\
(0.001)\end{array}$ & $\begin{array}{c}0.016 \\
(0.556)\end{array}$ & $\begin{array}{c}-0.157 \\
(0.000)\end{array}$ & $\begin{array}{c}-0.095 \\
(0.001)\end{array}$ & $\begin{array}{c}-0.003 \\
(0.926)\end{array}$ & $\begin{array}{c}0.018 \\
(0.510)\end{array}$ & $\begin{array}{c}0.001 \\
(0.977)\end{array}$ & $\begin{array}{c}-0.082 \\
(0.003)\end{array}$ & & $\begin{array}{l}-0.034 \\
(0.220)\end{array}$ & $\begin{array}{c}0.007 \\
(0.814)\end{array}$ & $\begin{array}{c}-0.003 \\
(0.902)\end{array}$ & $\begin{array}{c}-0.087 \\
(0.002)\end{array}$ & $\begin{array}{c}-0.144 \\
(0.000)\end{array}$ \\
\hline M_RET & $\begin{array}{c}-0.015 \\
(0.557)\end{array}$ & $\begin{array}{c}-0.016 \\
(0.563)\end{array}$ & $\begin{array}{c}-0.016 \\
(0.572)\end{array}$ & $\begin{array}{c}-0.005 \\
(0.846)\end{array}$ & $\begin{array}{c}0.001 \\
(0.979)\end{array}$ & $\begin{array}{c}0.064 \\
(0.020)\end{array}$ & $\begin{array}{l}-0.045 \\
(0.103)\end{array}$ & $\begin{array}{l}-0.022 \\
(0.428)\end{array}$ & $\begin{array}{c}0.018 \\
(0.525)\end{array}$ & $\begin{array}{l}-0.005 \\
(0.859)\end{array}$ & & $\begin{array}{c}0.019 \\
(0.493)\end{array}$ & $\begin{array}{c}0.004 \\
(0.886)\end{array}$ & $\begin{array}{c}0.048 \\
(0.084)\end{array}$ & $\begin{array}{c}0.043 \\
(0.120)\end{array}$ \\
\hline SPREAD & $\begin{array}{c}0.018 \\
(0.525)\end{array}$ & $\begin{array}{c}0.007 \\
(0.813)\end{array}$ & $\begin{array}{c}0.014 \\
(0.622)\end{array}$ & $\begin{array}{c}0.094 \\
(0.001)\end{array}$ & $\begin{array}{c}0.065 \\
(0.019)\end{array}$ & $\begin{array}{c}0.012 \\
(0.653)\end{array}$ & $\begin{array}{c}-0.009 \\
(0.742)\end{array}$ & $\begin{array}{c}0.117 \\
(0.000)\end{array}$ & $\begin{array}{c}0.073 \\
(0.008)\end{array}$ & $\begin{array}{c}-0.012 \\
(0.665)\end{array}$ & $\begin{array}{c}0.006 \\
(0.816)\end{array}$ & & $\begin{array}{c}0.046 \\
(0.096)\end{array}$ & $\begin{array}{c}-0.046 \\
(0.095)\end{array}$ & $\begin{array}{c}-0.065 \\
(0.019)\end{array}$ \\
\hline CAR & $\begin{array}{c}-0.028 \\
(0.312)\end{array}$ & $\begin{array}{l}-0.023 \\
(0.399)\end{array}$ & $\begin{array}{c}0.102 \\
(0.000)\end{array}$ & $\begin{array}{c}0.095 \\
(0.001)\end{array}$ & $\begin{array}{c}0.117 \\
(0.000)\end{array}$ & $\begin{array}{c}0.011 \\
(0.703)\end{array}$ & $\begin{array}{c}0.000 \\
(0.997)\end{array}$ & $\begin{array}{c}0.091 \\
(0.001)\end{array}$ & $\begin{array}{c}0.006 \\
(0.838)\end{array}$ & $\begin{array}{l}-0.039 \\
(0.162)\end{array}$ & $\begin{array}{c}0.017 \\
(0.548)\end{array}$ & $\begin{array}{c}-0.008 \\
(0.782) \\
\end{array}$ & & $\begin{array}{c}-0.015 \\
(0.599) \\
\end{array}$ & $\begin{array}{c}-0.006 \\
(0.839) \\
\end{array}$ \\
\hline AB_DVOL & $\begin{array}{c}0.016 \\
(0.056)\end{array}$ & $\begin{array}{c}0.013 \\
(0.651)\end{array}$ & $\begin{array}{c}0.095 \\
(0.001)\end{array}$ & $\begin{array}{c}0.047 \\
(0.087)\end{array}$ & $\begin{array}{c}0.047 \\
(0.088)\end{array}$ & $\begin{array}{c}0.004 \\
(0.883)\end{array}$ & $\begin{array}{c}-0.006 \\
(0.818)\end{array}$ & $\begin{array}{c}-0.008 \\
(0.770)\end{array}$ & $\begin{array}{c}0.030 \\
(0.281)\end{array}$ & $\begin{array}{c}-0.047 \\
(0.091)\end{array}$ & $\begin{array}{c}0.047 \\
(0.094)\end{array}$ & $\begin{array}{l}-0.081 \\
(0.003)\end{array}$ & $\begin{array}{c}0.005 \\
(0.846)\end{array}$ & & $\begin{array}{c}0.048 \\
(0.083)\end{array}$ \\
\hline AB_DSEN & $\begin{array}{c}0.039 \\
(0.155)\end{array}$ & $\begin{array}{c}0.031 \\
(0.262)\end{array}$ & $\begin{array}{c}0.079 \\
(0.004)\end{array}$ & $\begin{array}{c}0.032 \\
(0.241)\end{array}$ & $\begin{array}{c}0.033 \\
(0.224)\end{array}$ & $\begin{array}{c}0.000 \\
(0.988)\end{array}$ & $\begin{array}{c}0.001 \\
(0.957)\end{array}$ & $\begin{array}{c}0.013 \\
(0.631)\end{array}$ & $\begin{array}{c}-0.002 \\
(0.938)\end{array}$ & $\begin{array}{l}-0.046 \\
(0.097)\end{array}$ & $\begin{array}{c}0.017 \\
(0.527)\end{array}$ & $\begin{array}{c}0.018 \\
(0.516)\end{array}$ & $\begin{array}{l}-0.020 \\
(0.477)\end{array}$ & $\begin{array}{c}0.048 \\
(0.000)\end{array}$ & \\
\hline
\end{tabular}


Firm performance, which is captured by operating income change $(\Delta \mathrm{OI})$, is strongly correlated with most of the impression management variables. Both READ and CAUS_R are inversely related to operating income change with significant (at the $1 \%$ level) Spearman correlations of -0.304 and -0.171 for READ and CAUS_R, respectively. These findings are in line with previous impression management literature. HEAD_B, TONE, and AB_TONE variables are positively associated with operating income change at high significance levels (all at the $1 \%$ level). These relationships were also expected and hypothesized based on previous impression management studies.

Overall, the correlation matrix shows mostly expected relationships between variables and does not reveal any relationship which potentially may cause an issue in the regression analyses. Although some of the impression management variables (e.g., READ and HEAD_B) are strongly correlated, such associations are expected and are not problematic as the correlation coefficients are not at alarmingly high levels (i.e., above 0.50). A widely accepted arbitrary rule of thumb is restricting the use of predictor variables with correlation coefficients above 0.8 or 0.9 (Farrar \& Glauber, 1967). In addition to the correlation checks, variance inflation factors (VIFs) will be calculated for each regression model presented in the next section to address the potential concerns of multicollinearity among variables.

\subsection{Regression results}

This part of the chapter presents results from OLS regressions performed to analyze the firm and the investor perspectives on impression management. The firm perspective regressions measure the relationship between impression management and 
firm performance. The investor perspective regressions analyze the associations between impression management and CAR as well as impression management and online investment discussion board user reaction through discussion volume and discussion sentiment, respectively.

\subsubsection{Firm performance and impression management}

Table 5.9 and Table 5.10 provide estimated coefficients, the t-statistics and statistical significance levels from OLS regressions of each of the studied impression management strategies on firm performance and control variables. The association between EPR tone and firm performance ( $\Delta \mathrm{OI}$ ) was tested using Eq. 2 (see Chapter 4). Although the main purpose of testing this relationship is to obtain residuals ( $\varepsilon$ in Eq. 2) which are used in the abnormal tone equation (Eq. 7), it is also important to examine the tone regression results and ensure that a positive relationship between EPR tone and firm performance exists. Tone regression results in Table 5.9 confirm that future firm performance is (0.642) positively associated with tone (TONE) in EPRs (significant at the $1 \%$ level). Similarly, there is a strong (significant at the $1 \%$ level) positive $(0.297)$ relationship between TONE and POS_EAR. Tone results also show that larger firms are significantly (at the $1 \%$ level) less likely to issue EPRs with more positive tone, in general. The Application Software industry (IND_AS), the Communication Equipment industry (IND_CE), the Industrial Products \& Manufacturing industry (IND_IP_M) are significantly and positively related to TONE, while the Biotechnology industry (IND_Bio) is negatively related to TONE.

Table 5.9 also displays regression results for the relationship between future firm performance $(\triangle \mathrm{FUT} \mathrm{OI})$ and abnormal tone $\left(\mathrm{AB} \_\mathrm{TONE}\right)$. The results indicate that 
abnormal tone in EPRs is negatively associated with future firm performance but only at the $10 \%$ level of significance. A firm's market value is also negatively related to ABTONE. In terms of results for industries, the Application Software industry (IND_AS), the Communication Equipment (IND_CE) industry and the Industrial Products and Manufacturing industry (IND_IP_M) show statistically significant associations with AB_TONE. More specifically, firms in these industries generally have higher abnormal tone compared to the reference group.

Table 5.9. Firm performance on tone and abnormal tone

\begin{tabular}{|c|c|c|c|c|}
\hline \multirow{3}{*}{$\Delta \mathrm{OI} / \Delta \mathrm{FUT}$ OI } & \multicolumn{2}{|c|}{ TONE } & \multicolumn{2}{|c|}{ AB_TONE } \\
\hline & $\beta \mathrm{j}$ & t-stat & $\beta \mathrm{j}$ & t-stat \\
\hline & 0.642 & $2.69 * * *$ & -1.838 & $-1.82 *$ \\
\hline POS_EAR & 0.297 & $2.63^{* * *}$ & -0.023 & -0.15 \\
\hline $\operatorname{lnMV}$ & -0.177 & $-3.61 * * *$ & -0.132 & $-1.98 * *$ \\
\hline BTM & -0.068 & $-1.87^{*}$ & -0.080 & -1.61 \\
\hline M_RET & -0.009 & -0.01 & 0.009 & 0.03 \\
\hline IND_AS & 0.998 & $5.47 * * *$ & 0.295 & $3.16^{* * *}$ \\
\hline IND_Bio & 0.229 & $2.43 * *$ & 0.030 & 1.32 \\
\hline IND_C_BS & -0.148 & -0.76 & -1.458 & -1.47 \\
\hline IND_CE & 1.058 & $5.18^{* * *}$ & 0.574 & $2.03^{* *}$ \\
\hline IND_IP_M & 0.996 & $5.37^{* * *}$ & 0.140 & $3.55^{* * *}$ \\
\hline IND_M_M & -0.428 & -1.13 & -1.624 & -0.11 \\
\hline IND_OTHER & 0.289 & 1.41 & 0.447 & 1.58 \\
\hline $\mathrm{R}^{2}$ & & $13.2 \%$ & & $8.3 \%$ \\
\hline Adjusted-R ${ }^{2}$ & & $12.4 \%$ & & $7.2 \%$ \\
\hline $\mathrm{N}$ & & 1317 & & 1317 \\
\hline
\end{tabular}

Table 5.10 contains regression results for reading complexity, causal reasoning intensity, and headline impression management bias. The association between reading complexity (READ) and firm performance $(\triangle \mathrm{OI})$ was tested based on Eq. 8 (see Chapter 4). The results of OLS regression indicate that the reading complexity of EPRs is 
negatively $(-2.008)$ related to firm performance (significant at the $1 \%$ level). Similarly, there is a significant (at the $1 \%$ level) negative $(-0.788)$ association between the positive earnings (POS_EAR) variable and reading complexity. That is, reading complexity of EPRs is generally higher when there is decreased firm performance and/or negative earnings. Moreover, there is a significant (at the $5 \%$ level) positive relationship (0.212) between firms' market value (lnMV) and reading complexity suggesting that larger firms generally issue less readable EPRs. Reading complexity results also indicate that EPRs by firms in all industries, other than the Oil \& Gas industry, which is used as the reference group, are generally more difficult to read as seen in positive coefficients and significant t-statistic values. Among all industries the Metals \& Mining industry differs least from the reference group. Market returns (M_RET) and book-to-market (BTM) ratio were not found to be significantly related to reading complexity.

The relationship between causal reasoning intensity (CAUS_R) and firm performance $(\Delta \mathrm{OI})$ was examined using Eq. 9 from Chapter 4. As Table 5.10 shows, causal reasoning intensity regression results are somewhat similar to reading complexity regression results. Causal reasoning intensity in EPRs is negatively associated (-1.562) with increased firm performance, however this relationship is less significant (at the 5\% level) than it was for reading complexity (at the $5 \%$ level). The positive earnings variable (POS_EAR) is also negatively (-1.851) associated with causal reasoning intensity at the $1 \%$ significance level. Market returns and Book-to-Market ratio were not found to be significantly related to causal reading complexity. All industry groups, except for the Biotechnology industry and the Metals \& Mining industry, affect causal reasoning more positively than the Oil \& Gas industry, the reference group. 
Table 5.10. Firm performance on readability, causal reasoning intensity, and headline impression management

\begin{tabular}{|c|c|c|c|c|c|c|}
\hline \multirow{3}{*}{$\Delta \mathrm{OI}$} & \multicolumn{2}{|c|}{ READ } & \multicolumn{2}{|c|}{ CAUS_R } & \multicolumn{2}{|c|}{ HEAD_B } \\
\hline & $\beta \mathrm{j}$ & t-stat & $\beta \mathrm{j}$ & t-stat & $\beta \mathrm{j}$ & t-stat \\
\hline & -2.008 & $-4.87 * * *$ & -1.562 & $-2.19 * *$ & 0.041 & $1.76^{*}$ \\
\hline POS_EAR & -0.788 & $-4.03 * * *$ & -1.851 & $-3.61 * * *$ & 0.253 & $2.09 * *$ \\
\hline $\operatorname{lnMV}$ & 0.212 & $2.51 * *$ & 0.220 & 0.99 & 0.077 & $6.04 * * *$ \\
\hline BTM & -0.078 & -1.24 & -0.154 & -0.93 & 0.046 & $4.87 * * *$ \\
\hline M_RET & -0.272 & -0.68 & -0.623 & -0.59 & -0.001 & 0.01 \\
\hline IND_AS & 1.207 & $3.83 * * *$ & 2.894 & $3.49 * * *$ & 0.512 & $10.81 * * *$ \\
\hline IND_Bio & 2.154 & $6.14 * * *$ & 0.434 & 0.47 & 0.361 & $6.85^{* * *}$ \\
\hline IND_C_BS & 1.493 & $2.25^{* *}$ & 1.861 & $2.11 * *$ & 0.180 & $3.58^{* * *}$ \\
\hline IND_CE & 3.309 & $9.38 * * *$ & 3.177 & $3.42^{* * *}$ & 0.329 & $6.20^{* * *}$ \\
\hline IND_IP_M & 1.434 & $4.47 * * *$ & 4.667 & $5.54 * * *$ & 0.410 & $8.51 * * *$ \\
\hline IND_M_M & 1.334 & $1.79 *$ & 1.202 & 1.50 & 0.041 & 0.90 \\
\hline IND_OTHER & 0.760 & $2.14 * *$ & 1.747 & $1.87^{*}$ & 0.461 & $2.16^{* *}$ \\
\hline $\mathrm{R}^{2}$ & & $11.3 \%$ & & $10.2 \%$ & & $22.8 \%$ \\
\hline Adjusted-R ${ }^{2}$ & & $10.5 \%$ & & $19.3 \%$ & & $22.1 \%$ \\
\hline $\mathrm{N}$ & & 1317 & & 1317 & & 1317 \\
\hline
\end{tabular}

Oil \& Gas industry is the reference group for the industries variable.

To determine how operating income affects headline impression management, headline impression management bias (HEAD_B) is regressed into the operating income change $(\Delta \mathrm{OI})$ measure and other control variables as defined in Eq. 10 in Chapter 4.

Table 5.10 above also contains regression results for headline impression management bias. The impact of firm performance on headline impression management bias appears to be statistically significant only at the $10 \%$ level, and the estimated coefficient is positive as expected. The positive earnings (POS_EAR) variable is associated with the outcome variable more strongly. The positive earnings variable positively impacts (0.253) headline impression management bias at the significance level of 5\%. Both market value and book-to-market ratio are significantly (at the $1 \%$ level) and positively associated with headline impression management bias. All industries, except for the 
Metals \& Mining industry, are more positively related to the dependent variable than the reference group with high significance (at the $1 \%$ level).

\subsubsection{Impression management and CAR}

Table 5.11 contains results for regressing three-day CAR on the four impression management variables (AB_TONE, READ, CAUS_R, and HEAD_B) along with firm performance and industry variables. This OLS regression is based on Eq. 11 from Chapter 4. As discussed in Chapter 4, benchmark stock returns variable (M_RET) is used to control for the effect of market performance. Average spread (SPREAD) is also used as another control variable in the three-day CAR equation. The regression results indicate that abnormal tone (AB_TONE) and headline impression management bias (HEAD_B) are both positively associated with the three-day CAR. The strength of the relationship for both variables is significant at the $1 \%$ level. However, reading complexity (READ) and causal reasoning (CAUS_R) are not found to be strongly related with the CAR. The positive earnings (POS_EAR) and book-to-market (BTM) control variables are also significantly (at the $1 \%$ level) related to the three-day CAR with positive relationships. Among the industry groups, the Application Software (IND_AS) industry, the Biotechnology industry (IND_Bio) industry, and the Consulting \& Business services (IND_C_BS) industry differ significantly from the reference group. More specifically, the three-day CAR of firms in these three groups are generally lower than the reference group (Oil \& Gas industry). The significance value for the Metals \& Mining industry indicates that this industry is the most similar to the reference group regarding the effect to CAR. 
Table 5.11. Impression management strategies on three-day CAR

\begin{tabular}{|l|c|c|}
\cline { 2 - 3 } \multicolumn{1}{c|}{} & \multicolumn{2}{c|}{ three-day CAR } \\
\cline { 2 - 3 } \multicolumn{1}{c|}{} & \multicolumn{1}{c|}{ t-stat } \\
\hline AB_TONE & 0.0043 & $3.20^{* * *}$ \\
\hline READ & -0.0001 & -0.91 \\
\hline CAUS_R & -0.0003 & -0.62 \\
\hline HEAD_B & 0.0240 & $3.40^{* * *}$ \\
\hline$\Delta$ OI & 0.0100 & $1.73^{*}$ \\
\hline POS_EAR & 0.0210 & $2.73^{* * *}$ \\
\hline lnMV & -0.0049 & -1.49 \\
\hline BTM & -0.0068 & $-2.79 * * *$ \\
\hline M_RET & 0.0120 & 0.78 \\
\hline SPREAD & -0.0250 & -0.75 \\
\hline IND_AS & -0.0390 & $-3.05 * * *$ \\
\hline IND_Bio & -0.0440 & $-3.16^{* * *}$ \\
\hline IND_C_BS & -0.0520 & $-3.93 * * *$ \\
\hline IND_CE & -0.0220 & -1.57 \\
\hline IND_IP_M & -0.0210 & -1.64 \\
\hline IND_M_M & -0.0075 & -0.63 \\
\hline IND_OTHER & -0.0180 & -1.30 \\
\hline & \multicolumn{2}{|c|}{} \\
\hline R ${ }^{2}$ & \multicolumn{2}{|c|}{$5.8 \%$} \\
\hline Adjusted-R ${ }^{2}$ & $4.6 \%$ \\
\hline N & 1317 \\
\hline$* * * * *$ and ${ }^{*}$ indicate statistical significance at the $1 \%, 5 \%$ and $10 \%$ levels, respectively; \\
\hline Oil \& Gas industry is the reference group for the industries variable. \\
\hline
\end{tabular}

\subsubsection{Impression management and online user reaction}

Table 5.12 and Table 5.13 help test hypotheses H9 and H10 on the relationship between impression management and online discussion board user reaction. More specifically, as defined in Eq. 12 and Eq. 13, OLS regressions were performed to examine how impression management strategies impact three-day abnormal discussion volume and three-day abnormal discussion sentiment, respectively. The results from Table 5.12 indicate that among the impression management predictors only headline impression management bias (HEAD_B) has a strong association with the abnormal 
discussion volume (AB_DVOL). This predictor is positively related to abnormal discussion volume at a $1 \%$ significance level, suggesting that EPRs with impression management in the headline receive more discussion posts in online discussion boards. The strength of the relationship between abnormal tone (AB_TONE) and abnormal discussion volume is only significant at the $10 \%$ significance level, and the two variables are positively associated with each other.

Table 5.12. Impression management strategies on abnormal discussion volume

\begin{tabular}{|l|c|c|}
\cline { 2 - 3 } \multicolumn{1}{c|}{} & \multicolumn{2}{c|}{ AB_DVOL } \\
\cline { 2 - 3 } \multicolumn{1}{c|}{} & $\beta \mathrm{j}$ & $\mathrm{t}$-stat \\
\hline AB_TONE & 0.094 & $1.78^{*}$ \\
\hline READ & -0.098 & -1.36 \\
\hline CAUS_R & -0.003 & -0.105 \\
\hline HEAD_B & 1.180 & $2.60^{* * *}$ \\
\hline AOI & -0.015 & -0.014 \\
\hline POS_EAR & -1.022 & $-2.09^{* *}$ \\
\hline lnMV & 0.333 & 1.58 \\
\hline BTM & -0.024 & -0.15 \\
\hline M_RET & 1.716 & $1.73 *$ \\
\hline IND_AS & 0.371 & 0.45 \\
\hline IND_Bio & 2.148 & $2.42^{* *}$ \\
\hline IND_C_BS & 1.999 & $2.35^{* *}$ \\
\hline IND_CE & 5.407 & $5.88^{* * *}$ \\
\hline IND_IP_M & 2.289 & $2.76^{* * *}$ \\
\hline IND_M_M & -0.425 & -0.55 \\
\hline IND_OTHER & 0.386 & 0.43 \\
\hline DOW_FRI & -0.136 & -0.22 \\
\hline DOW_MON & 1.040 & $2.05 * *$ \\
\hline & & \\
\hline R & & $6.3 \%$ \\
\hline Adjusted-R ${ }^{2}$ & & $5.0 \%$ \\
\hline N & & 1317 \\
\hline$* * * * *$ and * indicate statistical significance at the $1 \%, 5 \%$ and $10 \%$ levels, respectively; \\
\hline Oil \& Gasis & & \\
\hline
\end{tabular}

Oil \& Gas industry is the reference group for the industries variable.

The results from Table 5.12 above suggest that EPRs with higher abnormal tone are discussed more within 3 days of EPR. On the contrary, the abnormal discussion 
volume regression results show that EPRs with higher levels of reading complexity (READ) are generally discussed less, as the reading complexity variable is negatively (0.098) associated with the dependent variable. However, this relationship is not significant. Among the control variables contemporary market return (M_RET), some industry groups (IND_Bio, IND_C_BS, IND_CE, IND_IP_M), and the day of week Monday (DOW_MON) variables are significantly associated with abnormal discussion volume. Results indicate that abnormal discussion volume is generally higher when contemporary market returns are higher (marginally significant), while discussion volume is generally significantly higher on Mondays.

Table 5.13. Impression management strategies on abnormal discussion sentiment

\begin{tabular}{|c|c|c|}
\hline & \multicolumn{2}{|c|}{ AB_DSEN } \\
\hline & $\beta \mathrm{j}$ & t-stat \\
\hline AB TONE & 0.014 & 0.28 \\
\hline READ & 0.031 & 0.74 \\
\hline CAUS_R & -0.002 & -0.11 \\
\hline HEAD_B & 0.280 & 1.61 \\
\hline$\Delta \mathrm{OI}$ & -0.016 & 0.98 \\
\hline POS_EAR & -0.017 & -0.41 \\
\hline $\operatorname{lnMV}$ & 0.117 & 0.94 \\
\hline BTM & 0.045 & 0.48 \\
\hline M_RET & 0.400 & 0.69 \\
\hline IND_AS & 1.883 & $3.87^{* * *}$ \\
\hline IND_Bio & 1.391 & $2.66^{* * *}$ \\
\hline IND_C_BS & 0.809 & 1.62 \\
\hline IND_CE & 1.042 & $1.93 *$ \\
\hline IND_IP_M & 1.852 & $3.80^{* * *}$ \\
\hline IND_M_M & 0.350 & 0.77 \\
\hline IND_OTHER & 0.863 & 1.63 \\
\hline $\mathrm{R}^{2}$ & & $2.9 \%$ \\
\hline Adjusted-R ${ }^{2}$ & & $1.7 \%$ \\
\hline $\mathrm{N}$ & & 1317 \\
\hline
\end{tabular}

Oil \& Gas industry is the reference group for the industries variable 
This study also explored online discussion sentiment in reaction to apparent impression management strategies as formulated in H10. Results from Table 5.13 below show that none of the impression management variables are found to significantly impact abnormal discussion sentiment. The results show headline impression management bias is positively, though not significantly, related to abnormal discussion sentiment. Some of the industry variables are found to have strong significance. Results of this regression indicate that abnormal sentiment is generally higher (at the $1 \%$ significance level) for the Application Software industry, the Biotechnology industry and the Industrial Products \& Manufacturing industry compared to the reference industry. However, the overall variance explained by the predictors seems to be low as indicated by the R-squared of $2.9 \%$.

\subsection{Additional analysis}

\subsubsection{Splitting industries into two groups}

Regression results on industry groups show that, in general, there is a significant difference between the Oil \& Gas industry (the reference group) and other industry groups, with the exclusion of the Metals \& Mining industry. Significance values for the Metal \& Mining industry in Tables 5.9 - 5.13 confirm insignificant differences (with the exception of $10 \%$ significance in the readability regression) between the Metals \& Mining industry and the Oil \& Gas industry, while most of the other industries are generally significantly different than the Oil \& Gas industry in each of the tables. Since both the Metals \& Mining industry and the Oil \& Gas industry are made up of natural resource firms, these results were not unexpected. These results confirm that the two natural resource industries are similar regarding both the firm and the investor 
perspectives on impression management. However, this finding also leads to another exploratory test - repeating the regressions while splitting industries into a natural resource industry group and an Other industries group. This allows for a check of whether the industry information from the extended industry classification is helping with the overall strength of the models. Moreover, results of splitting industries into these two groups will possibly lead to stronger and more general findings on the difference between the natural resource firms and other firms in the TSX Venture Exchange. Therefore, this section re-estimates OLS regressions defined in Eq. 2, Eq. 7, Eq. 8, Eq. 9, Eq.10, Eq. 11, Eq. 12, and Eq. 13 with only two groups (natural resource industries and other industries) for the IND variable.

Table 5.14. Tone and abnormal tone regression results with the new industry grouping

\begin{tabular}{|c|c|c|c|c|}
\hline \multirow[t]{2}{*}{3} & \multicolumn{2}{|c|}{ TONE } & \multicolumn{2}{|c|}{ AB_TONE } \\
\hline & $\beta \mathrm{j}$ & t-stat & $\beta \mathrm{j}$ & t-stat \\
\hline$\Delta \mathrm{OI} / \Delta \mathrm{FUT} \_\mathrm{OI}$ & 0.657 & $2.76^{* * *}$ & -1.963 & $-1.71^{*}$ \\
\hline POS_EAR & 0.221 & $1.94 * *$ & -0.032 & -0.21 \\
\hline $\operatorname{lnMV}$ & -0.207 & $-4.20 * * *$ & -0.104 & $-1.52 *$ \\
\hline BTM & -0.096 & $-2.60 * *$ & -0.107 & $-2.12 * *$ \\
\hline M_RET & -0.041 & -0.172 & 0.034 & 0.10 \\
\hline INDUSTRY & 0.807 & $6.74 * * *$ & 0.523 & $3.12 * * *$ \\
\hline $\mathrm{R}^{2}$ & & $9.5 \%$ & & $4.3 \%$ \\
\hline Adjusted-R ${ }^{2}$ & & $9.1 \%$ & & $3.8 \%$ \\
\hline $\mathrm{N}$ & & 1317 & & 1317 \\
\hline
\end{tabular}

Table 5.14 displays tone and abnormal tone regressions with the new industry groupings where the INDUSTRY variable includes all industries except for the two natural resource industries, the Metals \& Mining industry and the Oil \& Gas Industry, which are used as the reference group. The results show that INDUSTRY is statistically significant at the $1 \%$ level indicating that other industries differ significantly from the 
two natural resource industries. There are no apparent differences for other variables in both the estimated coefficients and the significance levels. However, the overall strength of the model is now lower for both the tone and the abnormal tone regressions. This suggests that information gained from the extended industry grouping used in previous regressions may be beneficial to the study of the relationship between firm performance and tone management.

Table 5.15. Readability, causal reasoning, and headline impression management regression results with the new industry grouping

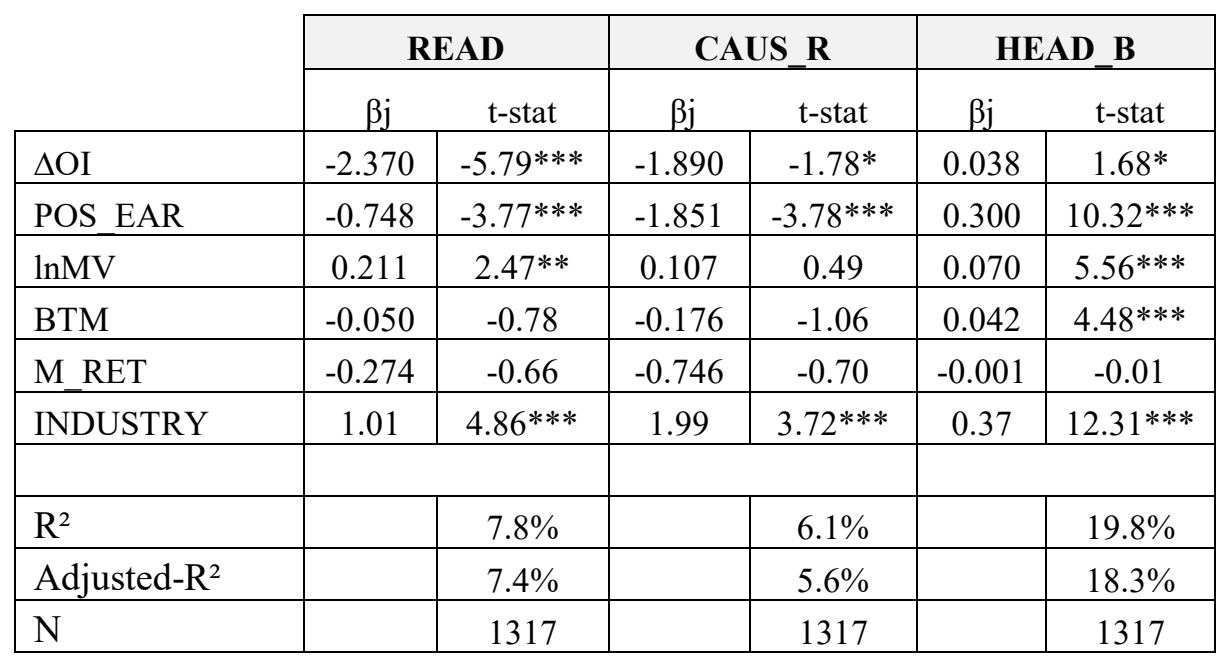

$* * *, * *$ and $*$ indicate statistical significance at the $1 \%, 5 \%$ and $10 \%$ levels, respectively;

INDUSTRY includes all industries except for the Oil \& Gas and Metals \& Mining industries

As shown in Table 5.15, the INDUSTRY variable is also statistically significant in the readability, causal reasoning, and headline impression management regressions. Similar to the observations in the tone regressions (Table 5.14), while the other results are not seemingly different from the initial regression results, the overall models are not as strong as the previous models with the extended industry grouping. $\mathrm{R}^{2}$ and Adjusted- $\mathrm{R}^{2}$ values for now lower, suggesting that the extended industry classification is a valuable piece in the regressions. 
Table 5.16 estimates three-day CAR regression with the new industry groupings. As expected, the INDUSTRY variable is significant while the other predictors have the same level of significance as the initial regression in Table 5.11. The sign of the relationship between INDUSTRY and the dependent variable is negative as it was for all industry groups that were significant in Table 5.11. However, the overall strength of the model is lower than the initial model $\left(\mathrm{R}^{2}\right.$ of $4.6 \%$ as opposed to $\left.5.8 \%\right)$ indicating that the incremental information gained from the extended industry grouping is beneficial to the overall three-day CAR model as well.

Table 5.16. Three-day CAR regression results with the new industry grouping

\begin{tabular}{|c|c|c|}
\hline \multirow{3}{*}{ AB_TONE } & \multicolumn{2}{|c|}{ Three-day CAR } \\
\hline & \multicolumn{2}{|r|}{ t-stat } \\
\hline & 0.0049 & $3.15^{* * *}$ \\
\hline READ & -0.0001 & 1.07 \\
\hline CAUS_R & -0.0003 & $-2.43 * *$ \\
\hline HEAD_B & 0.0250 & $3.67 * * *$ \\
\hline$\Delta \mathrm{OI}$ & 0.0130 & 0.86 \\
\hline POS_EAR & 0.0210 & $2.84 * * *$ \\
\hline $\operatorname{lnMV}$ & -0.0045 & -1.40 \\
\hline BTM & -0.0066 & $-2.73 * * *$ \\
\hline M_RET & 0.0120 & 0.76 \\
\hline SPREAD & -0.0250 & -0.76 \\
\hline INDUSTRY & -0.0300 & $-3.65 * * *$ \\
\hline $\mathrm{R}^{2}$ & & $4.6 \%$ \\
\hline Adjusted-R ${ }^{2}$ & & $3.9 \%$ \\
\hline $\mathrm{N}$ & & 1317 \\
\hline
\end{tabular}

As shown in Table 5.17, estimating abnormal discussion volume and abnormal discussion sentiment regressions with the new industry grouping leads to similar effects as seen in the three-day CAR regression above. The INDUSTRY variable is significant while the overall model is weaker than the previous regressions in Table 5.12 and Table 
5.13 in both cases. For abnormal discussion sentiment, headline impression management, which had a slightly insufficient t-statistic to be included in the $10 \%$ level of significance, now becomes marginally significant. Another notable observation for the abnormal discussion volume regression with the new industry grouping is that headline impression management (HEAD_B) is slightly less statistically significant (significant at the $5 \%$ level as opposed to the $1 \%$ level previously).

Table 5.17. Abnormal discussion volume and abnormal discussion sentiment regression results with the new industry grouping

\begin{tabular}{|l|c|c|c|c|}
\cline { 2 - 5 } \multicolumn{1}{c|}{} & \multicolumn{2}{c}{ AB_DVOL } & \multicolumn{2}{c|}{ AB_DSEN } \\
\cline { 2 - 5 } \multicolumn{1}{c|}{} & \multicolumn{1}{c}{$\mathrm{j}$} & $\mathrm{t}$-stat & $\beta \mathrm{j}$ & $\mathrm{t}$-stat \\
\hline AB_TONE & 0.072 & 0.85 & 0.026 & 0.53 \\
\hline READ & -0.012 & -0.17 & 0.024 & 0.56 \\
\hline CAUS_R & -0.010 & -0.36 & 0.009 & 0.56 \\
\hline HEAD_B & 0.949 & $2.11^{* *}$ & 0.407 & $1.76^{*}$ \\
\hline$\triangle$ OI & -0.039 & -0.04 & -0.072 & 0.58 \\
\hline POS_EAR & -0.972 & $-1.98^{* *}$ & -0.181 & -0.64 \\
\hline lnMV & 0.398 & $1.89^{*}$ & 0.06 & 0.50 \\
\hline BTM & 0.039 & 0.24 & 0.008 & 0.08 \\
\hline M_RET & 1.710 & $1.70^{*}$ & 0.386 & 0.66 \\
\hline INDUSTRY & 2.231 & $4.17^{* * *}$ & 1.114 & $3.59^{* * *}$ \\
\hline DOW_FRI & -0.228 & -0.36 & NA & NA \\
\hline DOW_MON & 1.063 & $2.07 * *$ & NA & NA \\
\hline & & & & \\
\hline$R^{2}$ & & $5.3 \%$ & & $2.7 \%$ \\
\hline Adjusted-R ${ }^{2}$ & & $4.2 \%$ & & $1.7 \%$ \\
\hline N & & 1317 & & 1317 \\
\hline
\end{tabular}

$* * *, * *$ and $*$ indicate statistical significance at the $1 \%, 5 \%$ and $10 \%$ levels, respectively; INDUSTRY includes all industries except for the Oil \& Gas and Metals \& Mining industries

\subsubsection{Logistic regression on headline impression management}

In the discussion of descriptive statistics on impression management strategies (Table 5.2) it was illustrated that headline impression management bias is calculated using Eq. 6 (defined in Chapter 4) which considers scores for thematic manipulation, repetition, and reinforcement. Since scores for thematic manipulation and reinforcement 
can also be negative, the overall headline impression management bias score can range between -1 and 1 . However, as shown in Table 5.2, there were very few cases of negative thematic manipulation (25) and negative reinforcement (2). Therefore, the average headline impression management bias was 0.96 while the vast majority of cases, where headline impression management was detected, equaled one. More precisely, the dependent variable (HEAD_B) in the headline impression management regression (Table 5.10) included mostly cases with either no impression management ( 0 values) or with impression management (1 values). Values that ranged either between -1 and 1 , not including 0 or 1, were documented only in 26 cases. Kuhn and Johnson (2013) argue that the lack of unique numbers in a variable may lead to problematic outcomes in an OLS regression. Therefore, this study also considers logistic regression by reclassifying values that are not equal to either one or zero.

Table 5.18. Firm performance on headline impression management (Logistic regression)

\begin{tabular}{|l|c|c|}
\cline { 2 - 3 } \multicolumn{1}{c|}{} & \multicolumn{2}{c|}{ HEAD_B } \\
\cline { 2 - 3 } \multicolumn{1}{c|}{} & $\beta j$ & Z-stat \\
\hline$\Delta$ OI & 0.19 & $1.68^{*}$ \\
\hline POS_EAR & 1.45 & $2.16^{* *}$ \\
\hline lnMV & 0.38 & $5.40 * * *$ \\
\hline BTM & 0.25 & $4.64 * * *$ \\
\hline M_RET & -0.04 & -0.13 \\
\hline IND_AS & 2.76 & $9.90^{* * *}$ \\
\hline IND_Bio & 1.95 & $6.52 * * *$ \\
\hline IND_C_BS & 1.62 & $5.74 * * *$ \\
\hline IND_CE & 1.89 & $6.47 * * *$ \\
\hline IND_IP_M & 2.19 & $7.94 * * *$ \\
\hline IND_M_M & 0.27 & 0.96 \\
\hline IND_OTHER & 2.51 & $8.09 * * *$ \\
\hline \multicolumn{2}{|l}{} & \\
\hline R & & $21.3 \%$ \\
\hline Adjusted-R & & $19.8 \%$ \\
\hline N & & 1317 \\
\hline$* * * * *$ and * indicate statistical significance at the $1 \%, 5 \%$ and $10 \%$ levels, respectively;
\end{tabular}


The reclassification is performed by coding a score that is above or equal to 0.5 as 1 , and 0 otherwise. Table 5.18 displays the results of a logistic regression which replicates headline impression management OLS regression. The logistic regression is based on Eq. 10 in Chapter 4. The results indicate no considerable difference in either the significance of the predictors or the sign of coefficients. This confirms that the overall findings regarding the impact of firm performance and control variables on headline impression management are similar in both regression types.

\subsubsection{Delayed stock market response}

Based on the findings of previous literature (Table 2.5) on stock market reaction to apparent impression management, this study tested the short-term impact of impression management strategies. As Table 5.11 showed, abnormal tone (positive association) and headline impression management (negative association) are significantly associated with three-day CAR. Moreover, firm performance ( $\triangle \mathrm{OI})$, positive earnings (POS_EAR), book-to-market (BTM), and some industry groups (IND_AS, IND_Bio, IND_C_BS) also impact the dependent variable. It is of interest whether these results hold in longer windows. Therefore, this section tests the $(+2,+31)$ and $(+2,+61)$ windows for CAR in the following two equations.

$$
\begin{aligned}
& \text { CAR }[+2,+31]_{i, q, t}=\alpha+\beta_{0} \mathrm{AB}_{-} \mathrm{TONE}_{i, q, t}+\beta_{1} \mathrm{READ}_{i, q, t}+\beta_{2} \mathrm{CAUS}_{-} \mathrm{R}_{i, q, t}+\beta_{3} \mathrm{HEAD}_{-} \mathrm{B}_{i, q, t}+ \\
& \beta_{4} \Delta \mathrm{OI}_{i, q, t}+\beta_{5} \mathrm{POS}_{-} \mathrm{EAR}_{i, q, t}+\beta_{6} \operatorname{lnMV}_{i, q, t}+\beta_{7} \mathrm{BTM}_{i, q, t}+\beta_{8} \mathrm{M}_{-} \mathrm{RET}_{i, q, t}+\beta_{9} \mathrm{IND}_{i, q, t}+\beta_{10} \mathrm{SPREAD}_{i, q, t}+ \\
& \varepsilon_{i, q, t}
\end{aligned}
$$


$\operatorname{CAR}[+2,+61]_{i, q, t}=\alpha+\beta_{0} \mathrm{AB}_{-} \mathrm{TONE}_{i, q, t}+\beta_{1} \mathrm{READ}_{i, q, t}+\beta_{2} \mathrm{CAUS}_{-} \mathrm{R}_{i, q, t}+\beta_{3} \mathrm{HEAD}_{-} \mathrm{B}_{i, q, t}+$ $\beta_{4} \Delta \mathrm{OI}_{i, q, t}+\beta_{5} \mathrm{POS}_{-} \mathrm{EAR}_{i, q, t}+\beta_{6} \operatorname{InMV}_{i, q, t}+\beta_{7} \mathrm{BTM}_{i, q, t}+\beta_{8} \mathrm{M}_{-} \mathrm{RET}_{i, q, t}+\beta_{9} \mathrm{IND}_{i, q, t}+\beta_{10} \operatorname{SPREAD}_{i, q, t}+$ $\varepsilon_{i, q, t}$

where:

$\operatorname{CAR}[+2,+31]=30$-trading-day cumulative stock returns starting the second day after the issue of EPRs;

$\operatorname{CAR}[+2,+61]=60$-trading-day cumulative stock returns starting the second day after the issue of EPRs;

Other variables are as defined in Eq. 2 and Eq. 11.

Table 5.19 presents regression results for 30-day and 60-day CARs. For impression management strategies, 30-day CAR shows no real change in the coefficients of impression management strategies. However, it appears abnormal tone is not associated with 30-day CAR. Moreover, headline impression management is now only statistically significant at the $10 \%$ level. These results suggest that the effect of these two impression management strategies weakens in the longer term (30 days). Other notable results in the 30-day CAR regression include a stronger impact of firm size (lnMV), market returns (M_RET), firm performance $(\Delta \mathrm{OI})$ and weaker book-to-market (BTM) and industry impacts. The results of 60-day CAR regression indicate that, among the four impression management strategies, only abnormal tone has statistically significant (at the $10 \%$ level) association with CAR in the 60 days starting the second day after the issue of EPRs. The negative impact of abnormal tone suggests that delayed market response reverses the effect of tone management. Also, the effect of market returns, firm size, and firm performance is stronger than in the three-day CAR regression. Overall, the results 
from the 30-day and 60-day CAR regressions suggest that the effect of impression management dissipates over time, while the effects of overall market returns and firm fundamentals such as firm size and firm performance start to prevail.

Table 5.19. Impression management strategies on longer-term CAR

\begin{tabular}{|c|c|c|c|c|}
\hline & \multicolumn{2}{|c|}{ 30-day CAR } & \multicolumn{2}{|c|}{ 60-day CAR } \\
\hline & $\beta \mathrm{j}$ & t-stat & $\beta \mathrm{j}$ & t-stat \\
\hline AB TONE & 0.0020 & 0.76 & -0.0038 & $-1.66^{*}$ \\
\hline READ & -0.0010 & -0.47 & -0.0006 & -0.21 \\
\hline CAUS_R & -0.0003 & -0.39 & -0.0003 & -0.62 \\
\hline HEAD_B & 0.0180 & $1.73 *$ & -0.0013 & -0.72 \\
\hline$\Delta \mathrm{OI}$ & 0.0790 & $2.50 * *$ & 0.0890 & $2.13 * *$ \\
\hline POS_EAR & 0.0940 & $6.23^{* * *}$ & 0.0370 & $2.37 * *$ \\
\hline $\ln \mathrm{MV}$ & -0.0160 & $-2.43 * *$ & -0.0030 & $-3.37 * * *$ \\
\hline BTM & 0.0035 & 0.73 & -0.0062 & -0.34 \\
\hline M_RET & 0.056 & $1.82 *$ & 0.0139 & $3.44 * * *$ \\
\hline SPREAD & 0.0041 & 0.06 & -0.0560 & -0.64 \\
\hline IND_AS & -0.034 & $-1.79 *$ & -0.0500 & $-1.69 *$ \\
\hline IND_Bio & -0.010 & $-1.68 *$ & -0.0310 & -0.84 \\
\hline IND_C_BS & 0.001 & 0.38 & -0.0600 & $-1.74 *$ \\
\hline IND_CE & -0.002 & -0.05 & -0.0026 & -0.07 \\
\hline IND_IP_M & -0.016 & -0.64 & -0.0460 & -1.36 \\
\hline IND_M_M & -0.074 & -0.32 & 0.0004 & 0.01 \\
\hline IND_OTHER & -0.043 & -1.57 & -0.0680 & $-1.86^{*}$ \\
\hline $\mathrm{R}^{2}$ & & $6.0 \%$ & & $4.1 \%$ \\
\hline Adjusted-R ${ }^{2}$ & & $4.8 \%$ & & $2.9 \%$ \\
\hline 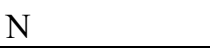 & & 1317 & & 1317 \\
\hline
\end{tabular}

\subsubsection{Delayed online discussion board volume reaction}

The effects of impression management strategies on abnormal discussion volume was examined in Section 5.2.2 and results were presented in Table 5.12. While those results show 3-day impacts of impression management strategies around the issuance of 
EPRs, it is worthwhile to examine longer term impacts. Therefore, to examine the 60-day impact of impression management strategies, the following regression is estimated:

$$
\begin{aligned}
& \text { AB_DVOL[+2, }+61]_{i, q, t}=\alpha+\beta_{0} \text { AB_TONE }_{\mathrm{i}, \mathrm{q}, \mathrm{t}}+\beta_{1} \mathrm{READ}_{\mathrm{i}, \mathrm{q}, \mathrm{t}}+\beta_{2} \mathrm{CAUS}_{-} \mathrm{R}_{\mathrm{i}, \mathrm{q}, \mathrm{t}}+ \\
& \beta_{3} \text { HEAD_B }_{\mathrm{i}, \mathrm{q}, \mathrm{t}}+\beta_{4} \Delta \mathrm{OI}_{\mathrm{i}, \mathrm{q}, \mathrm{t}}+\beta_{5} \operatorname{lnMV}_{\mathrm{i}, \mathrm{q}, \mathrm{t}}+\beta_{6} \mathrm{BTM}_{\mathrm{i}, \mathrm{q}, \mathrm{t}}+\beta_{7} \mathrm{M}_{-} \mathrm{RET}_{\mathrm{i}, \mathrm{q}, \mathrm{t}}+\beta_{8} \mathrm{IND}_{\mathrm{i}, \mathrm{q}, \mathrm{t}}+ \\
& \beta_{9} \text { WeekDay }+\varepsilon_{\mathrm{i}, \mathrm{q}, \mathrm{t}}
\end{aligned}
$$

where

AB_DVOL $[+2,+61]=60$-day abnormal discussion volume (measured as the average discussion volume for the 60 days following the second day after the EPR issue, minus the average discussion volume for three days surrounding the issue of EPR); Other variables are as defined in Eq. 2 and Eq. 11.

Table 5.20 results indicate that the longer-term effects of abnormal discussion volume (AB_DVOL) and headline impression management (HEAD_B) are lower than previously. Abnormal tone is no longer statistically significant, even at the $10 \%$ level, while headline impression management is only marginally significant at the $10 \%$ level. However, reading complexity is now statistically significant at the $10 \%$ level as it has a positive impact on 60-day abnormal discussion volume. In terms of the association for the control variables, the market returns (MRET) variable is now negatively related to the dependent variable and is more statistically significant (at the 5\% level). Industry groups show similar results to those in Table 5.12; however, they now show lower statistical significance in general. Overall, the main findings from the 60-day abnormal discussion volume regression results include diminishing effects of abnormal tone and headline impression management, as well as increasing effects of reading complexity over time. 
Table 5.20. Impression management strategies on 60-day abnormal discussion volume

\begin{tabular}{|l|c|c|}
\cline { 2 - 3 } \multicolumn{1}{c|}{} & \multicolumn{2}{c|}{ 60-day AB_DVOL } \\
\cline { 2 - 3 } \multicolumn{1}{c|}{} & $\beta j$ & t-stat \\
\hline AB_TONE & 0.062 & 1.25 \\
\hline READ & 0.073 & $1.80^{*}$ \\
\hline CAUS_R & 0.001 & 0.04 \\
\hline HEAD_B & 0.484 & $1.89^{*}$ \\
\hline AOI & 0.840 & 1.45 \\
\hline POS_EAR & 0.173 & 0.63 \\
\hline lnMV & -0.070 & -0.58 \\
\hline BTM & 0.073 & 0.81 \\
\hline M_RET & -1.273 & $-2.28^{* *}$ \\
\hline IND_AS & 0.062 & 0.13 \\
\hline IND_Bio & 0.411 & $1.72^{*}$ \\
\hline IND_C_BS & 0.251 & 0.52 \\
\hline IND_CE & 1.521 & $2.88^{* * *}$ \\
\hline IND_IP_M & 1.446 & $1.73^{*}$ \\
\hline IND_M_M & 0.235 & 0.54 \\
\hline IND_OTHER & 0.448 & 0.89 \\
\hline DOW_FRI & 0.354 & 0.99 \\
\hline DOW_MON & 0.145 & $1.81^{*}$ \\
\hline & & \\
\hline R & & $4.4 \%$ \\
\hline Adjusted-R ${ }^{2}$ & & $2.1 \%$ \\
\hline N & & 1317 \\
\hline
\end{tabular}

$* * *, * *$ and $*$ indicate statistical significance at the $1 \%, 5 \%$ and $10 \%$ levels, respectively;

\subsubsection{Online discussion views as an alternative to discussion volume}

As discussed in previous chapters, this study used discussion volume as the measure of user reaction in addition to discussion sentiment. Abnormal discussion volume (AB_DVOL) was obtained from the difference between the average discussion volume in the first 3 days after the issuance of an EPR and the average discussion volume in the 60 days preceding the issuance of the EPR (see Section 4.2.3). The regression results (Table 5.12) on the relationship between the impression management strategies 
and AB_DVOL indicate a statistically strong positive association (at the $1 \%$ level) for headline impression management and somewhat strong positive association (at the $10 \%$ level) for abnormal tone. Reading complexity and causal reasoning intensity were not found to be significant. This section examines whether these results change if discussion volume is replaced by discussion views (number of times each discussion post is viewed by online investment discussion board users).

\section{Figure 5.1. Abnormal Discussion Volume and Abnormal Discussion Views}

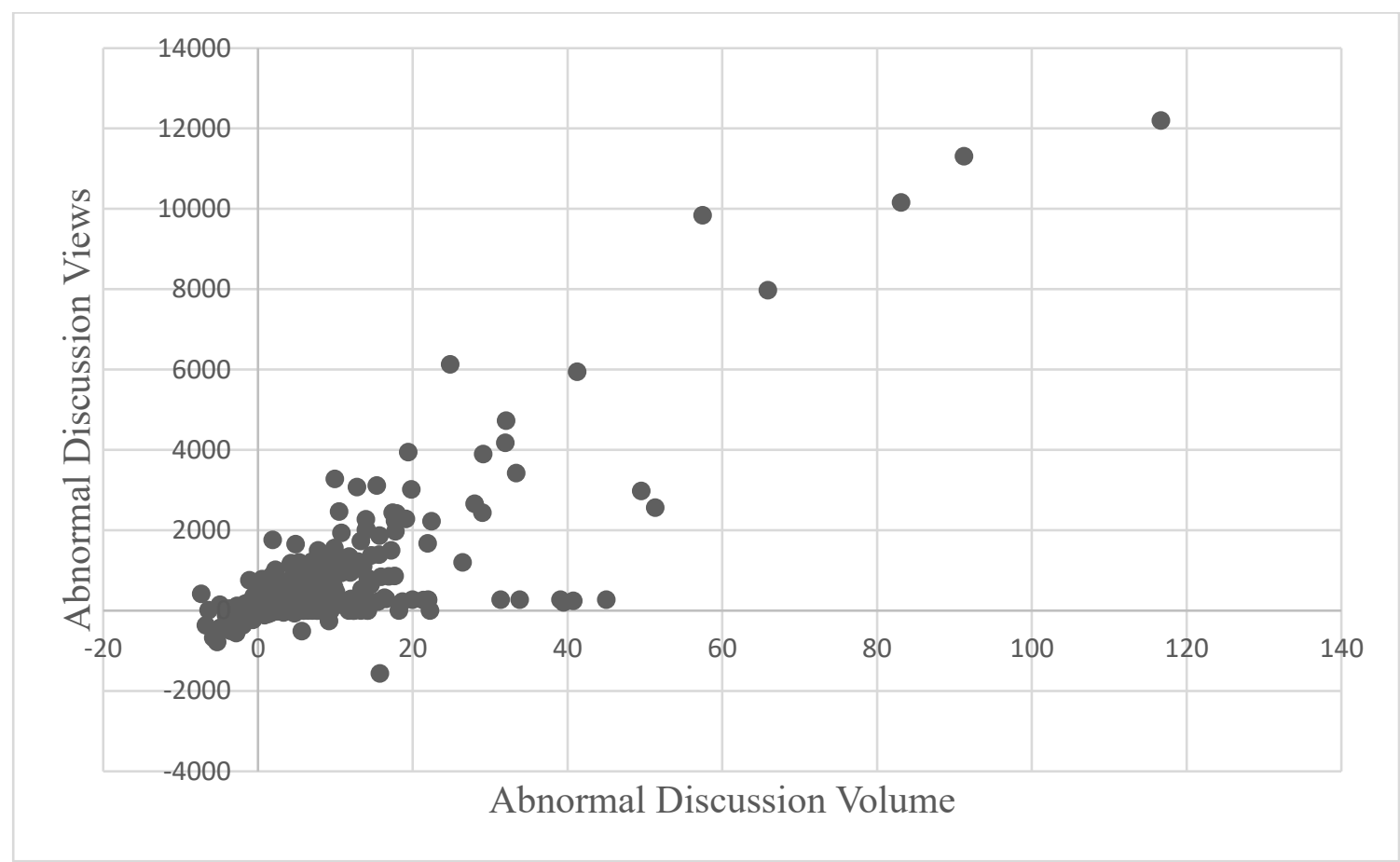

As Figure 5.1 displays, abnormal discussion views are generally higher for EPRs with higher abnormal discussion volume. In fact, the correlation coefficient between the two measures is 0.8246 confirming the strong relationship. Therefore, this section reestimates the abnormal discussion volume regression by using abnormal discussion view as the dependent variable. Similar to abnormal discussion volume, abnormal discussion views is obtained by subtracting the average number of discussion views in the 60 days 
preceding the issuance of an EPR from the average number of discussion views in the first 3 days after the issuance of the EPR.

Table 5.21. Impression management strategies on abnormal discussion views

\begin{tabular}{|l|c|c|}
\cline { 2 - 3 } \multicolumn{1}{c|}{} & \multicolumn{2}{c|}{ AB_DVIEW } \\
\cline { 2 - 3 } \multicolumn{1}{c|}{} & $\beta j$ & t-stat \\
\hline AB_TONE & 18.50 & $1.97^{* *}$ \\
\hline READ & 0.46 & 0.95 \\
\hline CAUS_R & 1.22 & 0.68 \\
\hline HEAD_B & 90.78 & $2.05^{* *}$ \\
\hline AOI & -36.61 & -0.33 \\
\hline POS_EAR & -26.06 & -0.49 \\
\hline lnMV & 71.54 & 3.14 \\
\hline BTM & -2.28 & -0.13 \\
\hline M_RET & 112.51 & 1.05 \\
\hline IND_AS & 66.49 & 0.75 \\
\hline IND_Bio & 204.50 & $2.13^{* *}$ \\
\hline IND_C_BS & 192.23 & $2.09^{* *}$ \\
\hline IND_CE & 612.29 & $6.17^{* * *}$ \\
\hline IND_IP_M & 72.16 & $1.81^{*}$ \\
\hline IND_M_M & -27.10 & -0.33 \\
\hline IND_OTHER & -10.60 & -0.11 \\
\hline DOW_FRI & 62.843 & 0.92 \\
\hline DOW_MON & 44.687 & $1.82^{*}$ \\
\hline & & \\
\hline R & & $6.5 \%$ \\
\hline Adjusted-R ${ }^{2}$ & & $5.2 \%$ \\
\hline N & & 1317 \\
\hline
\end{tabular}

$* * *, * *$ and $*$ indicate statistical significance at the $1 \%, 5 \%$ and $10 \%$ levels, respectively;

Table 5.21 shows the results of the abnormal discussion views regression.

Abnormal tone and headline impression management, now at the 5\% level, are still statistically significant, while readability and causal reasoning are still insignificant. The t-statistic for the market returns (M_RET) variable is now not enough to be included in the $10 \%$ significant level, as it was in the abnormal discussion volume regression. The 
positive earnings (POS_EAR) control variable is also insignificant now. The effects of industry groups on abnormal discussion views are similar to those observed in the abnormal discussion volume regression (Table 5.12). Overall, despite these two differences in the results of the control variables, abnormal discussion volume regression findings are confirmed by the results of the abnormal discussion views regression. This suggests that discussion views can be used as an alternative measure of online discussion board volume reaction.

\subsection{Multicollinearity checks}

To address any multicollinearity concerns variance inflation factors (VIFs) were calculated for each regression model and each predictor in the regression models. Appendix F shows VIF values for the models and the highest VIF value for predictors in each model. All VIF values for models are below 1.30, while the maximum VIF value for predictors in each regression is below 2.35. These values are well below the guidelines of less than 4 or 10, respectively (O'Brien, 2007). Therefore, no evidence of the presence of multicollinearity problems was found as all VIF values are within the acceptable range. 


\section{Chapter 6 - Discussion and Conclusion}

This chapter provides a discussion of the results presented in the preceding chapter and makes a conclusion for the overall study. The discussion section explains findings in reference to the formulated hypotheses, research propositions, and existing impression management literature. The conclusion section provides a summary of findings, recaps contributions, and identifies areas for future research.

\subsection{Discussion}

Regression results on the firm perspective on impression management were presented in Table 5.9 (tone and abnormal tone) and Table 5.10 (readability, causal reasoning, headline impression management bias). Section 5.2.5 included the analysis of association and significance of the relationship between firm performance and each impression management strategy. This analysis also illustrated how control variables were related to impression management strategies studied in this research. Next, in this section of this chapter, the focus will be on explaining the regression results by comparing them with findings in prior impression management literature.

\subsubsection{Findings on the firm perspective}

The main focus in the investigation of the firm perspective on impression management was on the relationship between firm performance and impression management strategies (tone management, readability manipulation, causal reasoning, headline impression management). Hypotheses 1-4 in Table 6.1 compare findings from regression with formulated hypotheses for the firm perspective on impression 
management. Findings for each of the studied impression management strategies are discussed below in detail.

\subsubsection{Abnormal tone}

As formulated in the first hypothesis (H1), the study investigated whether future firm performance explains abnormal tone expressed in EPRs. Since abnormal tone is derived from the tone equation (Eq. 2) by controlling for firm fundamentals, it is important to ensure that there is a positive relationship between current firm performance and tone. This is based on the premise that disclosure tone is generally positive when firms have positive performance. Regression results (left side of Table 5.9) confirmed that current firm performance has a significantly positive impact on EPR tone. These results are consistent with the extant literature on tone management (Smith and Taffler, 2000; Rutherford, 2005; Henry, 2008; Kothari et al., 2009; Loughran and McDonald, 2011; Davis and Tama-Sweet, 2012; Huang et al., 2014). Abnormal tone, that part of tone that cannot be explained by current firm performance, may exist because firms may be signaling about future performance (Smith and Taffer, 1992; Baginski et al., 2000; Rutherford, 2003; Matsumoto et al., 2006; Huang et al., 2014).

Therefore, impression management by manipulating tone would exist if future performance cannot explain abnormal tone. Hence, the first hypothesis (H1) which states no association between future firm performance and abnormal tone is rejected. The regression results show there is a moderate negative relationship (significant at 10\% level) between future firm performance and abnormal tone. This is an indication of impression management through tone management, because abnormally positive tone cannot be explained by future firm performance. 
There are other notable findings from the regression results of the control variables. Both the tone and abnormal tone regression results indicate that firm size has a significantly negative impact on tone and abnormal tone, respectively. These results are in line with the existing literature which finds that smaller firms are more likely to engage in impression management (Schipper, 1989; Baker and Kare, 1992; Wareld et al., 1995; Tama-Sweet, 2011). This study finds this relationship between impression management and firm size of smaller and larger TSX Venture firms exclusively in the context of lowvisibility firms. This is an important finding that extends our understanding of impression management in the context of low visibility firms. Regression results for industries confirm that there is no significant difference in abnormal tone between firms in the two natural resource industries (Metals \& Mining and Oil \& Gas), while firms in the Application Software, Communication Equipment, and the Industrial Products and Manufacturing industries express significantly more abnormal tone in their EPRs. One explanation for these differences in industry results may be that natural resource firms are more likely to deal with more precise estimates (e.g., barrels of oil, ounces of gold) than other industries, leaving less room for tone management. 
Table 6.1. Main findings for each hypothesis.

\begin{tabular}{|c|c|c|c|}
\hline Hypothesis & $\begin{array}{l}\text { Null } \\
\text { Hypothesis } \\
\text { Rejected? }\end{array}$ & Main Finding & Brief Interpretation \\
\hline $\begin{array}{l}\text { H1: Future firm performance is not } \\
\text { associated with abnormal tone in EPRs. }\end{array}$ & Yes & $\begin{array}{l}\text { There is a moderate negative } \\
\text { association between future firm } \\
\text { performance and abnormal tone. }\end{array}$ & $\begin{array}{l}\text { The lower future financial performance is, } \\
\text { the greater the abnormal tone. }\end{array}$ \\
\hline $\begin{array}{l}\text { H2: Firm performance is not associated } \\
\text { with the reading complexity of EPRs. }\end{array}$ & Yes & $\begin{array}{l}\text { There is a significantly negative } \\
\text { association between firm performance } \\
\text { and reading complexity. }\end{array}$ & $\begin{array}{l}\text { The lower financial performance is, the more } \\
\text { difficult the EPR is to read. }\end{array}$ \\
\hline $\begin{array}{l}\text { H3: Firm performance is not associated } \\
\text { with causal reasoning intensity. }\end{array}$ & Yes & $\begin{array}{l}\text { There is a significantly negative } \\
\text { association between firm performance } \\
\text { and causal reasoning. }\end{array}$ & $\begin{array}{l}\text { The lower financial performance is, the } \\
\text { greater is the use of causal reasoning } \\
\text { intensity. }\end{array}$ \\
\hline $\begin{array}{l}\text { H4: Firm performance is not associated } \\
\text { with impression management in the } \\
\text { headline of EPRs. }\end{array}$ & No & $\begin{array}{l}\text { There is a positive, but insignificant, } \\
\text { association between firm performance } \\
\text { and headline impression management. }\end{array}$ & $\begin{array}{l}\text { There is no significant relationship between } \\
\text { firm financial performance and headline } \\
\text { impression management. }\end{array}$ \\
\hline $\begin{array}{l}\text { H5: There is no association between } \\
\text { abnormal tone in EPRs and short-term } \\
\text { cumulative abnormal return. }\end{array}$ & Yes & $\begin{array}{l}\text { Abnormal tone has a significantly } \\
\text { positive impact on three-day } \\
\text { cumulative abnormal returns. }\end{array}$ & $\begin{array}{l}\text { The greater the abnormal tone is, the higher } \\
\text { three-day CAR. }\end{array}$ \\
\hline $\begin{array}{l}\text { H6: There is no association between } \\
\text { reading complexity of EPRs and short- } \\
\text { term cumulative abnormal return. }\end{array}$ & No & $\begin{array}{l}\text { The impact of reading complexity on } \\
\text { three-day cumulative abnormal } \\
\text { returns is negative but insignificant. }\end{array}$ & $\begin{array}{l}\text { There is no significant association between } \\
\text { reading complexity and three-day CAR. }\end{array}$ \\
\hline $\begin{array}{l}\text { H7: There is no association between } \\
\text { causal reasoning intensity and short-term } \\
\text { cumulative abnormal return. }\end{array}$ & No & $\begin{array}{l}\text { The impact of causal reasoning on } \\
\text { three-day cumulative abnormal } \\
\text { returns is negative but insignificant. }\end{array}$ & $\begin{array}{l}\text { There is no significant association between } \\
\text { causal reasoning intensity and three-day } \\
\text { CAR. }\end{array}$ \\
\hline $\begin{array}{l}\text { H8: There is no association between } \\
\text { headline impression management bias }\end{array}$ & Yes & $\begin{array}{l}\text { Headline impression management } \\
\text { bias has a significantly positive }\end{array}$ & $\begin{array}{l}\text { The greater headline impression management } \\
\text { is, the higher three-day CAR. }\end{array}$ \\
\hline
\end{tabular}




\begin{tabular}{|c|c|c|c|}
\hline Hypothesis & $\begin{array}{l}\text { Null } \\
\text { Hypothesis } \\
\text { Rejected? }\end{array}$ & Main Finding & Brief Interpretation \\
\hline $\begin{array}{l}\text { and short-term cumulative abnormal } \\
\text { return. }\end{array}$ & & $\begin{array}{l}\text { impact on three-day cumulative } \\
\text { abnormal returns. }\end{array}$ & \\
\hline $\begin{array}{l}\text { H9: There is no association between } \\
\text { impression management and online user } \\
\text { reaction, as measured by discussion } \\
\text { volume. }\end{array}$ & Yes & $\begin{array}{l}\text { Headline impression management } \\
\text { bias has a significantly positive } \\
\text { impact on three-day abnormal } \\
\text { discussion volume. Abnormal tone } \\
\text { has somewhat significant and positive } \\
\text { impact on three-day abnormal } \\
\text { discussion volume. }\end{array}$ & $\begin{array}{l}\text { The greater headline impression management } \\
\text { and the abnormal tone are, the more online } \\
\text { investment discussions within the three days } \\
\text { around the issuance of EPRs. }\end{array}$ \\
\hline $\begin{array}{l}\text { H10: There is no association between } \\
\text { impression management and online user } \\
\text { reaction, as measured by discussion } \\
\text { sentiment. }\end{array}$ & No & $\begin{array}{l}\text { None of the impression management } \\
\text { strategies has a significant impact on } \\
\text { three-day abnormal sentiment. }\end{array}$ & $\begin{array}{l}\text { Abnormal optimistic sentiment is not related } \\
\text { with the use of any impression management } \\
\text { strategies. }\end{array}$ \\
\hline
\end{tabular}




\subsubsection{Reading complexity}

The second hypothesis (H2) was designed to investigate the association between firm performance and EPR readability. More specifically, the purpose of this hypothesis was to determine whether there is a relationship between firm performance and the reading complexity of EPRs. Extant literature has found that poorly performing firms obfuscate performance by increasing the textual complexity of their disclosures. The results of the reading complexity regression (Table 5.10) confirm the findings of prior literature that investigate the relationship between firm performance and disclosure documents (Subramanian et al., 1993; Clatworthy and Jones, 2001; Rutherford, 2003; Courtis, 2004; Li, 2006; Richards, 2011). The results indicate firm performance has a significantly negative impact on the reading complexity of EPRs indicating that TSX Venture firms engage in readability manipulation such that the EPRs of firms with worse financial performance increase reading complexity.

Moreover, the significantly negative positive earnings variable is also in line with Henry (2008) who finds that profitable firms issue EPRs with better readability. The effects of firm performance and positive earnings are stronger for all industry groups compared to the reference group (the Oil \& Gas industry) suggesting that Oil \& Gas industry firms are least likely to manage the reading complexity of their EPRs based on performance. Consistent with the earlier discussion about natural resource industries, among all industry groups, the association between the Metals \& Mining industry and reading complexity is the closest to the Oil \& Gas industry. Similarities between the two natural resource industries may be explained by the concept of mimetic isomorphism. According to this concept, given the prevalence of a practice and behavior in an industry, 
firms try to adopt the practices of successful firms within the industry (Haveman, 1993). Therefore, since there are many ways of preparing EPRs, which are voluntary in nature, it is possible that many Metals \& Mining and Oil \& Gas firms are following successful firms within the overall natural resource industry.

Interestingly, the negative association between firm performance and reading complexity is stronger when the firm size is larger. This suggests that larger firms in the sample are more likely to engage in readability manipulation than smaller firms. This finding contradicts the results of the abnormal tone regression, which showed that smaller firms are more likely to engage in tone management. Unlike tone management, readability manipulation involves managing the syntactical complexity of disclosures (Clatworthy and Jones, 2001) and requires more time and care (Merkl-Davies and Brennan, 2007).

To prepare disclosures that communicate information using techniques of readability manipulation, firms usually hire professional outside agencies (Merkl-Davies and Brennan, 2007). Since it is not mandatory to employ outside professional agencies to prepare EPRs, it is possible that larger firms (typically with more financial resources) are more likely to do so, and thus more likely to manage reading complexity. Moreover, Courtis (2001) argues that larger and older firms are more likely to have established sophisticated information and communication systems and to employ specialized consultants to prepare their disclosures. The above points may serve as explanations for the positive association between firm size and reading complexity. This suggests firms' choices of various impression management strategies may be independent. 


\subsubsection{Causal reasoning intensity}

As discussed in the previous chapters, causal reasoning intensity is related to reading complexity. Therefore, hypothesis $3(\mathrm{H} 3)$ was formulated based on a similar reasoning to the hypothesis on reading complexity $(\mathrm{H} 2)$. Regression results from Table 5.10 indicate that, as expected, firm performance impacts causal reasoning in a manner similar to the way it affects reading complexity. Specifically, lower firm performance results in greater causal reasoning intensity. The strength of the relationship between firm performance is not as strong as it is for reading complexity (significant at the $1 \%$ level), but the relationship is still statistically significant at the 5\% level. Similarities can be observed about the positive earnings variable as well, which also has a significantly negative impact on casual reasoning. This indicates unprofitable firms are more likely to issue EPRs with greater causal reasoning intensity. Firm size, however, is not statistically significant, though it is positively related to causal reasoning, as expected. As for industries, EPRs by the Application Software, Communication Equipment, and Industrial Products \& Manufacturing industries exhibit more causal reasoning intensity than the Oil \& Gas industry, while the Metals \& Mining industry does not differ from the reference group significantly as expected. It may be that economic trends in global commodities markets such as for oil and gas and metals and mining products are thought to be sufficiently well known that less causal reasoning (at the firm level) is required.

\subsubsection{Headline impression management bias}

The study also tested the relationship between firm performance and headline impression management bias (H4), which includes such impression management strategies as thematic manipulation, emphasis by reinforcement, and repetition of 
performance figures (discussed in Chapter 4). The literature review chapter of this study discussed the findings of prior impression management studies which provide evidence that firms highlight the positive aspects of their performance by placing information in a prominent location in disclosures and repeating positive information (Kohut and Segars, 1992; Nelson and Pritchard 2007; Davison, 2008; Soobaroyen and Ntim 2013; Pesci et al., 2015). The investigation of headline impression management in this study follows Guillamon-Saorin et al. (2012) who examined thematic manipulation, repetition, and reinforcement practices in the EPRs of large Spanish firms. Their results show that only a very few EPRs include negative thematic manipulation (3 out of 82), and no EPRs included negative reinforcement ( 0 out of 70 ) and negative repetition ( 0 out of 35 ).

As displayed in Table 5.4, this study finds similar results in terms of numbers. Only 25 (out of 540) (4.6\%) EPRs included negative thematic manipulation, and only 2 (out of 214) EPRs had negative reinforcement, while 150 EPRs included repetition in their headlines with no negative repetition. In terms of the association between firm performance and headline impression management overall, Guillamon-Saorin et al. (2012) find a strong (at the 5\% level) positive association between the two. The present study also finds a positive association between firm performance and headline impression management, suggesting stronger performance leads to greater impression management in EPR headlines, however, the association is only marginally significant at the $10 \%$ level.

One of the major differences between Guillamon-Saorin et al. (2012) and this study is in the use of net earnings as a key performance figure in Guillamon-Saorin et al. (2012) as opposed to operating income in this study. Operating income will generally be 
greater than net earnings as interest and taxes will not be deducted in determining operating income. As discussed in previous chapters, the main reason for using operating income is that TSX Venture Exchange companies are small, emerging companies most of which have not achieved profitability. Therefore, the finding on the association of firm performance and headline impression management is not as strong as those of Guillamon-Saorin et al. (2012) perhaps because most companies use net earnings more than operating income change to emphasize positive news, since operating income tends to be more stable than net earnings. Nevertheless, for the most part, this study provides evidence which supports the results of Guillamon-Saorin et al. (2012).

\subsubsection{Findings on the investor perspective}

The investor perspective on impression management investigated stock market and online investment discussion board reactions to impression management measures defined in Chapter 4. Hypotheses H5-H8 tested the stock market reaction, while hypotheses $\mathrm{H} 9 \mathrm{H} 10$ explored the online investment discussion board reaction. The following subsections discuss the findings for these hypotheses.

\subsubsection{Stock market reaction}

Hypothesis 5 was formulated to examine the effect of abnormal tone on three-day CAR. Regression results in Table 5.11 indicate that abnormal tone in EPRs is positively associated with cumulative abnormal return (significant at the $1 \%$ level), rejecting the null hypothesis. In other words, greater abnormal tone is associated with increased CAR. This association is consistent with prior impression management research that finds positive short-term market reaction to tone and abnormal tone in disclosure documents (Henry, 2008; Feldman et al., 2010; Davis and Tama-Sweet, 2012; Huang et al., 2014; 
Arslan-Ayaydin et al., 2016). It confirms the expectation that investors respond favorably to inflated tone in EPRs over a short (three-day) horizon. As expected, the impact of abnormal tone on three-day CAR is even stronger for improved firm performance $(\Delta \mathrm{OI})$ and positive earnings. Moreover, statistically significant and positive book-to-market (BTM) is consistent with prior literature (Porta et al., 1997; Huang et al., 2014; ArslanAyaydin et al., 2016) suggesting that market surprise is greater for higher book-to-market firms than lower book-to-market firms. Most industry groups (IND_AS, IND_Bio, IND_C_BS) have significantly negative associations with short-term market reaction, compared to the reference group. Results of re-estimated regressions (Table 5.16) with only two industry groupings, natural resource industries (Oil \& Gas and Metals \& Mining industries) and other industries, confirm the finding that other industries experience more negative three-day CAR than the natural resource industries. This suggests that when natural resource firms do engage in impression management, there is a greater CAR.

Previous studies also examine longer-term market reaction to abnormal tone and find that the positive short window effect either reverses or disappears (Huang et al., 2014; Arslan-Ayaydin et al., 2016). Arslan-Ayaydin et al. (2016) test a 60-day window and find no significant association between abnormal tone and CAR. Huang et al. (2014) test both 60-day and 120-day windows and report statistically significant negative associations between abnormal tone and CAR. Therefore, this study tested the longerterm impact of abnormal tone in Section 5.3.3 to examine whether the effect holds or reverses in the longer run. The results in Table 5.19 show that abnormal tone does not explain 30-day CAR starting the second day after the issue of EPRs. The results also indicate that there is a negative association (at the 10\% level) in the 60 days starting the 
second day after the issue of EPRs. These findings are consistent with Huang et al. (2014) and Arslan-Ayaydin et al. (2016), confirming that longer term market response to tone management reverses or becomes insignificant. This suggests investors have a comparatively short window of opportunity for gains should they seek to maximize their market returns through following an investment strategy based upon identifying and reacting to abnormal tone in EPRs.

Table 5.11 also displays results for reading complexity (H6) and causal reasoning intensity (H7), two related impression management strategies. As discussed in the previous chapters, existing literature on disclosure readability finds a positive relationship between the reading ease of disclosure documents and stock trading volume (You and Zhang, 2009; Lawrence, 2013; Asay et al., 2016). However, the present study offers no conclusive evidence on the predictive power of readability or verbal complexity of disclosure documents. Results indicate that neither readability nor causal reasoning intensity impression management strategies were found to impact three-day CAR significantly. Results for 30-day and 60-day CAR regressions (Table 5.19) also show insignificant results for these impression management strategies. These findings are consistent with Henry (2008) who finds that reading complexity does not affect market returns.

CAR regressions (three-day, 30-day, and 60-day) also included headline impression management which consists of thematic manipulation, reinforcement, and repetition (H8). Headline impression management was found to have a statistically significant (significant at the $1 \%$ level) impact on three-day CAR, such that greater headline impression management bias results in greater CAR. The null hypothesis on the 
relationship between headline impression management and short-term CAR was formulated to explore whether or notfirms emphasize positive performance. The results indicate that firms can influence short-term market reaction around the issuance of EPRs by highlighting positive performance through thematic manipulation, reinforcement and repetition strategies in their EPR headlines. Positive stock market reaction to headline impression management still holds in the 30-CAR as shown in Table 5.19, but the strength (at the $10 \%$ level) of the association is only marginally significant.

This result is contrary to the abnormal tone result (see Table 5.19) which suggested a reversing effect of tone management. Perhaps, the persistent, though weaker, impact of headline impression management on CAR may be explained by the difference in what the two impression management strategies measure. Headline impression management is based on emphasizing strong firm performance while abnormal tone is based on masking poor performance by manipulating tone. More precisely, as shown in Table 5.9, abnormal tone in EPRs is higher when future performance or current earnings are negative, while headline impression management is higher when current firm performance or earnings are positive, as shown in Table 5.10.

Table 5.19 shows that the effect of headline impression management becomes insignificant in the 60-day CAR regression. This result suggests a disappearing stock market reaction to headline impression management in the longer run. Overall, these results indicate that the market views repetition, reinforcement, and thematic manipulation in the headline portion of an EPR very positively around the issue of earnings press releases. However, this positive reaction subsides within a month, and completely disappears within 60 days of the EPR issue. 


\subsubsection{Online discussion volume and sentiment reaction}

To understand how online investment discussion board reacts to impression management in EPRs this study formulated hypotheses H9 and H10. The purpose of testing H9 was to explore whether impression management strategies are related to the volume of online posts as measured by abnormal discussion volume. Chapter 5 includes the results for both short-term (Table 5.12) and longer-term (Table 5.20) abnormal discussion volumes. For the short-term abnormal discussion volume response, the threeday abnormal discussion volume results show headline impression management (significant) and abnormal tone (somewhat significant) are associated with abnormal discussion volume around the issuance of EPRs. These results may indicate that online discussion board participants pay more attention to the headlines of EPRs, rather than reading or analyzing the body portion of EPR. These two impression management strategies were also found to significantly affect online discussion board participants' reactions when abnormal discussion volume was replaced by abnormal discussion views as the dependent variable in Section 5.3.5. These findings are consistent with the market response results suggesting that online investment board participants are affected by tone management and headline impression management strategies to investors, at least in the short term.

Neither readability nor causal reasoning intensity was found to significantly influence 3-day abnormal discussion volume. Prior readability literature suggests that reading complexity negatively impacts short-term trading volume (You and Zhang, 2009; Lawrence, 2013; Asay et al., 2016). Therefore, for abnormal discussion volume, it was somewhat expected that online participants would discuss EPRs with higher reading 
complexity or higher causal reasoning intensity. However, although both variables are negatively associated with abnormal discussion volume around the issue of EPRs, they are not significant.

An interesting finding from the control variables is that firms with negative earnings are discussed more than firms with positive earnings around the issue of EPRs. This is in line with Lerman (2017) who suggests that for good performers online discussion board participants are mainly interested in discussing the good earningsrelated news, while for bad performers, participants also discuss other non-earningsrelated news. Moreover, prior literature finds evidence that investors spend more effort on information acquisition and processing when faced with negative surprises (Francis and Schipper 1999; Hope 2003).

The results of the 60-day abnormal discussion volume regression generate a few additional findings for the longer-term impact of impression management strategies on investment discussion board volume reaction. Reading complexity in the longer window is now positive and significant, suggesting that online participants are now taking the time to discuss harder-to-read EPRs, which they may have initially avoided around the issue of EPRs. Also, the effects of abnormal tone and headline impression management are weaker in the longer-term. This suggests that EPRs with higher abnormal tone and catchy headlines, which initially drew strong attention from investment board participants, now do not receive as much attention. Notable differences (between the three-day and 60-day abnormal discussion board regressions) for the control variables include change in the sign of the market returns variable and an insignificant positive earnings variable. The negative market returns control variable indicates that abnormal 
discussion volume is generally higher when market returns are lower, suggesting that discussion board participants are posting more due to being nervous or else seeking buying opportunities. Also, the positive earnings variable loses significance over time, probably because it is not an important factor in participants' conversations anymore.

Results for industry groups show that discussion boards for the Biotechnology, Communication Equipment, Industrial Products \& Manufacturing industries (for both the three-day and 60-day abnormal discussion volume), and the Consumer \& Business Services industry (for three-day abnormal volume) contain more discussion than other industries. In general, compared to firms in natural resource industries (Oil \& Gas and Metals \& Mining industry) firms in other industries are discussed more, as confirmed by the results in Table 5.17.

H10 was designed to explore how online discussion sentiment (the use of more optimistic or positive words) responds to impression management strategies in EPRs. Results from Table 5.13 show that none of the impression management strategies has a significant impact on abnormal discussion sentiment around the issuance of EPRs. Although headline impression management is positively associated with abnormal discussion sentiment and has the highest level of significance among the impression management strategies, the impression management strategy is not statistically significant. It is, however, statistically significant when industries are classified in two groups (see Table 5.17). Therefore, headline impression management leads to a higher level of online discussion sentiment (optimistic or positive comments) for firms that are not in natural resource industries. 
Low model strength (as measured by $\mathrm{R}^{2}$ ) and mostly insignificant predictors reveal two possible explanations. First, it is possible that abnormal discussion sentiment cannot be conclusively explained by impression management in EPRs. Perhaps online discussion board participants do not sufficiently carefully examine the content of EPRs to be able to react to abnormal tone, readability, and causal intensity clues. This may also explain why headline impression management is the most statistically significant among the impression management strategies. Moreover, the link between impression management and discussion sentiment has not been studied in previous literature, as most prior literature investigated the predictive power of discussion sentiment for stock market activity. Therefore, testing for this association was exploratory in nature in this study.

Second, low model significance and mostly insignificant predictors for the abnormal discussion sentiment regression may be due to the inability of the dependent variable to reliably capture tone in discussions. Although, this study uses an extensive list of words based on three dictionaries (Henry (2008) and Loughran and McDonald (2011) dictionaries, supplemented by DICTION's optimism-increasing and optimism-decreasing word lists), they may not be suited to capture online discussion sentiment to the full extent. Morville (2005) argues that online discussion board messages are highly ambiguous and can be difficult to correctly classify based on word counts. Das and Chen (2007) test the accuracy of buy, hold, and sell recommendation classifications based on standard dictionaries. They find that standard dictionaries correctly classify the average sentiment for each recommendation type, however they also report quite a large standard deviation, indicating high ambiguity of online messages. To address this ambiguity problem, in a recent study, Renault (2017) constructed a lexicon of words used by online 
investors to measure the sentiment of online discussions. He finds that the specifically designed lexicon outperforms standard dictionary-based methods. Therefore, it is possible that the abnormal discussion sentiment model in this study can be improved by using a lexicon that is specifically designed for the audience of online investment discussion board participants.

\subsection{Conclusion}

\subsubsection{Summary}

The overarching objective of this study has been to understand whether, and how, TSX Venture firms engage in impression management and how investors react to such engagement in impression management. This broad goal, which connects several areas of research while exploring impression management in the context of low-visibility firms, represented the primary unique contribution of the study. The study is also unique in that it covers multiple impression management strategies to investigate both the firm and the investor perspectives in the context of low-visibility firms. It is also a pioneering study that complements findings regarding stock market reaction to apparent impression management with insights from online investment discussion board reaction. Therefore, findings of this research shed light into areas of the impression management literature that have either lacked research or never been studied before.

\subsubsection{Firm perspective}

On the firm perspective, to determine the usage of impression management, the associations between firm performance and impression management strategies were examined. The findings reveal that TSX Venture firms engage in all studied impression management strategies to some extent. Regression results indicate that firms manage 
reading complexity and causal reasoning intensity of EPRs based on firm performance. Firms also manage EPR tone by inflating it so much that it cannot be explained by future financial performance. Moreover, the headline impression management results indicate that firms highlight positive performance by thematically manipulating topics, reinforcing performance, and repeating performance figures in EPR headlines. These results collectively confirm that low-visibility firms engage in impression management in their voluntary disclosures. Engagement in impression management strategies is significantly stronger for firms that are not in natural resource industries.

The results of additional checks within industry groupings showed that the Oil \& Gas and Metals \& Mining industries are similar to each other, and differ significantly from other industries. Another finding on the firm perspective is that there is a higher level of tone management by smaller firms in the sample. This is consistent with prior literature that smaller firms are more likely to engage in impression management (Schipper, 1989; Baker and Kare, 1992; Wareld et al., 1995; Tama-Sweet, 2011). However, reading complexity and headline impression management results show contradictory results as these two impression management strategies are more significant when firms are larger.

Unlike tone management, readability manipulation involves managing syntactical complexity of disclosures (Clatworthy and Jones, 2001) and requires more time and care (Merkl-Davies and Brennan, 2007). To prepare disclosures that communicate information by employing proper techniques of readability manipulation, firms usually hire professional outside agencies (Merkl-Davies and Brennan, 2007). Since it is not mandatory to employ outside professional agencies to prepare EPRs, it is possible that 
larger firms with more financial resources are more likely to do so. Moreover, Courtis (2001) argues that larger and older firms are more likely to have established sophisticated information and communication systems and to employ specialized consultants to prepare their disclosures. Perhaps, higher headline impression management can also be explained by higher likelihood of using professional agencies, whose experience is used to emphasize positive performance, by larger firms.

\subsubsection{Investor perspective}

The investor perspective investigated how stock market and online discussion board participants react to impression management. For stock market reaction the impact of the studied impression management strategies on CAR was examined. Results confirm the expectations that investors favorably respond to abnormal tone around the issuance of EPRs. However, this impact of abnormal tone dissipates in the 30-day window and becomes negative in the 60-day window. These findings are in line with prior literature on the effect of tone on CAR (Huang et al., 2014; Arslan-Ayaydin et al., 2016). Similar findings are generated for the impact of headline impression management. In particular, investors are positively influenced by thematic manipulation, reinforcement, and repetition strategies in EPR headlines, however this impact is not as significant in the 30day window and insignificant in the 60-day window.

Reading complexity and causal reasoning intensity were not found to explain either short-term, or longer-term, CAR. These results are consistent with Henry (2008) who also found no impact of verbal complexity on stock market returns. Notable findings from the effects of control variables include significant associations for book-to-market and industry variables. Consistent with prior literature (Porta et al., 1997; Huang et al., 
2014; Arslan-Ayaydin et al., 2016), the impact of impression management on the shortterm CAR is greater for higher book-to-market firms, suggesting that market surprise is more positive when higher book-to-market firms engage in impression management. The industry results show firms that are not in natural resource industries experience lower CAR both around the issuance of EPRs and in the longer periods (30-day and 60-day windows).

As more direct measures of retail investor reaction, online investment board discussion volume and sentiment were also studied in response to impression management strategies. Headline impression management was found to be the single most significant predictor of abnormal discussion volume around the issue of EPRs. This finding suggests that investment discussion board participants may be 'lazy' investors who are drawn by impression management in EPR headlines and pay little or no attention to the content of EPRs. Abnormal tone was also found to positively impact discussion volume to some extent; however, this impact is not as significant as headline impression management. These findings remained mostly unchanged when their robustness was checked by replacing discussion volume with the number of views (for each EPR) in the regressions. Therefore, headline impression management bias and abnormal tone explain greater volume of discussions or views in the short-term.

For control variables, results indicate that EPRs of firms with negative earnings experience significantly higher discussion volume than positive earnings firms around the issue of EPRs. This finding is consistent with Lerman (2017) who finds that, for good performers, online discussion board participants are mainly interested in discussing the good earnings-related news, while for bad performers, participants also discuss other 
non-earnings-related news. These results, however, were largely different in the longerterm. In particular, in the 60-day window, headline impression management bias becomes less significant (but still marginally significant at the 10\% level) and abnormal tone becomes insignificant, while reading complexity becomes significant. These results suggest that in the longer-term online participants may dedicate more time to discuss harder-to-read EPRs which they initially avoided around the issuance of EPRs. These results also indicate that 60-day window discussion volume is higher when market returns are lower, suggesting that discussion board participants may be posting more due to being nervous or else seeking buying opportunities.

This study also explored the association between impression management strategies and online discussion sentiment. Overall it was found that none of the impression management strategies significantly explain online discussion sentiment. It is possible that, as suggested earlier, online discussion participants are 'lazy' investors who do not read through EPRs, making it difficult to estimate associations between their sentiment and impression management strategies. Another possible explanation may point to a limitation of this study in terms of measuring the sentiment in online discussion boards. Although this study uses extensive word lists based on three dictionaries, these lists may not be suited to fully capture the sentiment of online discussions due to the highly ambiguous nature these discussions (Morville, 2005; Das \& Chen, 2007; Renault, 2017). Therefore, perhaps, using a dictionary that is specifically designed to measure sentiment in online discussion boards can yield better results. 


\subsubsection{Contributions}

This study contributes to the literature on voluntary disclosures, impression management, firm visibility, and online investment discussion board usage. By studying several impression management strategies simultaneously, the study offers a breadth of knowledge on how firm engage in various impression management practices in EPRs. Since there has been no study that studied impression management and its consequences specifically in the context of low-visibility firms, the findings of this research also contribute to the understanding of low-visibility firms.

Another contribution of this study is the investigation of both the firm and the investor perspectives. This allows for effective examination of investor reaction to apparent impression management strategies by keeping the underlying sample unchanged for both perspectives. Finally, the usage of online discussion boards as a direct measure of investor reaction is also a novel idea in the impression management literature. Findings from volume and sentiment reaction to apparent impression management can be valuable in understanding impression management consequences overall. Moreover, it may be of use for bridging the gap between impression management and stock market reaction.

The contributions of this study also include methodological findings in terms of research approach. One such contribution is the finding that there is a clear distinction between the impression management practices of the natural resource industries (Oil \& Gas and Metals \& Mining) and all other industries. This finding can help future research with grouping industries into the two distinctive categories or focusing on the impression management practices of distinct industries. Another methodological finding that can benefit future research is regarding the collection of EPRs. As described in Chapter 4, 
this study explored the options of collecting EPRs from multiple sources including corporate websites, GlobeNewswire, and SEDAR. The search results revealed that SEDAR is the most complete source for the EPRs of TSX Venture Exchange firms. Future research should obtain EPRs from SEDAR without having to explore other options.

Finally, computer-assisted content analysis methods to analyze the content of both EPRs and online discussions also contribute to existing literature from the point of the method of analysis. The contribution is the use of a Python script to perform textual data mining and content classification of EPRs and online posts. For example, the process of determining the headline and the body of EPRs, as well as obtaining processed narrative content, can benefit future studies. Moreover, the computerized process of constructing headline impression management bias scores (thematic manipulation, reinforcement, and repetition) can also be of great use for future research when manual content analysis is not feasible.

\subsubsection{Limitations}

There are several limitations of this study. First, there might be certain methodological limitations arising from the sampling design and the choice of performance measure. In the final sample, this study only considered firms which issued three or more EPRs throughout the study period. This introduces a selection bias to the study as the results may not be applicable to the general population of low-visibility firms. Since the non-issuers and non-frequent issuers of EPRs comprise a significant portion of the initial sample, addressing this selection bias requires additional attention that needs to be considered in the sampling design. Second, this study used 'change in 
operating income' as a performance measure to investigate firms' use of impression management strategies. However, despite being widely used in impression management literature, earnings or operating income may not be applicable to certain firms. For example, junior mining companies in the natural resource industries may be more interested in managing the impressions of investors around exploration operations. Therefore, it would be less appropriate to measure the performance of junior miners based on income statement items than other operational measures (i.e., successful drilling programs).

Due to restrictions on obtaining Stockhouse data prior to January 1, 2016, the study period was constrained to be 30 months from January 1, 2016 to July 1, 2018. Increasing this timeframe would probably generate more robust findings on impression management practices of firms. For example, it would allow for more efficient tests of systematic differences, if any, between non-issuers, non-frequent issuers, and frequent issuers of EPRs. Any identifiable differences can be modeled for by including variables that account for the characteristics of non-EPR issuing and EPR-issuing firms. More longitudinal data can also increase the reliability of findings on the investor perspective as more data would help better determine investor reaction, specifically in response to impression management.

There is a possibility that high reading complexity and causal reasoning intensity are not deliberate and may be due to bad writing (Baker and Kare, 1992). Merkl-Davies and Brennan (2007) argue that lack of skill is an unlikely explanation because (1) corporate disclosures are probably written by professional agencies and (2) firms try to avoid the adverse effects (e.g., reputation loss) of badly written disclosures. Nevertheless, 
since this study examines voluntary disclosures of small and emerging firms, which have smaller financial resources than larger firms, it is possible that reading complexity and causal reasoning intensity may be unintentional. This limitation could probably be addressed to some extent by controlling for additional firm factors when measuring reading complexity or causal reasoning intensity. For example, scaling reading complexity score of a firm's EPR by the average reading complexity for that firm's EPRs might yield better results. However, such a method performs better with more longitudinal data, which points to another limitation of this study.

\subsubsection{Implications}

The findings of this study have implications for regulators, investors, firms, and academics. Regulators may want to review or set rules around the presentation of performance results in EPRs and EPR headlines or educate investors on the consequence of impression management by low-visibility firms. For example, findings indicate that firms manage tone and manipulate readability in their EPRs, while investors show positive short-term reaction which subsides or reverses in the longer term. Equipped with this knowledge, financial regulators such as the OSC or the Investment Industry Regulatory Organization of Canada (IIROC) may find it necessary to prepare educational materials designed to increase investors' knowledge of impression management.

For investors, this research will bring awareness to the short-term and the longerterm impacts of impression management strategies on stock price and investor perceptions, and may encourage greater engagement with text in the body of EPRs, rather than just the headlines. For example, the strong positive association between headline impression management bias and online discussion volume in the three-day window may 
suggest that most retail investors are drawn to positively emphasized or 'catchy' headlines as opposed to carefully reading the content of EPRs. This knowledge may help investors avoid focusing too much on headlines which are very likely to be manipulated by firms as indicated by the results of this study.

Low-visibility firms with different characteristics (e.g., firm size and industry) may want to better understand the consequences of manipulating and managing their voluntary disclosures and the voluntary disclosure practices among their peers. Discussed benefits (in the literature review) of disclosing voluntary information for increasing firm visibility and lowering the cost of capital, as well as provided statistics on EPRs and TSX Venture firms, can be beneficial to non-issuers as well as non-frequent issuers of EPRs when considering whether to issue EPRs. Also, once informed about various impression management strategies, low-visibility firms can be more efficient when managing the content of their disclosures.

Lastly, for academics, this dissertation will hopefully increase attention to lowvisibility firms, in particular, TSX Venture Exchange firms, which play an important role in the Canadian economy. Thanks to the breadth of analysis in this study, many research areas covered both in the firm and investor perspectives can serve as a basis for future research. The next section highlights some possible venues of research for future studies in the domain of impression management by low visibility firms.

\subsubsection{Future research}

The investigation of impression management in the context of low-visibility firms can be improved by addressing certain limitations of this study. One of the areas for such 
improvement is increasing the sample size. This can be achieved by performing a longerterm analysis (more than 2.5 years) and/or including more disclosure sources (rather than just one document) in the investigation. Future research could consider a broad range of disclosures, including conference calls, MD\&As, CEO letters, non-GAAP indicators, etc. by low-visibility firms. Covering several disclosure sources will enable future research to achieve more generalizable findings on low-visibility firms' impression management practices that extend beyond just EPRs.

The investigation of more disclosure sources and disclosure documents will also enable researchers to study the effect of various voluntary disclosures and disclosure channels on firm visibility and impression management. Defining a more comprehensive visibility measure can help future studies increase the sample of low-visibility firms by selecting low-visibility firms from other exchanges such as the TSX. This will also help explore differences and similarities between the impression management practices of low-visibility firms on the TSX Venture and other exchanges. Moreover, increased sample size will benefit future studies in terms of controlling for potential methodological limitations more efficiently.

Future studies could also address methodological limitations of this study, for example regarding selection bias and the choice of performance measure. Controlling for selection bias can be achieved by designing a two-stage model where the first stage choice model identifies exogenous independent variables which can validly be excluded in the second stage model (Little, 1985). For example, the first stage regression determines underlying factors that affect firms' decisions to issue an EPR, while the second stage regression models the firms' decisions to manage impressions. 
A similar two-stage model can also be employed to limit the potential effect of model weakness arising from the choice of performance measure when studying firms' use of impression management strategies. This can ensure the model properly accounts for impression management motivations of EPR-issuing firms whose performance cannot be measured based on income statement items. For those firms which can be studied based on income statement items, future research should consider interacting the positive earnings variable with the operating income change variable. This analysis can yield additional findings on the characteristics of low-visibility firms that may be relevant when examining the firms' decisions to engage in impression management. Additional methodological approaches could also be considered, such as the use of a matched pair research design to compare impression management activities across firms matched on key characteristics such as industry, performance, number of analysts, life cycle stage, etc.

Future research should also consider using more advanced computer-assisted methods or alternative analytical methods to analyze the content of EPRs and online discussions. As the regression results of this study indicate, the industry variable has a strong impact on impression management in general. In addition, there is a clear distinction between the natural resource industries and other industries. These results may suggest the use of certain words, phrases, templates within industries may be affecting the findings regarding the industry impact. In order to limit this effect - the effect of words or features that are specific to disclosures of certain industries - content analysis techniques that minimize this effect should be considered. One such technique can be the use of TF-IDF (Term Frequency Inverse Document Frequency) which is one of the most 
popular algorithms used in text categorization and term weighting (Shi et al., 2009). The TFIDF technique can help efficiently obtain content in EPRs specific to each company by reducing the impact of common words and/or features in most other EPRs.

In terms of alternative analytical methods, future research could consider the use of Generalized Least Squares (GLS) regression analysis, rather than the Ordinary Least Squares (OLS) regressions used in the present research.

For the analysis of online discussion sentiment, developing a field-specific dictionary of words can benefit future research. Using a dictionary which is designed specifically to account for the particularities of investment board discussion lexicon will improve on the methodology used in this study to measure online discussion board sentiment. Moreover, future research should consider more advanced sentiment tools that take into account a wide range of online discussion features (e.g., user ratings, use of certain symbols and emojis, sentence structure) to obtain user emotions, in addition to sentiment. These improvements may lead to more insightful findings on the association between impression management and online discussion reaction.

Finally, future research should consider investigating impression management for non-EPR issuing firms. Almost half (or 48\%) of the firms in the initial sample did not issue any EPRs throughout the study period. Since the focus of this study was on frequent EPR-issuers, non-EPR-issuers were not included in the analysis. However, the study of impression management practices of non-EPR-issuers can be equally important. Therefore, future studies should explore other possible disclosures issued by non-EPRissuing firms to investigate how these firms manage impressions in those disclosures. 


\section{References}

Abrahamson, E., \& Amir, E. (1996). The information content of the president's letter to shareholders. Journal of Business Finance \& Accounting, 23(8), 1157-1182.

Abarbanell, J. S., Bushee, B. J., \& Smith Raedy, J. (2003). Institutional investor preferences and price pressure: The case of corporate spin-offs. The Journal of Business, 76(2), 233261.

Aerts, W. (1994). On the use of accounting logic as an explanatory category in narrative accounting disclosures. Accounting, Organizations and Society, 19(4-5), 337-353.

Aerts, W. (2005). Picking up the pieces: impression management in the retrospective attributional framing of accounting outcomes. Accounting, Organizations and Society, 30(6), 493-517.

Aerts, W., \& Cheng, P. (2011). Causal disclosures on earnings and earnings management in an IPO setting. Journal of Accounting and Public Policy, 30(5), 431-459.

Aerts, W., \& Cheng, P. (2012). Self-serving causal disclosures and short-term IPO valuationevidence from China. Accounting and Business Research, 42(1), 49-75.

Aerts, W., \& Yan, B. (2017). Rhetorical impression management in the letter to shareholders and institutional setting: A metadiscourse perspective. Accounting, Auditing \& Accountability Journal, 30(2), 404-432.

Allee, K., \& DeAngelis, M. (2014). The structure of voluntary disclosure narratives: Evidence from conference calls. Working paper, University of Wisconsin and Michigan State University.

Allee, K. D., Bhattacharya, N., Black, E. L., \& Christensen, T. E. (2007). Pro forma disclosure and investor sophistication: External validation of experimental evidence using archival data. Accounting, Organizations and Society, 32(3), 201-222.

Alsaeed, K. (2006). The association between firm-specific characteristics and disclosure: The case of Saudi Arabia. Managerial Auditing Journal, 21(5), 476-496. 
Amihud, Y., \& Mendelson, H. (1986). Liquidity and stock returns. Financial Analysts Journal, 42(3), 43-48.

Arbel, A., \& Strebel, P. (1982). The neglected and small firm effects. Financial Review, 17(4), 201-218.

Arbel, A., Carvell, S., \& Strebel, P. (1983). Giraffes, institutions and neglected firms. Financial Analysts Journal, 39(3), 57-63.

Arbel, A. (1985). Generic stocks: An old product in a new package. The Journal of Portfolio Management, 11(4), 4-13.

Arslan-Ayaydin, Ö., Boudt, K., \& Thewissen, J. (2016). Managers set the tone: Equity incentives and the tone of EPRs. Journal of Banking \& Finance, 72, S132-S147.

Asay, H. S., Elliott, W. B., \& Rennekamp, K. (2016). Disclosure readability and the sensitivity of investors' valuation judgments to outside information. The Accounting Review, 92(4), $1-25$.

Atiase, R. K. (1985). Predisclosure information, firm capitalization, and security price behavior around earnings announcements. Journal of Accounting Research, 23(1), 21-36.

Atiase, R. K., Bamber, L. S., \& Freeman, R. N. (1988). Accounting Disclosures Based On Company Size: Regulations A. Accounting Horizons, 2(1), 18.

Antweiler, W., \& Frank, M. Z. (2004). Is all that talk just noise? The information content of internet stock message boards. The Journal of finance, 59(3), 1259-1294.

Antweiler, W., \& Frank, M. (2005). The market impact of corporate news stories. Working paper, University of British Columbia.

Bhattacharya, N., Black, E.L., Christensen, T. and Mergenthaler, R.D. (2007). Who trades on pro forma earnings information? The Accounting Review, 82 (3), 581-619.

Baginski, S. P., Hassell, J. M., \& Hillison, W. A. (2000). Voluntary causal disclosures: Tendencies and capital market reaction. Review of Quantitative Finance and Accounting, 15(4), 371-389. 
Baginski, S.P., J.M. Hassell and M.D. Kimbrough. (2004). Why do managers explain their earnings forecasts? Journal of Accounting Research, 22 (1), 1-29.

Baker, H. E., \& Kare, D. D. (1992). Relationship between annual report readability and corporate financial performance. Management Research News, 15(1), 1-4.

Baker, H. K., Powell, G. E., \& Weaver, D. G. (1999). Does NYSE listing affect firm visibility?. Financial Management, 28(2), 46-54.

Baker, H. K., Nofsinger, J. R., \& Weaver, D. G. (2002). International cross-listing and visibility. Journal of Financial and Quantitative Analysis, 37(3), 495-521.

Barber, B., \& Lyon, J. (1997). Detecting long-run abnormal stock returns: The empirical power and specification of test statistics. Journal of Financial Economics, 43, 341-372.

Barber, B. M., \& Odean, T. (2007) All That Glitters: The Effect of Attention and News on the Buying Behavior of Individual and Institutional Investors. Review of Financial Studies, 21 (2), 785-818, doi:10.1093/rfs/hhm079.

Barber, B. M., Lee, Y. T., Liu, Y. J., \& Odean, T. (2008). Just how much do individual investors lose by trading? The Review of Financial Studies, 22(2), 609-632.

Barber, B. M., Odean, T., \& Zhu, N. (2008). Do retail trades move markets? The Review of Financial Studies, 22(1), 151-186.

Barry, C. B., \& Brown, S. J. (1986). Limited information as a source of risk. The Journal of Portfolio Management, 12(2), 66-72.

Barton, J., \& Mercer, M. (2005). To blame or not to blame: Analysts' reactions to external explanations for poor financial performance. Journal of accounting and economics, 39(3), 509-533.

Bartov, E., Faurel, L., \& Mohanram, P. (2017). Can Twitter help predict firm-level earnings and stock returns? The Accounting Review, 93(3), 25-57.

Bhagwat, V., \& Burch, T. (2016). Pump it up? Tweeting to manage investor attention to earnings news. SSRN Electronic Journal, doi:10.2139/ssrn.2382962. 
Bhushan, R. (1989). Firm characteristics and analyst following. Journal of Accounting and Economics, 11(2-3), 255-274.

Benson, D. F., Brau, J. C., Cicon, J., \& Ferris, S. P. (2015). Strategically camouflaged corporate governance in IPOs: Entrepreneurial masking and impression management. Journal of Business Venturing, 30(6), 839-864.

Becker-Blease, J. R., \& Paul, D. (2003). Does Index Inclusion Improve Firm Visibility and Transparency? Working paper. Babson College Wellesley.

Blankespoor, E., Miller, G. S., \& White, H. D. (2013). The role of dissemination in market liquidity: Evidence from firms' use of Twitter. The Accounting Review 89 (1), 79-112.

Botosan, C. A. (1997). Disclosure level and the cost of equity capital. The Accounting Review, 72(3), 323-349.

Botosan, C. A., \& Plumlee, M. A. (2002). A re-examination of disclosure level and the expected cost of equity capital. Journal of accounting research, 40(1), 21-40.

Botosan, C. A. (2006). Disclosure and the cost of capital: what do we know?. Accounting and business research, 36(sup1), 31-40.

Bowen, R.M., A.K. Davis \& D.A. Matsumoto. (2002). Do conference calls affect analysts' forecasts? The Accounting Review, 77 (2), 285-316.

Bowen, R. M., Davis, A. K., \& Matsumoto, D. A. (2005). Emphasis on pro forma versus GAAP earnings in quarterly press releases: Determinants, SEC intervention, and market reactions. The Accounting Review, 80(4), 1011-1038.

Brennan, N. M., Guillamon-Saorin, E., \& Pierce, A. (2009). Methodological Insights: Impression management: developing and illustrating a scheme of analysis for narrative disclosures-a methodological note. Accounting, Auditing \& Accountability Journal, 22(5), 789-832.

Briloff, A. J. (1972). Unaccountable accounting. Harpercollins.

Brockman, P., Subasi, M., \& Uzmanoglu, C. (2017). Investor conferences, firm visibility, and stock liquidity. Financial Review, 52(4), 661-699. 
Bujaki, M., \& McConomy, B. (2002). Corporate governance: Factors influencing voluntary disclosure by publicly traded Canadian firms. Canadian Accounting Perspectives, 1(2), 105-139.

Bujaki, M., \& McConomy, B. (2012). Metaphor in Nortel's letters to shareholders 19972006. Accounting, Auditing \& Accountability Journal, 25(7), 1113-1139.

Bushee, B. J., Core, J. E., Guay, W., \& Hamm, S. J. (2010). The role of the business press as an information intermediary. Journal of Accounting Research, 48(1), 1-19.

Bushee, B. J., \& Miller, G. S. (2012). Investor relations, firm visibility, and investor following. The Accounting Review, 87(3), 867-897.

Bushman, R. M., \& Smith, A. J. (2001). Financial accounting information and corporate governance. Journal of accounting and Economics, 32(1-3), 237-333.

Chae, J. (2005). Trading volume, information asymmetry, and timing information. The Journal of Finance, 60(1), 413-442.

Chen, H., Noronha, G., \& Singal, V. (2004). The price response to S\&P 500 index additions and deletions: Evidence of asymmetry and a new explanation. The Journal of Finance, 59(4), 1901-1930.

Chen, H., P. De, Y. Hu, \& B. Hwang. (2014). Wisdom of crowds: The value of stock opinions transmitted through social media. Review of Financial Studies, 27 (5), 1367-1403. https://doi.org/10.1093/rfs/hhu001

Chen, T. (2017). Investor Attention and Global Stock Returns. Journal of Behavioral Finance, 18(3), 358-372.

Clapham, S. E., \& Schwenk, C. R. (1991). Self-serving attributions, managerial cognition, and company performance. Strategic Management Journal, 12(3), 219-229.

Clatworthy, M., \& Jones, M. J. (2001). The effect of thematic structure on the variability of annual report readability. Accounting, Auditing \& Accountability Journal, 14(3), 311326.

Clatworthy, M., \& Jones, M. J. (2003). Financial reporting of good news and bad news: evidence from accounting narratives. Accounting and Business Research, 33(3), 171-185. 
Clatworthy, M. A., \& Jones, M. J. (2006). Differential patterns of textual characteristics and company performance in the chairman's statement. Accounting, Auditing \& Accountability Journal, 19(4), 493-511.

Collins, D. W., Kothari, S. P., \& Rayburn, J. D. (1987). Firm size and the information content of prices with respect to earnings. Journal of Accounting and Economics, 9(2), 111-138.

Collins, D. W., Li, O. Z., \& Xie, H. (2009). What drives the increased informativeness of earnings announcements over time? Review of Accounting Studies, 14(1), 1-30.

Copeland, T. E., \& Galai, D. (1983). Information effects on the bid-ask spread. The Journal of Finance, 38(5), 1457-1469.

Courtis, J.K. (1998). Annual report readability variability: tests of the obfuscation hypothesis. Accounting, Auditing \& Accountability Journal, 11(4), 459-72.

Courtis, J.K. (2004). Corporate report obfuscation: Artefact or phenomenon? British Accounting Review, 36 (3), 291-312.

Coval, J. D., \& Moskowitz, T. J. (2001). The geography of investment: Informed trading and asset prices. Journal of Political Economy, 109(4), 811-841

Da, Z., J. Engelberg, and P. Gao. (2011). In search of attention. Journal of Finance, 66 (5), 1461-1499. https://doi.org/10.1111/j.1540- 6261.2011.01679.x

Das, S., and M. Chen. (2007). Yahoo! for Amazon: Sentiment extraction from small talk on the web. Management Science, 53 (9): 1375- 1388. https://doi.org/10.1287/mnsc.1070.0704

Davis, A. K., Piger, J. M., \& Sedor, L. M. (2006). Beyond the numbers: An analysis of optimistic and pessimistic language in EPRs (No. 2006-005). Federal Reserve Bank of St. Louis.

Davis, A.K., J.M. Piger \& L.M. Sedor. (2007). Beyond the numbers: Managers' use of optimistic and pessimistic tone in EPRs. Working paper, Available at Social Science Research Network (SSRN), http://ssrn.com/abstract=875399.

Davis, A. K., \& Tama-Sweet, I. (2012). Managers' use of language across alternative disclosure outlets: EPRs versus MD\&A. Contemporary Accounting Research, 29(3), 804-837. 
Davis, A. K., Piger, J. M., \& Sedor, L. M. (2012). Beyond the numbers: Measuring the information content of EPR language. Contemporary Accounting Research, 29(3), 845868.

Davison, J. (2008). Rhetoric, repetition, reporting and the "dot. com" era: words, pictures, intangibles. Accounting, Auditing \& Accountability Journal, 21(6), 791-826.

Demers, E., \& Vega, C. (2008). Soft information in earnings announcements: News or noise? (Vol. 951). Board of Governors of the Federal Reserve System.

Diamond, D. W. (1985). Optimal release of information by firms. The Journal of Finance, 40(4), 1071-1094.

Diamond, D. W., \& Verrecchia, R. E. (1991). Disclosure, liquidity, and the cost of capital. The Journal of Finance, 46(4), 1325-1359.

DICTION. (2018). DICTION Overview. Retrieved from https://www.dictionsoftware.com/ (September 16, 2018).

DiMaggio, P. J., \& Powell, W. W. (1983). The iron cage revisited: Institutional isomorphism and collective rationality in organizational fields. American sociological review, 48(2), 147-160.

Ding, R., \& Hou, W. (2015). Retail investor attention and stock liquidity. Journal of International Financial Markets, Institutions and Money, 37, 12-26.

D'Aveni, R. A., \& MacMillan, I. C. (1990). Crisis and the content of managerial communications: A study of the focus of attention of top managers in surviving and failing firms. Administrative science quarterly, 634-657.

Elliott, J., Morse, D., Richardson, G., (1984). The association between insider trading and information announcements. Rand Journal of Economics, 15, 521-536.

Elliott, A. J. (2006). The hierarchical model of approach-avoidance motivation. Motivation and emotion, 30(2), 111-116.

Fadhel, K. (2002). Positivist and Hermeneutic Paradigm, A Critical Evaluation under their Structure of Scientific Practice. The Sosland Journal, 6(5). 21-28 
Farrar, D. E., \& Glauber, R. R. (1967). Multicollinearity in regression analysis: the problem revisited. The Review of Economic and Statistics, 49(1), 92-107.

Figer, R. C. (2014). Internet Use and Social Capital: The Case of Filipino Migrants in Japan. Online Journal of Communication and Media Technologies, 4(3), 101-123.

Francis, J. \& K. Schipper. (1999). Have Financial Statements Lost Their Relevance? Journal of Accounting Research, 37(2): 319-352.

Francis, J., Schipper, K., \& Vincent, L. (2002). Expanded disclosures and the increased usefulness of earnings announcements. The Accounting Review, 77(3), 515-546.

Frankel, R., \& Li, X. (2004). Characteristics of a firm's information environment and the information asymmetry between insiders and outsiders. Journal of Accounting and Economics, 37(2), 229-259.

Feldman, R., Govindaraj, S., Livnat, J., \& Segal, B. (2010). Management's tone change, post earnings announcement drift and accruals. Review of Accounting Studies, 15(4), 915-953.

Felton, J. and J. Kim. (2002). Warnings from the Enron Message Board. Journal of Investing, 11(3): 29-52.

Frederickson, J. R., \& Miller, J. S. (2004). The effects of pro forma earnings disclosures on analysts' and nonprofessional investors' equity valuation judgements. The Accounting Review, 79(3), 667-686.

Freeman, R. (1987). The association between accounting earnings and security returns for large and small firms. Journal of Accounting and Economics, 9, 195-228.

Gabrovšek, P., Aleksovski, D., Mozetič, I., \& Grčar, M. (2017). Twitter sentiment around the Earnings Announcement events. PloS one, 12(2).

Gervais, S., Kaniel, R., \& Mingelgrin, D. H. (2001). The high-volume return premium. The Journal of Finance, 56(3), 877-919.

Gibbins, M. (1982). Regression and other statistical implications for research on judgment using intercorrelated data sources. Journal of Accounting Research, 20(1),121-138. 
Gibbins, M., Richardson, A., \& Waterhouse, J. (1990). The management of corporate financial disclosure: opportunism, ritualism, policies, and processes. Journal of Accounting Research, 28(1), 121-143.

Gillaerts, P., \& Van de Velde, F. (2010). Interactional metadiscourse in research article abstracts. Journal of English for Academic purposes, 9(2), 128-139.

Glosten, L. R., \& Milgrom, P. R. (1985). Bid, ask and transaction prices in a specialist market with heterogeneously informed traders. Journal of Financial Economics, 14(1), 71-100.

Golec, J. H., \& Vernon, J. A. (2007). Financial risk in the biotechnology industry (No. w13604). National Bureau of Economic Research.

Goffman, E. (1959). The presentation of self in everyday life. London: Harmondsworth.

Graham, J. R., Harvey, C. R., \& Rajgopal, S. (2005). The economic implications of corporate financial reporting. Journal of accounting and economics, 40(1-3), 3-73.

Guillamon-Saorin, E. (2006). Impression management in financial reporting. Evidence from the UK and Spain. Unpublished doctoral dissertation, University College Dublin.

Guillamon-Saorin, E., Osma, B. G., \& Jones, M. J. (2012). Opportunistic disclosure in press release headlines. Accounting and Business Research, 42(2), 143-168.

Hamrouni, A., Benkraiem, R., \& Karmani, M. (2017). Voluntary information disclosure and sell-side analyst coverage intensity. Review of Accounting and Finance, 16(2), 260-280.

Handa, P., \& Linn, S. C. (1993). Arbitrage pricing with estimation risk. Journal of Financial and Quantitative Analysis, 28(1), 81-100.

Haveman, H. A. (1993). Follow the leader: Mimetic isomorphism and entry into new markets. Administrative science quarterly, 593-627.

Healy, P., \& Palepu, K. (2001). Information asymmetry, corporate disclosure, and the capital markets: A review of the empirical disclosure literature. Journal of Accounting and Economics, 31(1-3), 405-440.

Henry, E. (2006). Market reaction to verbal components of EPRs: Event study using a predictive algorithm. Journal of Emerging Technologies in Accounting, 3(1), 1-19. 
Henry, E. (2008). Are investors influenced by how EPRs are written?. The Journal of Business Communication, 45(4), 363-407.

Hope, O. (2003). Disclosure Practices, Enforcement of Accounting Standards, and Analysts' Forecast Accuracy: An International Study. Journal of Accounting Research, 41(2): 235272.

Hofstedt, T. R., \& Hughes, G. D. (1977). An experimental study of the judgment element in disclosure decisions. The Accounting Review, 52(2), 379.

Hooghiemstra, R. (2000). Corporate communication and impression management-new perspectives why companies engage in corporate social reporting. Journal of business ethics, 27(1-2), 55-68.

Hooghiemstra, R. (2001). Cultural differences in self-serving behaviour in accounting narratives. In APIRA Conference, Adelaide (pp. 15-17).

Hoskin, R. E., Hughes, J. S., \& Ricks, W. E. (1986). Evidence on the incremental information content of additional firm disclosures made concurrently with earnings. Journal of Accounting Research, 1-32.

Hou, K., Xiong, W., and Peng, L. (2009). A Tale of Two Anomalies: The Implications of Investor Attention for Price and Earnings Momentum. SSRN Electronic Journal, 2009, doi:10.2139/ssrn.976394.

Hsieh, C. C., Hui, K. W., \& Zhang, Y. (2016). Analyst report readability and stock returns. Journal of Business Finance \& Accounting, 43(1-2), 98-130.

Hu, X., Tang, J., Gao, H., \& Liu, H. (2013). Unsupervised sentiment analysis with emotional signals. In Proceedings of the 22nd international conference on World Wide Web (pp. 607-618). ACM.

Huang, P. H. (2005). Moody investing and the Supreme Court: Rethinking the materiality of information and the reasonableness of investors. Supreme Court Economic Review, 13, 99.

Huang, X., Teoh, S. H., \& Zhang, Y. (2014). Tone management. The Accounting Review, 89(3), 1083-1113. 
Jameson, D. A. (2000). Telling the investment story: A narrative analysis of shareholder reports. The Journal of Business Communication, 37(1), 7-38.

Jiang, F., Lee, J., Martin, X., \& Zhou, G. (2019). Manager sentiment and stock returns. Journal of Financial Economics, 132(1), 126-149.

Jones, M. J. (1988). A longitudinal study of the readability of the chairman's narratives in the corporate reports of a UK company. Accounting and Business Research, 18(72), 297-305.

Kaboub, F. (2001). Positivist and hermeneutic paradigms: A critical evaluation under the structure of scientific practice. University of Missouri-Kansas City, Kansas City, MO.

Kadlec, G. B., \& McConnell, J. J. (1994). The effect of market segmentation and illiquidity on asset prices: Evidence from exchange listings. Journal of Finance, 49(2), 611-636.

Kaplan, S. E., Pourciau, S., \& Reckers, P. M. (1990). An examination of the effect of the president's letter and stock advisory service information on financial decisions. Behavioral Research in Accounting, 2(1), 63-92.

Kasznik, R. (1999). On the association between voluntary disclosure and earnings management. Journal of Accounting Research, 37(1), 57-81.

Kelly, B. T., \& Ljungqvist, A. (2007). The value of research. SSRN Electronic Journal, https://papers.ssrn.com/sol3/papers.cfm?abstract_id=1005686.

Kim, C., Wang, K., \& Zhang, L. (2019). Readability of 10-K reports and stock price crash risk. Contemporary Accounting Research, 36(2), 1184-1216.

Kimbrough, M. D., \& Wang, I. Y. (2013). Are seemingly self-serving attributions in EPRs plausible? Empirical evidence. The Accounting Review, 89(2), 635-667.

Kintsch, W., \& Yarbrough, J. C. (1982). Role of rhetorical structure in text comprehension. Journal of Educational Psychology, 74(6), 828.

Kohut, G. F., \& Segars, A. H. (1992). The president's letter to stockholders: An examination of corporate communication strategy. The Journal of Business Communication, 29(1), 7-21.

Kostoff, R. N., Eberhart, H. J., \& Toothman, D. R. (1997). Database tomography for information retrieval. Journal of Information Science, 23(4), 301-311. 
Kothari, S. P., Li, X., \& Short, J. E. (2009). The effect of disclosures by management, analysts, and business press on cost of capital, return volatility, and analyst forecasts: A study using content analysis. The Accounting Review, 84(5), 1639-1670.

Kothari, S., \& Warner, J. (1997). Measuring long-horizon security price performance. Journal of Financial Economics, 43, 301-339.

Krische, S. D. (2005). Investors' evaluations of strategic prior-period benchmark disclosures in earnings announcements. The Accounting Review, 80(1), 243-268.

Kross, W., \& Kim, M. (2000). Differences between market responses to earnings announcements in the 1990s v. 1960s. SSRN Electronic Journal, https://papers.ssrn.com/sol3/papers.cfm?abstract_id=2552.

Kuhn, M., \& Johnson, K. (2013). Applied predictive modeling. (Vol. 26). New York: Springer.

Landsman, W. R., \& Maydew, E. L. (2002). Has the information content of quarterly earnings announcements declined in the past three decades? Journal of Accounting Research, 40(3), 797-808.

Lang, M. H., \& Lundholm, R. J. (1996). Corporate disclosure policy and analyst behavior. Accounting Review, 71(4), 467-492.

Lang, M. H., \& Lundholm, R. J. (2000). Voluntary disclosure and equity offerings: reducing information asymmetry or hyping the stock? Contemporary accounting research, 17(4), 623-662.

Lawrence, A. (2013). Individual investors and financial disclosure. Journal of Accounting and Economics, 56(1), 130-147.

Leary, M. R., \& Kowalski, R. M. (1990). Impression management: A literature review and twocomponent model. Psychological Bulletin, 107(1), 34.

Lee, F., Peterson, C., \& Tiedens, L. Z. (2004). Mea culpa: Predicting stock prices from organizational attributions. Personality and Social Psychology Bulletin, 30(12), 16361649.

Lee, Y. J. (2012). The effect of quarterly report readability on information efficiency of stock prices. Contemporary Accounting Research, 29(4), 1137-1170. 
Lehavy, R., \& Sloan, R. G. (2008). Investor recognition and stock returns. Review of Accounting Studies, 13(2-3), 327-361.

Lerman, A. (2017). Individual investors' attention to accounting information: Message board discussions. SSRN Electronic Journal, 2017, doi:10.2139/ssrn.1540689.

Leung, H., \& Ton, T. (2015). The impact of internet stock message boards on cross-sectional returns of small-capitalization stocks. Journal of Banking \& Finance, 55, 37-55.

Leung, S., Parker, L., \& Courtis, J. (2015). Impression management through minimal narrative disclosure in annual reports. The British accounting review, 47(3), 275-289.

Li, F. (2006). Do stock market investors understand the risk sentiment of corporate annual reports? SSRN Electronic Journal, 2006, doi:10.2139/ssrn.898181.

Li, F. (2008). Annual report readability, current earnings, and earnings persistence. Journal of Accounting and Economics, 45(2-3), 221-247.

Li, C. (2010). Groundswell. Winning in a world transformed by social technologies. Strategic Direction, 26(8).

Li, F. (2010). The information content of forward-looking statements in corporate filings-A naïve Bayesian machine learning approach. Journal of Accounting Research, 48(5), 1049-1102.

Little, R. (1985). A note about models for selectivity bias. Econometrica, 53 (6): 1469-1474.

Lo, K., \& Lys, T. (2000). Bridging the gap between value relevance and information content. SSRN Electronic Journal,https://papers.ssrn.com/sol3/papers.cfm?abstract_id=253369.

Maat, H. P. (2007). How promotional language in press releases is dealt with by journalists: genre mixing or genre conflict? The Journal of Business Communication, 44(1), 59-95.

Matsumoto, D., M. Pronk and E. Roelofsen. (2006). Do analysts mitigate optimism by management? Working paper, University of Washington.

McShane, M. (2017). Natural language understanding (NLU, not NLP) in cognitive systems. $A I$ Magazine, 38(4), 43-56. 
Merton, R. C. (1987). A simple model of capital market equilibrium with incomplete information. The Journal of Finance, 42(3), 483-510.

Merkl-Davies, D. (2007). The obfuscation hypothesis re-examined: Analyzing impression management in corporate narrative report documents (Order No. 10089232). Available from ProQuest Dissertations \& Theses Global. (1779212230). Retrieved from http://proxy.library.carleton.ca/login?url=https://search-proquestcom.proxy.library.carleton.ca/docview/1779212230?accountid=9894 (March 11, 2017).

Merkl-Davies, D. M., \& Brennan, N. M. (2007). Discretionary disclosure strategies in corporate narratives: incremental information or impression management?. Journal of Accounting Literature, 27, 116-196.

Merkl-Davies, D. M., Brennan, N. M., \& McLeay, S. J. (2011). Impression management and retrospective sense-making in corporate narratives: A social psychology perspective. Accounting, Auditing \& Accountability Journal, 24(3), 315-344.

Miller, D. J. (2006). Technological diversity, related diversification, and firm performance. Strategic Management Journal, 27(7), 601-619.

Neu, D. (1991). Trust, impression management and the public accounting profession. Critical Perspectives on Accounting, 2(3), 295-313.

Neu, D., Warsame, H., \& Pedwell, K. (1998). Managing public impressions: Environmental disclosures in annual reports. Accounting, Organizations and Society, 23(3), 265-282.

Neurath, O. (1973). Memories of Otto Neurath. In Empiricism and Sociology (pp. 1-83). Springer, Dordrecht.

Newell, A., \& Simon, H. A. (1972). Human problem solving. 4 (9). Englewood Cliffs, NJ: Prentice-Hall.

O'Brien, P. C., \& Bhushan, R. (1990). Analyst following and institutional ownership. Journal of Accounting Research, 28, 55-76.

O’Brien, R. M. (2007). A caution regarding rules of thumb for variance inflation factors. Quality \& quantity, 41(5), 673-690. 
Ontario Securities Commission. (2018). Disclosure Documents. Retrieved from https://www.osc.gov.on.ca/en/Investors_disclosure-requirements_index.htm (November 12, 2018).

Osma, B. G., \& Guillamón-Saorín, E. (2011). Corporate governance and impression management in annual results press releases. Accounting, Organizations and Society, 36(4-5), 187-208.

Park, J. H., Gu, B., Leung, A. C. M., \& Konana, P. (2014). An investigation of information sharing and seeking behaviors in online investment communities. Computers in Human Behavior, 31, 1-12.

Petrova, E., Georgakopoulos, G., Sotiropoulos, I., \& Vasileiou, K. Z. (2012). Relationship between cost of equity capital and voluntary corporate disclosures. International Journal of Economics and Finance, 4(3), 83.

Pesci, C., Costa, E., \& Soobaroyen, T. (2015). The forms of repetition in social and environmental reports: insights from Hume's notion of 'impressions'. Accounting and Business Research, 45(6-7), 765-800.

Price, S. M., Doran, J. S., Peterson, D. R., \& Bliss, B. A. (2012). Earnings conference calls and stock returns: The incremental informativeness of textual tone. Journal of Banking \& Finance, 36(4), 992-1011.

Porta, R. L., Lakonishok, J., Shleifer, A., \& Vishny, R. (1997). Good news for value stocks: Further evidence on market efficiency. The Journal of Finance, 52(2), 859-874.

Prokofieva, M. (2014). Twitter-based dissemination of corporate disclosure and the intervening effects of firms' visibility: Evidence from Australian-listed companies. Journal of Information Systems, 29(2), 107-136.

Readability Formulas. (2018). The Gunning's Fog Index (or FOG) Readability Formula. Retrieved from http://www.readabilityformulas.com/gunning-fog-readabilityformula.php (October 17, 2018).

Renault, T. (2017). Intraday online investor sentiment and return patterns in the US stock market. Journal of Banking \& Finance, 84, 25-40. 
Rennekamp, K. (2012). Processing fluency and investors' reactions to disclosure readability. Journal of Accounting Research, 50(5), 1319-1354.

Richards, G. W. (2011). Readability and Thematic Manipulation in Corporate Communications: A Multi-Disclosure and Trans-Tasman Investigation. UC Research Repository. Retrieved from

https://ir.canterbury.ac.nz/bitstream/handle/10092/7370/GlennRichardsMastersThesis.pdf ?sequence $=1 \&$ isAllowed=y (May 19, 2017).

Riess, M., Rosenfeld, P., Melburg, V., \& Tedeschi, J. T. (1981). Self-serving attributions: Biased private perceptions and distorted public descriptions. Journal of Personality and Social Psychology, 41(2), 224.

Roberts, J. (1990). Strategy and accounting in a UK conglomerate. Accounting, Organizations and Society, 15(1-2), 107-126.

Rutherford, B.A. (2003). Obfuscation, textual complexity and the role of regulated narrative accounting disclosure in corporate governance. Journal of Management and Governance, 7: $187-210$.

Rutherford, B. A. (2005). Genre analysis of corporate annual report narratives: A corpus linguistics-based approach. The Journal of Business Communication, 42(4), 349-378.

Sabherwal, S., Sarkar, S. K., \& Zhang, Y. (2008). Online talk: does it matter?. Managerial Finance, 34(6), 423-436.

Sabherwal, S., Sarkar, S. K., \& Zhang, Y. (2011). Do internet stock message boards influence trading? Evidence from heavily discussed stocks with no fundamental news. Journal of Business Finance \& Accounting, 38(9-10), 1209-1237.

Salancik, G. R., \& Meindl, J. R. (1984). Corporate attributions as strategic illusions of management control. Administrative science quarterly, 29(2), 238-254.

Săndulescu, M. S., \& Albu, C. N. (2018). Impression management in the letters to shareholders of listed entities: A Romanian case study. Accounting and Management Information Systems, 17(3), 353-373.

Seasholes, M. S., \& Wu, G. (2007). Predictable behavior, profits, and attention. Journal of Empirical Finance, 14(5), 590-610. 
Schipper, K. (1989). Earnings management. Accounting Horizons, 3(4), 91.

Schlenker, B. R. (1980). Impression management. Monterey, CA. Brooks/Cole Publishing Company.

Schneider, B. (1982). Interactional psychology and organizational behavior. Michigan State University East Lansing Department of Psychology.

Schrand, C. M., \& Walther, B. R. (2000). Strategic benchmarks in earnings announcements: The selective disclosure of prior-period earnings components. The Accounting Review, 75(2), 151-177.

Shi, C., Xu, C., \& Yang, X. (2009). Study of TFIDF algorithm. Journal of Computer Applications, 29(6), 167-170.

Seethamraju, R. (2014). Effectiveness of using online discussion forum for case study analysis. Education Research International, 2014, 1-10. Retrieved from https://www.hindawi.com/journals/edri/2014/589860/

Simon, H. A. (1982). Models of bounded rationality: Empirically grounded economic reason (Vol. 3). MIT press.

Skinner, D. J. (1994). Why firms voluntarily disclose bad news. Journal of accounting research, 32(1), 38-60.

Smith, M., \& Taffler, R. (1992). Readability and understandability: Different measures of the textual complexity of accounting narrative. Accounting, Auditing \& Accountability Journal, 5(4), 84.

Smith, M., \& Taffler, R. J. (2000). The chairman's statement-A content analysis of discretionary narrative disclosures. Accounting, Auditing \& Accountability Journal, 13(5), 624-647.

Short, J. C., \& Palmer, T. B. (2003). Organizational performance referents: An empirical examination of their content and influences. Organizational Behavior and Human Decision Processes, 90(2), 209-224.

Spivey, N. N. (1990). Transforming texts: Constructive processes in reading and writing. Written communication, 7(2), 256-287. 
Sprenger, T. O., Tumasjan, A., Sandner, P. G., \& Welpe, I. M. (2014). Tweets and trades: The information content of stock microblogs. European Financial Management, 20(5), 926957.

Statista. (2016). Worldwide desktop market share of leading search engines. Retrieved from https:/www.statista.com/statistics/216573/worldwide-market-share-of-search-engines/ (August 1, 2016).

Statistics Canada. (2017). Gross domestic product. Statistics Canada Table no. 36-10-0434-02. Ottawa. Version updated November 2017. Ottawa. Retrieved from https://www150.statcan.gc.ca/t1/tbl1/en/tv.action?pid=3610043402 (June 16, 2018).

Statistics Canada. (2017). Labour force characteristics by industry. Statistics Canada Table no. 14-10-0023-01. Ottawa. Version updated November 2017. Ottawa. Retrieved from https://www150.statcan.gc.ca/t1/tbl1/en/tv.action?pid=1410002301 (June 16, 2018).

Subramanian, R., Insley, R. G., \& Blackwell, R. D. (1993). Performance and readability: A comparison of annual reports of profitable and unprofitable corporations. The Journal of Business Communication (1973), 30(1), 49-61.

TMX Group. (2016). TSX Venture Exchange. Retrieved from https://www.tmxmoney.com/en/index.html

TMX Group. (2017). The Mig Report. Retrieved from https://www.tsx.com/resource/en/1656/mig-report.pdf

TMX Group. (2017). S\&P/TSX Venture Composite Methodology. Version updated September 2017. Retrieved from https://web.tmxmoney.com/assets/docs/indices/JX/Methodology_JX.pdf (April 22, 2018).

TMX Group. (2017). 2017 Guide To Listing. Retrieved from https://www.tsx.com/ebooks/en/2017-guide-to-listing/\#23/z

TMX Group (2017). TSX Venture Exchange and Toronto Stock Exchange: Realizing your vision. 2018 Guide to listing. Retrieved from https://www.tsx.com/ebooks/en/2018guide-tolisting/files/assets/common/downloads/publication.pdf?uni=c7603e862142bf5f84929dba 5debdfad (February 14, 2018). 
TMX Group (2018). TMX Money: S\&P/TSX Venture Composite Index characteristics. Version updated February 2018. Retrieved from https://web.tmxmoney.com/index_profile.php?qm_symbol=^JX (February 21, 2018).

Thompson, R. B., Olsen, C. and Dietrich, J.R. (1987). Attributes of News About Firms: An Analysis of Firm-Specific News Reported in Tire Wall Street Journal Index. Journal of Accounting Research: 245-274.

Tumarkin, R., \& Whitelaw, R. F. (2001). News or noise? Internet postings and stock prices. Financial Analysts Journal, 57(3), 41-51.

Tumarkin, R. (2002). Internet message board activity and market efficiency: a case study of the internet service sector using RagingBull.com. Financial Markets, Institutions \& Instruments, 11(4), 313-335.

Wareld, T. D., Wild, J. J., \& Wild, K. L. (1995). Managerial ownership and accounting earnings. Journal of Accounting and Economics, 20, 61-91.

Wasko, M. M., \& Faraj, S. (2005). Why should I share? Examining social capital and knowledge contribution in electronic networks of practice. MIS quarterly, 29(1), 35-57.

Watts, R. L., \& Zimmerman, J. L. (1990). Positive accounting theory: a ten year perspective. Accounting review, 65(1), 131-156.

Welker, M. (1995). Disclosure policy, information asymmetry, and liquidity in equity markets. Contemporary Accounting Research, 11(2), 801-827.

Wisniewski, T. P., \& Yekini, L. S. (2015). Stock market returns and the content of annual report narratives. Accounting Forum, 39 (4), 281-294.

Wysocki, P. D. (1999). Cheap Talk on the Web: The Determinants of Postings on Stock Message Boards. SSRN Electronic Journal, doi:10.2139/ssrn.160170.

Yan, B., Aerts, W., \& Thewissen, J. (2019). The informativeness of impression managementfinancial analysts and rhetorical style of CEO letters. Pacific Accounting Review. 31(3), 462-496.

You, H., \& Zhang, X. J. (2009). Financial reporting complexity and investor underreaction to 10-K information. Review of Accounting Studies, 14(4), 559-586. 
Yuthas, K., Rogers, R., \& Dillard, J. F. (2002). Communicative action and corporate annual reports. Journal of Business Ethics, 41(1-2), 141-157.

Zhang, S., Aerts, W., \& Pan, H. (2019). Causal language intensity in performance commentary and financial analyst behaviour. Journal of Business Finance \& Accounting, 46(1-2), 331. 


\section{Appendices}

Appendix A. Comparisons of firm visibility proxies between S\&P/TSX Venture and S\&P/TSX indices

\begin{tabular}{|c|c|c|c|c|}
\hline $\begin{array}{c}\text { Comparison } \\
\text { metrics }\end{array}$ & Statistic & $\begin{array}{c}\text { S\&P/TSX } \\
\text { Venture Index }\end{array}$ & $\begin{array}{c}\text { S\&P/TSX } \\
\text { Index }\end{array}$ & $\begin{array}{c}\text { Difference } \\
\text { (z-stat) }\end{array}$ \\
\hline $\begin{array}{c}\text { Analyst } \\
\text { coverage }\end{array}$ & Mean & 1.46 & 6.7 & $28.17^{* *}$ \\
\cline { 2 - 5 } & Median & 1.0 & 6.0 & $21.11^{* * *}$ \\
\hline $\begin{array}{c}\text { Institutional } \\
\text { Ownership }\end{array}$ & Mean & $8.6 \%$ & $66.3 \%$ & $18.72^{* * *}$ \\
\cline { 2 - 5 } & Median & $7.3 \%$ & $72.8 \%$ & $16.31^{* * *}$ \\
\hline $\begin{array}{c}\text { Firm size } \\
\text { (market cap in } \\
\text { C\$ Billion) }\end{array}$ & Mean & 0.062 & 8.988 & \\
\cline { 2 - 5 } & Median & 0.029 & 2.89 & \\
\hline Number of \\
constituents
\end{tabular}

Source: Calculated from Bloomberg, 2017

$* * *$ and $* *$ indicate statistical significance at the $1 \%$ and $5 \%$ levels, respectively. 


\section{Appendix B. An example of a discussion board page of a firm on Stockhouse.com - Snipp Interactive Inc.}

\section{*औ* * RE:RE:RE:SNIPP INTERACTIVE REPORTS EBITDA POSITIVE Q3-2017}

posted October 30, 2017 12:34 pm by Dougal12 $\boldsymbol{\star} \star \mathbf{y}$

Dont kid yourself , $\$ 637 \mathrm{k}$ loss is not good news, furthermore assets have reduced by almost $\$ 2 \mathrm{MM}$, on top of that shareholers have been diluted and the deficit has increased by almost \$4MM. Net current...read more

\section{**** Add this record news release to the financials}

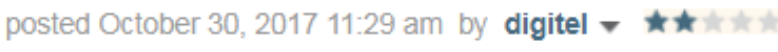

Snipp Announces a Record-Breaking US \$14MM+ of High Margin Live \& Pre-Live Campaigns in Market Today V.SPN | October 4, 2017 (TheNewswire)...read more

\section{*** * RE:RE:SNIPP INTERACTIVE REPORTS EBITDA POSITIVE Q3-2017}

posted October 30, 2017 10:42 am by Donlin $\mathbf{v} \star \boldsymbol{t}$ t

Dam it. Snipp is down this AM on good news. The market was obviously looking for a trillion in revenue and all of people changing their employment status to volunteer work. Oh well...read more

\section{*ネネ* RE:SNIPP INTERACTIVE REPORTS EBITDA POSITIVE Q3-2017}

posted October 30, 2017 09:11 am by digitel $\boldsymbol{\nabla} \star \star \star k t * k$

Sustainable improvements and more to come! "Q3 2017 provides definitive proof that our growth strategy is gaining momentum. We achieved an EBITDA positive quarter by continuing to focus on both...read more

\section{*** * SNIPP INTERACTIVE REPORTS EBITDA POSITIVE Q3-2017}

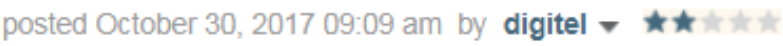

SNIPP INTERACTIVE REPORTS EBITDA POSITIVE Q3-2017 FINANCIAL RESULTS Snipp Interactive Inc. has released its financial results for the third quarter of 2017 and the nine months ended Sept. 30, 2017...read more

\section{**\#* RE:Company turns EBITDA positive}

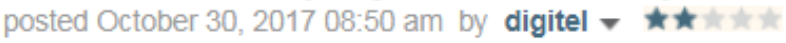

"The Company's Bookings Backlog (programs that have been sold, but whose revenues have not yet been recognized) stood at \$5.5MM" EBITDA positive and book backlog increased vs. previous...read more

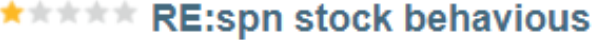

posted October 30, 2017 08:43 am by Donlin $\mathbf{v} \star \boldsymbol{\star}$

From what I have read SPN's performance is a definite turnaround story. Now will the market recognize that. Hopefully the $52 \mathrm{~W}$ high will be surpassed over the next few days. The...read more

\section{\#*** Company turns EBITDA positive}

posted October 30, 2017 08:28 am by digitel * t

From the MD\&A as posted on SEDAR: Key Highlights for Q3 2017 • The Company's Bookings Backlog (programs that have been sold, but whose revenues have not yet been recognized) stood at $\$ 5.5 \mathrm{MM}$ at...read more 


\section{Appendix C. An example of an online post from a Stockhouse.com user - digitel}

$\begin{array}{ll}\text { digitel } & \begin{array}{l}\text { October 30, 2017 - 09:11 AM 85 Reads } \\ \text { Post\# 26875353 }\end{array} \\ \text { User Actions } \boldsymbol{*} & \end{array}$

\section{RE:SNIPP INTERACTIVE REPORTS EBITDA POSITIVE Q3-2017}

Sustainable improvements and more to come!

"Q3 2017 provides definitive proof that our growth strategy is gaining momentum. We achieved an EBITDA positive quarter by continuing to focus on both our top and bottom lines. We improved our key metrics across the board, with significant gains in our EBITDA performance compared to the same period last year," said Atul Sabharwal, Snipp's co-founder and CEO. "It is important to note that these are sustainable improvements that will continue into the future. In the coming quarters, we will be focusing on further reducing our cost structure while increasing revenue - a two-pronged strategy that will remain in place through the first half of 2018. "

Read more at http://www.stockhouse.com/companies/bullboard? symbol=v.spn\&postid=26875348\#KD7Z10Gvublq6fHp.99 


\section{Appendix D. The body of an EPR issued by C-Com Satellite Systems Inc. on July 18,2017}

OTTAWA, July 18, 2017 - C-COM Satellite Systems Inc. (TSXV: CMI), a leading global provider of mobile auto-deploying satellite antenna systems, announced today financial results for its second quarter ended May 31, 2017.

The company has generated revenues of $\$ 3,030,499$ and a net after tax profit of $\$ 145,909$ or 0 cents per share. This compared to revenues of $\$ 1,804,131$ and a net after tax profit of $\$ 15,811$ or 0 cents per share as reported in Q2 2016, representing an increase of $68.0 \%$ and $822.8 \%$ respectively.

The working capital of the Company has decreased by $2.0 \%$ to $\$ 19,515,047$ at May 31, 2017 as compared to $\$ 19,922,385$ at May 31, 2016.

During Q2 the Company commenced payments to the University of Waterloo under the joint research and development contract signed January 2017 for the development of a phased array in-motion antenna. The large increase in research and development expense and resulting lower net after tax profit in Q2 is almost entirely attributable to the payments made to the University.

The Company also announced the payment of its quarterly eligible dividend in the amount of $\$ 0.0125$ per common share payable on August 17th, 2017 to all shareholders of record as of August 3rd, 2017. Based on the closing price of $\$ 1.00$ per share on July 17th, 2017, this dividend represents a yield of $5.00 \%$ on an annualized basis. This is the Company's 21 st consecutive quarterly dividend and its 25 th consecutive profitable quarter.

"Our new generation product sales continue to grow and C-COM's highly ambitious and revolutionary Ka-band flat panel antenna project remains on track as the company's longterm focus. We are very confident in growing and expanding our innovative product line of mobile antenna systems, which continue to gain acceptance from our worldwide customer base," said Leslie Klein, President and CEO of C-COM Satellite Systems Inc.

$\mathrm{C}-\mathrm{COM}$ is at the forefront of developing new products for new markets and is expanding its worldwide reseller network for its proprietary iNetVu ${ }^{\circledR}$ Mobile antenna systems. One of the new products the Company is developing is an in-motion Ka-band antenna system, which will deliver broadband Internet over satellite into vehicles and trains while in full motion. This new product will work with the most advanced Ka-band high throughput satellites. CCOM also continues to establish new partnerships with companies around the world interested in combining the capabilities of the $i \mathrm{Net} \mathrm{Vu}{ }^{\circledR}$ antennas with the products and services they offer. 
Appendix E. Descriptive statistics on firm fundamentals and stock related data

\begin{tabular}{|c|c|c|c|c|c|c|c|c|}
\hline & \multicolumn{8}{|c|}{ Application Software } \\
\hline & Count & Mean & Std & Min & 0.25 & 0.5 & 0.75 & Max \\
\hline Operating Income & 217.000 & -1.159 & 3.092 & -31.695 & -1.500 & -0.617 & -0.023 & 3.371 \\
\hline Operating Income change & 217.000 & -0.007 & 3.072 & -28.595 & -0.332 & 0.031 & 0.431 & 17.924 \\
\hline Market Cap & 217.000 & 38.039 & 47.700 & 2.329 & 11.796 & 24.528 & 36.364 & 262.864 \\
\hline BTM & 217.000 & 0.098 & 1.239 & -11.086 & 0.065 & 0.171 & 0.347 & 2.023 \\
\hline three-day CAR & 217.000 & -0.006 & 0.130 & -0.369 & -0.064 & -0.001 & 0.044 & 0.985 \\
\hline \multirow[t]{2}{*}{ Spread } & 217.000 & 0.051 & 0.084 & 0.002 & 0.007 & 0.015 & 0.046 & 0.456 \\
\hline & \multicolumn{8}{|c|}{ Oil \& Gas } \\
\hline Operating Income & 198 & -3.016 & 9.641 & -80.626 & -2.448 & -0.965 & -0.502 & 51.384 \\
\hline Operating Income change & 198 & -0.832 & 13.039 & -89.511 & -1.108 & 0.058 & 1.643 & 82.267 \\
\hline Market Cap & 198 & 80.330 & 92.757 & 6.584 & 19.343 & 38.363 & 90.638 & 445.218 \\
\hline BTM & 198 & 1.424 & 1.587 & -0.903 & 0.349 & 0.957 & 1.894 & 7.519 \\
\hline three-day CAR & 198 & 0.007 & 0.122 & -0.415 & -0.049 & 0.001 & 0.057 & 0.793 \\
\hline \multirow[t]{2}{*}{ Spread } & 198 & 0.038 & 0.061 & 0.005 & 0.009 & 0.018 & 0.039 & 0.388 \\
\hline & \multicolumn{8}{|c|}{ Metals \& Mining } \\
\hline Operating Income & 190 & -1.308 & 4.658 & -48.473 & -1.266 & -0.655 & -0.209 & 6.908 \\
\hline Operating Income change & 190 & 0.012 & 5.188 & -37.556 & -0.705 & 0.021 & 0.485 & 26.293 \\
\hline Market Cap & 190 & 47.986 & 33.099 & 1.216 & 22.262 & 41.504 & 67.448 & 207.713 \\
\hline BTM & 190 & 1.743 & 2.460 & -0.204 & 0.434 & 0.905 & 2.079 & 14.144 \\
\hline three-day CAR & 190 & -0.003 & 0.094 & -0.260 & -0.050 & -0.001 & 0.032 & 0.510 \\
\hline \multirow[t]{2}{*}{ Spread } & 190 & 0.017 & 0.019 & 0.005 & 0.007 & 0.011 & 0.020 & 0.192 \\
\hline & \multicolumn{8}{|c|}{ Industrial Products \& Manufacturing } \\
\hline Operating Income & 175 & 0.325 & 2.778 & -12.155 & -0.640 & -0.100 & 0.427 & 19.972 \\
\hline Operating Income change & 175 & 0.171 & 2.270 & -11.488 & -0.458 & 0.120 & 0.638 & 12.739 \\
\hline Market Cap & 175 & 41.843 & 38.076 & 4.377 & 17.549 & 26.226 & 49.628 & 168.938 \\
\hline BTM & 175 & 0.403 & 0.844 & -4.943 & 0.097 & 0.374 & 0.842 & 2.027 \\
\hline three-day CAR & 175 & 0.011 & 0.116 & -0.212 & -0.052 & 0.000 & 0.044 & 0.583 \\
\hline Spread & 175 & 0.044 & 0.058 & 0.005 & 0.015 & 0.028 & 0.046 & 0.388 \\
\hline
\end{tabular}


Appendix E. (cont.)

\begin{tabular}{|c|c|c|c|c|c|c|c|c|}
\hline & \multicolumn{8}{|c|}{ Consulting \& Business Services } \\
\hline & Count & Mean & Std & Min & 0.25 & 0.5 & 0.75 & Max \\
\hline Operating Income & 150 & -0.408 & 2.126 & -17.059 & -0.520 & -0.002 & 0.460 & 3.366 \\
\hline Operating Income change & 150 & 0.043 & 2.046 & -15.339 & -0.401 & 0.098 & 0.581 & 7.250 \\
\hline Market Cap & 150 & 68.331 & 128.620 & 1.371 & 16.217 & 26.906 & 62.874 & 844.806 \\
\hline BTM & 150 & 0.648 & 0.927 & -4.608 & 0.278 & 0.596 & 1.007 & 3.729 \\
\hline three-day CAR & 150 & -0.032 & 0.093 & -0.549 & -0.073 & -0.016 & 0.019 & 0.173 \\
\hline \multirow[t]{2}{*}{ Spread } & 150 & 0.050 & 0.072 & 0.003 & 0.009 & 0.022 & 0.054 & 0.388 \\
\hline & \multicolumn{8}{|c|}{ Biotechnology } \\
\hline Operating Income & 131 & -0.573 & 1.550 & -7.362 & -1.489 & -0.751 & 0.430 & 3.803 \\
\hline Operating Income change & 131 & -0.032 & 1.411 & -4.791 & -0.439 & -0.042 & 0.370 & 8.108 \\
\hline Market Cap & 131 & 84.833 & 197.365 & 2.001 & 16.681 & 25.011 & 90.503 & 1545.307 \\
\hline BTM & 131 & 0.250 & 0.423 & -0.828 & 0.069 & 0.157 & 0.346 & 1.571 \\
\hline three-day CAR & 131 & -0.016 & 0.111 & -0.315 & -0.064 & -0.009 & 0.020 & 0.498 \\
\hline \multirow[t]{2}{*}{ Spread } & 131 & 0.056 & 0.062 & 0.004 & 0.011 & 0.028 & 0.077 & 0.286 \\
\hline & \multicolumn{8}{|c|}{ Communication Equipment } \\
\hline Operating Income & 128 & -1.637 & 4.825 & -25.882 & -1.701 & -0.890 & 0.202 & 18.552 \\
\hline Operating Income change & 128 & -0.230 & 3.442 & -19.640 & -0.393 & 0.001 & 0.275 & 20.983 \\
\hline Market Cap & 128 & 43.795 & 39.515 & 3.553 & 14.553 & 36.931 & 55.875 & 252.461 \\
\hline BTM & 128 & 0.597 & 0.686 & -0.473 & 0.104 & 0.446 & 0.876 & 3.086 \\
\hline three-day CAR & 128 & 0.004 & 0.130 & -0.413 & -0.056 & 0.001 & 0.046 & 0.474 \\
\hline \multirow[t]{2}{*}{ Spread } & 128 & 0.024 & 0.045 & 0.004 & 0.007 & 0.012 & 0.024 & 0.351 \\
\hline & \multicolumn{8}{|c|}{ Other industries } \\
\hline Operating Income & 126 & 1.465 & 3.382 & -11.755 & -0.116 & 0.667 & 2.724 & 19.940 \\
\hline Operating Income change & 126 & 0.415 & 3.797 & -15.872 & -0.131 & 0.254 & 0.932 & 14.406 \\
\hline Market Cap & 126 & 77.659 & 107.815 & 8.437 & 15.999 & 32.612 & 84.262 & 455.334 \\
\hline BTM & 126 & 0.817 & 0.537 & -0.290 & 0.501 & 0.854 & 1.069 & 2.375 \\
\hline three-day CAR & 126 & 0.019 & 0.104 & -0.411 & -0.017 & 0.008 & 0.057 & 0.346 \\
\hline Spread & 126 & 0.050 & 0.056 & 0.005 & 0.015 & 0.029 & 0.061 & 0.293 \\
\hline
\end{tabular}


Appendix F. Variance inflation factors (VIFs) for regression models and predictors

\begin{tabular}{|l|l|c|c|}
\hline Table number & Dependent variable & Model VIF & Max VIF for predictors \\
\hline $\mathbf{5 . 9}$ & TONE & 1.152 & 2.049 \\
\hline $\mathbf{5 . 9}$ & AB_TONE & 1.091 & 2.043 \\
\hline $\mathbf{5 . 1 0}$ & READ & 1.127 & 2.049 \\
\hline $\mathbf{5 . 1 0}$ & CAUS_R & 1.114 & 2.049 \\
\hline $\mathbf{5 . 1 0}$ & HEAD_B & 1.295 & 2.049 \\
\hline $\mathbf{5 . 1 1}$ & Three-day CAR & 1.062 & 2.349 \\
\hline $\mathbf{5 . 1 2}$ & AB_DVOL & 1.067 & 2.324 \\
\hline $\mathbf{5 . 1 3}$ & AB_DSEN & 1.030 & 2.321 \\
\hline $\mathbf{5 . 1 4}$ & TONE & 1.105 & 1.275 \\
\hline $\mathbf{5 . 1 4}$ & AB_TONE & 1.045 & 1.279 \\
\hline $\mathbf{5 . 1 5}$ & READ & 1.085 & 1.275 \\
\hline $\mathbf{5 . 1 5}$ & CAUS_R & 1.065 & 1.275 \\
\hline $\mathbf{5 . 1 5}$ & HEAD_B & 1.247 & 1.275 \\
\hline $\mathbf{5 . 1 6}$ & Three-day CAR & 1.048 & 1.454 \\
\hline $\mathbf{5 . 1 7}$ & AB_DVOL & 1.056 & 1.428 \\
\hline $\mathbf{5 . 1 7}$ & AB_DSEN & 1.028 & 1.431 \\
\hline $\mathbf{5 . 1 8}$ & HEAD_B & 1.271 & 2.049 \\
\hline $\mathbf{5 . 1 9}$ & 30-day CAR & 1.064 & 2.344 \\
\hline $\mathbf{5 . 1 9}$ & 60-day CAR & 1.043 & 2.344 \\
\hline $\mathbf{5 . 2 0}$ & 60-day AB_DVOL & 1.046 & 2.318 \\
\hline $\mathbf{5 . 2 1}$ & AB_DVIEW & 1.070 & 2.318 \\
\hline
\end{tabular}




\section{Appendix G. List of abbreviations}

\begin{tabular}{|l|l|}
\hline Abbreviation & \\
\hline AB_DSEN & Abnormal Discussion Sentiment \\
\hline AB_DVIEW & Abnormal Discussion View \\
\hline AB_DVOL & Abnormal Discussion Volume \\
\hline AB_TONE & Abnormal Tone \\
\hline ASX & Australian Stock Exchange \\
\hline BT & British Telecommunications \\
\hline BTM & Book-to-Market Ratio \\
\hline CAPM & Capital Asset Pricing Model \\
\hline CAR & Cumulative Abnormal Return \\
\hline CAUS_R & Causal Reasoning \\
\hline CausS & Causal Sentences \\
\hline CPA & Chartered Professional Accountants \\
\hline CSA & Canadian Securities Administrators \\
\hline CV & Coefficient of Variation \\
\hline D_WEEK & Day of Week \\
\hline EPR & Earnings Press Release \\
\hline FLS & Forward-looking Statements \\
\hline FUT_OI & Future Operating Income \\
\hline GAAP & Generally Accepted Accounting Principles \\
\hline GDP & Gross Domestic Product \\
\hline GLS & Generalized Least Squares \\
\hline HEAD_B & Headline Impression Management Bias \\
\hline IIROC & Investment Industry Regulatory Organization of Canada \\
\hline IM & Impression Management \\
\hline IND & Industry (Variable) \\
\hline IND_AS & Industry - Application Software \\
\hline IND_Bio & Industry - Biotechnology \\
\hline IND_C_BS & Industry - Consulting \& Business Services \\
\hline IND_CE & Industry - Communication Equipment \\
\hline IND_IP_M & Industry - Industrial Products \& Manufacturing \\
\hline IND_M_M & Industry - Metals \& Mining \\
\hline IND_OTHER & Industry - Other industries \\
\hline IPO & Initial Public Offering \\
\hline IR & Investor Relations \\
\hline IRH & Investor Recognition Hypothesis \\
\hline LIWC & Linguistic Inquiry and Word Count \\
\hline M_RET & Contemporaneous Benchmark Annual Stock Returns \\
\hline
\end{tabular}




\begin{tabular}{|l|l|}
\hline Abbreviation & \\
\hline MD\&A & Management Discussion and Analysis \\
\hline MSH & Morgan Stanley High-Tech Index \\
\hline Neg_Rein & Negative Reinforcement \\
\hline Neg_Rep & Negative Repetition \\
\hline Neg_TM & Negative Thematic Manipulation \\
\hline NegIMScore & Negative Impression Management Score \\
\hline NegW & Negative Words \\
\hline NYSE & New York Stock Exchange \\
\hline OI & Operating Income \\
\hline OLS & Ordinary Least Squares \\
\hline OSC & Ontario Securities Commission \\
\hline POS_EAR & Positive Earnings \\
\hline Pos_Rein & Positive Reinforcement \\
\hline Pos_Rep & Positive Repetition \\
\hline Po__TM & Positive Thematic Manipulation \\
\hline PosIMScore & Positive Impression Management Score \\
\hline PosW & Positive Words \\
\hline READ & Reading Complexity \\
\hline S\&P & Standard \& Poor's \\
\hline SBF & Société des Bourses Françaises \\
\hline SEC & Securities and Exchange Commission \\
\hline SEDAR & System for Electronic Document Analysis and Retrieval \\
\hline SVI & Search Volume Index \\
\hline TONE & Tone in an EPR \\
\hline TFIDF & Term Frequency Inverse Document Frequency \\
\hline TotS & Total Sentences \\
\hline TotW & Total Words \\
\hline TSX & Toronto Stock Exchange \\
\hline VIF & Variance Inflation Factor \\
\hline & \\
\hline
\end{tabular}

